\title{
Summaries of Physical Research in the Geosciences
}

Published: September 1986

DOE/ER--0292

DE86 015659

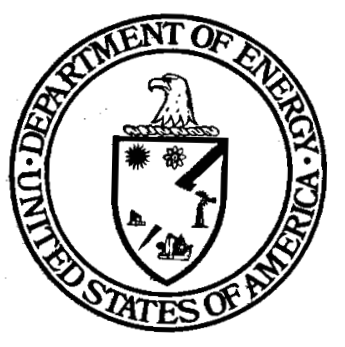

\section{U.S. Department of Energy}

Office of Energy Research

Division of Engineering, Mathematics \& Geosciences

Washington, D.C. 20545 


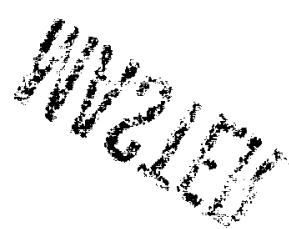

- 


\section{DISCLAIMER}

This report was prepared as an account of work sponsored by an agency of the United States Government. Neither the United States Government nor any agency Thereof, nor any of their employees, makes any warranty, express or implied, or assumes any legal liability or responsibility for the accuracy, completeness, or usefulness of any information, apparatus, product, or process disclosed, or represents that its use would not infringe privately owned rights. Reference herein to any specific commercial product, process, or service by trade name, trademark, manufacturer, or otherwise does not necessarily constitute or imply its endorsement, recommendation, or favoring by the United States Government or any agency thereof. The views and opinions of authors expressed herein do not necessarily state or reflect those of the United States Government or any agency thereof. 


\section{DISCLAIMER}

Portions of this document may be illegible in electronic image products. Images are produced from the best available original document. 
FOREWORD

INTRODUCTION TO THE GEOSCIENCES RESEARCH PROGRAM OF THE OFFICE OF BASIC ENERGY SCIENCES

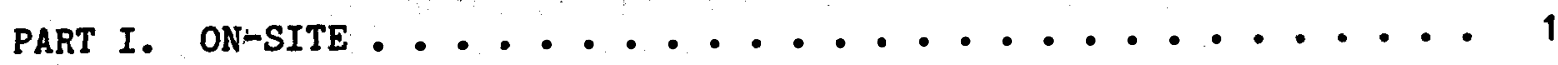

ARGONNE NATIONAL LABORATORY ............... 2

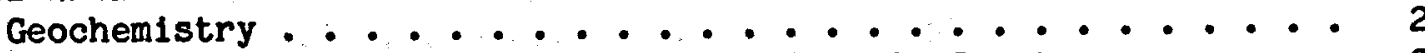

A. Trace Element Migration in the Earth's Crust ...... 2

B. Migration of Heavy Element Chemical Species in

Geologic Media................. 4

C. Thermochemistry of Geothermal Materials ....... 5

LAWRENCE BERKELEY LABORATORY . . . . . . . . . . . . . 7

Geology, Geophysics, and Earth Dynamics ........ 7

A. Deep Electromagnetic Sounding of the Crust ....... T

B. Fast ASP Development ............... 7

C. Center for Computational Seismology ......... 9

D. Test of an MHD Source for Crustal Electromagnet Sounding - 10

E. Effect of Fracture Characteristics upon Acoustic Wave

Propagation in Boreholes ........... 11

F. Microcrack Growth in Crystalline Rock ........ 11

G. Advanced Research Concepts............ 13

Geochemistry .......................... 14

A. Thermodynamics of High Temperature Brines ...... 14

B. Thermodynamic Properties of Sillcate Materials ...... 15

C. Generation of Petroleum and its Precursor Compounds . . 15

D. Studies of the Interactions Between Mineral Surfaces and Ions in Solution ............... 16

E. Ablogenic Methane Production from Igneous and Metamorphic Rocks..................... 16

F. Nonisothermal Reservoir Dynamics .......... 17

G. Chemical Transport in Natural Systems ........ 17

H. Impacts and Mass Extinctions ............ 19

Energy Resource Recognition, Evaluation, and Utilization.... 21

A. Hydrothermal Chemistry .............. 21

B. Pre-Drilling Data Review for the Long Valley Caldera, California .................. 22

C. Reflection Profiling at the Salton Sea Deep Hole .....23

D. Geophysical Measurements Facility .......... 23

E. Geomechanical Laboratory Studies ........... 24

F. Continental Sclent1fic Drilling Review Group ...... 24

G. Aqueous Solutions Database . . . . . . . . . 25

H. Fundamental Studies of Fluid Flow in Fractured Rock Masses under Stress .............. 25

I. Transport Propertles of Rock-Fluid Systems at Elevated Temperatures and Pressures ........... 26 
LAWRENCE LIVERMORE NATIONAL LABORATORY ................ 28

Geology, Geophysics, and Earth Dynamics .......... 28

1. Rock Mechanles ................. 28

B. Diffusion in Silicate Materials .......... 30

C. Electrical Conductivity and Temperature in Upper

Mantle . . . . . . . . . . . . . . 32

D. Attenuation and Dispersion in Partially Saturated

Rocks ................. 33

E. Surface Wave Method for Determining Earthquake

Mechanisms with Applications to Regional Stress

Field Studies ................ 33

F. Advanced Concepts ............. 34

Geochemistry ................ . . . 35

A. Thermodynamics, Kinetics, and Transport in Aqueous

Electrolyte Solutions ............ 35

B. Kinetic and Compositional Model of High Pressure

Kerogen Pyrolysis ............. 36

Energy Resource Recognition, Evaluation, and Utilization . . . 38

A. Continental Drilling Program Information and Data

Management Unit ............. 38

B. Viscosity and Electrical Conductivity of Rock Melts:

Continental Scientific Drilling Program . . . . . . 39

C. Seismic Studies of Possible Magma Injection and Magma

Chambers in the Long Valley Reglon .......... 40

D. Shallow Hole Investigations of Long Valley, Valles, and Salton Sea Thermal Regimes ........... . 41

E. Salton Sea Scientific Drilling Program Science

Management Activities ............. 43

F. SSSDP: Constraints from Borehole Gravity on Geothermal

System Models and Resource Definition for the Salton

Sea Geothermal Field............... 43

G. SSSDP: Physical and Chemical Laboratory Studies of

Cores from the Salton Sea Scientific Drilling Project . 43

H. Underground Imaging .............. 43

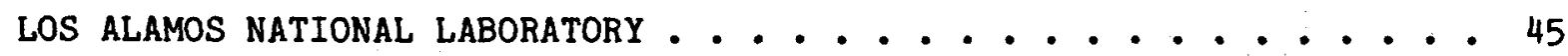

Geology, Geophysics, and Earth Dynamics ........... 45

A. Electrical Conductivity, Temperature, and Radiative

Transport in the Earth . . . . . . . . . . 45

B. Nonlinear Generation of Acoustic Beams . . . . . . . 46

C. Creep Deformation of Rock ............. 46

D. Pore-Size Distribution from NMR Measurements . . . . . 47

E. Advanced Geoscience Concepts Research . . . . . . . . 47

Geochemistry .................... 49

A. Coal Maturation: Occurrence, Form, and Distribution

of Sulfur and Mineral Matter in Peat .......... 49

B. Rock-Water Interactions and Element Migration in the Jemez Hydrothermal System ............ 50

C. Thermodynamic Properties of Aqueous Solutions at High

Temperatures and Pressures ............ 51 
D. The Geochemistry of Technetium and Ruthenium and Geochemical Controls on the Redistribution of

Multivalent Elements in the Lithosphere $\because . . . \because 51$

E. Trace Element Geochemistry of Volcanic Gases from Basaltic Volcanoes of Oceanic Hotspots . . . . . 52

F. RAMAN Spectroscopy of Aqueous Solution Species . . . . 53

Energy Resource Recognition, Evaluation, and Utilization . . . 55

A. Field and Geochemical Studies of the Polvadera Group, Jemez Volcanic Fleld, New Mexico . . . . . . 55

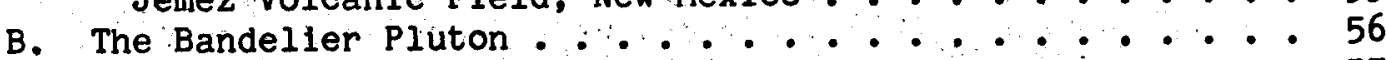

C. Valles Caldera Drilling Program: Core hole vc-1 . . . 57

D. Valles Caldera Driling Program: Core hole VC-2a .... 58

E. Developmerit and Initiation of Sample Management Policy Procedures and CSDP............. 58

Solar-Terrestrialatmospheric Interactions . . . . . . . . 60

A. Energy Transport in Space Plasma ......... 60

B. Electrodynamical Aspects of the Solar Wind-

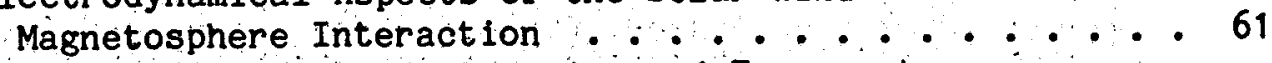

C. Energetic Particle Acceleration and Transport in the Terrestrial Magnetosphere ......... 62

OAK RIDGE NATIONAL LABORATORY . . . . . . . . . . . 64

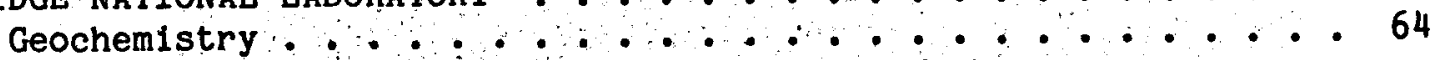

A. Geochemistry of Crustal Processes to High Temperatures and Pressures . . . . . . . . 64

B. Oxygen and Hydrogen Isotope Systematics in Geothermal and Magma/Hydrothermal Regimes ...... 71

PACIFIC NORTHWEST LABORATORY . . . . . . . . . . . 72

Geochemistry - . . . . . . . . . . 72

A. Chemical Migration by Contact Metamorphism Between

Pegmatite-Country Rock . . . . . . . 72

Energy Resource Recognition, Evaluation, and Utilization . . 74 A. Remote Sensing: Geoscience Data Analysis and

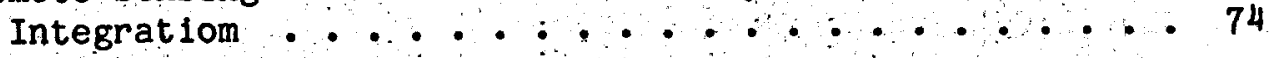

Solar-Terrestrial-Atmospheric Integrations _ _ _ . . . . 77

A. DOE Insolation/Aeronomy Studies ... . . . . . . 77

SANDIA NATIONAL LABORATORIES

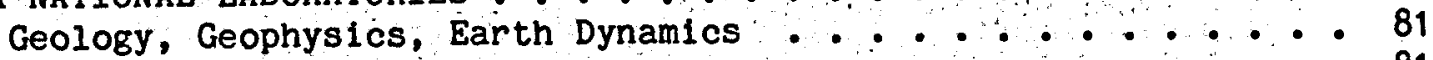

A. Crustal Strain . . . . . . . . . 81

B. Time-Dependent Deformation and Fracture of Brittle

Rock . . . . . . . . . . . 82

C. Creep Mechanisms and Microstructure in Rock Salt . . . 82

D. Acoustic Emissions and Damage in Geomaterials ..... 83

E. Advanced Concepts .......................... 84 
Geochemistry ................... 86

A. Magmatic Volatiles ................ 86

B. Clay - $\mathrm{H}_{2} \mathrm{O}$ Interactions ............... 88

C. Chemical Diffusion Processes in Silicate Minerals ... 88

Energy Resource Recognition, Evlation, and Utilization . . . . 90

A. CSDP - High Temperature Geophysical Research Techniques . 90

B. Magmatic Emplacement ... . . . . . . . . . . . 91

C. CSDP Long Valley - Mono Craters Site Assessment . . . . 92

D. Inyo Domes Research Drilling Program . . . . . . . . 93

E. Geosclence Research Drilling office . . . . . . . 94

PART II. OFF-SITE . . . . . . . . . . . . . . 95

UNIVERSITY OF ALASKA . . . . . . . . . . . . . . . . 96

Magnetic Field Anninilation in the Magnetosphere and

its Applications ..................... 96

ARIZONA STATE UNIVERSITY . . . . . . . . . . . . . . . 98

Drilling Investigation of a Young Magmatic Intrusion

Beneath the Inyo Domes, Long Valley, California:

Structural and Emplacement Studies . . . . . . . . . 98

UNIVERSITY OF ARIZONA . . . . . . . . . . . . . . . . . 101

Solar Varlability: Changes in Figure and Mean Diameter . . . 101

BROWN UNIVERSITY . . . . . . . . . . . . . . . . . . 104

Thermal Regimes of Major Volcanic Centers: Magnetotelluric

Constraints on the Coupling of Deep-Seated Magma Genesis

to High Level Geothermal Reservolrs ........... 104

CALIFORNIA INSTITUTE OF TECHNOLOGY ................. 107

In Situ Stress in Deep Boreholes ............... 107

Infrared Spectroscopy and Hydrogen Isotope Geochemistry of

Hydrous Silicate Glasses . . . . . . . . . . . 109

UNIVERSITY OF CALIFORNIA . . . . . . . . . . . . . . . . . . . 111

Advective-Diffusive/Dispersive Transport of Chemically

Reacting Species in Hydrothermal Systems . . . . . . . . 111

Isotopic Studies on Rare Gases in Terrestrial Samples and in

Natural Nucleosynthesis ................. 114

Sulfide-Oxide-Silicate Phase Equilibria and Associated Fluid Inclusion Properties in the Salton Sea Geothermal System,

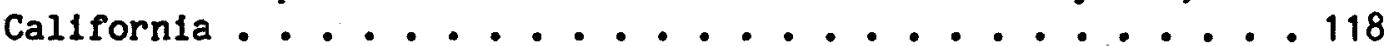

Long Valley Caldera: Monitoring Studies of Gas Composition and $\mathrm{He}, \mathrm{Ar}$, and Carbon Isotopes ........... 119

UNIVERSITY OF CALIFORNIA AT LOS ANGELES . . . . . . . . . . . 121

Adiabats and Gruneisien Parameter at High Temperatures and

High Pressure ..................... . 121

Determination of Thermodynamic Functions of Minerals at

High Temperature . . . . . . . . . . . . . . 122 
THE UNIVERSITY OF CHICAGO .................... 124 Depth to and Concentrations of Water in Large Bodies of Silicic Magma .................. . 124

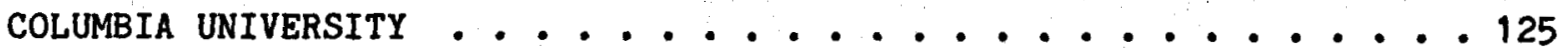

Energetics of Silicate Melts from Thermal Diffusion Studies . - 125 Seismo-tectonics of the Eastern Aleutian Arc and Associated

Volcantc Systems....................... 126

Study of the Time-dependent Transmissivity of Joints . . . . 127

HARVARD UNIVERSITY . . . . . . . . . . . . . 128

Energetic and Thermochemical Properties of Rocks and

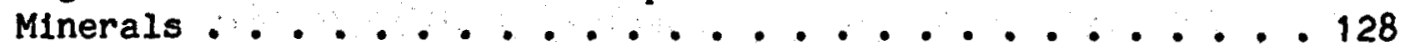

UNIVERSITY OF HAWAII AT MANOA ................ 129

Physlcal Characterization of Magma Samples......... 129

UNIVERSITY OF MARYLAND . . . . . . . . . . . . 131

Study of the Salton Sea Geothermal System Using ${ }^{10} \mathrm{Be}$ Isotope

and Trace Element Chemistry ........................... 131

MASSACHUSETTS INSTITUTE OF TECHNOLOGY . . . . . . . . . 133

Microcracks and Energy .................. . . 133

In-Situ Permeability Determination Using Borehole and

Selsmic Logging Data .................. 136

MICHIGAN STATE UNIVERSITY

The Effects of Pressure, Volatiles, and Thermal History

on Chemical Heterogenelty In Magma Systems . . . . . . 137

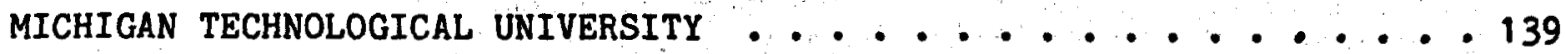

Geothermal Alteration of Sediments in the Salton Sea

Sclentific Drill Hole ................ 139

NATIONAL ACADEMY OF SCIENCES/NATIONAL RESEARCH COUNCIL . ...... 140

I. Studies In Geophysics ................ 140

II. Committee on Seismology ......................... 142

III. U. S. Geodynamies Committee ..................... 43

IV. Continental Scientific Driling Committee ........ 147

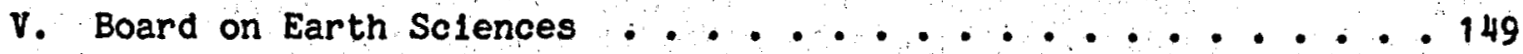

VI. Geophysics Film Committee . . . . . . . . . 151

UNIVERSITY OF NEVADA . . . . . . . . . . . . . 153

A. Shallow-Crustal Magma Zones In and South of Long Valley . 153 
THE RESEARCH FOUNDATION OF THE CITY UNIVERSITY OF NEW YORK . . . 155 Deep-Burial Diagenesis in Carbonates . . . . . . 155

STATE UNIVERSITY OF NEW YORK ....................... 157 Thermal Evolution of Sedimentary Basins . . . . . . . 157 Geochemistry and Origin of Regional Dolomites . . . . 158

UNIVERSITY OF NORTH CAROLINA . . . . . . . . . . . . 161 Activity - Composition Relationships in Silicate Melts . . . 161

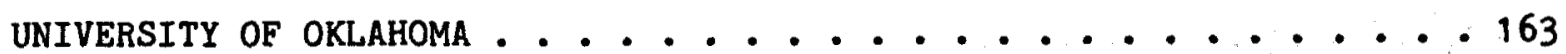

A Study of the Source Material, Mechanisms of Generation, and Migration of Oils in the Anadarko Basin, Oklahoma ... 163 Workshop in Continental Scientific Drilling ........ 165

THE PENNSYlVANIA STATE UNIVERSTTY . . . . . . . . . 166 The Geochemistry of Coal Origins in Relation to Coal

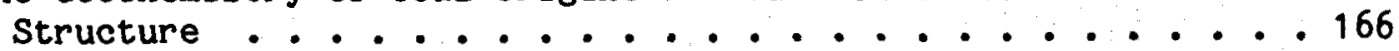

PRINCETON UNIVERSITY . . . . . . . . . . . . . 169 Silicate, Aluminosilicate and Borosilicate Melts:

Thermochemical Studies by High Temperature Calorimetry . . . 169

SOUTH DAKOTA SCHOOL OF MINES AND TECHNOLOGY . . . . . . 171 Thermally Induced Chemical Migration: A Natural AnaloB Approach . . . . . . . . . . . . . . . 171 Cores from the Salton Sea Scientific Drilling Program: Metamorphic Reaction Progress as a Function of Chemical and Thermal Environment ............... . 172

UNIVERSITY OF SOUTHERN CALIFORNIA . . . . . . . . . . . . 173 Continental Scientific Drilling Program: The Selsmology of Continental Thermal Regimes . . . . . . . . . . 173

STANFORD UNIVERSITY ............................ 174 Porosity with Fluids: Origin and Effects on Physical

Properties of Crustal Rocks ............. . 174

Structure and Emplacement of the Inyo Domes Intrusion, Long Valley, California ............... 176

TEXAS A \& M UNIVERSITY . . . . . . . . . . . . . . . 178 Stress-Induced Selsmic Anisotropy ............ 178

I. Mechanical Properties of Rocks at High Temperatures

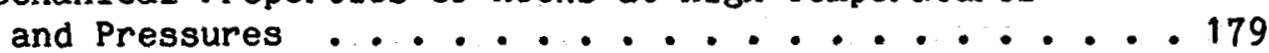
II. Geoscience Research Council .......... 181

UNIVERSITY OF TEXAS ARLINGTON ................ 182 Volcanological Investigation of the Banco Bonlto Eruption and Subsurface Geology of the Ring Fracture Zone, Valles Caldera, New Mexico ............... 182

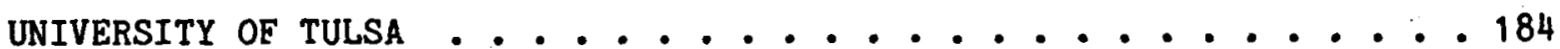
Stability of Natural Gas in the Deep Subsurface ...... 184 
\& UNIVERSITY OF UTAH RESEARCH INSTITUTE . . . . . . . . . . . 182

Caldera Processes: Hydrothermal Dynamics and Ore

Deposition in the Sulphur Springs Vapor Dominated Zone,

Valles Caldera, New Mexico (VC-2a) ......... 185

Logging and Hydrothermal Alteration Studies of Hole VCA1,

Valles Caldera, New Mexico ............. 186

UNIVERSITY OF WASHINGTON . . . . . . . . . . . . 187

Two- and Three-Dimensional Magnetotelluric Inversion ..... 187

UNIVERSITY OF WISCONSIN ................. 188

Thermal Stress Microfracturing of Granite ........ 188

Deformation and Stress Modeling of Recent Magmatic Tectonics

at Long Valley, Callfornia . . . . . . . . . 189

WOODS HOLE OCEANOGRAPHIC INSTITUTION . ............ 190

Organic Geochemistry of Outer Continental Margin and

Deep Ocean Sediments .................. 190

YALE UNIVERSITY . . . . . . . . . . . . . . . . 191

Opening Mode Crack Growth in Rock ........... 191

GEOSCIENCE RESEARCH HISTORICAL SUMMARY . . . . . . . . . . 192

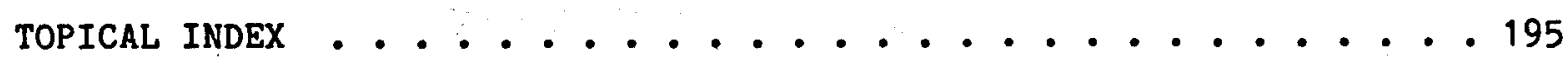

INDEX OF TECHNICAL CONTRIBUTORS . . . . . . . . . 196 
The Department of Energy supports research in the geosciences in order to provide a sound foundation of fundamental knowledge in those areas that are germane to the Department of Energy's many missions. The Division of Engineering, Mathematical and Geosciences -- part of the Office of Basic Energy Sciences which is under the Director of Energy Research -- supports the Geosciences Research Program. The partlcipants in this program include Department of Energy laboratories, Industry, universities, and other governmental agencies. Their support, formalized by a contract between the Department of Energy and the organization performing the work, provides funds for salaries, equipment and other materials, and an overhead allowance.

The summaries in this document, prepared by the investigators, describe the scope of the individual programs and detall the research performed during 1984-1985. The Geosciences Research Program includes research in geology, petrology, geophysics, geochemistry, hydrology, solar-terrestrial relationships, aeronomy, seismology, and natural resource analysis, including their various subdivisions and interdisciplinary areas. All such research is related either directly or Indirectly to the Department of Energy's technological needs. 
The Geosciences Research Program is directed by the Department of Energy's Office of Energy Research, within the Office of Basic Energy Sclences, Division of Engineering, Mathematical, and Geosciences. Research supported by this program may be directed toward a specific energy technology, na-. tional security, conservation of the environment, or the safety objectives of the Department of Energy. The purpose of this program is to develop geoscience or geosciences-related information relevant to one or more of these Department of Energy objectives or to develop the broad, basic understanding of geoscientific materials and processes necessary for attaining long-term Department of Energy goals. In general, individual research efforts supported by this program may involve elements of all four objectives.

The Geosciences Research Program is divided into five broad categories:

- Geology, geophysics, and earth dynamics

- Geochemistry

- Energy resource recognition, evaluation and development

- Hydrologic and marine sclences

- Solar-terrestrial-atmospheric interactions.

The following content outline of these categories is intended to be $11^{k}$ lustrative rather than exhaustive, and will evolve with time. Individual research efforts at the Department of Energy, .university, college, corporate, not-for-profit, and other Federal agency laboratories supported by this program frequently have components in more than one of the categories or subcategories listed.

1. Geology, Geophysics, and Earth Dymamics

A. Large-Scale Earth Movements. Research related to the physical aspects of large-scale plate motion, mountain building, and regional scale uplift or subsidence.

B. Evolution of Geologic Structures. Research bearing on the history and development of geolog1c structures (e.g., folds, faults, landslides, and volcanoes) on a local or subreglonal scale.

C. Properties of Earth Materials. Research on physical properties of rocks and minerals determined in the laboratory or in the field (in situ) by direct or indirect techniques.

D. Rock Flow, Fracture, or Fallure. Research related to response of minerals, rocks, and rock units to natural or artificially induced stress, including the strain rates that range from those appropriate to drilling to viscoelastic response. 
2. Geochemistry

A. Thermochemical Properties of Geologic Materials. Research related to thermodynamic and transport properties of natural geologic materials and their synthetic analogues. Emphasis is on generic rather than site-specific studies.

B. Static Rock-Water Interactions, Laboratory-based research on chemical, mineralogical, and textural consequences of interaction of natural aqueous fluids, or thelr synthetic analogues; with rocks and minerals.

C. Organic Geochemistry. Research on naturally occurring carbonaceous and blologically derived substances of geologic importance, including research on the origin and development of coal, petroleum and gas.

D. Geochemical Migration. Research on chemical migration in materials of the earth's crust, emphasizing a generic rather than specific understanding, which may (ultimately) lead to predictive capability. These experimental and theoretical studies focus on chemical transport induced by pressure, temperature, and composition gradients within, between, and by a phase or phases. This component is part of a multiagency (Department of Energy, National Science Foundation, U. S. Geological Survey) joint program.

3. Energy Resource Recognition, Evaluation, and Utilization

A. Resource Definition and Utilization. The principal goal of this research is to develop new and advanced techniques that are physically, chemically, and mathematically based, for energy and energyrelated resource exploration, definition, and use.

B. Reservoir Dymamics and Modeling. Research related to dynamic modeling of geothermal and hydrocarbon reservoirs in their natural and perturbed (by production, injection, or reinjection) states.

C. Magma Energy Resources. Field, laboratory, experimental, and theoretical research bearing on the origin, migration, emplacement, and crystallization of natural silicate liquids or their synthetic analogues. These studies emphasize the extraction of energy from such liquids.

D. Information Compilation, Evaluation, and Dissemination. These research activities are principally oriented toward evaluating existing geoscientific data to identify significant gaps, including the necessary compilation and dissemination activities.

E. Continental Scientific Drilling Program (CSDP). Research on advanced technology and services as well as scientificaliy motivated projects concerned with utilizing shallow $(0.3 \mathrm{~km})$, intermediate $(0.3$ to $1 \mathrm{~km})$, and deep ( $1 \mathrm{~km})$ drill holes in the United States 
continental crust to (a) obtain samples for detailed physical, chemical, mineralogical, petrologic, and hydrologic characterization and interpretation; (b) correlate geophysical data with laboratorydetermined properties; and (c) use the drill hole as an experimental facility for studying crustal materials and processes. The Department of Energy focuses on drilling through an active hydrothermal system (or systems) into a magma chamber or into hightemperature igneous rocks. Research includes aspects of driling technology development for such hostile environments. Part of a multiagency (U. S. Geological Survey, National Sclence Foundation, and Department of Energy) coordinated program under the aegis of an Intergency Accord on Continental Sclentific Drilling.

4. Hydrologic and Marine Sciences

A. Ground Water Hydrology. Research related to chemical and physical princlples underlying the flow of water through porous and permeable rocks near the earth's surface.

B. Fresh Water Systems. Research on the chemistry, physics, and dynamics of fresh water systems, including streams, rivers, and lakes.

C. Oceanography. Research involving materials and processes of the marine environment. Princlpal emphasis is on geological, geophysical, and geochemical research related to rocks and sediments beneath the water column.

\section{Solar-Terrestrial-Atmospheric Interactions}

A. Magnetospheric Physlas. Research directed toward developing a fundamental understanding of the interactions of the solar wind with the terrestrial magnetic fleld. Research related to the earth's magnetosphere as a model magnetohydrodynamic generator and associated plasma physics research.

B. Upper Atmosphere Chemistry and Physics. Research on thermal, compositional, and electrical phenomena in the upper atmosphere, and the effects induced by solar radiation.

C. Solar Radiation. Research on the solar constant, spectral distribution, and characteristics of solar radiation of the earth, including the long-term effects of solar radiation on the climate.

D. Meteorology and Climatology. Interrelationships of weather and climate with energy systems. 


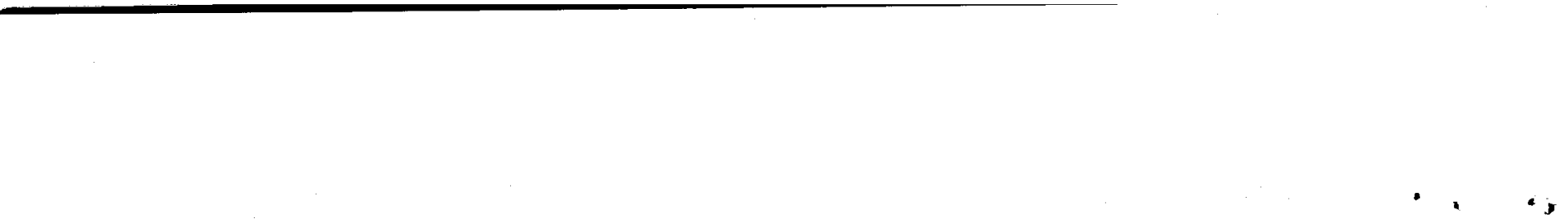


$a^{2}+$

PART I

ON-SITE

$-1-$ 
Contractor:

ARGONNE NATIONAL LABORATORY

Argonne, Illinols 60439

Contract:

109 ENG 38

Category :

Geochemistry

Person in Charge:

F. A. Cafasso

Scope of Work

Geoschemistry research at Argonne National Laboratory is focused on research in the areas of geochemical migration and mineral thermochemistry. In the migration area, chemical and isotopic studies of hydrothermally altered materials are being done as part of an effort to describe the trace element redistribution processes in active hydrothermal systems while thermodynamic studies of actinide complex formation reactions with inorganic constituents (e.g., $\mathrm{CO}_{3}{ }^{=}, \mathrm{SO}_{4}{ }^{2}$ ) in groundwater are being pursued to develop a better understanding of the chemistry underlying actinide element transport. The thermochemistry part of the program is largely focused on measuring, by a varlety of calorimetric methods, the ther modynamic properties of zeolites and related materials. The intent is to develop thermodynamic-structure correlations of these materials and to use the data to explain mineral equilibria.

A. Trace Element Migration in the Earth's Crust (N. Sturchio, M. Seitz, S. Boggs, D. Livermore, and C. Johnson)

The objective of this program is to achieve a deeper understanding of the geochemistry of trace element migration in the Earth's crust. We are particularly concerned with the redistribution of trace elements under hydrothermal conditions, and are directing our efforts toward studies of the active hydrothermal systems associated with the Yellowstone, Valles, and Long Valley calderas. This work has relevance to the exploration for and utilization of geothermal and nuclear energy and hydrothermal ore deposits.

Our approach involves chemical and isotopic analysis of rock, mineral, water, and gas samples from drill holes and surfacial manifestations in these systems. These analytical data are coupled with other available data to interpret various aspects of the geochemical evolution of the systems. A general understanding of the evolution of each individual system is required before optimal interpretations of trace element migration can be made. Therefore, some of our work is directed toward basic problems such as the time scale of hydrothermal activity and the nature of previous conditions in each system. In this context, we are exploring the application of U-series disequilibrium in geochronologic and tracer studies. Oxygen, hydrogen, carbon, and sulfur isotopes are useful in establishing previous conditions of temperature and water/rock ratios. 
$4 \quad$ - Several detailed studies of hydrothermally-altered rhyolite from Yellowstone drill cores $Y-7$ and $Y-8$ have been completed. These included (1) a study of the redistribution of major, minor, and trace elements; (2) a study of oxygen 1sotope ratios; and (3) a study of Useries disequilibrium. We found extensive mobility of the alkalis, alkaline earths, $\mathrm{Mn}, \mathrm{Sb}$, and $\mathrm{U}$ in the altered rhyolite. The patterns of element redistribution correlate closely with the hydrothermal mineralogy and extent of alteration. The effect Ive water/rock ratio has been at least 10,000, and may have been much larger. Oxygen isotope exchange between thermal water and primary or secondary minerals has not reached equilibrium except for calcite. Oxygen isotope ratios in obsidian-replacing smectite and veinlet celadonite and silica Indicate that these phases preclpitated from thermal water enriched in ${ }^{18} 0$ relative to present thermal water. U-series disk equilibrium is extreme, and is consistent with a major redistribution of $U$ about $13,000-27,000$ years ago. Along with other observations on hydrothermal selfisealing and the timing of the Pinedale glaciation, the U-series data suggest a hydrogeologic connection between the Pinedale deglaciation and the initiation of thermal activity in Biscuit Basin.

Two more regional Yellowstone projects have been initiated: (1) a Useries geochronologic study of hydrothermal activity in the Park (in collaboration with members of the U. S. Geological Survey, Menlo Park), and (2) a study of oxygen and carbon lsotope ratios of hydrothermal precipitates in additional drill cores (In collaboration with Prof. K. Muehlenbachs, University of Alberta).

Also under investigation is the history of hydrothermal activity at the Valles and Long Valley calderas through U-series geochronology of hydrothermal precipitates. We have begun a study of $U$ in thermal waters of the Baca geothermal system. We are analyzing thermal water and gas samples from the Nevado del Ruiz volcano in Columbla following the November 13, 1985 eruption in an attempt to determine the relations between volcanic and hydrothermal processes.

A second element of the program has involved laboratory experiments on the effects of dissolved organic substances on the migration of ac tinides in basalt groundwater systems. In this connection, batch partitioning experiments were performed in which humic and fulvic acids were added in varlous amounts ranging from $1410 \mathrm{mg} / \mathrm{L}$ to actiniderspiked groundwaters. We found that sorption of $241 \mathrm{\mu m}$ on basalt is reduced strongly by the addition of humic and fulvic acids, but sorption of $237 \mathrm{~Np}$ is reduced only slightly. A study of the average distribution ratios obtained for $241 \mathrm{Am}$ in batch partitioning experiments using groundwaters containing natural concentrations of indigenous dissolved organic substances showed that the distribution ratios are positively correlated with dissolved organic carbon, as well as $\mathrm{Ca}$ and $\mathrm{Mg}$. This suggests a possible inhibiting effect on actinide-organic complexation due to the concentrations of $\mathrm{Ca}$ and. $\mathrm{Mg}$. No further work in organoactinide geochemistry is planned. 
B. Migration of Heavy Element Chemical Species in Geologic Media (A.* :* Friedman, F. Schreiner, and W. Uliman)

This activity is concerned with the measurement of the thermodynamic properties of aqueous actinide complexation reactions that may be important in describing the groundwater migration of actinides.

Our thermodynamic studies have involved titration microcalorimetric measurements of complexing reactions of uranyl, neptunyl and plutony 1 lons with sulfate and carbonate. Earlier work on the uranyl and nep tunyl systems has been followed by measurements of the reactions leading to the formation of sulfate and carbonate complexes of the dioxo plutonyl (VI) ion, $\mathrm{PuO}_{2}^{+2}$.

Standard state enthalpies for the formation of $\mathrm{PuO}_{2}\left(\mathrm{SO}_{4}\right)^{0}$, $\mathrm{PuO}_{2}\left(\mathrm{SO}_{4}\right)_{2}^{-2}, \mathrm{PuO}_{2}\left(\mathrm{CO}_{3}\right)_{2}=2$, and $\mathrm{PuO}_{2}\left(\mathrm{CO}_{3}\right)_{3}^{-4}$ were derived from the calorimetric enthalpies obtained at ionic strengths in the 0.5 to 0.9 mol/l range by application of a computer code developed at the U.S. Geological Survey. The code, designated as PHREEQE, makes use of a modifled Debye Huckel and Davies expressions to convert concentration data at the experimental ionic strengths to ionic activities.

With the acquisition of the data on the plutonium systems a complete set of enthalpies for the formation of sulfate and carbonate complexes of the dioxo lons of hexavalent actinides has been determined. For the majority of the species these data include the first direct calorimetric enthalpy determinations, complementing equilibrium constant measurements yielding Gibbs energies for the same complexes.

The aggregate data indicate that in most natural waters sulfate complex formation should not be of major importance. Equilibrium constants for the formation of the $1: 1$ dioxo actinide ion - sulfate complexes vary from 1584 to 2818 in the series $\mathrm{UO}_{2}^{+2}, \mathrm{NpO}_{2}^{+2}, \mathrm{PuO}_{2}^{+2}$. While calorimetric data show that complexes with more than one sulfate group exist, they are much less stable than the 1:1 complexes. The standard state enthalpy value for the uranyl monosulfato complex is $\Delta H^{\circ}=+19.6^{\circ}$ $\pm 0.6 \mathrm{~kJ} / \mathrm{mol}$. The corresponding values for the neptunyl and plutonyl complexes are smaller by $2.9 \mathrm{~kJ} / \mathrm{mol}$ and $3.5 \mathrm{~kJ} / \mathrm{mol}$, respectively.

In contrast to the sulfate complexes, the carbonate complexes are notable for their rather high stabilities. All three dioxo actinide ions form well-defined carbonato lons with carbonate to actinide ratios of $2: 1$ and $3: 1$. Equilibrium constants for the $2: 1$ complexes are of the order of $10^{+15}$; those for the $3: 1$ complexes are even higher, viz. $-10^{+22}$. 
$x$ The carbonato complexes form according to equation 1

$$
\mathrm{ACO}_{2}+2+\mathrm{jCO}_{3}+2 \mathrm{An}\left(\mathrm{CO}_{3}\right)_{\mathrm{j}}^{2(1-\mathrm{j})}
$$

where $f$ may assume the values 2 or 3 . The standard state enthalpies of reaction for the varlous values of $j$ have large negative values. From the calorimetric data an average enthalpy decrease of $\Delta H^{\circ}=-14.0 \pm$ $0.5 \mathrm{~kJ} / \mathrm{mol}$ is calculated for the attachment of one carbonate group in reaction 1. This enthalpy which is strongly negative compared to that of sulfate reflects the fact that a substantially higher energy is involved in the bonding of a carbonate group to the actinide central atom. The stability of the aqueous carbonate complexes results in the hexavalent actinides remaining in solution at $\mathrm{pH}$ values above 8 . This behavior may be significant because both neptunium and plutonium can be oxidized under the influence of radiation to the hexavalent state. As a consequence, it is likely that both elements would remain in solution in carbonate ${ }^{z}$ rich waters.

C. Thermochemistry of Geothermal Materials (P. A. G. O'Hare, G. K. Johnson, I. R. Tasker, D. A. Howell, and W. S. W1se)

The objective of this program is to measure precisely, by calorimetry, thermodynamic properties of zeolites, sllicates, and structurally related compounds. Materlals selected for study are of ten key components of geologic ensembles, they may have actual or potential technological value, or they may be of basic scientific interest in terms of structure or chemical bonding. Calorimetric techniques used are as follows: solution calorimetry in aqueous HF or combustion calorimetry in $\mathrm{F}_{2}$ or $\mathrm{O}_{2}$ for the determination of standard molar en thalpies of formation, $\Delta_{f} H_{m}^{\circ}$; low-temperature calorimetry (5 to $350 \mathrm{~K}$ ) for the determination of molar heat capacities, $\mathrm{C}_{\mathrm{p}, \mathrm{m}}$, and the derived standard molar entropy, $S_{m}^{0}$; drop calorimetry $(T \geq 350 \mathrm{~K})$ for the determination of enthalpy increments, $\left\{\mathrm{H}_{\mathrm{m}}^{\circ}(\mathrm{T})-\mathrm{H}_{\mathrm{m}}^{\circ}(298.15 \mathrm{~K})\right\}$, and the derived $\mathrm{C}_{\mathrm{p}, \mathrm{m}}(\mathrm{T})$; and differential scanning calorimetry for the determination of $\mathrm{C}_{\mathrm{D}, \mathrm{m}}$ and temperatures and enthalpies of transition of decomposition. Measurements cover the temperature range from 5 to $1500 \mathrm{~K}$ or the upper temperature limit of stability.

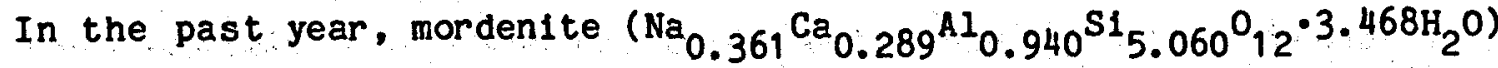
and the corresponding anhydride have been studied extensively and the following preliminary thermodynamic values have been obtained.:

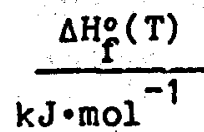

Mordenite $-(6756.2 \pm 4.5)$

Dehydrated Morden1 te $-(5661.8 \pm 4.6)$

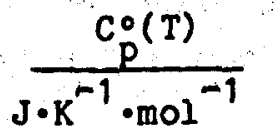

$(484.33 \pm 0.97)$

$(295.76 \pm 0.59)$

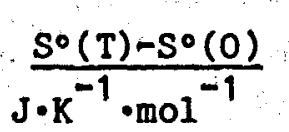

$(486.54 \pm 0.97)$

$(299.10 \pm 0.60)$
$\frac{\Delta G_{f}^{0}(T)}{k J \cdot m_{0 I}^{-1}}$

$(-6247.6 \pm 4.5)$

$(-5338.6 \pm 4.6)$ 
Studies of silicalite $\left(\mathrm{SiO}_{2}\right)$ have been concluded with the determination ., of the high temperature enthalpy increments:

$$
\begin{aligned}
& \left\{H_{m}^{\circ}(T)-H_{m}^{\circ}(298.15 \mathrm{~K})\right\} /\left(\mathrm{J} \cdot \mathrm{mol}^{-1}\right)=592881(\mathrm{~T} / \mathrm{K})^{-1}-15773.2 \\
& \quad+38.7780(\mathrm{~T} / \mathrm{K})+2.7288142 \times 10^{-2}(\mathrm{~T} / \mathrm{K})^{2}+7.6509874 \times 10^{-6}(\mathrm{~T} / \mathrm{K})^{3} .
\end{aligned}
$$

For stilbite $\left(\mathrm{Ca}_{1} .019^{\mathrm{Na}} 0.136^{\mathrm{K}_{0}} 0.006^{\mathrm{Al}} 2.180^{\mathrm{S} 1} 6.820^{\mathrm{O}} 18.733 \mathrm{H}_{2} \mathrm{O}\right)$

the following values have been obtained at $T=298.15 \mathrm{~K}: \Delta_{\mathrm{f}} \mathrm{H}_{\mathrm{m}}^{\circ}(\mathrm{T})=$

$-(11034.6 \pm 6.6) \mathrm{kJ}^{2} \mathrm{~mol}^{H 1} ; \mathrm{c}_{\mathrm{p}, \mathrm{m}}^{0}(\mathrm{~T})=(808.73 \pm 1.62) \mathrm{J} \cdot \mathrm{K}^{-1} \cdot \mathrm{mol}^{-1} ; \mathrm{S}_{\mathrm{m}}^{0}(\mathrm{~T})-\mathrm{S}_{\mathrm{m}}^{0}(0)$

$=(805.54 \pm 1.61) \mathrm{J} \cdot \mathrm{K}^{+1} \cdot \mathrm{mol}^{-1} ;$ and $\Delta_{\mathrm{f}} \mathrm{G}_{\mathrm{m}}^{\circ}(\mathrm{T})=-(10143.0 \pm 6.6) \mathrm{kJ} \cdot \mathrm{mol}^{-1}$.

Three compositions of faujasite with different Alinto-si ratios have been synthesized and their thermodynamic properties are being measured. 
A. Deep Electromagnetic Sounding of the Crust (H. F. Morrison, N. E. Goldstein)

The electrical resistivity of the shallow crust is related mainly to the degree of connected pores and fractures, the degree of saturation and the salinity of pore fluids, as well as past and present-day thermal effects which increase conductivities due to increased fracturing, hydrothermal alteration and elevated temperatures. Less is known about in situ conductivities of rocks in the lower crust (depths of $10 \mathrm{~km}$ or more) except from laboratory experiments and from deep sounding data. Deep zones of anomalously high conductivities have been reported in a number of areas, and there has been considerable speculation on possible cause(s). Although it was initlally believed that some of the conductors might be extensive regions of partial melt, recent information suggests that brine-filled and/or graphite-lined microfractures are also likely causes of deep crustal anomalies.

The objectives of our investigations are to develop and apply advanced techniques for carrying out deep electromagnetic soundings, to develop better numerical methods for data processing and interpretation, and to develop better conceptual models for deep crustal anomalies.

During fleld surveys conducted in 1984 and 1985 we acquired a 3 Gbyte data base of simultaneous natural magnetic and electric fields together with biasial tilt signals. These data were collected at stations on two orthogonal arrays in eastern California-western Nevada, with station separations ranging from $100 \mathrm{~m}$ to $120 \mathrm{~km}$. The purpose of this work is to develop better noise cancellation techniques for magnetotellur 1c and controlled*source soundings. We have developed a linear fitting, least-squares method which accurately predicts 40 to $70 \mathrm{~dB}$ of the natural magnetic fleld at any station from data at one or more other stations. This approach $1 . \mathrm{s}$ valuable for cancelling natural geomagnetic noise during a controlled-source sounding.

Numerical processing techniques employing both standard FFT's in the frequency domain and by convolution in the time domain are also under development.

B. Fast ASP Development (E. Majer and T. V. McEvilly)

The problem of in-field processing of selsmic data has been addressed in many different aspects. Depending upon the type of data sought, various amounts of computing power have been transported to the field. 
In 1977, as part of the Department of Energy's geothermal program, Lawrence Berkeley Laboratory began an effort to design and build an Automated Seismic Processor (ASP) that would detect and process data from microearthquake arrays. At that time it was not uncommon to use an 8- to 12-element microearthquake array to record 20 to 30 events per day. To provide faster answers to baslc earthquake monitoring problems, the ASP was designed as a low-power ( -1 watt/channe1), portable, in-field processing system. The ASP was built and designed using CMOS technology based upon the RCA 1802 microprocessor. Each seismic input channel is controlled by an 1802. These individual channel devices, or WORKERS, are responsible for making a detection on a single channel of data, picking the P-Swwave performing FFTs on the windowed P-S-waves, and determining the quality of the data. Once detected by each of the individual WORKERS, the information is sent to a central microprocessor (LSI 11/23) that performs the event association and determines if it is a valid event, i.e.. not a noise spike or other noise. If the event is valid, then the $11 / 23$ is programmed to perform a number of higherílevel processing sequences, 1.e., to determine event location, source properties, brvalues, etc.

The ASP concept has served us well, but with the increased avallabllity of off-the-shelf board sets and the dramatic improvement in CPU and memory since 1977, we felt that a new improved version of the ASP was necessary. We wanted the new version not only to be faster (e.8., a sample rate of $500 \mathrm{sam} / \mathrm{s}$ at $16 \mathrm{bits}$ rather than $100 \mathrm{sam} / \mathrm{s}$ at $12 \mathrm{bits}$ for very detailed microearthquake studies) but to include many features that cannot be attained with CMOS technology (e.g., it is relatively expensive with CMOS technology to devote a CPU or microcomputer to each channel of data). Therefore, in the Fall of 1984 we began designing and bullding a prototype Fast ASP system. The system is designed to carry out all of the functions of the ASP, in addition, the Fast ASP will have the capability to store the time series data for each event ( 80 -mbyte disk drives; tape drive for backup).

The system is designed around the Motorola 68000 series CPU and a VME/VMX bus. We are currently using 68010s, but we plan to use 68020s as soon as they are available in board sets with sufficient memory. The flrst stage of the project is to bulld a 24-channel, fully operational system. The target parameters for this firstestage system are as follows:

1. 24 channels, 500 samples/s/channel.

2. 12 bit $A / D$.

3. Storage capacity for up to 100 events (1.e., full waveform data plus processed data).

4. Capability of performing all present ASP processing plus the capability to designate a $P$ or an $S$ channel (for threecomponent data).

5. Streaming a disk at high data rates for $A E$ data. The data would be read back at slower rates for full processing.

6. Enhanced processing for array studies (i.e., $F-K$ analysis, beam forming).

7. Ethernet connection for networking to other systems. 
- At the present time we have bullt and or acquired all hardware to meet the above objectives. The only exception being the integration of an array processor into the system to obtain the necessary speed. The event detection, preprocessing, and FFT's 8 will be done in the workers with the software written in $\mathrm{C}$ and assembly. The higher level process ing (location, moment tensor, bvalues, etc.) will remain in Fortran. The overall system is controlled with a UNIX 4.2 (UNIX is a tradename of Bell Labs Inc.) CPU. This allows for I/O flexibility and Interfact ing with other systems.

Upon completion of the prototype system (summer 1986), it w11l be field tested. During our first field test with the ASP, we discovered many operational bugs that could have been found only through actual use. Upon successful debugging, the 24 -channel system will be expanded to 96 channels by adding additional CPUs and analog-to-digital (A/D) convert ers. Plans also call for interfacing the system with digital telemetry for full digital capability.

C. Center of Computational Seismology (T. V. McEviliy and E. L. Majer)

The purpose of The Center for Computational Selsmology (CCS) is to provide a facility with a wide range of computational tools to serve DOE programs in the baslc energy sciences and other areas of energy research. Research over the entire spectrum of selsmology is carried out at CCS, from basic studies in earthquake source mechanisms to the applied work of reflection seismology. The corner stones of ccs are the solid theoretical base provided by the involvement with the departfi ment of Geology \& Geophysics and Eng ineering Geoscience from UC Berkeley, and the hardware and software facilities found at a national lab such as LBL.

In the pst year, having successfuliy lmplemented a solid base of software and addressed our data base problems, CCS has evolved into a useful and flexible research tool. CCS now has 1 ts own dedloated DEC VAX $11 / 780$ (VMS), in addition to significant Cray XMP access provided by DOE's office of Baslc Energy Sclences. The software base $1 \mathrm{~s}$ made up of some three years of our own efforts in coding internal analysis routines in addition to the processing tools of DISCO (DIgicon Inc., INGRES, (Relational technology) and the Geoquest Inc. AIMS package. We now have the ability to address research toplos that we were previously not capable of embarking on. For example, we nave been putting together a solld program in fracture detection using selsmologioal methods. The thrust is to integrate theoretical studies in wave propagation with the already existing software tools of reflection seismology and vertical selsmic profiling (VSP). In addition to this work, we are also supporting the data processing efforts of CALCUST, a consortium of several California universities to use innovat ive reflec tion techniques to address the structural complexities of California. Overall, cCS has grown into a mature research unit carrying out a broad range of research toplcs. Following is a list of the princlple res search projects during the last year. 
(1) CALCRUST, California Consortium for Crustal Reflection Studies.' "

(2) Use of Shear wave Vertical Seismic Profiling for Fracture Detection.

(3) Vertical Seismic Profiling at The Salton Sea Scientific Drilling Site.

(4) The Application of Tomographic Inversion Techniques to Seismic Data.

(5) The Application of Vertical Selsmic Profiling/Tomographic Techniques for The Delineation of Geothermal Reservoirs.

(6) The Development of Selsmic Techniques for the Real Time Monitoring of Grout Injections.

(7) The use of High Frequency Selsmic Monitoring for Mapping Hydrofractures.

(8) Crustal Velocity and Attenuation Modeling Across the San Adreas Fault Zone in Central California

(9) Synthetic Modeling of Global Digital Seismic Network Data

(10) Lateral Variations in Mantle P-Wave Velocity from Tectonically Regionalized Tau Estimates

(11) Tectonically Reglonalized source and Receiver Tau Perturbations for estimation of P-Wave Travel Time Corrections.

(12) Velocity Inversion of Near-Field Acceleration Data

(13) Aftershocks from Nuclear Explosions as Possible Indicators of Fault Movement.

(14) Data Base Studies with the Center for Seismic Studies

(15) Extremal Inversion of Static Earth Displacements Due to Volume Sources.

D. Test of an MHD Source for Crustal Electromagnetic Sounding (N. E. Goldstein and H. F. Morrison)

An engineering test of a horizontal loop electromagnetic sounding system using a magnetohydrodynamic (MHD) generator will be conducted in conjunction with field tests of the generator at a site in southern California. Crustal conductivity mapping will be greatly facilitated if compact and transportable electromagnetic loop sources are developed with moments $>10^{9} \mathrm{Amp}^{*} \mathrm{~m}^{2}$. The Russians have reported considerable success with such a system using MHD generators of up to $60 \mathrm{MW}$ with pulse durations of up to 10 seconds.

A $5.0 \mathrm{MW}$ prototype MHD generator has been built by STD Corporation of Monrovia, California. The unit is trailer mounted and can deliver multiple pulses of 10,000 Amp into a $0.06 \mathrm{ohm} 100 \mathrm{p}$ for 3 to 5 seconds. Further tests are planned in August-September 1986, using this source to drive an EM loop transmitter. With a square loop of $250 \mathrm{~m}$ on a side the moment will be $-6 \times 10^{\circ} A-m^{2}$, more than enough for sounding to 5 to 7 $\mathrm{km}$. Several soundings will be made using this source, SQUID mag netometers, a remote reference cancellation scheme, and accurate current monitoring. This experiment will yield a conductivity profile of an interesting geological area within $10 \mathrm{~km}$ of the San Andreas Fault and in the area of planned Cajon Pass hole. It will further enable us to access the practical limitations of this, and more powerful MHD generators, for future routine crustal surveys. 

Boreholes (M. S. King)

Fluid flow in rock is governed by the product of a single rock parameter, permeability, and the hydrological potential gradient existing in the rock mass. The determination of permeability is critical to any endeavor for which a knowledge of fluid flow is required. Such flelds of interest lie in geothermal energy extraction, oil and gas recovery, deep crustal studies, energy storage in aquifers, and the storage of hazardous wastes. In rocks of low porosity, including many igneous, metamorphic and massive calcareous types, the in situ pert meability is controlled by the presence of fractures rather than by the rock matrix permeability.

Geophysical borehole methods are avallable for detecting the presence of fractures adjacent to a borehole and therefore offer the potential to assess the rock mass permeability in those cases that it is control led by fractures. In particular, the borehole sonic log has shown considerable promise for locating fractures in rock. Field experiments have been conducted in which digitized sonic log waveforms were ob tained across single, horizontal, 1solated fractures intersecting a borehole in a crystalline rock mass. The fluid flow characteristics of these isolated fractures were measured using conventional borehole packer techniques, and the results compared. The field test will be extended to zones in the same rock mass where systems of fractures intersect the borehole, and again the results of sonic and conventional packer tests will be compared. The theoretical aspects of elastic wave propagation along a borehole intersecting a fracture of systems of fractures are also being studied, to establish the importance of frack ture parameters, such as frequency of occurrence, aperture, and roughness, on velocity and attenuation. The theoretical studies are

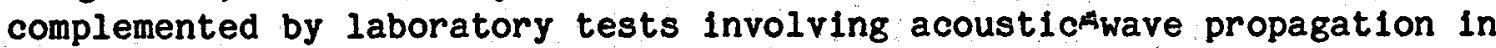
rock specimens containing systems of fractures and microcracks. The field and laboratory experiments, and theoretical studies will estabtlish correlations between acoustic wave parameters and the permeability of the rock mass adjacent to the borehole.

F. Microcrack Growth in Crystalline Rock (L. R. Myer and N. G. Cook)

The objective of this research is to develop a better understanding through theoretical and laboratory investigations, of the inter relationships between microcrack formation, changes in microcrack density, and the thermomechanical properties of crystaline rock. Analogous in many ways to the effects of microcracks on properties of laboratory slzed samples are the effects of joints and fractures on the thermomechanical properties of rock masses. Comparative evaluation of the effects of microt and macro ${ }^{4}$ cracks on physical properties of rocks has become an important element of this research.

In earlier stages of this research program fracture mechanics concepts were employed to evaluate the effective moduli of an elastic solid containing strongly interacting rocks. The same concepts have been 
used to evaluate the stiffness of a single fracture represented in two dimensions by a series of coplanar closely spaced cracks.

Stiffness of a single fracture is an essential element in a new model of the propagation of seismic waves across such a feature. Essentially, a single fracture is modeled as a zero thickness interface which produces a discontinuity in seismic wave displacements while seismic stresses remain continuous across the fracture. The magnitude of the seismic displacement discontinuity is dependent upon the stiffi ness of the fracture, that is, the ratio of stress to displacement across the fracture. A consequence of the theory is that the attenuation and decrease in group velocity of a wave propagating across a fracture is dependent upon frequency and the contrast in acoustic impedance between the fracture and adjacent rock.

The seismic displacement discontinuity theory has been verified in laboratory tests using steel samples with a single interface calculable stiffness. Laboratory tests have not been performed on cylindrical samples of granitic rock containing a single natural fracture. In these tests compressional and shear waves with a center frequency of about $400 \mathrm{kHz}$ were propagated across the fracture while it was sub jected to normal stresses ranging from about $1.4 \mathrm{MPa}$ to about $82 \mathrm{MPa}$. Effects of the fracture on wave propagation were evaluated from the ratio of spectral amplitudes of the measurements on the fractured sample to those of Identical measurements on the fractured sample to those of Identical measurements on a sample without a fracture. In addition to the seismic measurements, fracture deformations were obtained under quasinstatic loading conditions. From these measurements values of incremental displacement discontinuity as a function of stress across the fracture were derived.

Above a normal stress of about $70 \mathrm{MPa}$, the presence of the fracture had little effect on the transmitted wave as evidenced by a spectral ratio of nearly unity. Correspondingly, the incremental displacement discon' tinuity across the fracture approached zero. At lower normal stress the effect of the fracture was to cause a frequency dependent attenuar tion of the transmitted wave. Corresponding to the increase in attenuation was a significant increase in the incremental displacement discontinuity. As the normal stress across the fracture decreased the stiffness of the fracture also decreased, leading to the observed frequency dependent attenuation.

In addition to the single fracture seismic wave studies, a technique was developed for study of the effect of anisotropy in microcrack density on acoustic waves properties. In this technique, a cylindrical core is encased in a titanium sleeve and the space between the core and the sleeve is fllled with a Wood's metal-like alloy. Acoustic wave transducers are attached to the sample so that the wave propagate diametrically from one side of the sample to the other. By rotating the transducers around the sample of the effects of anisotropy on the wave properties can be evaluated. In an initial test on anisotropic Bandera sandstone, $a$ 10\% anisotropy in both compressional and shear wave velocities was evident. 
G. Advanced Research Concepts (T. V. McEv111y)

Research performed under this project allows selected new sclentific concepts in the Geosciences to be pursued to a stage sufficient for the investigator to present the concept in terms of a well formulated technical proposal. Work on such conceptual research topics may in clude literatrue reviews, scoping studies, first*order conputational efforts or generation of basic experimental data. New toples are selected annually based on the concepts' scientific merit, its relationship to Geosciences Program plans and the efforts potential contribution to the research missions of the Lawrence Berkeley Laboratory.

In fiscal year 1986 AGRC emphasizes innovative research initiatives in geophysical remote sensing of the earth's crust. Topics encompass early Investigations of long ${ }^{*}$ distance remote referencing of electromagnetic surveys, borehole $t$ based seismic profiling employing polarized shear waves, and acoustic tomography to character ize heterogeneous rock masses. A second activity is in the area of adranced hydrological/geochemical transport code development.

Beyond FY 1986, AGRC w111 emphasize characterization of physical chemical processes at great depths in the earth's crust. In addition to activities supporting the CSDP and URL initiatives, we plan to explore the concept of a centrifuge for $\mathrm{h} / \mathrm{gh}$ temperature (to $1600^{\circ} \mathrm{C}$ ) environments to investigate properties of silicate melts. 
Contractor:

Contract:

Category:

Person in Charge:
LAWRENCE BERKELEY LABORATORY

University of California

Berkeley, California 94720

DE-AC03-76SF00098

Geochemistry

T. V. McEvilly

A. Thermodynamies of High Temperature Brines (K. S. Pitzer)

This project covers theoretical and experimental studies concerning the thermodynamic properties of aqueous electrolytes at high temperatures. The components important in natural waters and brines are emphasized. The resulting data are important in understanding certain geothermal and other natural resources and in fission-product waste disposal. Moreover, this information has a wide range of applicability, since similar solutions arise in many industrial processes and in high pressure steam power plants.

The experimental program involves measuring the heat capacity and the density of solutions in the range 0 to $300^{\circ} \mathrm{C}$ and 0 to kbar. These measurements suffice to give a comprehensive equation of state, provided that other thermodynamic properties are known for a particular system at room temperature and pressure.

Theoretically based equations have been developed for the thermodynamic properties of aqueous $\mathrm{NaCl}$ valid from $273-823 \mathrm{~K}$, to $1 \mathrm{kbar}$, and to saturation with the solid. Recently, an equation was developed for $\mathrm{NaCl}$ in steam valid to the pressure of the three-phase line below $900 \mathrm{~K}$ and to 500 bars from $900 \mathrm{~K}$ to $1300 \mathrm{~K}$ and probably to still higher temperature. This result clarifies the $\mathrm{NaCl} \sim \mathrm{H}_{2} \mathrm{O}$ phase diagram where there were conflicting data above $900 \mathrm{~K}$.

Other theoretical work has yielded equations predicting the properties of mixtures based on the knowledge of the pure component solutions in water. In a number of cases, the calculated results for mixed brines are well verified by direct measurement. Phase equilibria can be predicted. In collaboration with the Whiteshell Nuclear Research Establishment, Atomic Energy of Canada, equations hąve bẹtn developed for systems involving such fission product lons as $\mathrm{Cs}^{+}, \mathrm{Sr}^{++}, \mathrm{I}^{-}, \mathrm{IO}_{3}$. When these data are combined with earlier results, a comprehensive treatment can be given of phase equilibria over a range of temperaturess for sol utions conțianing the gecochemically important lons $\mathrm{H}^{+}, \mathrm{LI}^{+}, \mathrm{Na}^{+}$, $\mathrm{K}^{+}, \mathrm{Cs}^{+}, \mathrm{Mg}^{+7}, \mathrm{Ca}^{++}, \mathrm{Sr}^{++}, \mathrm{Sr}^{+7}$, and $\mathrm{F}^{-}, \mathrm{Cl}^{-}, \mathrm{I}^{-}, \mathrm{IO}_{3}, \mathrm{SO}_{4}=\mathrm{HCO}_{3}$, $\mathrm{OH}^{2}$. 
B. Thermodynamic Properties of Silicate Materials (I.S.E. Carmichael, R. A. Lange, D. A. Snyder)

Accurate data for the thermochemical and physical properties of sillcate minerals and melts is tantamount to modern quantitative igneous petrology. There is a growing need for these data for predictive phase equilibria models, heat balance calculations during magma evolution, and for developing and constraining chemlcal models of silicate 11quids. It is the objectlve of this project to measure these thermodynamic parameters and the physical properties of silicates and their melts.

Currently, the emphasis is on determining the enthalples and enthalpies of fusion of refractory minerals. A highly accurate adiabatic high temperature drop calorimeter has been brought to its final stages of construction and is being prepared for calibration. This instrument w11l operate between 1800 and $2700 \mathrm{~K}$ and hence is sultable for measurements on corundum, $\mathrm{Al}_{2} \mathrm{O}_{3}$, and minerals (e.g., forsterite, $\mathrm{Mg}_{2} \mathrm{SiO}_{4}$, and spinel, $\mathrm{MgAl}_{2} \mathrm{O}_{4}$ ) that constitute the source regions of many magmas. Enthalpies of fusion of these minerals, whlch have never before been determined, promise to provide a large piece in the puzzle of magma generation and evolution.

\section{Generation of Petroleum and its Precursor Compounds (0. Weres)}

The objective of this project is to simulate the generation and evolum tion of petroleum hydrocarbons and their precursor compounds in the laboratory. The ultimate purpose is to improve understanding of the chemical reactions that produce petroleum in nature. The knowledge may lead to improved methods of findings and recovering oll and gas. This work has contributed to a better understanding of the hydrothermal chemistry of organic compounds, a topic with applications broader than petroleum geochemistry.

A variety of organic compounds and polymers have been reacted with clay and brine in an autoclave at $315^{\circ} \mathrm{C}$ for several years. The reaction products are extracted and ldentified using gas chromatography, coupled gas chromatography - mass spectrometry, and mass spectrometry.

A series of experiments with alcohols, alkenes, and alkanes have demonstrated why alkenes are largely absent from petroleum. Alkenes rapidly add to alkanes producing alkanes of higher molecular welght. All reactions of hydrocarbons may be explained in terms of free radical chain mechanisms, and there is no clear evidence for lonic reaction mechanisms.

Experiments with carboxylic acids have demonstrated the source of the abundance acetate ion in hot gas fleld waters. Larger molecules and polymers that contain carboxylate groups preferentially decompose to yleld acetic acid. Acetate then slowly decomposes to methane and bicarbonate ion, and may be an important precursor of natural gas in certain situations. 
A computer program which models phase relations in the system brine oil - gas at high temperature and pressure has been completed and used to explain the production of liquid hydrocarbons from geopressured gas wells. A small amount of oll is present, dispersed in the formation. The more soluble aromatic hydrocarbons dissolve in the brine, and are produced with the brine and gas. Gas dissolved in the brine combines with the remaining paraffinic hydrocarbons to form a supercritical gas phase, which is very fluid and able to migrate to the wellbore. Increasing production of gas condensate indicates the supercritical gas phase is migrating toward the wellbore, and appearance of alkanes CH8 and up indicates that production of oil is imminent.

D. Studies of the Interactions Between Mineral Surfaces and Ions in Solution (D. L. Perry)

This project determines the basic surface chemistry of common minerals (both synthet 1c and natural) and the chemical reactions of metal ions with the mineral surfaces. The research consists of the following areas: 1) basic spectroscopy of natural minerals and their synthetic counterparts, 2) spectroscoplc studies of the chemlcal states of metal ions that have been adsorbed onto the mineral faces from solution, and 3) syntheses and spectroscopy of model compounds that form in the mineral/metal ion reactions.

Multiple experimental techniques used in the spectroscopic studies include $x$-ray photoelectron, electron paramagnetic resonance, Auger, and infrared spectroscopy. Secondary ion mass spectrometry, along with depth profiling, has also been used to study the extent of radionuclide migration into the mineral bulk. The research to date has focused on the interaction of uranium with zeolites, components of basalt and tuff, two of the leading candidate host rocks for nuclear waste repositories.

Other research has involved the reductive chemisorption of high-valent metal ions such as uranium(VI) onto sulfide substrates (galena, pyrite, etc.). The chemical states of the metal ions can then be translated into oxidation states and functional groups and chemical species; this work is also being conducted using complementary laserioriented techniques (Raman and Fourier transform infrared spectroscopy).

The results of these studies will provide a more comprehensive under standing of the bonding between metal ions and geologic materials, and they will provide a larger data base for theoretical models used to predict metal ion migration in geologic media.

E. Ablogenic Methane Production from Igneous and Metamorphic Rocks ( $J$. Apps)

The purpose of this project is to determine the origin and conditions of formation of methane associated with igneous rocks. The possibility exists that methane derived from abiogenic sources may have contributed substantially to the world's oil and gas accumulations. The problem is being approached from three directions: (1) through examination of the 
thermodynamics of methane stability in the upper mantle and lower crust, (2) by theoretical simulation of the hydrolys is from mafic and ultramafic rocks between 25 and $500^{\circ} \mathrm{C}$. (3) through autoclave exper $1^{\mathrm{m}}$ ments of mafic rock hydrolysis between 150 and $400^{\circ} \mathrm{C}$.

Investigations have focused on refinement of the thermodynamic properties of minerals participating in hydrolysis reactions involving maflc and ultramafic rocks, and the role of seawater components in inhibiting or modifying methane formation. Computer code modifications to facilitate theoretical modeliing have been completed. Modification of an autoclave for experimental verification of theoretical modelling results is under way.

\section{F. Nonisothermal Reservoir Dynamics (C. F. Tsang)}

This project encompasses a wide range of fundamental studies of fluid, heat and solute transport in rock. These studies are relevant to geologlcal disposal of nuclear waste, chemical waste disposal, under 4 ground energy storage, geothermal energy and other energy-related problems. The goal is to better understand various physical and chemit cal transport processes in porous or fractured media and their effects, through theoretical considerations, mathematical modeling and laboratory investigations.

The following topics are addressed:

a. Coupled thermothydromechanical effects are being studied based on numerical modeling. The main computer code being used is rocMAS, developed by LBL under DOE funding. Besides applying to nuclear waste storage scenarios, a case study in petroleum reservoir rem search is also beling addressed. The latter is related to hydrofracturing an oil reservoir by injecting water that is colder than the formation temperature. Recent indications from an 011 fleld show that the pressure required for hydrofracturing is lower by about $5 \mathrm{MPa}$ in the nonisothermal than in the 1sothermal case. Such a study not only validates our computer code, but also provides the physical insight and understanding of coupled processes in oll reservolrs.

b. The work on borehole/surface resistivity measurement of hot water or contaminant plume movements in an aquifer is continuing. A small fleld experiment will be carried out to validate the tech nique and computer results. If proven by the field test data, we may have a useful and economic method to trace fluid plume movements. The project is jointly funded by the thermal energy storage program of DOE.

c. Advanced well test techniques are being developed with emphasis on nonkconventional measurements. Conventional methods mainly use pressure or flowhrate measurements while we are exploring methods involving temperature, tracer and geophysical measurements. These new testing methods are needed to better characterize the aquifers and fractured porous media of concern in toxic or radioactive waste transport. 
G. Chemical Transport in Natural Systems (C. L. Carnahan and J. S. Remer)

The existence of coupling between transport processes to create flows of heat, volume, and solutes driven by forces seemingly unrelated to the flows has been known for many years. The coupled effects cannot be explained within the framework of equilibrium thermodynamics nor by invocation of the classical phenomenological relations of Fourier, Darcy, Fick, and Ohm. A new approach, the thermodynamics of irrevers ible processes, has provided a theoretical basis for interpretation and study of the coupled processes, which include chemical osmosis, thermal osmosis, thermal diffusion (Soret effect), ultrafiltration, electroosmosis, electrophoresis, and coupled chemical diffusion.

We have been applying the thermodynamics of irreversible processes to theoretical studies of chemlcal transport in systems where the coupled effects could be expected to be significant relative to the direct effects predicted by Fourier's Law, Darcy's Law, and Fick's Law. Such systems are acted upon by gradients of temperature, pressure, and composition, and may contain materials that behave as semipermeable membranes, in which coupled osmotic effects are especially prominent. It appears from data reported in the literature that water-saturated clays and shales can behave as osmotic membranes in nature, creating, for example, observed anomalous pressure differences between aquifers of different salinities. In addition to their intrinsic geological interest, semipermeable clays are used as barriers to migration of toxic chemical wastes and of radioactive wastes at uranium mill tailings dumps, and have been proposed for use as barriers to migration of radioactive wastes at underground nuclear waste repositorles where thermal, as well as chemical, driving forces will be present.

During 1985, we developed a numerical simulator of the coupled (and direct) processes occurring in the presence of continuousiy evolving fields of temperature, pressure and composition. We extended previous work by others and derlved governing equations for temperature and pressure that include explicit contributions from entropy production by irreversible processes. Because of the nonlinear nature of the govern ing equations, considerable difflculty was encountered in their solution. In addition, no analytical solutions are avallable for verification of computed results, and many manual calculations have been done for this purpose. The results have been generally very good. Simulations run in the coupled modes have produced highly interesting results that agree qualitatively with our expectations of coupled system behavior. For example, in simulations with a boundary condition specifying zero flow of water in the presence of elther a solute concentration gradient or a temperature gradient, the computed pressure gradient is observed to change so that an advective flow of water cancels the chemical osmotic flow in the first instance or the thermal osmotic flow in the second instance.

Our research has been aided significantly by access to the Cray XaMP computer at the National Magnetic Fusion Energy Computer Center.

$$
-18-
$$


"H. Impacts and Mass Extinctions (L. Alvarez, F. Asaro, H. V. Michel, and W. Alvarez)

The overall objective of this project is to determine the relationship between asteroldal or other large-body impacts on the Earth and repeated massive extinctions of life which have occurred in the last 570 million years (MY). The primary mechanism for the research consists of intensive chemical and selective mineralogical studies (on sediments near both major and minor extinction boundaries) which are run in parallel with floral and faunal fossil studies by collaborating geologists and paleontologists. A secondary but major objective is to ascertain if a series of time markers of very high precision and accuracy (in the form of iridium and other geochemical anomalies) can be developed for relative dating and correlation of sediments in many different parts of the world. A minor objective is to evaluate the major chemical and mineralogical alterations which have occurred in the sedimentation of the $65 \mathrm{MY}$ old Cretaceous-Tertiary ( $\mathrm{K}=\mathrm{T}$ ) boundary, the one most closely linked to a large body impact, in order to predict the behavior expected in older boundaries.

We have bullt and tested an Irldium coincidence Spectrometer (ICS) which can measure low-level Ir contents of very calcareous samples after neutron irradiation 500 times faster than by instrumental neutron activation analysis with the same precision. No chemical separations are needed and the time for sampled preparation is very minimal. The instrument is 100 times faster than measurements made on partially separated iridium extracts which involve techniques developed at LBL in the past for large scale sampling. It is 10 to 100 times less labor intensive and more economical than analyses made on completely separated iridium fractions. The ICS is not subject to uncertainties in chemical yield of Ir like radiochemical measurements or the possibility of laboratory contamination by stable Ir carrier.

A $21 / 2$ year systematic search for Ir anomalies (utilizing our radiochemical separation method) in the 500,000 year span of the paleomagnetic zone anomaly 29 reversed (G-zone in Italy) has been completed. Besides the huge Cretaceous - Tertiary $(K-T)$ boundary iridium splke, - 3000 partsmpermtrililion (ppt) Ir, there is a plateau with sloping sides under the peak as high as $30 \mathrm{ppt}$ of Ir. The plateau extends 1.1 meters below the $\mathrm{K}-\mathrm{T}$ boundary into the Cretaceous system and up about 1.5 meters into the Tertiary system and rests on a background of $12 \mathrm{ppt}$ Ir.

The lack of any significant Ir anomaly over a halftmllition year span ather than the one at the $K-T$ boundary indicates these anomalies are very unusual events not related to ordinary deposition of sediments. These data give strong support to the asteroid (or comet) impact theory.

A prominent Ir anomaly (180 ppt) has been identified in - 39 million year old sediments form DSDP Hole 592 taken from between Australia and 
New Zealand. This is the most southerly $36^{\circ} 28.40^{\prime}$ south latitude) of the approximately 10 locations where this Iridium horizon has been identified and confirms its worldiwide distribution. Preliminary measurements indicate there may be considerable fine structure in the Ir anomaly with very small peaks ( $9 * 30 \mathrm{ppt}$ ) in the region 1 meter below to 14 meters above the main Ir peak.

Fine structure in Ir anomalies is expected if the theory of multiple comet impacts associated with periodic extinctions is correct. Also the enhanced deposition of cosmic dust associated with such impacts would lead to Ir plateaus under the major Ir anomalies. 
contractor:

Contract:

Catagory:

Person in Charge:
LAWRENCE BERKELEY LABORATORY

Uni versity of California

Berkeley, Callfornia 94720

DE $-A C 03-76 S F 00098$

Energy Resource Recognition, Evaluation, and Utilization

T. V. MCEvilly

A. Hydrothermal Chemistry (A. F. White and H. A. Wollenberg)

This project supports the CSDP program by providing geochemical input to define potential thermaliregimes drilling targets and to investigate those targets. Activities are centered at the Valles Caldera, New Mexico, Long Valley Caldera, Callfornia and the Salton Sea geothermal field Callfornia.

A detalled computer model of chemical reactions of hydrothermal fluids within the Valles Caldera has been completed. These are the first results from use of a reaction path model to characterize the hydrothermal evolution from initial ground water recharge to discharge from a thermal spring system. The model demonstrates quantitatively that the liquid and gas chemistry in the reservolr can be produced completely by reaction with reservolr rocks along a thermal gradient with no magmatic input required. High measured $\mathrm{CO}_{2}$ pressures are reproduced by sillcate metamorphic reactions in carbonate rocks underlying the caldera. Reaction kinetics were $e_{1}$ employed with an estimated reactive rock'water ratio of $0.5 \mathrm{~kg} . \mathrm{kg}^{\prime}$ based on an independent estimate from ${ }^{18} 0$ shifts and lithium mass balances. A total reaction time of $3.5 \times 10^{5}$ years was calculated for the hydrothermal system. The chemistry of the retrograde thermal discharge system cul imating in hot springs outside the topographic confines of the caldera was also modeled. Cationchloride radios indicate that chemical reequilibration ceases to occur at temperatures below $295^{\circ} \mathrm{C}$. The effects of chemical reactions on the $\mathrm{Na}-\mathrm{K}$ and $\mathrm{Na}-\mathrm{K}-\mathrm{Ca}$ geothermometers are quant 1 tatively explained. Fluld and gas samples were collected from the Casa Diablo geothermal fleld and other hot springs in Long Valley. The alteration mineralogy of rock cuttings from a number of wells is also being characterized. Integration of this data will permit characterization of equilibrium conditions in the Long Valley hydrothermal system. Isotope ratios of meteoric water, ground water, and rock are being investigated to determine the recharge source and circulation time of the hydrothermal fluids. Carbon-13 data indlcate that altered roof pendant carbonate rocks within the caldera are significant contributors or the dissolved $\mathrm{CO}_{2}$ in the geothermal fluids. The ${ }^{13} \mathrm{C}$ slgnature at Long Valley can therefore not be attributed solely to a magmatic $\mathrm{CO}_{2}$ source. 
The major project activity at the Salton Sea, in cooperation with LANL and SNL, has been attempts at in situ downhole sampling of brines at the SSSDP well. Due to high temperatures $\left(300\right.$ to $\left.350^{\circ} \mathrm{C}\right)$ and the cort rosive nature of the saturated brine, a large number of technical difficulties were anticipated and encountered in the use of downhole samplers. Two successful runs were made, one using the LANL twotilter evacuated sampler and one with the LBL flow through sampler. Analyses of fluids collected by both samplers are currently being conducted. Results will provide important information on effects of sampler design and comparisons with analyses of flashed wellihead samples obtained during a flow test.

B. Pre-Drill ing Data Review for the Long Valley Caldera, Calfornia (N. E. Goldsteín, T. V. McEvilly, H. F. Morrison, Harold Wollenberg)

The Long Valley caldera is one of the best studied Pleistocene silicic volcanic features in the world, and a prime candidate site for a phased, deep exploratory hole to penetrate into the "near-magmatic" environment. To help determine the site for this hole, LBL is coordinating and expediting the processing and interpretation of uninterpreted geophysical data sets for the caldera. This preadrilling data review, co-funded by DOE/GTD and DOE Basic Energy Sciences, will lead to a major workshop in early 1987, where improved interpretations regarding subsurface structure and thermal conditions will be presented. To carry out the data review we have identified all ret search being conducted in Long Valley and all researchers with data sets under or needing evaluation. Three working groups, seismology, electrical"gravity*magnetics, and hydrologyageochemistry, have been organized to keep the various researchers informed of what the others are doing and to plan presentations at the workshop.

New studies underway because of this project include:

a. 2-D and 3-D resistivity models, based on nearly 60 new magnetotelluric soundings, an airborne electromagnetic survey (INPUT), and various controlledsource soundings.

b. Processing and interpretation of two lines of high resolution CDP and wide angle reflection seismic data.

c. 3-D inversions of Pawave delay and seismic wave attentuation, using data from teleselsms and local earthquakes.

d. 3-D density inversions, using over 400 gravity stations with topographic, isostatic and regional corrections, and constraints from drill hole and seismic refraction analyses.

e. Combined interpretations of gravity, Pewave delay and magnetic data.

In addition to the new data from the $2346 \mathrm{ft-deep}$ Shady Rest core hole in the caldera's west moat, we are currently negotiating with Unocal, Geothermal Division to find a basis by which Unocal will provide us 
1th data from their 44-16 well in the west moat and their sets of surface geophysical data.. We have also Identified several studies recently completed by. graduate students that include a Curle 1 sotherm analysis based on the high level aeromagnetic data and 3 KD extremal inversions of vertical uplift and Pwave travel time data. Results of these studies will be folded into the subsurface models.

C. Reflection Proflling at the Salton Sea Deep Hole (E. Majer and T. V. MoEvilly)

As a first step in determining the seismic properties of the Salton Sea geothermal zone, a multi-source (PA, SVH, and SH), multi-offset Vertical Selsmic Propile (VSP) was carrled out in the Salton Sea deep well. The objective of this study is to determine the selsmic structure and lithology near and away from the well, and correlate the VSP data with the well $\log$ and core information. A second objective is to look below the well for reflections from the basement structure and/or other features that may be acting as reflectors, 1.e. plutions or other intrusive bodies. Also, the VSP data would be very useful for planning any subsequent surface reflection studies or further VSP work.

The VSP work was carried out late March of 1986. The VSP survey ex. tended to a depth of 5700 feet, at which point the high temperatures prohibited any further extension of survey. Two complete of isets were carried out in the 42 hours of $\mathrm{rig}$ time allocated. At the near $(500$ feet) and far (2500 feet) of fsets the three component geophone was moved from 5700 feet to 2000 feet in 50 foot intervals. At each interval in the well a $\mathrm{P}-\mathrm{SV}-$, and SH-wave source was recorded. In total, over 2000 "shots" were recorded at almost 150 levels in the well. Currently, the data are being processed at the Center for Computational Seismology at LBL. Preliminary processing indicates that there is severe $S$-wave attenuation at the bottom of the survey zone, with not as severe P-wave attenuation. After complete processing the velocity, attenuation and Swave polarization anomalles will be compared with the known structure. The VSP data will allow extrapolation of the physical properties measured in the well to zones below and away from the well.

D. Geophysical Measurements Facility (E. Majer and T. V. McEvilly)

The Geophysical Measurements Fac1lity (GMF) was established at LBL to facilitate the use of fleld instrumentation in BES and other programs, by estabilshing a facility to maintain geophysclal equipment in a fleldmready and callbrated state. Many projects that involve field measurements often are required unexpectedly to devote large propor tions of the funds refurbishing, renting, and/or buying equipment in order to carry out the experiment. The concept behind GMF is to minit mize the unexpected peripheral costs assoclated with the collection field data. BES developing programs such as Continental Scientific Drilling have heavy elements of fleld geophysical studies. By sharing properly maintalned equipment overall fleld costs w11l be minimized. GMF, whlle valuable in LBL programs, is meant to provide a facility avallable to all agencies particlpating in DOE programs. For example, Sandia has placed a portable drilling rig at GMF. 
The list of equipment at GMF is quite long, and it includes a variety of seismic (ASP(2), digital recorders, two seismic vibrators, VSP recording and processing system, acoustic emission system) and electrif cal instruments (controlled source EM, DC resistivity, SQUID magnetometers). There is also a large varlety of general field and test equipment (meters, scopes, etc.) at GMF. Ths most recent addir tions are a complete VSP recording and infield processing system, and a complete well logging vehicle. The well logging truck was donated by Dressertatlas. It will be outfitted with 18,000 feet of new high temperature $\left(300^{\circ} \mathrm{C}\right) 7$ itconductor cable. GMF is now serving many DOE programs; BES Geothermal, Waste Isolation, and it has succeeded in its goal of providing a pool of field'ready state-of-the-art equipment for the collection of geophysical. field data.

E. Geomechanical Laboratory Studies (L. Myer)

A study was initiated to obtain physical properties of core recovered from the Salton Sea borehole. Measurements will be performed in a test apparatus developed as part of a OBES-sponsored study of transport properties of rock-fluid.systems at elevated temperatures and pressures. Emphasis will be placed on measurement of acoustic wave properties and intact and fractured rock permeabilities. Measurements of compressional and shear wave velocities and attenuation will be made on cores from different depths to evaluate changes in these properties as a function of depth and proximity to production zones. Measurements will be made on both intact samples and samples containing fractures. This data will be important to the evaluation of VSP surveys already completed at the site.

The effort in the initial phase of this study was directed toward readying apparatus for measurement of the permeability of low per; meability rocks. The technique used for these measurements is based on the pulse decay method in which the permeability of a sample is related to the rate of decay over time of a small differential pressure over the length of a sample.

F. Continental Scientific Drilling Review Group (T. V. McEvilly and H. Wollenberg)

Technical analysis and reviews are carried out in connection with the proposed and ongoing Continental Scientific Drilling projects. For this purpose, appropriate experts are drawn together from other Federal Agencles, universities, industry and other DOE laboratories. For FY 1986-87 they are Kelit1 Ak1, University of Southern California; James Combs, Geothermal Resources International; William Dolan, AMAX; John Elchelberger, Sandia National Laboratories; Wilfred Elders, University of California at Riverside; Robert Fournier, United States Geological Survey; Carel Otte, UNOCAL; James Papike, South Dakota School of Mines; John Sass, United States Geological Survey; Daniel Weill, Chairman, National Science Foundation; Harold Wollenberg, Lawrence Berkeley Laboratory; Lee Younker, Lawrence Livermore Laboratory. 
G. Aqueous Solutions Database (S. L. Phillips)

The focus of this project is a National resource of mainiy generic chemical thermodynamic data for geoscientific research and advanced development. This computerized tabulation centers around internally consistent values of Gibbs energy of formation, enthalpy of formation, entropy and heat capacity mainly for inorganic materials at $25^{\circ} \mathrm{C}$ and at zero 1onic strength. Uncertainties are included for most values. From these intrinsic data, equilibrium constants can be calculated up to $300^{\circ} \mathrm{C}$ and saline brines for those reactions important to geoscientific research. Hydrolysis and complexation of metal lons, and solubility of silica are examples of chemical reactions. Besides generic geologic materials, data are avallable for minerals associated with basalts, tuff, granite and salt. Values of thermodynamic properties for several hundred geologic materials are available over ARPANET, and in LBL report 14996 (rev. 1). In 1986; a comprehensive model relevant to prediction of the blogeologlcal cycling of selentum in the aquatic/terrestrial environment was completed. Equilibrium constants were calculated, e.g., for solubility of metal selenides, formation of metal selenate ion pairs, and biomethylation of selenium. Property values for two methylation products $\left(\mathrm{CH}_{3}\right)_{2} \mathrm{Se}(\mathrm{g})$ and $\left(\mathrm{CH}_{3}\right)_{2} \mathrm{Se}_{2}(\mathrm{~g})$ were calculated based on the incremental change in $\Delta_{f} G$ and $S$ for $-\mathrm{CH}_{3}$ groups added to $\mathrm{H}_{2} \mathrm{~S}(\mathrm{~g})$, assuming the increment is 1 dentical for $\mathrm{H}_{2} \mathrm{Se}(\mathrm{g})$. The correlation coefficient for the linear relation was 0.99 . The selenium database was reviewed by recognized experts, prior to incorporation in the larger Aqueous Solutions Database.

A premprocessor was planned and designed together with M.D. Siegel of Sandia (Albuquerque) to permit use of our internally consistent therw modynamic database for statistical analysis of the various uncertainties relevant to the storage of nuclear waste materials. Important Gibbs energy values are selected with their assoclated uncer" tainties in the factorial design procedure, using the Sandia developed Lat in Hypercube Sampling methodology. The resulting equilibrium constants form the input data to the PHREEQE computer code.

H. Fundamental Studies of Fluid Flow in Fractured Rock Masses under Stress (P. A. Witherspoon, Y. W. Tsang and L. Myer)

Fluld flow and mass transport in fractured rock masses are processes of importance in many areas of practical interest such as the isolation of nuclear and toxic wastes, recovery of fossil fuel and the development of geothermal energy. Prerequisite to predicting these processes in a rock mass is an understanding of them in a single fracture. In this research, fluid flow and mass transport in a single fracture subjected to stress is being studied. Recent experimental evidence suggests that flow in natural fractures under modest stress is predominately through interconnected channels. A theoretical study has been completed in whlch fluid flow through a single fracture was modelled by flow in channels characterized by an aperture density distribution function and 
a spatial correlation parameter.: The aperture density distribution function was represented by a Gamma function consisting of one parameter. Thus channels with statistically generated aperture profiles were defined based on two parameters. Tracer transport be tween two points in a fractured media was represented by a number of such channels. Calculated tracer breakthrough curves were found to have features that corresponded well to those in recent data by other investigators. Calculated pressure profiles along the channels sug gested possible measurements that may be useful in identifying the geometrical characteristics of channels. Both the tracer breakthrough and pressure profile seem to be insensitive to the value of spatial correlation chosen. However, their dependence on the form of the aperture distribution function remains to be studied. Finally, predictions were made for tracer breakthrough curves in the case of a single fracture under various values of normal stress. These calculations showed that very small decreases in the mean aperture result in very large increases in breakthrough times because on flow rates of the effect of constrictions in the channel.

The laboratory phase of this program was begun with the measurements of the hydraulic conductivity of a single natural fracture in granite under normal stresses ranging from about $1.5 \mathrm{MPa}$ to $75 \mathrm{MPa}$. Flow tests were conducted on fractures orlented roughly orthogonal to the long axis of the cylindrical samples using the quadrant flow technique. In this technique fluid flow from one quadrant of the intersection between the fracture and the cylindrical surface of the sample is measured.

In addition to hydraulic measurements careful measurements were made of the mechanical deformation of the fracture in response to effective stresses up to $75 \mathrm{MPa}$. With a resolution of better than $0.5 \mu$ these measurements permitted a careful evaluation of the change in mean fracture aperture with effective stress.

At effective stresses of less than $20 \mathrm{MPa}$, the fluid flow was found to be proportional to the mean fracture aperture raised to a power somewhat greater than three. It is believed that this deviation from the "cubic law" is because changes in contact area with effective stress cause the effective hydraulic aperture of the fracture to change more rapidly than the mean aperture between the fracture surfaces. At effective stresses higher than $20 \mathrm{MPa}$, the mean fracture aperture continues to diminish with increasing stress; but this has little effect on specific flow because contact area is changing ilttle with increasing stress.

I. Transport Properties of Rock-Fluid Systems at Elevated Temperatures and Pressures (M. S. King, L. R. Myer, and W. H. Somerton)

The purpose of this research program is to develop and test a theoretin cal model for the transport properties of rock-fluid systems at elevated temperatures and pressures, with particular attention paid to the behavior of tight, crystalline rocks. Transport properties of such rocks are strongly influenced by the presence and distribution of interconnected fissures and cracks within the rock. These in turn are 
- " affected by chemical processes that take place at a given confining pressure and temperature in the presence of a pore fluid. Consequently, any model must incorporate a description of these features and their behavior at elevated temperatures and pressures. A promising point of departure for establishing such a model is to study the propagation of elastic body waves through a material containing a distribution of pissures and cracks of different shapes and sizes. Recent studies of models in which the pore configuration is assumed to be a population of oblate spheroids embedded in an elastic matrix has shown that elastic-wave velocity data may be successfully inverted to provide a spectrum of aspect ratios for regularly-shaped cavities. This approach is being extended to cover a material containing fissures and fractures consisting of rough surfaces in contact, in addition to regularly-shaped cavities. The theoretical model will be tested by inverting compressional and shear-wave velocity data obtained from tests on specimens of different rock types conducted in a multipleproperties, highfipressure, high-temperature cell now in the final stages of construction. This cell makes possible simultaneous measurements of several physical properties on a rock specimen as it is subjected to a prescribed cycle of changes in confining and pore pressure at different temperatures. The effect of chemical processes on these physical properties will be monitored before making measurements, and comparative observations made of prem and post-test changes in petrofabric and compressional and shearmwave velocities and attenuation; fluid permeability; complex electrical resistivity and phase- angle/frequency relationships; thermal conductivity, diffusivity, and expansion coefficient; bulk and pore compressibility. The multiproperties cell is currently being used to test the feasibility of a transient test method of low-permeability shale specimens. 
Contractor:

Contract:

Category:

Person in Charge:
LAWRENCE LIVERMORE NATIONAL LABORATORY

University of California

Livermore, California 94550

W-7405-ENG-48

Geology, Geophysics, and Earth Dynamics

Scope of Work

L. W. Younker

The Geology, Geophysics, and Earth Dynamles Program at Lawrence Livermore National Laboratory consists of six projects: (A) Rock Mechanics, (B) Diffusion in Silicate Materials, (C) Electrical Conductivity and Temperature in Upper Mantle, (D) Attenuation and Dispersion in Partially Saturated Rocks, (E) Surface Wave Method for Determining Earthquake Source Mechanisms with Applications to Regional Stress Field Studies, and (F) Advanced Concepts.

A. Rock Mechanics (H. C. Heard, B. Bonner and W. B. Durham)

This laboratory program involves high pressure - high temperature research in two broad areas: 1) Effects of porosity on the mechanical and transport properties of rocks, and 2) Intrinsic physical properties of rocks and minerals. Under 1), we are working on three subtasks. The first seeks to quantitatively characterize the surface topography of natural and artificial joints and fractures in order to relate this to joint stiffness and fluid flow. To do this, we have constructed a computer controlled profilometer and have made measure ments on natural fractures from Fenton Hill (NM) and Stripa (Sweden). The second subtask concerns thermal and pressure-induced microfracturs ing in crystalline igneous rocks. Here, we wish to understand grain boundary crack formation as caused by changes in pressure/temperature. The resultant goal is to obtain a predictive capability for microcrack generation and related physical properties under arbitrary pressure temperature paths as may be followed by cooling and unloading in the crust, by operation of a geothermal production area or in a high level waste repository. Using a simple inclusion model (Van der Molen, 1981), crack densities for three granitic rocks, a gabbro, and two basalts have been calculated by combining the high temperature, high pressure Young's modulus and bulk modulus data of Heard and Page together with the theory of O'Connell and Budiansky (1974). These are then compared with cracked densitles derived from laboratory measurements of thermal expansion from Page and Heard (1981) and Heard and Page (1983). For all six rocks, the results are dependent upon the $P, T$ path to which the rock is subjected. Considering the simplicity of the model, we believe the comparisons are quite close for the three granitic rocks. The model underestimates the crack densities of the quartzfree gabbro and basalts. These results have been published (Wang and Heard, 1985). We are now extending these studies to examine crack location, crack volume and crack aspect ratio in four laboratory tested granitic rocks over a range of $P, T$

$$
-28-
$$


conditions. Dlagnostic techniques used in these studies include opt 1 th cal petrography, differential thermal strain measurements, acoustic emission and compressional velocity techniques. The third subtask emphasizes measurement of thermal conductivity and thermal diffusivity. Here, we wish to understand how microcrack formation, microcrack opening or closure, affects thermal transport in igneous crystaline rocks under pressure. For use primarily on relatively finefigrained rock samples of the order of $2.5 \mathrm{~cm}$ in diameter, our automated measurement technique produces precise and accurate measurements in a relatively short time, allowing detalled studies to be made of subtle variations of diffusivity with pressure and temperature and of variations from rock to rock. Five different igneous rock types have been measured and the results are now in press.

There are also three subtasks which comprise the broad area of intrint sic physical properties of rocks and minerals. The first of these seeks to determine the operative slip/twin systems and their charac teristic critical resolved shear stresses for dolomite single crystals plastically deformed at high temperature, high pressure, and under variable strain rates. Such data will aid in sorting out the confused state of strength measurements in dolomite aggregates and will be useful in predicting dolomite behavior in nature. A series of compresti sion tests have been carried out on single crystals of dolgmitf at 800 $\mathrm{MPa}$ confining pressure, $500-800 \mathrm{C}$ and at strain rates of $10^{-3} \mathrm{~s}$. These crystals were tested in several different crystallographic orientations with respect to the loading axis in order to preferentially favor or minimize slip on a single system. Results from these tests were then compared to a similar test series of dolomite crystals accomplished at $10^{-5} \mathrm{~s}^{-1}$ strain rate. These samples are being examined using TEM techniques. We are, currently repeating these test serles but at a strain rate of $10^{\circ} \mathrm{s}$. A second subtask is underway to help interpret these flow data in dolomite crystals. This involves the determination of the seven elastic constants forming the stiffness tensor of dolomite at high pressures and temperatures. These data. will be taken in existm ing apparatus by the ultrasonic method:. The fast subtask inyestigates the effect of trace amounts $(0.1-0.6 \%)$ of $\mathrm{K}, \mathrm{Mg}$, and $\mathrm{Ca}$ upon the steady state flow of $\mathrm{NaCl}$ at high pressures, temperatures, and varlable strain rates. The rheologlcal behavior of five different doped materials were determined in stepped strain rate testing at $200 \mathrm{MPa}$ pressure, in compressigh and at temperatures (T) of $200^{\circ}-500^{\circ} \mathrm{C}$, strain rates $(\varepsilon)$ of $10^{-3}$ to $10^{\mathrm{s}}$ and stress $(\sigma)$ of 1 to $55 \mathrm{MPa}$. All secon dary creep results were well fit by a power law flow equation of the form: $\varepsilon=A$ exp $(\infty Q / R T) \sigma$ where $Q$ is an activation evergy for steady state flow and $A, R$, and $N$ are constants. Extrapolation of these results to naturally occurring halite formations indfate that steadyr $^{\prime}$ state creep rafes in impure halite containing $\mathrm{K}^{+}, \mathrm{Mg}^{+}$, and $\mathrm{Ca}^{++}$can be as much as $10^{\text {fo }}$ lower at $20^{\circ} \mathrm{C}$ and 
as much as $10^{4}$ lower at $200^{\circ} \mathrm{C}$. Such data are vital to the accurate prediction of the behavior of high level radioactive waste repositories constructed in impure salt. A paper describing these results is now in press and is to be published in May, 1986.

B. Diffusion in Silicate Materials (F. J. Ryerson, H. C. Weed, A. J. Piwinskii)

1) Oxygen diffusion in olivine. Oxygen diffusion in single crystal San Carlos peridot has been measured at $1200^{\circ} \mathrm{C}$ and $1300^{\circ} \mathrm{C}$ at oxygen fugacities equivalent to the Nickel-Nickel Oxide buffer. Diffusion anneals were performed in $99 \%$ " ${ }^{\circ}$ cenriched $\mathrm{CO} / \mathrm{CO}_{2}$ gas mixtures. Results to date can be described by the following Arrhenius Law,

$$
D=5.8 \times 10^{7} \exp (-158,000 / R T)
$$

where $D_{m}$ s given in $\mathrm{cm}^{2}: \mathrm{s}^{-1}$. The activation energy, 158 Kcal mol ${ }^{-1}$, reflects the effects of both increasing oxygen fugacity and temperature, and is approximately twice as large as that measured for grain boundary diffusion of oxygen in polycrystalline olivine (Watson, 1986). The apparent activation energy is in good agreement with that for plastic creep if a $1 / 6$ dependence on oxygen fugacity is assumed.

2) Diffusion in Accessory Minerals. Diffusion coefficients for Sm, ' $\mathrm{Sr}$, and $\mathrm{Pb}$ in fluorapatite at $900^{\circ} \mathrm{m} 1250^{\circ} \mathrm{C}$ were obtained by measuring experimentally induced diffusional uptake profiles to these elements in the margins of gem-quality apatite crystals. The crystals were immersed in synthetic melts enriched in the trace elements of interest and presaturated in apatite, and the resulting diffusion gradients were characterized by electron microprobe analysis. Except in the case of $\mathrm{Pb}$, the diffusivities define good Arrhenius lines for the respective elements:

$$
\begin{gathered}
D_{S m}=2.3 \times 10^{-6} \exp (-52,200 / R T) \\
D_{S r}=412 \exp (-100,000 / R T) .
\end{gathered}
$$

(Diffusion perpendicular to and parallel to $c$ is measurably dife ferent in the case of $\mathrm{Sr}$; the Arrhenius equation given above is an average for the two directions.) Results on $\mathrm{Pb}$ were erratic, probably because extremely $\mathrm{Pb}-\mathrm{rich}$ melts were used for some of the experiments. Data believed to be reliable define the following Arrhenius line:

$$
D_{P b}=0.035 \exp (-70,000 / R T)
$$


Constraints based on closure of natural apatites with respect to $\mathrm{Pb}$ suggest that the experimental data can be extrapolated, with sizeh able uncertainty, to temperatures as $10 \mathrm{w}$ as $550^{\circ} \mathrm{C}$. When applied to the question of isotopic and trace element equilibration of residual or entrained apatites with crustal melts, the measured diffusivities indicate that $0.05^{4} \mathrm{~cm}$ crystals will rarely preserve the original Pbisotope characteristics of the source; the same is not true, however, of Sr (and, under some conditions, the REE), which may be unaffected at crystal cores during typical melting events.

3) Thermodynamics of silicate melts. Phase equilibria and spectron scopic data are used to develop a simple model for the interaction of various oxide components and molten $\mathrm{S}_{2} \mathrm{O}_{2}$. Network modifying oxides, $\mathrm{M}^{\mathrm{O}}$ produce nonbridging oxygens thereby depolymerizing the $\mathrm{SiO}_{2}$ network. The energetics of nonbridging oxygen formation are least favorable when the field strength of the metal cation is high. This produces relatively strong M=0 and S1-0-S1 bridging bonds at the expense of weaker SiMOFM bonds (De Jong et al., 1980). This relationship is manifested by an increase in positive deviaf tions from ideality with increasing cation field strength in $\mathrm{M}_{\mathrm{x}} \mathrm{O}_{\mathrm{y}}$ $\mathrm{SIO}_{2}$ systems; the activity coefficient of $\mathrm{S}_{10}$ is inversely correlated with SifioGM bond strength. Network forming oxides (aluminates, phosphates, titanates, zirconates, etc.) may copolymerize with the $\mathrm{SiO}_{2}$ network. Mixing on the same quasis lattice produces solutions which approach ideality. Deviations from ideality in such solutions can be linked to distortions in the $\mathrm{S}_{10}$ network. Discrete anion formers (phosphates, titanates, chromates, zirconates) complex with metal oxides other than $\mathrm{SiO}_{2}$ to form discrete structural units which do not copolymerize with $\mathrm{SiO}_{2}$. The $\mathrm{SiO}_{2}$ network is essentially shielded from the high charge density cations in such systems and unmixing is common. As a result, the relative deviations from ldeality in such melts are high. It is important to recognize that oxides such as $\mathrm{P}_{2} \mathrm{O}_{5}, \mathrm{TiO}_{2}$ ' and $\mathrm{ZrO}_{2}$ may act as elther networkaformers or discrete anion formers depending upon melt composition, and are probably dist tributed between these two "sites" in most geologically important liquids. The latter structural role is favored in more basic compositions.

4) Thermal Constraints on the Emplacement of the Rhyolite Conduit at Inyo Domes, Long Valley Caldera, California. Emplacement of a rhyolite condult at Inyo Domes into granitold rocks caused a heating in the country rocks that is recorded by isotopic systems in the constituent minerals. To estimate the magmatic temperature prevaling during eruption, we have analyzed microcline mineral separates from drill cores of host rock samples adjacent to the 
contact by the ${ }^{40} \mathrm{Ar} /{ }^{39} \mathrm{Ar}$ age spectrum technique. When compared to a 'background' microcline sample taken far from the possible there mal effect of the volcanic rock, samples about 3 and 8 metres from the contact indicate radiogenic $\mathrm{Ar}$ losses of 51 and 23 percent respectively. The age profiles revealed by these experiments are characteristic of recent episodic loss and together with Ar diffuk sion data (obtained as a by product of the laboratory gas extraction) contain an integrated temperatureatime history of the magmatic event. Using a solution of the diffusion equation for a time edependent diffusion coefficient in a plane sheet geometry in conjunction with a conductive thermal model which describes the conduit as a 51 in wide slab, our results require an initial condult temperature of between 950 and $1000^{\circ} \mathrm{C}$, consistent with preliminary estimates from mineral pair thermometry. However, if flow through the conduit persisted for times much longer than several weeks, then we would be overestimating the initial temperature by our treatment of the problem as an instantaneous intrusion. if sample taken from a breccia zone within the conduit reveals ${ }^{40} \mathrm{Ar}$ loss which is indicative of relatively short residence time for the xenolith in the magma.

C. Electrical Conductivity and Temperature in Upper Mantie (A. G. Duba) (Joint research with T. J. Shankland at LANL)

The thermoelectric effect $S$ and electrical conductivity $\sigma$ in the mantle minerals olivine and pyroxene are being measured as a function of temperature, orientation, oxygen fugacity, and iron content. The results apply to inference of upper mantle temperatures from electrical data. Although there are seismic models to explain the low velocity zone (LVZ) as solidmstate phenomenon not requiring partial melting, the most wellinconstrained laboratory electrical measurements are more consistent with the partial melting hypothesis for the high conduct tivity layer (HCL) apparently associated with the LVZ. If the LVZ/HCL is not a partial melt layer, then mantle geotherms would be cont siderably lower than previously inferred on the basis of a partial melt zone under extensive regions of the earth. Hence, it is necessary to better understand electrical conduction in mantle minerals to find whether electrical data are an important constraint on the low temperature geotherms suggested by solid state explanations of the LVZ.

To date, we have measured thermoelectric effect concurrently with electrical conductivity in the three principal directions in olivine from San Carlos, Arizona, at $120^{\circ} \mathrm{C}$ to $1500^{\circ} \mathrm{C}$ under controlled oxygen fugacity. Although there is little change in the activation energy for conduction for olivine, $S$ changes $s i g n$ from positive to negative around $1400^{\circ} \mathrm{C}$." Thus, electron holes as small polarons are the probable dominant carrlers below $1400^{\circ} \mathrm{C}$; however, the sign change in $S$ indicates a change to conduction by negative charge carriers above $1400^{\circ} \mathrm{C}$ in olivine. The important consequence of the sign change in $S$ is that olivine is probably a mixed electronic-ionic conductor over this 
- Geophysically significant temperature range, thus resolving an old controversy in the fleld. We have concurrently measured thermoelectric effect and conductivity in forsterite in all three principal directions and under both oxidizing and reducing conditions and find results consistent with negative electronic carriers as the conduction mechanism.

D. Attenuation and DIspersion in Partially Saturated Rocks ( $J$. G. Berryman, B. P. Bonner, R. C., Y. Chin, G. W. Hedstrom, and L. Thigpen)

The objective of this project is to combine theory and experiment to analyze attenuation and dispersion of waves in partially or fully saturated rocks over a broad range of frequencies. The techniques developed in this work will be applicable to many basic problems in energy recovery, particularly hydrocarbon and geothermal exploration and resource assessment. The results will also impact code calculations for the Nuclear Test Containment Program and waveform analysis for the Seismic Verification Program. The major accomplishments of this project so far include: (1) In collaboration with the Ultrasonics Group, Department of Welding Engineering, Ohio State University, we have obtained results which suggest that the additional (slow) surface wave predicted by the theory of Biot and observed by us in manufactured porous materlals may also be present in porous rock. We are also currently investigating the bulk slow wave in greater detail. (2) Recent theoretical efforts have led to a theory of wave propagation in partially saturated porous media. The constants in this theory have been determined for two models of the relative distribution of the $11 q u 1 d$ and gas in the pore space. These results have also been shown to be in good agreement with experiments which have measured wave speeds in partially saturated Massilon sandstone.

E. Surface Wave Method for Determining Earthquake Mechanisms w1th Applications to Regional Stress Fleld Studies (H. J. Patton and $S . R$. Taylor)

This project utilizes selsmic surface waves to map lateral shear velocity varlations in the Bas in and Range of western United States. In addition, surface-wave observations and moment tensor inversion methods are applied to determine source mechanisms and depths of earthquakes in selected areas of the Basin and Range and surrounding geologic regions. Interpretation of the velocity structures including effects of anisotropy will give insights into the processes controling Iithospheric extension of the Basin and Range and into possible flow of magma in the crust and upper mantle. Source mechanisms and depths along with better structural information will improve knowledge of the reglonal tectonic stress fleld and provide constraints useful for geophysical models of convective hydrothermal systems.

Our structural investigations have resulted in estimates of the lateral varlation of shear-velocity structure through the application of standard tomographic methods to an extensive dataset of Love- and Rayleighwave dispersion curves. Significant lateral heterogeneity is found to depths of over $80 \mathrm{~km}$, and in some areas there is evidence for 
shear-wave polarization anisotropy. We have published these results and are following them up with further investigations to confirm structures in particular areas of interest. As part of a cooperative study under the auspices of this program and the Institute of Geophysics and Planetary Physics (IGPP) here at Livermore, a field experiment consisting of a linear array of 12 three-component sensors about $350 \mathrm{~km}$ in length was carried out in northwestern Nevada to record broadband seismograms from an explosion at the Nevada Test Site. The data col lected on this experiment is still being processed, but preliminary results support the findings from our earlier tomographic studies showing high Rayleigh-wave velocities in a $300 \mathrm{~km}$ square area encompassing the Carson Sink, a major geologic structure associated with putative continental rifting. We have also published in the past year our results of studying source mechanisms of seven western United States earthquakes, four of which showed $P$ wave fault plane solutions inconsistent with surface-wave excitation. The discrepancies were reconciled in terms of probable errors in the Pawave solutions. For events in or on the margins of the Basin and Range, the minimum compressive stress axis is horizontal and oriented $\mathrm{N} 85^{\circ} \pm 16^{\circ} \mathrm{W}$.

F. Advanced Concepts (R. N. Schock and L. W. Younker)

Several activities were covered in this area. R. N. Schock and A. Duba collaborated with Prof. H. Tuller in the Electrical Engineering Department of MIT to analyze experiments on the electrical conductivity of olivine, and to plan new experiments to further elucidate conduction mechanisms in this mineral. The objective of this work is to undert stand the fundamental point defect structure of silicate minerals since it is now believed that point defects are responsible for all of the electrical, and most of the physical and acoustic behavior of minerals in the lower crust and mantle.

S. R. Taylor wrote a major review article summarizing the geophysical framework of the Appalachian Mountains. The article, contained in LLNL report UCRL-94837, is to be published in a GSA Memoir entitled "Geophysical Framework of North America", edited by L. Pakiser and.W. Mooney.

L. W. Younker participated in the development of a science plan for a Continental Drilling Program at Katmai Volcano, Alaska. 
$\therefore \quad$ Contractor:

Contract:

Category:

Person in Charge:

Scope of Work

The Geochemistry Program at Lawrence Livermore National Laboratory consists of two projects: (A) Thermodynamic, Kinetics, and Transport in Aqueous Electrolyte Solutions, and (B) Kinetic and Compositional Model of HighaPressure Kerogen Pyrolysis. Studies include laboratory measurements of diffusion coefficients and activity coefficients for mixed salts, and development of a model for the conversion of kerogen to oil and gas over a wide range of heating rates, temperatures and pressures.

A. Thermodynamics, Kinetics, and Transport in Aque Solutions (J. A. Rard and D. G. Miller)

Aqueous transport of dissolved chemical species is important in a wide varlety of geochemical phenomena. Geochemical applications include radloactive and chemical waste isolation, diagenesis, ore formation, and some mineral crystal growth and dissolution kinetics. Mutual diffusion coefficient data are required to understand and model these processes. Little data of thls type have been published, and the largest portion of accurate data have been measured at LLNL. Diffusion data are now avallable for most of the individual brine salts and for several other salts of diagenetic interest at $25^{\circ} \mathrm{C}$, but very iltte data are avallable for mixtures or at higher temperatures.

Osmotic and activity coefficients are required for thermodynamic equilibrium calculations, including speciation in solution, reaction thermodynamics. and solublitty calculations in brines. Activity/osmotic coefflcient data are avallable for many single salts in water, but such data are unavallable or inadequate (In quality of extent) for many important mixtures.

We have now completed mutual diffusion measurements for ten of the desired twelve compositions of aqueous $\mathrm{NaCl}-\mathrm{SrCl}_{2}$ at $25^{\circ} \mathrm{C}$. This system

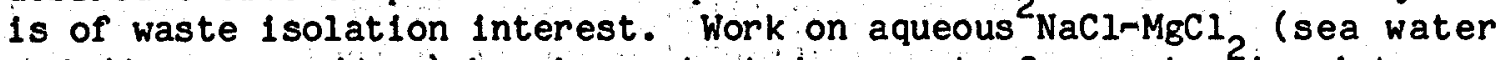
and its evaporites) has been started as part of an extensive internam tional collaboration to characterize the transport properties of this system. Our part, among the seven Amerlcan, Australian, Canadian, and German laboratories, is to determine the mutual diffusion coefficients for 12 to 15 compositions and to determine the lonic Onsager coeffim clents $1_{11}$ These will be compared with a new electrolyte theory of Friedmall: The results may be useful in predicting diffusion in geochemical systems. 
Extensive Isopiestic activity experiments have finally been completed for aqueous $\mathrm{NaCl}-\mathrm{MgCl}_{2}$ at $25^{\circ} \mathrm{C}$, and these data are presently being analyzed by Pitzer's method and by Scatchard's neutral electrolyte approach.

Theoretical work was continued on the theory of double diffusion convection as applied to multicomponent diffusion.

B. Kinetic and Compositional Model of High-Pressure Kerogen Pyrolysis (A. K. Burnham and J. J. Sweeney)

The objective of the work is to develop a model, applicable to dife ferent types of kerogen, of the conversion of kerogen to oil and gas that can be used over a wide range of heating rates, temperatures, and pressures. We want to be able to use the model to interpret laboratory and field data, such as Rocksteval results, and to quantify and predict the maturation state of hydrocarbons in a geologic basin with a known thermal history. The model calculates changes in composition of the oil and gas fraction with time and temperature. The compositional changes have been used to develop indicators of hydrocarbon maturity levels which can be used to make predictions for comparison with pubi lished data about present-day hydrocarbon composition and maturity levels in an oil field. We used geologic and geophysical data to determine the time temperature history of the kerogen-rich. (Type I lacustrine) Green River shale in the Uinta Basin of Utah. This thermal history was used in our chemical kinetic model to calculate the hydrocarbon maturity of the shale at the present day and at different depths and locations in the basin. We were able to estimate the true maturity of hydrocarbons recovered from the basin by using published chromatograms and results of Rock-Eval analyses. For the deepest parts of the basin, where migration is less likely, our model calculations of maturity agree very well with the estimates of the true maturity. In a part of the basin where our calculations indicate that the source rocks are very immature, the recovered oil shows a much higher estimated true maturity; this result is consistent with the theory that the ofl in this part of the basin has migrated from elsewhere. These results show that our pyrolysis model is valid when extrapolated to conditions on the geologic scale and that it can be used to study the details of hydrocarbon compositional changes with maturation and separate these changes from those due to other factors such as migration.

During the past year we have been continuously upgrading our model by making it easier to input parameters and by creating the capability to calculate more properties that can be measured in the laboratory. The

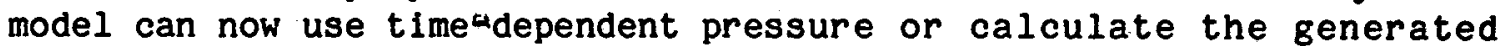
pressure in a sealed system. It currently calculates $\mathrm{H} / \mathrm{C}, \mathrm{N} / \mathrm{C}$, and $\mathrm{O} / \mathrm{C}$ ratios in the generated ofl and remaining solids, parameters related to the biomarker concentration of the generated o11, and the Rock-Eval transformation ratio in the absence of gas generation. We will soon be able to calculate the transformation ratio and the hydrogen index with contributions from the gas phase included.

$$
-36-
$$


We have also been making changes in the network of reactions used in the model to better account for gas generation and the effects of hydrogen pressure. We have included reactions incorporating a two-step coking process in which $\mathrm{CH}_{4}$ and $\mathrm{H}_{2}$ are released sequentially. We now can incorporate the cracking of $\mathrm{C}_{2} \mathrm{C}_{4}$ hydrocarbons to methane and allow for reactions of $\mathrm{H}_{2}$ with char and cokable oll that produce $\mathrm{CH}_{4}$ and uncokable oll, respectively. We have also devised a means to account for the dependence of pyrolysis stolchiometry hydrogen pressure.

Other work we have been doing on the model involves the study of act tivation energies used in the kinetic expressions. It has been observed by many workers that activation energies $(E)$ for pyrolysis of some kerogens and oils are small compared to those expected from chemin cal bonding data and that the $T$ of Rockteval analys is (the temperature at which 011 is generated most rapidly) often increases with maturity of the source rock. We are using our model and kinetic analysis programs to numerically study the effect of using a narrow distribution of activation energies in these situations.

All of this work is aimed at optimizing our abllity to characterize the process of conversion of kerogen to 011 and gas over conditions ranging from geologic basins to laboratory pyrolysis. We are in the process of obtaining kerogen samples of different types from different geologic basins that have a wellfknown thermal history. Eventually we hope to apply our model to the analysis of hydrocarbon generation and migration to other economically important basins, and develop a generalized calculational method for a wide varlety of kerogen types. 
Contractor:

Contract:

Category:

Person in Charge:

Scope of Work
LAWRENCE LIVERMORE "NATIONAL LABORATORY

University of Callfornia

Livermore, California 94550

W $7405 \div$ ENG -48

Energy Resource Recognition, Evaluation and Ut1lization

L. W. Younker

The Continental Scientific Drilling Program at Lawrence Livermore National Laboratory has focused on three research drilling efforts: Inyo Domes Drilling Project, Salton Sea Shallow Hole program, and the Salton Sea Sclentific Drilling Project. Additional CSDP related projects include a Continental Drilling Program Information and Data Management service, laboratory measurements of $v$ iscosity and electrical conductivity of rock melts, and seismic studies of possible magma related features in the Long Valley region.

A. Continental Drilling Program Information and Data Management Unit (G. Pawloski)

The extremely high cost of drilling makes it crucial that the geologic community be kept informed of the avallability of drill holes and the data obtained from them. Numerous government agencies, research groups, and industry firms have drilled holes for a variety of scientific purposes. In some cases, information has been disseminated on the avallability of these holes for research purposes, and cooperative programs have been initiated between a number of academic, government, and industrial groups. More often, however, this information has not been disseminated, and interested researchers have been unaware of the avallability of these drill holes until it is too late to participate effectively, or monies are spent drilling an unnecessary new hole. An information system has been established to avoid this problem. The efforts of a Continental Scientific Drilling Program (CSDP) can be expedited, unnecessary expenditures limited, and maximum effectiveness attained by (1) utilization of premexisting information; (2) reopening of abandoned holes; (3) participation in current industry drilling tests; and (4) participation in the drilling and study of future wells.

LLNL has developed a computerized data base, with software for plotting maps, for drill hole data acquired from research projects, and is providing information to the sclentific community on plans and drilling activities when requested. This year, effort was also devoted to the expansion of a separate computer file of information on drill holes which reached basement rock in the U.S. This file is the only such source of this information since a list was produced by the AAPG Exploration Committee in 1969. Our flle was assembled because of many requests from researchers about information on depth to basement in the U.S. 
LLNL has also established, using TERRASTATION, a site specific data base for the Salton Sea Geothermal Area, the location of a CSDP dedit cated drill hole. The data base contains information on 18 wells in the Salton Sea Geothermal Area near the dedicated well. The computer system, with the data base, was located at the well site throughout the drilling perlod. Geophysical $l o g$ data was read into the system of $f$ of field tapes soon after logs were run. This allowed timely predictions ahead of drilling using data from drill holes located in the area, and correlations of data from the new drill hole to existing drill holes. Geophysical and 11 thologic data was stored and processed on-site to infer information about the wells. LLNL is currently assisting the USGS in producing a data report on this dedicated drill hole, using output from the TERRASTATION.

B. Viscosity and Electrical Conductivity of Rock Melts: Continental Sclentific Drilling Program (A. J. Piwinskil, F. J. Ryerson, and H. C. Weed)

The rheological behavior of magmatic systems has a large influence on their ablilty to transfer heat and mass, both above and below the 1iquidus. Though much information is avallable about the viscous behavior of superliquidus magmas as a function of composition and temperature, little is known about the rheology of subliquidus systems. The goal of this program is to determine how rheological behavior is affected by bulk rock compositions, residual liquid composition, the volume of suspended crystals, and the temperature.. In order to do this, we are combining the results of onetatmosphere phase equilibria and experimental viscometry. The amount and type of crystalline phases present and the composition of the residual liquid can be determined as a function of temperature from the results of the phase equilibria. These characteristics of the system can then be correlated with the results from viscosity measurements.

Viscosity measurements are usually performed by fixing the temperature, and then determining the torque produced while shearing the sample at various fixed rotational speeds. We have now automated the viscometer so that the rotational speed and temperature can be elther fixed or else continuously varied as a function of time. The result is a digital or graphic record of temperature, torque, and rotational speed as functions of time.

We are using the automated viscometer to determine the rheological behavior of a calcialkaline basalt from Medicine Lake Highlands. Under continuously varled rotational speed at constant temperature, the basalt behaves as a non Newtonlan, pseudoplastic system. At $1210^{\circ} \mathrm{C}$ it is about 8 times more viscous than a tholeiltic basalt from Kilauea Iki, which we have already found to be pseudoplastic. This is ath tributed to the higher concentration of aluminum in the Medicine Lake system.

In addition to determining the rheological behavior of the basalt, we are instaling a new operating system in the viscometer computer to increase 1 ts efficiency. This of fers a substantial improvement in our capabilities for data reduction and modeling of the results. 
c. Seismic Studies of Possible Magma Injection and Magma Chambers in "ine Long Valley Region (J. J. Zucca, N. R. Burkhard, and A. T. Smith)

Resurgent Dome Area

Lawrence Livermore National Laboratory (LLNL) deployed a smail network of 14, three-component, digital selsmographs during August 1982 in the Mono-Craters area which is located just north of Long Valley Caldera. The network recorded a number of small earthquakes located to the south of Long Valley. One event shows a clear arrival between the $P$ and $S$ phases which appears to be a reflected phase that other researchers have observed in the Long Valley area. The reflected phase follows the P arrival by approximately $4.3 \mathrm{sec}$. The apparent velocity of the reflected arrival is approximately $7.0 \mathrm{~km} / \mathrm{sec}$ and particle motions Indicate that the reflection arrives at the surface as a $P$ wave. Travel time and amplitude modeling of the $P, S$ and reflected waves suggests that the reflected arrival is a $P$ to $P$ reflection from the base of a low velocity layer (LVL). The layer $1 \mathrm{~s}$ approximately $16 \mathrm{~km}$ thick and has a velocity contrast of $20 \%$ with the basement rocks. The base of the LVL apparently consists of high-velocity $(7.0 \mathrm{~km} / \mathrm{sec})$ material. A zone of partial granitic melt floored by ponded basalts or mafic. cumulate rocks could account for the computed velocity structure.

Western Moat - Inyo Dome Area

The Inyo Domes in the Long Valley Caldera are a line of rhyolite domes and associated phreatic craters produced approximately 600 years ago. A continuous dike between the domes and the explosion craters was postulated based on the mapping of surface features running from south of Deer Mountain northward to Obsidian Dome. Through this area, the dike trend is marked by grabens and extensional cracks seen on the surface. Corehole RDO-3A, drilled into a dike just south of obsidian Dome, encountered a broad ( $>100 \mathrm{~m}$ wide) zone of heavily fractured granite around the intrusion. Models of the mechanics of intrusion of this dike and its relation to the regional stress field make predick tions about the geometry of these features, and their changes with depth. Two seismic reflection surveys were shot September 27-29, 1985 crossing the trend of the dike north and south of Obsidian Dome. These surveys were designed for two purposes: (1) to determine if the dike can be detected with a surface seismic reflection technlque, and (2) to identify structural features associated with the intrusive process. The east-west CDP lines with up to 30 fold coverage and 55 foot group spacings were collected by Petty $\rightarrow$ Ray Geophysical shooting $1 / 1 / 2$ pounds of explosives in auger holes. Preliminary processing shows three results: clear reflections from the volcanic section above the Sierran Granite, a buried $460 \mathrm{~m}$ wide graben north of Obsidian Dome similar to that mapped on the surface in the southern portion of the chain, and localized reflections within the Sierran Granite $(1-2.5$ secs two way time). These localized reflections may come from the intrusion or from disturbed zones produced during intrusion.

$$
-40-
$$


D. Shallow Hole Investigations of Long Valley, Valles, and Salton Sea Thermal Regimes (L. W. Younker, P. W. Kasameyer, R. L. Newmark, and N. R. Burkhard) (Cooperative program with SNL, LANL, and LBL)

\section{Salton Sea Shallow Hole Program}

Analyses of thermal and 1 thologic data from industrial driliholes in the Salton Sea Geothermal Field (SSGF) has led to conflicting models for the natural circulation patterns in that hydrothermal system. These models agree on ultimate source of heat, on a young age for the present hydrothermal system, and on the general role that geochemical alteration plays in controlling permeability. However, they differ in several important areas: the degree of localization of the heat source, the direction of recharge, the relative importance of thermallymdriven and compositionally-driven convection, and the amount of vertical flow throughout the system. All models reproduce the uniformly high temperatures and geochemistry seen in the center of the fleld, but predict significant differences near the periphery and at greater depths in the field.

Resolution of these uncertainties has been limited by the difficulty of collecting thermal data under the Salton Sea, which covers a large part of the area of interest. Analyses of data released by a geothermal operator in the area (Kennecott) led us to the following conclusions:

1. The data from 250 foot holes will adequately represent the thermal regime in the "cap" of the geothermal field. Our previous experlence with deeper holes on land will enable us to extrapolate these temperatures to depths of $2-3000$ feet.

2. The offshore gradients are considerably lower than the earlier gradients measured in the upper 6 feet of sediments.

3. Contours indicate that the anomaly is probably centered over the Salton Buttes.

In order to collect data in the unexplored offshore area, as part of the Shallow-Hole Initiative, a heat flow survey with orliliholes apm proximately 250 feet in depth was undertaken in the fall of 1985. During November and December, 1985, nineteen holes were drilled $250 \mathrm{ft}$. below lake level of fshore in the region north of the volcanic domes whlch lle along the southern short of the Salton Sea. Temperatures have been logged perlodically in each hole and w111 continue to be logged up to about three months after drilling to ensure that temperam tures have reached equilibrlum. Natural gamma logs were run in several of the holes, short ( $3 \mathrm{ft}$. ) cores were obtalned from the bottom of four holes and cuttings were collected in all holes every ten feet when possible. Thermal conductivities are being measured on a number of core and cutting samples which represent the range of lithologles encountered. Particlpating scientists from organizations outside the national laboratories are conducting studies of the recovered material including analysts of the degree of alteration through study of both the pore fluids and solids and measurements of the bulk helium content. 
Thermal gradients over the lower $150 \mathrm{ft}$. range from about $.09{ }^{\circ} \mathrm{C} / \mathrm{m}$ to over $.92^{\circ} \mathrm{C} / \mathrm{m}$. Thermal conductivities measured on samples within hours after drilling range from about $.4 \mathrm{~W} / \mathrm{mk}$ to over $1.3 \mathrm{~W} / \mathrm{mk}$. Preliminary results indicate a pronounced asymmetry of the high temperature resource relative to the chain of volcanic buttes. These results provide valuable constraints on the size and shape of the thermal anomaly and the transition zone. We anticipate that these data will allow us to refine our models of the hydrothermal system at the Salton Sea Geothermal Field.

The Research Drilling Office at Sandia has been the operator for this experiment, and also provided the personnel and system for temperature logging. At present, we are still collecting data and have begun the process of analysis and interpretation.

Inyo Domes Drilling (Joint Research with SNL and MSU)

The three research holes cored into the Inyo Domes chain of 600-yearold rhyolite volcanoes have provided continuous samples and observations in near and far vent sections through the largest lava dome, the condult of the dome, and the feeder dike between domes. The suite thus includes samples cooled at time scales ranging from seconds to tens of years and emplaced under loads ranging from 1 to 200 bars. The prime objective of the thermal modeling work is to develop a detailed description of the thermal evolution of the Inyo magma in these four locations already sampled and in locations within the cal dera as sampled by the proposed drilling program, using constraints provided by the drilling, geophysical surveys, surface mapping, and geochemical studies on the core. This thermal history will be combined with results from an analysis of the core to develop an overall combined thermal/crystallization/degassing model for the Inyo event. Ultimately, the combined validity of the model will be tested in experiments using calculated cooling histories and appropriate water contents. The experiments will be run to see whether the widely varying crystallization behavior observed throughout the magma system can be duplicated.

Initial modeling will be based on observations from the thermally and geologically simple northern part of the chain. The hole proposed for FY87 will allow observations in the more complex. setting of the Long Valley Caldera. A similar modeling approach will be applied to obseri vations from the caldera hole. From the standpoint of thermal evolution, chief differences inside the caldera include: 1) the possibility that the dike is larger and/or closer to the surface, 2) the dike was emplaced into a pre-existing long-lived hydrothermal system, and 3) the heat transfer regime surrounding the intrusion was dominated by convection. Combined and comparative analysis of the thermal evolution of the Inyo dike in these two contrasting environments will enable us to test existing thermal modeling capabilities as well as assess the significance of several widely used geothermometers in these welledefined environments. Estimates of the thermal state of the Inyo dike will, in addition, also allow us to assess the significance of its contribution to the overall caldera thermal budget. 
E. Salton Sea Sclentiflc Drililng Program Solence Management Activities (A. G. Duba, P. W. Kasameyer, and L. W. Younker)

We have particlpated in the planning and execution of all phases of the SSSDP over the past year. The well was completed to 10,564 feet on March 17, 1986. The post drilling sclence phase at the SSSDP site was completed on March 31, 1986, with the exception of temperature measure ments which will continue for approximately six months. The SSSDP has produced over 700 feet of core, cuttings from most of the well at 10 foot intervals, commercial logs as well as USGS logs, and fluids from 2 depths. A preliminary report on the results of the program is being planned for the Geothermal Resources Counc1l Meeting to be held in Palm Springs, September 29, 1986 - October 1, 1986.

F. SSSDP: Constraints from Borehole Gravity on Geothermal System Models and Resource Definition for the Salton Sea Geothermal Field (J. R. Hearst, P. W. Kasameyer, and L. W. Younker)

A commercial borehole gravimeter will be modifled and tested to survive temperatures up to $250^{\circ} \mathrm{C}$. Gravimetric data will be collected in the SSSDP deep hole in the Salton Trough to the depth allowed by cooling the hole. The observed data will be compared to information from a density 108 to estimate the properties of structures hundreds of meters from the borehole. This experiment will demonstrate the usefulness of borehole gravity in a geothermal environment, and provide information regarding the lateral extent and shape of the dense "metamorphic zone" (of Randall).. The detalls of the lateral terminus of this zone have strong implications for different models of the evolution of the hydrothermal system in the Salton Sea Geothermal Field.

G. SSSDP: Physical and Chemical Laboratory Studies of Cores from the Salton Sea Scientific Driliing Project ( $W$. D. Daily and $W$. Lin)

We presently have the unique capability to measure electrical resistivity, compressional wave velocity, fluid permeablitty, and fluid chemistry simultaneously on a rock sample under in situ conditions to 8 $\mathrm{km}$ depth and temperatures up to $200^{\circ} \mathrm{C}$. We propose to extend this capability to $300^{\circ} \mathrm{C}$ and study the behavior of samples from the SSSDP drill hole under in situ conditions. The experiments will provide insight into the interpretation of well 108 and surface geophysical data, understanding of water transport mechanisms, interpretation of flow tests, and the extrapolation of properties measured in the borehole to greater depths.

H. Undergound Imaging (W. D. Daily, and J. G. Berryman)

The thrust of the underground imaging effort is development of data collection methods, data processing procedures, integrated data interpretation techniques, and enhanced means of data presentation in order to characterize the subsurface environment. Our work involves develop ing improved laboratory and fleld instrumentation, acquiring fundamental data on the properties of materials under varied conditions in the laboratory, and improving the overall data interpretation 
process. The results of this project will benefit many DOE programs including nuclear waste emplacement and monitoring, test ban verifica tion through on'site inspection and cavity detection, enhanced oll recovery, and basic research through imaging the detailed flow patterns of fluids in fractured rocks. A vigorous program is in progress to continue development of computed Impedance tomography (CIT) for geophysical applications: (1) Recent progress in field applications has included a comprehansive study of electromagnetic probing of the layered earth. For cross-borehole work, two 2 in computer codes have been written to do forward modeling of apparent resistivity for various electrode configurations. We have found several crosstborehole probing configurations which are more than an order of magnitude more sensitive to a conductive anomaly than that of conventional probing configurations. (2) In the laboratory, an automated data acquisition system has been built. (3) A method of displaying the CIT data as a function of time via video tape is currently being implemented and will become avallable for use in the near future. (4) Work has also been initiated to develop new, more quantitative algorithms for interpreting the laboratory CIT data. 
Contractor:

Contract:

Category:

Person in Charge:
LOS ALAMOS NATIONAL LABORATORY

University of California

Earth and Space Sciences Division

Los Alamos; New Mexico 87545

W-7405-ENG-36

Geology, Geophysics, and Earth Dynamics

T. J. Shankland

A. Electrical Conductivity, Temperature, and Radiative Transport in the Earth (T. J. Shankland, Joint research with A. G. Duba, Lawrence Livermore National Laboratory)

The thermoelectric effect $S$ and electrical conductivity in the mantle minerals olivine and pyroxene are being measured as a function of temperature, or ientation, oxygen fugacity, and iron content. "The results apply to inference of upper mantle temperatures from electrical data. Although there are selsmic models to explain the low velocity zone (LVZ) as solidistate phenomenon not requiring partial melting, the most wellinconstrained laboratory electrical measurements are more consistent with the partial melting hypothesis for the high conductivity layer (HCL) apparently associated with the LVZ. If the LVZ/HCL is not a partial melt layer, then mantle geotherms would be considerably lower than previously inferred on the basis of a partial melt zone under extens1ve regions of the earth. Hence, it is necessary to better understand electrical conduction in mantle minerals to find whether electrical data are an important constraint on low temperature geotherms suggested by solid state explanations of the LVZ.

To date, we have measured thermoelectric effect concurrently with electrical conductivity, $\sigma$, in the three principal directions in olivine from San Carlos, Arizona, at $1200^{\circ}$ to $1500^{\circ} \mathrm{C}$ under controlled oxygen fugacity.

Although there is little change in the activation energy for conduction for olivine, $S$ changes slgn from positive to negative around $1400^{\circ} \mathrm{C}$. Thus, electron holes as small polarons are the probable dominant carrlers below $1400^{\circ} \mathrm{C}$; however, the sign change in $S$ indicates a change to conduction by negative charge carriers above $1400^{\circ} \mathrm{C}$ in olivine. The important consequence of the sign change in $S$ is that olivine is probably a mixed electronictionlc conductor over this geophysically significant temperature range, thus resolving as old controversy in the fleld. We have concurrently measured thermoelectric effect and conduci tivity in forsterite in all three princlpal directions and under both oxidizing and reducing conditions and find results consistent with negative electronic carriers as the conduction mechanism.

From radiative heat transport calculations for silicic magmas, we infer that these materials are among the most highly thermally conductive materials in the earth, a matter of some consequence for those studying evolution of silicic magma chambers. Results of both the electrical 
and optical research efforts help determine temperature distributions in the crust and upper mantle. Because temperature differences drive tectonic motions on the earth's surface and interior, improved knowledge of thermal patterns is a requirement for evaluating seismic and volcanic hazards to waste isolation and power plant sites. Further, locating high temperatures is an essential for regional geothermal prospecting. The results should clarify our understanding of the regional geophysics needed for Continental Scientific Drilling site selection, and for nuclear event detection and discrimination.

B. Nonlinear Generation of Acoustic Beams (T. J. Shankland and J. N. Albright )

We are using the nonlinear elastic properties of rocks to generate lowfrequency, long wavelength acoustic beams in analogy with the case in laser optics. Two narrow beams of high-frequency sound can interact in a nonlinear medium to produce a narrow beam at their much lower. dif ference frequency. The lower frequency beam has the narrow width of the generating beams, but it can travel much farther because of lower attenuation. Such a narrow beam would permit examination of acoustic interfaces from mine interiors and wellbores without the ambiguities of conventional seismology that use undirected sources, for example, transducers or explosives that broadcast energy in an almost spherical pattern. Should beam formation prove possible, there would be numerous applications to problems such as mapping fractures, the boundaries of ore and coal bodies, burn fronts in underground retorts, and fluid locations in oil, gas, and geothermal reservoirs. of more interest to basic research in rock physics is the investigation of nonlinear properties of rocks and frequency dependence of elastic properties.

Nonlinear acoustic beams have previously been observed in homogeneous materials and fluids; however, rocks have the advantage of much greater nonlinear coefficients owing to the strong effect of crack closure on elastic properties. In preliminary results we observed difference frequency generation from vibroseis transducers operating in the field and from piezoelectric transducers on laboratory specimens at high frequencies. In the laboratory, we have shown that the intensity of the difference beam is proportional to the product of intensities of the driving beams as predicted by theory.

The definitive work, which has allowed us to discriminate between difference beams generated within the rock specimen and spurious sig nals generated in other experimental components such as transducers or electronics, has come from observations of the general case of two driving beams intersecting at arbitrary angles to produce a difference beam at a still different angle. In this case we have been able to verify the selection rules that govern these angles when sample velocities and frequency rations are specified.

C. Creep Deformation of Rock (J. D. Blacic)

Assurance of longtterm isolation of nuclear wastes in mined cavities in hard rock requires knowledge of time-dependent strength and transport properties of these rocks. Normal, shorthtime engineering tests do not 
encompass the full effects of phenomena such as water-aided stress corrosion and hydrolytic weakening. Therefore, we study creep deforman tion of basalt, granite, and tuff at simulated in situ conditions of temperature, presșure, pore pressure, and differential stress. Emphasis is placed on evaluating effects of water on time-dependent brittle deformation of intact vs. fractured samples and the ef fect of creep on fluid permeability. Results of the experiments will be formulated into creep constitutive relations in a form amenable to predictive computer models of repository designs.

D. Pore-Size Distribution from NMR Measurements (J. A. Brown and L. F. Brown).

Th1s study concerns the use of nuclear magnetic resonance (NMR) to characterize the internal pore structure of porous solids. There are three goals to this investigation. The first is the development of this new method for measuring the porersize distributions; the technique in theory w111 measure a different property of the individual pores (volume/surface rat10) than is being determined by current methods. The second goal is the use of this technique to see how the newly measurable aspects of the pore structure affect the gross properties of porous materlals. In order to be certain of what is being measured by this technique, there must be an advance in knowledge of the basic fluidisurface interactions that are responsible for the NMR signals. The third goal is the acquisitions of this increased knowledge.

An essential element in developing this method is devising a method for inverting the firstekind Fredholm integral equation associated with the technlque. During the year, extensive numerical modeling was carried out using both computer - generated and laboratory data. In previous years we had chosen regularization as the most promising approach to inverting the equation and had reported that an unusual kind of distor $\mathrm{H}$ tion of the result appeared when solving our equation. This year, we found that this distortion was caused by error in the data. We also developed a criterion that enabled us to place very narrow upper and lower bounds on the solution. These bounds were sufficiently close that anywhere within them the solution was deemed acceptable. Thus we now have a method for inverting the Fredholm equation associated with acquiring pore structures using NMR methods.

E. Advanced Geosclence Concepts Research (N. Marusak and C. W. Myers)

A major aspect of subsurface geologic interpretation is the comparison and correlation of geophysical logs by expert geosclentists. This research project proposed to create an expert system by applying pat tern matching techniques, developed in speech recognition technology to geophysical $10 \mathrm{~g}$ analysis or comparison.

The first part of the project involved extended discussions between the domain expert (geoscientist) and knowledge engineer (computer scientist) to evaluate the scope of the project and how it should be implemented. Initially, an IBM PC AT has been identifled as being able to handle this pilot project. 
In order for this expert system to be an assistant for the geologist, many geologic and geophysical parameters must be included in the system. Therefore, it was decided the project should be divided into four modules. The first is a forward chaining inference or a database with interpolation. The geologic and geophysical parameters for a specific location are predicted from data in nearby holes. The second module is a backward chaining inference. A site must be selected which meets certain given parameters and includes appropriate heuristics. The third module is the dynamic pattern matching used to correlate geophyslcal logs. This module accomplishes geophysical signature analysis. It will allow for missing section (faulting), non-linear stretching and lateral variation or interpolation. The last module is that the expert system should incorporate a natural language query. That is, the expert should be able to conduct a session at the terminal and have the interaction be in English. The expert should not be required to learn "computerise".

The protype of this project uses data from the Nevada Test Site as its Basis. A large database incorporating most of the test site data has already been established. The last two modules, dynamic pattern matching and natural language query, have been activated. Dynamic pattern matching of geophysical logs can in fact be done using certain algorithms related to speech recognition. Now, allowable variability and lateral variation are being incorporated into the module. The natural language query module is operational. A format has been set up which includes discrete information about 300 plus holes. The same query can be presented many different ways and gives the same answer. The first two modules, which are the most difficult, are partially completed. As part of both modules, a polynomial fit routine is being developed to be used on each stratigraphic layer to help determine structure and tec: tonic activity. There have been extensive discussions about the expert's thought processes and how one arrives at a decision. Many of these processes are being incorporated into expert system. 
?

Contractor:

Contract :

Category:

Person in Charge:

Scope of Work
LOS ALAMOS NATIONAL LABORATORY

University of California

Los Alamos, New Mexico 87545

W-7405-ENG-36

Geochemistry

R. W. Charles

Geochemistry research consists of six subtasks: (A) Coal Maturation: Occurence, Form, and Distribution of Sulphur and Mineral Matter in Peat; (B) Rock-Water Interactions and Element Migration in the Jemez and Long Valley Hydrothermal Systems; (C) Thermodynamic Properties of Aqueous Solutions at $H 1 \mathrm{gh}$ Temperatures and Pressures; (D) Geochemistry of Technetium and Ruthenium and Geochemical Controls on the Redistribution of Multivalent Elements in the Lithosphere; (E) Trace Element Geochemistry of Volcanic Gases from Basaltic Volcanoes of Oceanic Hotspots; and (F) RAMAN Spectroscopy of Aqueous Solution Species.

A. Coal Maturation: Occurrence, Form, and Distribution of Inorganic Phases within the Peat to-Lignite Transition (R. Raymond, Jr., A. D. Cohen, and D. L. B1sh)

Peat, the precursor of coal, is composed predominantly of plant components and secondarily of mineral matter derived from various sources. The elemental, mineralogic, and petrographic composition of a peat is controlled by a combination of both its botanical and despositional environment. The coal resulting from this peat is controlled by diagenetic alterations during peatification and later coalification. To evaluate the occurrence of inorganic phases in a coal deposit, one must understand the mechanisms for its introduction into the original peat deposit and the physical and chemical conditions affecting the peat during its transformation into coal.

The objectives of this research are: 1) to identify and correlate authegenic and detrital inorganic phases found in different peat types and compare these with those found in lignites; 2) to identify the processes that enhance and/or inhibit distribution and preservation of inorganic material in the initial coal-forming environment; and 3) to construct geochemical models for formation, preservation, alteration, and distribution of inorganics in peats and lignites based on the first two objectives.

To achleve the above objectives, we w1ll investigate the occurrence of inorganics within peat and lignite deposits and the physical and chemical conditions affecting these deposits. Deposits will be chosen such that the most reasonable correlations can be made between the depositional environments of the peats and those of the lignites. Our approach is to use scanning electron microscopy, $x$-ray power diffraction, xiray fluorescence spectrometry, fluorescent and optical 
microscopy, bulk chemical analyses, and conventional sedimentological analyses to characterize the modes of occurrence and content of biogenetically and non-biogenetically derived inorganic phases in the peats and lignites. We will then establish geochemical models for the alteration of those phases during the peat-to-lignite transition. This model should eventually allow us to predict the occurrence and distribution of inorganics within various lignite and higher rank coals seams.

Results to date suggest that factors controlling the amount and type of inorganic material in peats are: 1) underlying bedrock or sediments; 2) detrital source areas; and 3) the ecology of the peathforming botanical communities. Within this context, inorganic phase contents and major and trace element contents of peats relate directly to depositional and ecological setting rather than geographic provinces. When comparing peat and lignite deposits, volcanic ashfalinderived materials are easily distinguished from sedimentary materials in Costa Rican peats and 11 gnites based on differences in bulk inorganic contents and chemical compositions.

B. Rock-Water Interactions and Element Migration in the Jemez and Long Valley Hydrothermal Systems (R. W. Charles, D. R. Janecky, T. M. Benjamin, and P.S. Z. Rogers)

Field, experimental, and computational studies examine rock-fluid reactions in hydrothermal systems in the Jemez Mountains with applications to other geothermal and hydrothermal environments in the CSDP context. These investigations delve into the stable mineral assemblages characteristic of these environments.

Sample collection and experimental hydrothermal reactions investigate various natural hydrothermal systems, for instance, Sulphur Springs, Cochiti Mining District, and CSDP wells VC-1 and VC-2a in the Jemez, well RDO-2b at Long Valley, and the deep Salton Sea well (SSSDP). The discrimination of major, minor, and trace element (via nuclear microprobe) chemistry and associated phase equilibria during mobilization, transport, and deposition is the thrust of this investigation. Experimental systems are used to develop models for element migration in strong brines using single minerals as well as rocks.

The results will aid in developing a model relating the various hydrothermal systems using the mineral assemblages after the method of Schreinemakers as modified by Korzhinskii and Zen. Solubility (mass transport) models such as dissolved aqueous speciation models, EQ3 and Solveq; reaction path calculations, EQ6; and coupled flow and rock water interaction calculations are progressively upgraded as the experimental data is analysed. Activity coefficients in concentrated brines are obtained using various models, including Pitzer's models, where applicable.

Recent results define the state of local equilibrium at Sulphur Springs and the effects of groundwater upon alteration at depth in RDO-2b, Long Valley. Advances in analytical techniques using the nuclear microprobe 
Include the deconvolution of complex xiray spectra to quantitatively detect spatially resolved $(5 \mu \mathrm{m})$ trace element abundances to concentrak tions of about $10 \mathrm{ppm}$.

C. Thermodynamic Properties of Aqueous Solutions at High Temperatures and Pressures (P. S. Z. Rogers)

Knowledge of the thermodynamic propertles of aqueous solutions is basic to an understanding of many geochemical systems. Hydrothermal altera $t$ ion, element migration and geothermal activity, are a few examples of processes largely dependent on the properties of the assoclated aqueous fluid. Studies of these processes require information on the heat content and ion activities of mixed electrolyte solutions over a wide range of composition and temperature.

Construction of a flow microcalorimeter, designed to measure the heat capaclties of aqueous solutions from 298 to $623^{\circ} \mathrm{K}$ was completed last year. The calorimeter is completely automated, allowing the continuous recording of several experimental parameters. Operation of the calorimeter has shown that it maintains good temperature stability and that temperature discrimination in the measurement circuit is excela lent, with uncertainties in the temperature difference measurement ranging from only .0002 to $.0005 \% \mathrm{~K}$. This precision is better than that required for determining heat capacities to $0.1 \%$, leaving calibration of the calorimeter as the limiting factor in both the precision and accuracy of the heat capacity measurements. Heat capacity data are

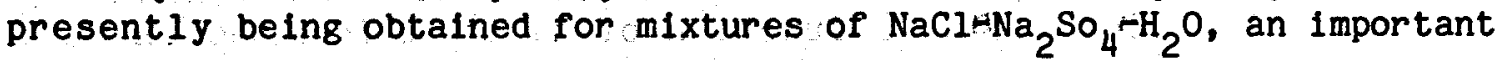
system in many cases of hydrothermal transport and deposition.

The number of different electrolyte solutions of interest at high temperatures is large, so a method of obtalning thermodynamic properties from a minimum amount of experimental data is desirable. Heat-capacity measurements are Ideal for this purpose because the heat capacity data can be integrated as a function of temperature to determine solution enthalpies and the ion activities of solution species. These thermodynamic properties w11: be used to provide an accurate model for electrolyte solutions at high temperature and pressures.

D. The Geochemistry of Technet Ium and Ruthenium and Geochemical Controls on the Redistribution of Multivalent Elements in the Lithosphere (D. $B$. Curtis, R. Perrin, and D. Rokop)

Technetium is an extremely rare element in nature. A single isotope, ${ }^{99}$ Tc, exists, a product of the fission of isotopes of U. This nuclide is radloactive, with a half 11 fe of $2.13 \times 15^{5} \mathrm{yr}$. Consequently, in a chemically unchanging environment; it will establish a state of radioact ive equilibrium with the parent element $U$. The result is an invariant ratio of the two elements, its magnitude dependent on the neutron fluence in the geologic environment and the time that has 
passed since the parent and daughter were fractionated with respect to one another. The value is expected to be on the order of $10^{-12} \mathrm{~g} \mathrm{Tc} / \mathrm{gU}$. Chemical changes with respect to these two elements can be charact terized and quantified by deviations from the anticipated ratio.

We have completed development of an analytical procedure that allows us to measure as little as $10^{-15} \mathrm{~g}$ of ${ }^{99} \mathrm{Tc}$ in as much as $10 \mathrm{~g}$ of material. This capability provides the means to determine Tc abundances in geologic materials that contain more than $100 \mathrm{ppm} U$.

Each of the two elements are multivalent. The high oxidation states belng more soluble than the lower ones. Therefore chemically induced changes in the relative abundances of these two elements are likely to be most extreme in a hydrologically active, oxidizing environment. The Koongarra $U$ deposit in the Australlan Northern Territory presents an excellent opportunity to study the dispersion of $\mathrm{Tc}$ in such an environment. This deposit has been characterized in detail in conjunce tion with attempts to develop the deposit for economic purposes. However, as yet the deposit has not been mined and the Australian Atomic Energy Commission has conducted extensive research on element migration at Koongarra. The deposit is distingulshed by a zone of alteration that extends from the surface to depths of about 30 meters. It is highly altered by a flow of oxidizing surface waters. Uranium is dispersed down the hydrologic gradient away from that portion of the lens ore that resides in the weathered zone. The concentration generally decreases as a function of distance from the lens and the mineralogy changes from secondary uranyl phosphates within the altered lens itself to $U$ dispersed on clay at the edges of the dispersion fan. Samples were collected from drill core taken at regular intervals along the hydrologic gradient. The samples grade from highly enriched ore to nearly ambient levels of $U$. These are being analyzed to determine the abundances of ${ }^{99}$ TC and $U$. The data will characterize the dispersion of Tc and $U$ along the hydrologic gradient and provide the means to examine the geochemical controls on the transport of these two multivalent elements in an oxidizing environment.

E. Trace Element Geochemistry of Volcanic Gases from Basaltic Volcanoes of Oceanic Hotspots (B. Crowe and D. Finnegan)

Field and laboratory studies are being undertaken to investigate the trace element compositions of volcanic gases of active volcanoes. We have sampled volcanic gases during four separate eruptions and at the cooling vents preceding and following eruptions of Kilauea and Mauna Loa Volcanoes, Hawai1. The collection system consists of a series of filters contained in a polycarbonate canister. Volcanic aerosols are pumped though the filters using a portable vacuum pump. The first collection filter is a particulate filter and efficientiy traps condensed gases and particles. The following filters are based-treated 
and absorb acidic gases that pass through the particulate filter. The filter canister and pump are portable and can be set up at the edge of a volcanic vent or connected to the wing struts of an airplane for sampling the eruption plume. After exposure to: volcanic aerosols, the filters are analyzed using nondestructive INAA for about 35 to 40 elements. The major goals of the project are: 1) Determine the characteristic trace element contents of volcanic aerosols associated with the eruption of Hawalian magmas, 2) Evaluate the variations in the trace element composition of aerosols through eruption cycles and 3 ) Evaluate the variations in the composition of aerosols immediately following eruptions and continuing through the perlod of magma recharge preceding subsequent eruptive activity. This information will be used to examine possible geochemical mechanism of trace element enrichment in the volcanic aerosols and the potential use of monitoring of selected trace elements in aerosols for the prediction of volcanic eruptions. During July of 1985, we conducted a sampling mission to collect aerosols for a complete eruption cycle of Kilauea volcano. Aerosols were collected at the vent edge starting four days after eruptive episode 33 and continued on a near-daily schedule until 3 days before the episode 34 eruption on July 26. Aerosols were not collected during the episode 34 eruption because of inclement weather. However, we were able to collect aerosols at the vent edge and a new fissure site that opened up-rift of the vent for 7 successive days following the eruption. Additionally, we sampled the volcanic plume by alrcraft during the episode 35 eruption. We have shown that calculation of conventional enrichment factors for volcanic aerosols is not suitable for ashiladen volcanic plumes. Variable mass loading of the particle filter by ash causes major variations in the calculated enrichment factors. This effect can be removed by normalizing the data to a volatile phase that is present in trace amounts in the ash such as fluorine or chlorine. Preliminary data normalized to chlorine show systematic varlations of selected trace metals with stages in an erupm tion cycle.

F. RAMAN Spectroscopy of Aqueous Solution Specles ( $T$. Benjamin, P. Rogers, and G. Bayhurst)

Knowledge of the specification behavior of metaliligand complexes is important to understanding the modeling mineral solubilities, metal ion transport, and ore deposition. However, data for the quantitative speciation of metal-iligand complexes in aqueous solutions at geologif cally significant pressures and temperatures are quite $11 \mathrm{mited}$. Few complexes have been studled above $100^{\circ} \mathrm{C}$, while there is a need for data to at least $600^{\circ} \mathrm{C}$. Speciation of geochemically important complexes (predominantly those involving metal chlorides) will be determined by high temperature and pressure Raman spectroscopy. Laser Raman spectroscopy is a powerful technique for the determination of structural speciation in aqueous solutions, because unlike the complementary technique of IR spectroscopy, it is relatively free of interferences due to the presence of water. 
This is a new project in 1986. Our objective is to gather and deconvolute Raman spectra generated by a continuous wave laser beam impinging upon a special diamond windowed, externally heated, high pressure ( $4 \mathrm{kbar}$ ) fluid cell. Thus far, we have developed a workable diamond cell and pressurizing fluid system and have obtained a Spec Physics Model 2025 argon Ion laser. The high power (5 watt visible and 0.4 watt UV) will improve the sensitivity and range of the Raman measurements. We have also initiated software development for the quantitative spectra deconvolution. The system has been tested to 3.5 kbar at ambient temperature. Sensitivity measured in the cell appears to be $10^{3} 3 \mathrm{~m}$ for $\mathrm{Zn}-\mathrm{Cl}$. As the Raman spectra cannot always be unambiguously deconvoluted, we are coordinating these experiments with calorimetry measurements and hydrothermal experiments to narrow the possible interpretations. 
Contractor:

Contract:

Category:

Person in Charge:
LOS ALAMOS NATIONAL LABORATORY

Earth and Space Sciences Division

Los Alamos, New Mexico 87545

W-7405-ENG-36

Energy Resource Recognition, Evaluation, and Utilization

F. E. Goff

A. Fleld and Geochemical Studles of the Polvadera Group Jemez Volcanic Field, New Mexico (W. Scott Baldridge and David T. Vaniman [Los Alamos National Laboratory])

The Polvadera Group consists of three major units (oldest to youngest): Lobato Basalt, Tschicoma Formation (mainly andesites, latites, and dacites), and El Rechuelos Rhyolite. These units span the age range from 10.8 to 2.0 million years ago and immediately preceded eruption of Bandelier tuff at 1.4 and 1.1 million years ago. In 1984 and 1985 we made major progress in understanding particularly the Lobato Bàsalt and El Rechuelos. Rhyolite.

Through detalled fleld mapping and $\mathrm{K}$-Ar dating (collabonatively with M. Shaflquilah of the University of Arizona) we recognized that the Lobato Basalt Mesa consists dominantly of a group of overlapping shield cones, each with numerous, smaller subsidiary and "parasitic" cones. Although individual shield cones are slightly different in age, all of the cones were erupted during the interval 10.8 to 9.2 milition years ago. Each shield cone is characterized by a slightly different composition, although all are tholelitic basalt generally. These differences in composition Indicate that each shield cone was fed by a separate magma chamber and "plumbing system." Late in the eruptive cycle a group of more evolved (1.e., higher In $\mathrm{SiO}_{2}$ and incompat1ble elements) hawafites were erupted from a series of vents, the locl of which were strongly controlled by fractures and faults which later displaced most or all of the basalts. A dacite dome was also emplaced fairly late in the Lobato cycle $(9.6 \mathrm{~m} . \mathrm{y}$. ago). These more silicic rocks may anticipate the petrogenic processes which later (at approximately 7 million years ago) gave $r$ ise to the voluminous Tschicoma magmas.

The El Rechuelos Rhyolite unit consists of a group of five rhyolite domes and a pumice ring. Previously, all of the domes and the pumlce ring were presumed to be 2 million years old, based on a single $\mathrm{KmAr}$ age date on one of the domes. We have dated several of the domes, and find that they range from 7.5 to $2.0 \mathrm{mililion}$ years of age. The earlier and intermediate domes $(7.5$ and 5.8 million years old, respectively) are equivalent in age to the much more voluminous rhyolitic volcanism in the southern Jemez volcanic fleld (Canovas Canyon and Bearhead Rhyolite), although they are 
petrographically distinctive. Therefore, we restrict the terminol ogy "El-Rechuelos Rhyolite" to the latest ( 2 million year old) domes: The $\mathrm{Nd}$ and $\mathrm{Sr}$ isotopic data suggest that lower and/or upper crust was involved, as well as crystal fractionation processes, in the petrogenesis of these rhyolitic magmas.

B. The Bandeller Pluton (K. H. Olsen and L. A. Ankeny)

Our basic scientific understanding of many aspects of the evolution of the continental crust and the development of ore deposits and large-scale hydrothermal systems depends on knowledge of processes of intrusion of magma, magmatically derived fluids, and associated heat into the uppercrust, and of the consequent processes of mag: matic differentiation and assimilation/modification of surrounding crustal rocks. The Jemez Mountains volcanic fleld (JMVF) of northern New Mexico is one of three glant, recently active, silicic caldera systems within the continental United States in which phases of such processes are still taking place. Coordinated interdisciplinary studies, including plans for deep scientific drilling, are in progress in the Jemez Mountains and elsewhere in order to increase fundamental understanding of thermal regimes in continental settings. The objective of our particular task has been to employ both "active" and "passive" seismological techniques to delineate contemporary structures and gross rock properties (elastic wave velocities, densities, inferred temperatures, etc.) beneath the JMV, which will supplement results from geological and petrological techniques and help provide constraints for developing evolutionary models.

We determine the three-dimensional velocity structure of the uppermost crust (to depths of about $10 \mathrm{~km}$ ) beneath the JMVF using a geotomographic inversion method. Our inversion for the JMVF employed a simultaneous inversion of travel paths from two data sets: (1) a "two-dimensional refraction" profiling experiment with 6 borehole explosions shooting into more than 80 portable seismograph sites, and (2) local earthquakes for the period of 1973-1984 as recorded by the Los Alamos Seismic Network. The main results of the geotomographic inversion show the presence of a prominent, approximately cylindrical=shaped zone of low $P$ wave velocity centered beneath the southern part of the resurgent dome (Redondo Peak) and south moat area of the Valles caldera. The velocity anomaly is defined by a lateral decrease in velocity from about $6.0 \mathrm{~km} / \mathrm{s}$ to as low as $5.6 \mathrm{~km} / \mathrm{s}$ (about a $5 \%$ reduction from the Prvelocity of sur: rounding crystalline basement rocks) and extends to depths of at least $10 \mathrm{~km}$ (where the present data set loses resolution). We interpret this velocity anomaly, about $15 \mathrm{~km}$ in diameter, as the upper part(?) of the pluton which constitutes the compositionally zoned magma chamber that was the source of two cataclysmic $1 \mathrm{~g}^{-}$ nimbrite eruptions ( 1.1 and $1.45 \mathrm{Ma}$ ) which deposited the Bandelier tuff (comprising a total of more than $600 \mathrm{~km}^{3}$ in northern New Mexico). 
A decrease in compressional wave velocity can be due to a number of factors, including compositional differences (rock type), elevated temperatures, pressure, porosity, fluld content, and degree of fracturing. Examination of avallable laboratory data on compresslonal wave velocity as a function of these parameters leads us to conclude that the principal factors controling the lowvelocity anomaly beneath the JMVF are a combination of a more silicio composition within the pluton (which petrological data suggest evolved over a least a 7-m.y. perlod) and elevated temperatures. Velocity/temperature partial derlvative data suggest horizontal temperature differences between surrounding basement and the center of the pluton of at least $150^{\circ} \mathrm{C}$ but probably less than $500^{\circ} \mathrm{C}$. Thus, temperature differences alone could explain the observed lowvelocity body, but we favor an interpretation that also includes higher silicic compositions suggested by petrological data and by gener ic arguments about the evolution of large ash flow caldera systems. At the relatively coarse resolution of the present data set, extens 1ve volumes of partlal melt are not required to explain the observed anomaly, but we cannot rule out that some small iso lated magma pockets could exist within the main coarsely resolved body. It is interesting to note that the strongest low-velocity values (as well as the minimum of a very prominent aeromagnetic low) are centered beneath the region of most recent volcanic activity in the JMVF, moat rhyolities of the 0.1 Ma Banco Bonito flow.

Evolutionary models of sillcic volcanic systems suggest that upper crustal plutons are underlain and fed by more mafic (basaltic) stillilike structures at midcrustal depths. Our present data for the JMVF are inadequate to confirm or deny the existence and/or depth of such a feature here, although partially molten midcrustal basaltic sills are known from seismic observations elsewhere in the Rio Grande rift. Although poorly resolved by the present seismic tomography survey, the region of the JMVF/Rio Grande $r$ ift immediately to the northeast of the Valles/Toledo calderas actually displays some of the more intense gravity and selsmicity anomalies of the area, perhaps suggesting that this region may contain the deeper parts of the "root system" of the JMVF. This region is the main target area for our future research related to the Jemez Mountalns volcanic fleld.

C. Valles Caldera Drilling Program: Core hole vcal (Fraser Goff, J. c. Rowley, and Jamie N. Gardner [Los Alamos National Laboratory])

Valles Caldera 1 is the first Continental Sclentific Drilling Program (CSDP) core hole drilled in the Valles caldera and the first continuously cored well in the caldera region. The object ives of VCA1 wre to penetrate a hydrothermal outflow plume near its source, to obtain structural and stratigraphic information near the intersection of the ring practure zone and the precaldera Jemez fault zone, and to core the youngest volcanic unit inside the caldera (Banco Bonito obsidian, $0.13 \mathrm{Ma}$ ). Preliminary FY84 results of the core hole was outlined in Summaries of Physical Research in the Geosclences 1985. 
In FY85 samples of core and coples of geophysical logs were dis tributed to interested researchers. A comprehensive lithologic 108 was prepared of the $856 \mathrm{~m}$ core. A comprehensive drilling report was prepared summarizing the details of the coring effort. A second temperature $10 \mathrm{~g}$ was run in July 1985. From comparison of the new log with the $\log$ run one day after coring (in September 1984), a zone at $483 \mathrm{~m}$ was identifled as a thermal aquifer. This zone was perforated from 482 to $485 \mathrm{~m}$ in late July 1985. After a month of equilibration, the thermal flulds were sampled with a downhole sampler. Three weeks later, the VC-1 well was swabbed out with a workover $\mathrm{rig}$ and the thermal fluids again sampled from $483 \mathrm{~m}$. Fluid samples were distributed to interested researchers. In September 1985 a detalled surface survey line was run through VC=1 in prepara* tion for a seismic refraction survey. This seismic survey was completed in late September 1985 and is intended to resolve deep structure in ringirfracture zone.

Results of the research of various VC -1 investigators were prepared for a special session of AGU (Fall, 1985). At that meeting the fluid geochemical data were presented proving that vC-1 penetrated the hydrothermal outflow plume of Valles caldera.

D. Valles Caldera Drllling Program: Core hole VCa2a (Fraser Goff [Los Alamos National Laboratory] and Dennis Nielson [University of Utah Research Institute])

Valles Caldera $\# 2 a$ is the second Continental Scientific Drilling Program (CSDP) core hole planned for Valles caldera. It will be drilled into the small vaporidominated hydrothermal system at Sulphur Springs located on the west edge of the Valles resurgent dome. Objectives are to study the vapor zone and the interface between vapor - and liquid-dominated zones, to study ore minerals and hydrothermal alterations associated with these zones, and the in tracaldera stratigraphy and structure associated with caldera resurgence. Intended depth is roughly $550 \mathrm{~m}$ and expected temperature is about $200^{\circ} \mathrm{C}$. In late FY85 preparations and negotiations had just begun.

E. Development and Initiation of Sample Management Policy Procedures for CSDP (Sue Goff [Los Alamos National Laboratory])

The Curation office, managed from Los Alamos National Laboratory, operates the Curation Facility at Grand Junction, Colorado. This facility, funded via the DOE Office of Basic Energy Sciences (OBES), is designed to provide the scientific community with access to geologic samples. The Core Repository occupies about 7,200 square feet of space in Building 7 at the DOE Grand Junction (Colorado) facility. The repository contains-in addition to the core- storage areamoffice space for the curator, a receptionist, and visiting scientists, as well as rooms housing specialized sample-preparation equipment. Core can be viewed in a large enclosed and heated area, which is equipped with samplenviewing tables designed for laying out 
numerous boxes of core. Most of the office furniture is now in place, and equipment recently installed includes a 24 "slab saw, a trim saw, a drill press, and a core splitter. Also avallable for visitor use are a binocular and a petrographic microscope. Presently archived at the repository are 5,517 feet of drill core from various OBES drilling projects.

The Curation office has also published Curatorial Policy Guidelines and Procedures for the Continental. Scientific Driling Program, which includes the Field Curation Manual for the Inyo Domes and the Valles Caldera drilling projects. In press are the Fleld Curation Manuals for the Salton Scientific Drilling Project and Shady Rest. 
Contractor:

Contract:

Category:

Person in Charge:
LOS ALAMOS NATIONAL LABORATORY

University of California

Los Alamos, New Mexico 87545

$W=7405-E N G=36$

Solar-Terrestrial-Atmospheric Interactions

D. N. Baker

\section{Scope of Work}

The objective of this program is to carry out theoretical and experimental research on the plasma physlcs of the solar wind and the earth's magnetom. sphere and ionosphere. The goal of this research is the description of the flow of plasma energy in this environment, the understanding of various electrodynamical processes whereby the earth's magnetosphere acquires plasma and energy from the impinging solar wind, alters the character of these, and dissipates them to the earth and to the surrounding medium, and the investigation of the detalled of acceleration processes affecting energetic particles in the magnetospheric system.

Since the solar wind and magnetospheric plasmas are the media through which solaragenerated disturbances propagate and in which solar wind convection energy is stored and subsequently released to the auroral 1onospheres, these studies help us understand the coupling of solar varlations to the nearfearth environment. This research is related to the Department of Energy's missions through applications to plasma physics problems relevant to fusion energy technology, understanding longterm solar wind and earth climate variability, and future space-based energy technologies.

\section{A. Energy Transport in Space Plasma (S. P. Gary)}

The longiterm goal of this research is to describe the flow of plasma energy in the near Earth plasma environment. Specifically, we use electron and ion distribution functions observed by Los Alamos plasma instruments to carry out fundamental studies of plasma instabilities and assoclated transport in and near the earth's bow shock, magnetosphere, and Ionosphere.

Our most important research of 1985 has been our study of ion beam instabilities associated with slow shocks in the Earth's magnetotall. These shocks, recently discovered by Los Alamos plasma instrumentation on the ISEE-3 satellite, are an important source of energy dissipation In the magnetota11. Large amplitude, low frequency magnetic waves have been observed upstream of these shocks and may be an important mechanism for this dissipation. Our research has provided the basis for the identification of the right-hand resonant ion beam instability and the ion cyclotron beam anisotropy instabllity as the sources of the observed rights and left -hand polarlzed waves, respectively. We have further examined the nonlinear properties of the right-hand instability 
- through computer simulations, and have predicted not only the evolution of ion distributions but also that relatively. high plasma beta is necessary in order that slow shocks accelerate lons by the Ferm 1 process.

B. Electrodynamical Aspects of the Solar WindrMagnetosphere Interaction (E. W. Hones, Jr., and J. Birn)

When the solar wind plasma impinges onto the earth's magnetosphere, it causes a convection pattern which transports plasma and energy through the magnetotall and into the lonosphere. . Two extreme cases can be considered and are probably realized in different combinations: (1) the lonosphere accepts the incoming plasma and energy at the required rate and the magnetosphere assumes an approximately steady state; (2) the ionosphere cannot dissipate the incoming energy and is essentially closed for the plasma inflow; in this case plasma and energy must become stored in the magnetotail until a sudden release becomes posa sible (magnetospheric substorm). A part of this second picture is the loss of plasma in the form of a plasmold, which becomes detached from the plasma sheet through magnetic reconnection. In addition to these responses there exist internal oscillations, which are probably generated by the solar wind via surface waves at the solar windmagnetosphere interface (magnetopause). These different responses constitute the main topics of our magnetospheric research.

In theory and numerical simulations we have concentrated on the response of the magnetotail to gradual external changes and forces causing a slow inflow of plasma energy and magnetic flux. We have used our self-consistent quasistatic magnetotall theory to show that plasma transport across an interface (separatrix) between different plasma regions must lead to large flow yelocities along the magnetic fleld at the seperatrix when it is connected to regions of smali field magnitude (magnetic "neutral" regions)...Such regions are probably realized in a reconnection site in the distant tall $\left(-100-200 R_{F}\right)$ recently explored by the satellite ISEE 3. The expected sheets of fast plasma flow connecting to this region could be realized by the plasma sheet boundary layer observed nearer to the earth.

We have also used our time dependent nonlinear MHD code to study the response of the geomagnetic tall to external electric fields that force an inflow of plasma, energy and magnetic flux. In a first phase these forces lead to the gradual deformation of the tail associated $w i t h$ the loading phase before the onset of a magnetospheric substorm. The onset of the fast release phase leading to reconnection, plasmoid formation and ejection requires the presence of a (localized) dissipation such as an anomalous resistivity caused by small scale wave turbulence. We found that a cont inued presence of the external forces is not necessary after the unstable evolution has started. The continuation of the external force, however, can modify the unstable evolution in a parametric way by changing characteristic scales and wave speeds.

$$
-61-
$$


The objective of Project PROMIS (Polar Region and Outer Magnetosphere International Study) is to acquire an extended body of coordinated data from ISEE 1, ISEE 2, and AMPTE-IRM in the magnetotail plasma sheet, from IMP 8 and IMP 7 in the solar wind, and from the auroral imagers on DE-1 and VIKING. The project was formulated to exploit the unique configuration of these satellites that will exist during March through June of 1986 when VIKING and DE-1 will be in position to take pictures, every 80 seconds and every 12 minutes, of the northern and southern polar regions, respectively, and the ISEE 1,2 and AMPTE-IRM orbits will lie in the magnetotail. The two auroral imagers offer the greatest capability that has ever existed for observing the configura tion and changes of the auroras, each one repeatedly photographing essentialiy the whole auroral oval during about 50 percent of each severalthour orbital period. This magnificient record of auroral behavior", combined with the long uninterrupted records of magnetotall and solar wind plasmas from the other PROMIS sateliltes, is expected to provide an unprecedented wealth of material for solar-terrestrial physics studies.

C. Energet 1c Particle Acceleration and Transport in Magnetospheric Systems (D. N. Baker)

By energetic particles we mean that population of lons and electrons that extends from just above the bulk thermal plasma population in a given region all the way to the highest velocity charged particles of the plasma distribution function. During the current year we have examined energetic particle phenomena spanning much of this energy range, and we have also extended our research efforts to consider energetic particle processes in a variety of magnetospheric systems (Jupiter, Mercury, Comet Giacobinifizinner) in addition to the tert restrial system. Our studies can be grouped into three general areas: 1) The acceleration of energetic particles in magnetospheric systems; 2) The subsequent transport of the energetic particles throughout these systems; and 3) The loss of particles from magnetospheric regions by leakage, by atmospheric precipitation, or by some other dissipative mechanism. Of major importance in this program of study is the utilization of the broadest range of observational data avallable and the application of theoretical ideas drawn from analogies with similar physical systems.

Considerable observational evidence is found that charged particles are accelerated to high energies in the outer terrestrial magnetosphere during geomagnetic disturbances. Our global model relating energetic ion populations to neartail magnetic reconnection at substorm onset followed by global redistribution is quite successful in explaining the primary observational features. The acceleration often appears to be quite impulsive causing temporally brief (tens of seconds), very in tense bursts of particles in the distant plasma sheet as well as in the neartall region. These bursts extend in energy from tens of keV to over $1 \mathrm{MeV}$ and are closely associated with substorm expansive phase onsets. 
"We have also developed a model of substorm processes in the Mercury Magnetosphere based upon Mariner 10 spacecraft observations. The model is predicated on close analogies observed with the terrestrial case and suggests that energetic particles up to $-500 \mathrm{keV}$ are produced by strong induced electric fields at $3-6 \mathrm{R}$ in the Hermean tall in association with a "substorm-like" neutral line formation.

We have continued our study of a quite different and much more energetic process, viz., the occurrence of highly relativistic electrons in the earth's outer magnetosphere. On the other hand, relativistic electrons may result from processes occurring in our nearest available "cosmic accelerator," 1.e.. the earth's magnetosphere. If this is the case, then we are witnessing the frequent and efficient generation of highiy energetic particles of the sort required in many other astrophysical contexts, such as astrophysical jets. On the other hand, these electrons may arise directly from the Jovian magnetosphere. In this case, this particle population is providing a remarkable example of heliospheric particle transport and indicates intimate coupling between two very different planetary magnetospheric systems. In either event; these particles may be a significant link between the hellosphere/outer magnetosphere system and the earth's middle atmos: phere.

Once energetic particles are produced by some physlcal process, they can serve as an excellent tracer population until they are eventually lost by dissipative effects. An example of a population indicative of both transport and loss processes in earth's magnetotall is that of "polar rain." Polar rain consists of -50 to $-500 \mathrm{eV}$ electrons which continually precipitate into one or the other of earth's polar cap lonosphere regions. Our observations from ISEEH 3 and our associated modeling of these observed features have clearly shown the solar wind heat flux source of polar raln. Furthermore, we have found these suprathermal electrons to be extremely important in mapping the topolm ogy of distant geomagnetotall fleld lines. 
Contractor:

Contract:

Category:

Person in Charge:
OAK RIDGE NATIONAL LABORATORY

Martin Marietta Energy Systems, Inc. Oak Ridge, Tennessee 37831

DEMAC05-840R21.400

Geochemistry

R. E. Mesmer

Scopy of Work

The primary focus of this program is studies of the high temperature and high pressure hydrothermal and igneous processes that control heat and material transport in the earth's crust. Our goal is to attain an under. standing of these processes that is sufficient for modeling the evolution of natural systems pertinent to DOE magma/hydrothermal energy programs. Studies of phase equilibria, crystallization kinetics and element parm titioning are conducted in rock forming silicate melt systems to $1200^{\circ} \mathrm{C}$ and $4 \mathrm{~kb}$ using facilities developed to perform these experiments under control led redox conditions. Aqueous systems are investigated at temperatures of $600^{\circ} \mathrm{C}$ and $1.4 \mathrm{~kb}$ with a unique array of hydrothermal facilities that permit study of metal hydrolysis, mineral solubilities, acid ionization, activity coefficients, isotopic exchange and reaction kinetics. In the past year, a significant portion of this program has been devoted to field studies in volcanic terranes of California and New Mexico and in crystalline rocks of the Southern Appalachians. Theoretical modeling complements the experimental and field approaches by extending the data to experimentally inaccessible $P-T-X$ regions and by establishing the critical relationship between complex natural processes and experiments. Stable isotopes are used extensively to study diffusion in melts, reaction kinetics and the provenance and flux of fluids in natural systems. Recent results of this program have provided a quantitative understanding of iron redox kinetics in silicate melts; the variation of ferrous-ferric ratios in rhyolite lavas; the role of organic complexes in mobllizing metals in hydrothermal regimes; and transport and deposition of metals in hydrothermal systems.

A. Geochemistry of Crustal Processes to High Temperatures and Pressures (R. E. Mesmer, M. T. Naney, D. R. Cole, D. Wesolowski, D. A. Palmer, S. E. Drummond)

$\mathrm{Fe}^{3^{+}}-\mathrm{Fe}^{2^{+}}$Variations in Rhyolite Lavas

Development of models for predicting the physical and chemical state of magma bodies beneath volcanic centers will ald practical utilization of magmainhydrothermal energy. The usefulness of geochemical data obtained by surface sampling as input for these models is I Imited by knowledge of the extent to which the eruption process modified the chemical properties of magma. DOE-sponsored Continental Sclentific Drilling Program (CSDP) projects are providing the opportunity to expand this knowledge for silicic magma systems by sampling both rhyolite dikes and associated extrusive units. 
One parameter potentially affected by the eruption process is oxidation state. The oxidation state of glassy volcanic rock can be indicative of the $T \leftrightarrow f_{0}$ conditions prevailing in the precursor magma at the time of quenching. ${ }^{2}$ However, the ferrous ferric ratio of the magma is sub ject to alteration during eruption and subsequent cooling. The extent of alteration is a function of the redox reaction mechanism and reacttion kinetics. A one atmosphere experimental study of changes in the ferrousterric ratios of silicate liquids as a function of time (under controlled $T=f$ conditions) indicates that rhyolite melts are un changed after 5 days at $1243^{\circ} \mathrm{C}$. This experimental result leads to the hypothes 1s that the ferrousaferric ratio of fresh, glassy rhyolite can preserve the oxidation state of the parent magma.

A unique opportunity to test this hypothesis was provided by DOE spon* sored CSDP projects that provided core materlal from nearly complete sections through rhyolite flows at Inyo Domes, CA and Valles Caldera, NM. Core samples have been analyzed by a mlcrofcolorimetric method for $\mathrm{Fe}^{2+}$ and total $\mathrm{Fe}$ content. The broad $\mathrm{range}$ of $\mathrm{Fe}^{2} / \mathrm{Fe}(\mathrm{tot})$ values measured indicates that rocks from different portions of the flows and feeder conduits sampled have experienced varying degrees of oxidation. The pattern of oxidation is systematic and can be related to the subi solidus cooling history.

Fresh glasses from flows (topshinteriorsubottoms) and the dike margin from Inyo Domes all have similar $\mathrm{Fe}^{2} / \mathrm{Fe}$ (tot) ratios ranging from 0.62 to 0.75. In addition, rapidiy quenched tephra glasses that are contems. poraneous with the Inyo Domes core samples have essentially the same value 40.74 . Materials with lower $\mathrm{Fe}^{2} / \mathrm{Fe}$ (tot) values have ext perlenced varying degrees of oxidation during subsolidus devitrification. The flow interlors and bulk of the feeder dike materlals sampled are crystalline and have microscopic textures that are consistent with subsolidus crystallization. These rocks have $\mathrm{Fe}^{2^{+}} / \mathrm{Fe}$ (tot) that cluster near 0.50 . The most oxidized $\mathrm{Fe}^{2} / \mathrm{Fe}$ (tot) values (approxiqating 0.15 ) were observed in samples of 11 thophysae. The uniform $\mathrm{Fe}^{2} / \mathrm{Fe}$ (tot) values of what appear to be fresh glassy rocks that have experlenced different cooling histories at Inyo Domes (flow topshinteriors and bottoms; condult dike margin; and alr fall tephra) are consistent with the hypothesis developed from experimental studies of iron redox kinetios in silicate melts.

In general, rocks sampled from the Banco Bont to rhyolite section of the Valles Caldera corehole have experienced significant oxidation compared to the Inyo Domes samples. Thls is reflected in the $\mathrm{Fe}^{2} / \mathrm{Fe}$ (tot) values measured, the $\mathrm{H}_{2} \mathrm{O}$ contents of samples measured by $\mathrm{H}$. $\mathrm{R}$. Westrich (SNL) and petrographic observation. Desp1te the pervasive oxidation observed in core samples, surface outcrop obsidian samples of the Banco Bonito rhyolite have $\mathrm{Fe}^{2} / \mathrm{Fe}(\mathrm{tot})$ values similar to those of fresh 
glass samples at Inyo Domes -0.62 to 0.71 . These are the highe'st values observed in the suite of Banco Bonito samples measured and may represent relatively unaltered material that reflects the preferuption $\mathrm{F}_{\mathrm{O}_{2}}$ condition in the magma chamber.

Origin of Microlites in Rhyolite: An Example from Inyo Domes, California

Microlites having an average length of 7 to $10 \mu \mathrm{m}$ are a ublquitous constituent of obsidians from the CSDP coreholes drilied at Inyo Domes, CA. SEM/EDX studies suggest that the microlites are dominantly blotite and hornblend with tabular and skeletal habits. Statistical analysis of the size distribution of microlites does not show any significant ( $\alpha$ $=0.99$ ) difference between samples cooled relatively quickly (at the base or distal protions of the obisidian flow) and those cooled more slowly (in the flow interior or near the vent). This suggests that crystallization of the microlites is independent of the postreruptive cooling history and that the microlites crystallized prior to eruption of the obisidian.

Other 1 ines of evidence are consistent with the premeruption crystallization of the microlites. (1) Airffall tephras represent the earliest eruption products of the Inyo system and glass from these tephras contains microlites. The $\mathrm{H}_{2} \mathrm{O}$ content $(1.5 \mathrm{wt} \%)$ of white Wing tephra glass erupted from the Glass Creek vent is higher than that of contemporaneous, but post-tephra, massive obsidian erupted $1.5 \mathrm{~km}$ north at Obsidian Dome $(0.1$ wt $\%)$, suggesting that the tephra glass represents quenched, undegassed magma. The presence of microlites in this $\mathrm{H}_{2} \mathrm{O}$ tephra glass is consistent with premeruption crystallization. (2) In the flow interior, microliteidefined flow banding is cut by devitrification textures that are related to the postmeruptive cooling of the obsidian. (3) The presence of hydrous phase microlites is consistent with crystallization from a hydrous melt and is not expected at the surface. (4) Crystallization of blotite and/or hornblend without plagioclase, sanidine, or quartz is not consistent with 200 and $800 \mathrm{MPa}$ equilibrium crystallization experiments with low $\mathrm{H}_{2} \mathrm{O}$ (e.g., 0.1 wt $\%$ ) model rhyolitic melts, but is consistent with 200 and $800 \mathrm{MPa}$ nonfequilibrium crystallization experiments conducted at moderate to high undercooling. These observations from natural obsidians, and from experiments suggest that the microlite assemblages crystallized prior to surface extrusion under non-equilibrium conditions in response to moderate or high undercooling. A likely mechanism to produce the necessary undercooling is the melt compositional change that accom panies the onset of degassing.

Careful characterization of microlite assemblages in rhyolites combined with data from experimental studies of both equilibrium and nonm equilibrium crystallization is silicic melt systems has the potential to provide a method for deciphering the kinetics of magma degassing processes in silicic magma hydrothermal systems.

$$
-66 m
$$


Sulfur Mobility in Sillcate Melts

We have conducted experiments that address the questions of how fast and in what form sulfur migrates through silicate melts and is exsolved into the atmosphere. Sulfur desorption (exsolution) experiments have

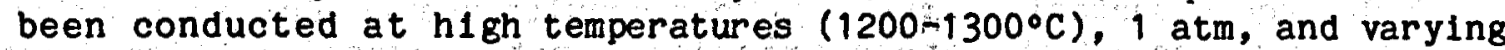
oxidation states (QFM and N1N10) for basalt-like melts. Our data indicate that sulfur exsolution is an extremely rapid process, wherein over $90 \%$ of the total sulfur orginaliy dissolved in the melt is lost in a few hours. At high temperatures $\left(1300^{\circ} \mathrm{C}\right)$, this rate is slightly faster for lower oxidation state conditions, whereas at lower temperam ture $\left(1200^{\circ} \mathrm{C}\right)$, this trend is reversed. Apparept diffusion coefficients estimated from these data range from about $10^{\circ 5.75}$ at $1200^{\circ} \mathrm{C}$ to 10 $\mathrm{cm}^{2} / \mathrm{sec}$ at $1300^{\circ} \mathrm{C}$, with an act $\mathrm{l}$ vation energy of $54.8 \mathrm{kcal} / \mathrm{mole}$. Application of laser-Raman spectroscopy proved unsuccessful in Ident tifying the form of sulfur in the quenched glass. However, thermodynamic calculations suggest the form of sulfur should be domfnantly as sulfate $\left(\mathrm{SO}_{4}{ }^{2}\right.$ ) for oxygen fugacities greater than bout 10 atm. These data w1ll prove useful in assessing the effects of crustalfiderived sulfur in our environment, as well as enable us to quantify the process of volatile exsolution from active volcanic systems.

\section{Oxyanion Migration}

High valence state elements such as $\mathrm{W}^{6^{+}}, \mathrm{Mo}^{6^{+}}, \mathrm{Cr}^{6^{+}}, \mathrm{Tc}^{7^{+}}, \mathrm{As}^{5^{+}}, \mathrm{S}^{6^{+}}$ and other important geochemlcal tracer and radionuclideranalog elements exist as oxyanions ( $\mathrm{WO}_{4}{ }^{2}, \mathrm{MOO}_{4}{ }^{2}, \mathrm{CrO}_{4}{ }^{2}, \mathrm{TCO}_{4}, \mathrm{SO}_{4}{ }^{2}$ ) and their protanated and polynuclear forms in hydrothermal flulds. "Our studles of these species commenced $\mathrm{WIth} \mathrm{WO}_{4}{ }^{2}$ and $\mathrm{SO}_{4}{ }^{2}$ hydrolysis and continue with $\mathrm{CrO}_{4}^{2}$.

The speclation of $\mathrm{Cr}^{2}$ in 0.1 to 5.2 molal $\mathrm{NaCl}$ solutions was studied in the range 25 to $175^{\circ} \mathrm{C}$ and total $\mathrm{Cr}^{6}$ concentrations of 0.001 to 0.03 molal, us ing a hydrogen-electrode EMF celi. Reduct 1 on of $\mathrm{Cr}^{6}$ to $\mathrm{Cr}^{3}$ prevented measurements at higher temperature. $\mathrm{CrO}_{4}{ }^{2}$ is the dominant Cr(VI) specles in neutral and basic aqueous solutions. This species hydrolizes to form HCrO and or $\mathrm{Cr}_{2} \mathrm{O}_{7}{ }^{2}$ with decreasing $\mathrm{pH}$, depending on the tempecature and total chromium concentration (hish $\mathrm{Cr}$ and low $\mathrm{T}$ favors $\mathrm{Cr}_{2} \mathrm{O}_{7}{ }^{2}$ ). In highly saline, hl gh temperature fiulde, $\mathrm{CrO}_{3} \mathrm{Cl}^{2}$ becomes an important specles in acid solutions. 
The equilibrium quotients relating these species have been accurately determined over a wide range of temperature and lonic strengths at pressures near vapor saturation, and the thermodynamic parameters of the hydrolysis reactions have been computed. The temperature and lonic strength dependences of the reactions $\mathrm{CrO}_{4}{ }^{2}+\mathrm{H}^{+}=\mathrm{HCrO}_{4}$ and $\mathrm{WO}_{4}==$ $\mathrm{HWO}_{4}$ are remarkably similar. These results are useful in predicting the behavior of the other transition metal oxyanions listed above, particularly $\mathrm{MOO}_{4}{ }^{2}$.

Formation Constants for Aqueous Ferrous Acetate Complexes at Elevated Temperatures and Pressures from Magnetite Solubility Experiments

Our previous results on the kinetics of acetate decarboxylation demonstrated that acetate 1 s sufficiently stable below $300^{\circ} \mathrm{C}$ to be effective in transporting metals in hydrothermal solutions by enhancing the solubility of minerals through complexation. The overall reaction studied to evaluate metalracetate formation constants is expressed by the general reaction:

$$
\begin{aligned}
& \mathrm{Fe}_{3} \mathrm{O}_{4} \text { (magnetite) }+2 \mathrm{CH}_{3} \mathrm{COOH}=\mathrm{Fe}\left(\mathrm{CH}_{3} \mathrm{COO}\right)_{\mathrm{n}}^{2 \mathrm{Cn}} \\
& +\left(2 \mathrm{n} \text { ) } \mathrm{CH}_{3} \mathrm{COO}^{\circ}+\mathrm{H}_{2} \mathrm{O}+\mathrm{Fe}_{2} \mathrm{O}_{3}\right. \text { (hematite). }
\end{aligned}
$$

The experiments cover a range from $1000-250^{\circ} \mathrm{C}, 250-1250^{\circ}$ bars and $\mathrm{CH}_{3} \mathrm{COO}$ concentrations from 0.005 to $1.0 \mathrm{~m}$ and indicate that the first and second ferrous acetate complexes (1.e., $n=1$ and 2 for the above reaction) dominate over this entire range of conditions. The data illustrate that the solubility of magnetite in acetate solutions varies in a simple and regular manner with changes in temperature, pressure and composition and that the random error in the measurements is aobut $0.05 \mathrm{log}$ units. A comparison of these data for the ferrous acetate complexes with literature data for the chloride complexes shows that the forqation constant of $\mathrm{FeCH}_{3} \mathrm{COO}^{+}$is about 100 times larger than that of $\mathrm{FeCl}^{+}$, and that $\mathrm{Fe}\left(\mathrm{CH}_{3} \mathrm{COO}\right)_{2}$ is favored by a fact or of 10,000 over $\mathrm{FeCl}_{2}$. Consequently, these data lend credibility to the hypothesis that organic complexes are responsible for the mobility of metals in some hydrothermal systems, particularly in sedimentary basins where measured acetate levels reach $0.1 \mathrm{~m}$, and in any setting where a hydrothermal fluid has access to organic material. The implications of these data for radioactive waste disposal, secondary permeability in petroleum resorvoirs, and corrosion in steam generators, anong other geologic and industrial processes, are sufficlent to warrant further investigations of organic complexing of metals in hydrothermal solutions. 
Direct Comparison of the Formation Constants for Complexes of Hydrolyzing and NonrHydrolyzing Ligands at Elevated Temperatures by Hydrogen-Electrode EMF Techniques

Preliminary experiments in the aqueous $\mathrm{Fe}^{2}{ }^{+} \mathrm{CH}_{3} \mathrm{COO}^{n}-\mathrm{NaCl}$ system show that: (1) EMF techniques are capable of producing accurate data for metal complexes; (2) the method is inherently more accurate and much easier than conventional solubility methods; (3) the method could be used to advantage with spectral techniques that could resolve the 1dentity of the species; (4) acetate complexes of iron are indeed much stronger than the analogous chloride complexes; (5) this method is amenable to measurements if any system wherein the total metal concentration can exceed $10^{3} \mathrm{~m}$ and the difference between the formation constants of the hydrolyzing and non-hydrolyzing 1 igand do not exceed about 3 orders of magnitude.

It is highly advantageous to use a non-complexing, non-hydrolyzing electrolyte as a supporting medium for studies of the complexing of metals with hydrolyzing ligands in the absence of competing ligands. We currently are experimenting with sodium trifluoromethanesulfonate as a non complexing electrolyte. The results at this juncture are encouraging and, if successful, will allow this EMF technique to be elevated from a relative to an absolute method for measuring the stability constants of complexes that mobilize metals in geothermal systems, petroleum reservolrs and waste repositories.

Mineral Growth Rates and Their Application to Quantifying Geological Systems

The purpose of this investigation is to evaluate the growth rates of crystals (planar for simplicity) from elther solutions or melts for a linear rate of cooling. We have used a finite difference solution to quantify growth rates for simple geological-analog systems where the solutions and granite melts. For cases where the surface kinetics are slow compared to the diffusion of components to the surface (1.e., quartz in hydrothermal solutions), the growth rate tends to increase linearly with time. On the other hand, for cases where the surface kinetics are rapidly compared with diffusion (1.e., quartz in melts), the growth rate is proportional to the square root of time. Regardless of the system, fast cooling rates cause non linear growth rates after extended times. This effect is amplified for phases with solubilities which are highly temperature dependent. With a knowledge of the composition of the system, its cooling history (e.g., from fluid inclusions), and the size of individual mineral grains, we can use this model to quantify the duration of the depositional process. This approach will prove useful in quantifying mineral deposition in the pores or fractures of Important geological systems such as 011 and natural gas reservoirs, geothermal fields, nuclear waste repositories, and cooling magma chambers. 
Modeling of Stable Isotopic Exchange Between Minerals and Fluids During Simultaneous Diffusion and Chemical Reaction

Heretofore, isotopic exchange in natural systems has been modeled for conditions where only one mechanism was thought to prevail, 1.e., only diffusion or only surface reactions. It is clear, however, that many geologic systems involve fluid-inineral interaction where both processes occurred simultaneously. Initially, we chose to model oxygen isotopic exchange between $\mathrm{K}$-feldspar (of spherical geometry) and a $0.1 \mathrm{~m} \mathrm{NaCl}$ solution where the surface reaction mechanism for isotope exchange is first order, reversible, and many times faster than exchange accompanyin ing diffusion. When the surface reaction is very rapid, we can assume that the immobilized component. (new phase) is always in equilibrium with the component free to diffuse (1.e., $\mathrm{H}_{2} \mathrm{O}$ or $\mathrm{OH}^{2}$ ), and diffusion is the rate controlling process. The most interesting result of these calculations is that the overall diffusion process coupled with a surface reaction is slower than the simple diffusion process by a factor of about $\left(K^{\prime}+1\right)$, where $K^{\prime}$ is the equilibrium isotope partition ratio between solid and solution corrected for concentration. Thus, at $650^{\circ} \mathrm{C}$ and a grain radium of $0.022 \mathrm{~cm}$, an i sotopic equilibration time of about 3000 years is obtained compared to only about 300 years for simple diffusion. Using this isotoplc approach, we can estimate the duration of fluidisrock interaction in geothermal and magma ${ }^{\text {nhydrothermal }}$ systems.

Stable Isotope Geochemistry of Carbonates in the Brevard Fault Zone

The leading candidate for the first ultradeep $(>10 \mathrm{~km})$ CSDP borehole is the ADCOH site in northwestern South Carolina and is intended to test the thin-skinned tectonics hypothesis suggested by recent mapping and COCORP selsmic profiling. According to this theory, the Blue Ridge thrust extends southeastward as a subhorizontal detachment zone beneath the crystalline Blue Ridge and Pledmont Terranes.' The Brevard Fault zone is believed to be a splay off this major sole thrust. The ADCOH drill site is targeted to intercept the Brevard Fault at approximately $4 \mathrm{~km}$, and the Blue Ridge Thrust at $7=8 \mathrm{~km}$.

Tectonic slices of massive dolomitic marble occur at several localities along the Brevard Fault. These are belleved to represent fragments of the CambrowOrdovician platform carbonate sequence which seismic evidence suggests underlies the crystalline thrust sheets. A thin but laterally extensive stratigraphic sequence of graphitic schists at the base of the Chauga River Belt has apparently acted as the locus for Brevard Fault zone displacements. This sequence contains a number of thin but laterally extensive calcite marble horizons.

Stable carbon and oxygen isotope analyses were performed on over 90 samples of the tectonic slice and Chauga River carbonates, as well as representative units of the Cambro-0rdovician platform carbonates. The carbon and oxygen isotopic signatures of the Shady and Conasauga samples are within the normal range for unmetamorphosed Cambrian carb; onates worldwide. The Knox Group appears to be somewhat depleted 
in ${ }^{13} \mathrm{C}$, but is within the normal oxygen range. The Chauga $\mathrm{R} 1 \mathrm{ver}$ and slice carbonates are distinctly anomalous, being strongly depleted in both ${ }^{13} \mathrm{C}$ and ${ }^{18} \mathrm{O}$.

Mathematical modeling demonstrates that the strong ${ }^{13} \mathrm{C}$ and ${ }^{18} \mathrm{O}$ depletion of the slice and Chauga River carbonates could have resulted from open system exchange with an infiltrating hydrothermal fluid at waterrock mass ratios of around 1-3. Two types of fluids could have produced the observed trends $--300^{\circ} \mathrm{C}$ fluids with initial carbon $\left(\delta^{18} \mathrm{C}_{\mathrm{PDB}}\right)$ and oxygen ( $\delta^{18} 0_{\text {SMOW) }}$ ) 1sotopic compositions of -10 and 2 permil, respectively; or -150 dC fluids with carbon and oxygen isotopic compositions of 410 and -5 permil, respectively. The first type of fluid could have been produced during dewatering of the shelf sequence associated with Alleghenian overthrusting." The second type of fluid could represent a deeply circulating ( $5 \mathrm{H} 7 \mathrm{~km}$ ) groundwater of meteoric origin. The carbon 1sotopic compositions of the various carbonate units appear to be a useful tool for correlation purposes.

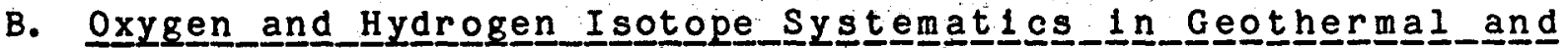
Magma/Hydrothermal Regimes (D. Wesolowski)

Selection of a number of gritoids in the Southern Appalachians as potential high level waste repository sites has focused attention on their intrusive, hydrothermal and metamorphic histories. An oxygen isotope survey of granitoids of the region has revealed a large area of the Slate, Raleigh and Eastern Slate Belts of North Carol ina and Virginia in which the granitoid plutions exhibit anomalously low and highly varlable whole-rock $\delta ! 0$ values. Many of the granitoids in the study area have $8^{18} 0$ values less than 6 permil, with several in the range $\rightarrow 1$ to 3 permil. These very low and highly variable oxygen isotope signatures are indicative of extensive exchange of the intrusions with isotopically depleted waters of elther meteoric or regional metamorphic origin.

The granitolds of the main Slate Belt, including the Highpoint, Parks Crossroads, Roxboro, Vance County and Burkeville plutons are lower Cambrian in age and exhibit shallow, subvolcanic characteristics. Thus, the depleted oxygen 1sotopic signatures of these intrustions could be explained as having resulted from the shallow ( $1 \mathrm{H} 2 \mathrm{~km}$ ) cirs culation of heated, isotopically depleted meteoric waters so common in such settings throughout geologic $t$ ime. The occurrence of numerous "volcanic exhalative" base and preclous metal and pyrophyllite deposits in this region are evidence of intense hydrothermal circulation in the volcanic country rocks surrounding the granitolds. The Raleigh and Eastern Slate Belts both contain strongly depleted granitolds which are belleved to be Alleghenian in age $(-600$ million years ago).

If these intrusives were subvolcanlc and associated with meteoric hydrothermal alteration, then one might expect some coeval Alleghenian sediments or volcanics in the area. No sedimentary or volcan lc rocks of this age have been reported from el ther the Ralel gh or Eastern Slate Belt. Another possibility is that the Alleghenian intrusives assimilated isotopically depleted slate belt volcanics during intrusion. 
Contractor:

Contract :

Category:

Person in Charge:
PACIFIC NORTHWEST LABORATORY

Battelle Memorial Institute : Richland, Washington 99352

DEMACO6-76RLO 1830

\section{Geochemistry}

J. C. Laul

A. Chemical Migration by Contact Metamorphism Between Pegmatite - Country Rock (J. C. Laul)

The major objectives of this research program are to gain a quantitative understanding of chemical migration during contact metamorphism in diverse geological media and to understand aqueous fluid evolution in granite pegmatites and country rock systems. The study includes the understanding of dispensing solutions derived from pegmatites, and composition and evolution of the solutions. While the study focuses on some forty major, minor and trace elements, specific emphases are on the rare earth elements (REE) and $\mathrm{Ba}, \mathrm{Sr}, \mathrm{K}, \mathrm{Rb}, \mathrm{Cs}, \mathrm{As}, \mathrm{Sb}, \mathrm{Pb}, \mathrm{Cl}$, $\mathrm{Zr}, \mathrm{Hf}, \mathrm{N1}$, Th, and $\mathrm{U}$. The trace elements study may enable us to understand and predict the long-term $\left(10^{3} \times 10^{7}\right.$ year) behavior and move ment of radionuclide in diverse geologic media over a range of temperatures pertinent to nuclear waste.

The geological site under study is pegmatite-country rocks in the Black Hills, South Dakota. Five different pegmatites are to be addressed (a) composition of fluids, (b) capability of dispensing fluids into country rocks, and (c) partitioning of mobile elements between mineral phases and fluids derived from pegmatites. Chemical studies of the $T$ in Mountain, Etta, Bob Ingersoll, and Peerless pegmatites show that there is virtually no migration of $\mathrm{REE}, \mathrm{Al}, \mathrm{V}, \mathrm{Sc}, \mathrm{Cr}, \mathrm{Hf}$, and $\mathrm{Th}$ elements. On the other hand, elements $K, L i, R b, C s, A s, S b, Z n$, and $\mathrm{Pb}$ have migrated 4 to 90 meters. The degree of migration varies depending on the element. Minerals biotite and muscovite are effective trace ele ment traps for $\mathrm{Li}, \mathrm{F}, \mathrm{Rb}$, and Cs. The REE concentration in biot 1 te and muscovite in all pegmatites are high and indigenous. Similar types of chemical studies in other pegmatites emphasizing minerals such as apatite and tourmaline as a recorder of melt/fluid evolution are partly complete. The REE concentrations in tourmalines are very low, indicating their partition coefficients in tourmalines are quite low. The REE patterns in tourmalines are severely fractionated from Iight REE to heavy REE, whlch reflect the progressive change in the composition of the pegmatite's fluid phase during crystallization. Some tourmal ines, biotites and muscovites exhibit positive Eu anomalies, some negative Eu anomalies, and some show no Eu anomalies. The varying degree of Eu anomalies reflect the degree of redox state of the fluid environment. An investigation is being made as to whether there were mulitple or single episodes of fluid migration into the country rocks. The chemical data on some 40 major, minor and trace elements are obtained by neutron activation analysis (INAA and RNAA), atomic adsorption and $x^{-}$ ray fluorescence. 
$+.+$

This study is in collaboration with J. J. Papike of South Dakota School of Mines and Technology, Rapid C1ty, South Dakota, who will obtain mineralogic and petrologic data on the same samples. 
Contractor:

Contract:

Category:

Person in Charge:

Scope of Work

Since 1976, PNL has been conducting research in areas of remote sensing, image processing, and computer graphics most relevant to the geoscientific interests of the Department of Energy. The goal of this task is to develop practical, interactive computer techniques for processing, analyzing, and displaying combinations of remote sensing and geosciences data so scientists can interpret more complex data combinations, more completely and more rapidly. Successful techniques are being integrated into basic research and technology programs involving resource discovery, energy development, environmental conservation, and the national security objectives of the Department of Energy.

The current scope of research responsibilities involves:

(A) Maintaining cognizance and acquiring appropriate remote sensing and geosclence data sets to support continuing research efforts.

(B) Upgrading computer capabilities (hardware and software), as required, to advance the state of the art in digital processing, analysis, and display of remote sensing (imagery) and geosciences (point, line, and map) data.

(C) Demonstrating and applying experimentally developed techniques within basic research and technology programs internal and exter nal to DOE.

A. Remote Sensing: Geoscience Data Analysis and Integration (G. E. Wukelic, H. P. Foot, J. R. Eliason, J. E. York)

Remote Sensing and Geosciences Data Base Expansion

Additional Landsat 5 Thematic Mapper (TM) data of interest to this geosciences task are now being acquired for PNL by the Earth Observation Satellite Company (EOSAT). Acquisition emphasis is on the CSDP sites, the Hanford site, Yellowstone National Park, and the Diablo Canyon nuclear power plant. Also, during 1985 conventional imagery from Seasat for Long Valley, California, were acquired and processed. We have also acquired an experimental data set from NASA's airborne Imaging Spectrometer (AIS) for processing, and plan to secure samples of SPOT stero data for sites of interest during the no-fee period for requesting SPOT acquisitions in 1986.

$$
-74-
$$


A1so during the past year, PNL has acquired over $40 \%$ (17 quadrangles) of highrresolution (1:24,000 scale) topographlc data for the Hanford site, and we are attempting to obtain a similar data set for the entire Washington State Cascade Range. We cont inue to emphasize acquiring avallable geologic and geophysical data ltems and maps to support preparation of integrated multiparameter graphics of the CSDP sites such as the USGS microselsmic data for the Hollister, Long Valley and Geysers areas.

\section{Hardware and Sof tware Development}

Beginning in FY 1985, task emphasis was placed on procuring, install ing, and developing a second-generation interactive, image processing and data integration system for geoscientiflc analysis (referred to as geodata). The new system, which is a combination Symbollos- Microvaxbased system, will incorporate selected knowledge représentation techniques (developed under artiflcial intelligence research) with conventional image processing/data integration functions currently performed on the existing geodata system.

To date, most of the Symbolics system components have been installed and are operational. A programming package KEE (Knowledge Eng ineering Environment) for supporting the development of knowledgerassisted software has been installed and experimentation has commenced. Also, initial conversion of existing minicomputer software to run on the MicroVAX Station II computer has been completed, and device drivers and interfaces are under development to support MicrovaX Iinks to the image digitizing/processing inputhoutput devices. Major attention during this geodata system upgrade is being given to increasing the speed of data processing and analysis functions, providing for incorporating more geoscientific parameters and simplifying user interactions.

Demonstration and Application of -Task Developed Capabilities

1. Quantitative Uses of Remote Sensing Data

Since 1982, PNL has been involved as a Landsat Thematic Mapper investigator, as part of a cooperative PNLFNASA GSFC agreement, which continues until 1988. This research has contributed to the assessment of the quality of the data and energyerelated applications of landsat TM data, especially for geoscienific interests.

To date, this subtask has made extensive qualitative use of TM acquisitions to prepare multisource, computer composites (combining Landsat, topography, and Geologic data) mostly for the continental scientific drilling and wind energy sites. Major progress included the ability to vary the viewing angle to simulate an apparent view point on or near the earth's surface. Also, programs have been developed and successfully tested for reducing topographyinduced variations in the landsat reflectance data which significantly increases the geologic mapping potential of such data. Currently, 
we are investigating the parameters limiting the quantitative uses of satellite multispectral data, including ground truth measurement uncertainties, calibration factors and equations, and atmospher ic and sub-pixel effects. Experience acquired from this research is being effectively transferred and utilized in a variety of DOE programs internal and external to PNL.

\section{Application to CSDP}

A secondifgeneration set of geodata products for the Valles Caldera site is now in preparation. Cloud free Landsat TM imagery was acquired for this site during the summer of 1985. This data set contains seven spectral bands and has a $30 \mathrm{~m}$ resolution element. A higheresolution digital elevation model composed of seventeen 7.5 min. quadrangles has been interpolated to a $15 \mathrm{~m}$ sample spacing, and the Landsat $T M$ data resampled to register it with this grid. Resampling to a $15 \mathrm{~m}$ grid minimized any loss of resolution caused by resampling. A geologic map of the region has been digitized and resampled to the same Grid. From these merged data sets, high resolution geodata products are belng prepared. For example, the elevation data are being used to remove or accentuate solar ilf lumination effects on the imagery. Both techniques have proven useful. Output products with $2-5$ times improved spatial resolution will be possible with the new integrated data set.

3. Application of Structural Analysis

Results of exploratory studies to develop digltal quantitative spatial analysis techniques for determining the relationships among geologlcal, geophysical, and geochemical structures show promise for alding both geoscientific and geoexploration studies. The technique, based primarily on digital terrain elevation model data, has been discussed with geoscientists at the other national laboratorles, and is currently being proposed as a separate BES task. 
Contractor:

Contract:

Category:

Person in Charge:

Scope of Work
PACIFIC NORTHWEST LABORATORY

Battelle Memorial Institute

Richland Washington 99352

DE-AC06-76RLO 1830

Solar-Terrestrial-Atmospheric Interactions

R. A. Stokes and E. W. Kleckner

The isolation/aeronomy program encompasses the area of aeronomy in the upper atmosphere, and the area of insolation and radiative transfer in the lower atmosphere. Spectfically, the aeronomy program is concerned with the plasmasphere/magnetosphere reglons and the fonosphere/upper atmosphere regions. Significant advances have been achieved over the past two decades in expanding our basic knowledge of the earth's atmosphere and magnetosphere, and the sun as an interacting system. It is important that the physics of this coupling region be well understood in order to obtain definitive solarterrestrial causeneffect relationships.

The isolation program relies on a data base of direct and diffuse solar radiation measurements made in visible and nearifinfrared spectral passbands. The research has two goals. One is to quantify the spectral characteristics of scattered and direct sunilght. This is germane to energy generating solar technologies, including photovoltaics and day lighting. However, the primary emphasis of the isolation task is to characterize the influence of trace specles in the troposphere and lower stratosphere on solar radiation. These man-made or naturally produced trace species include aerosols, molecules, and clouds.

A. DOE Insolation/Aeronomy Studies (J. J. Michalsky, E. W. Pearson, B. A. LeBaron, N. R. Larson, E. W. Kleckner, D. W. Slater)

A new approach to estimating aerosol turbidity as a function of time has ylelded unexpected results regarding the behavior of the El Chichon stratospheric aerosol at northern mid-latitudes. Formerly, we subtracted monthly averages of pre-El Chichon data which were edited to remove values suspected of being influenced by the local tropospheric effects of Mt. St. Helens throughout its series of eruptions in 1980 . The present method uses a technique known as robust, locally-welghted regressions to derive a seasonal background estimate by folding all preweruption data onto one year. An estimate for the entire unfolded data set is then obtained with the same technique, and the difference is taken as the El Chichon perturbation. With the new method, the entire 1980-1985 data set is used. Large, but brief excursions from the seasonal means are given low weight by the method. Therefore, Mt. St. Helens' eplsodes are effectively prohibited from having undue influence on the results. Before the eruption of El Chichon, the 
differenced plot for $1010 \mathrm{~nm}$ shows less than 0.005 variability in optical depth. The arrival of El Chichon aerosol is evident in the fall of 1982, followed by an annual cycle superimposed on a decaying exponential, with maxima in the winter and minima in the summer. At shorter wavelengths, it becomes clear that there is an upward trend even in what was considered background. These results have been presented on three different occasions, and a draft has been completed for submittal to Geophysical Research Letters. Data from the very clean stratospheric period of $1978-79$ are being reduced to determine a better background. These new results, the time-dependent size distribution behavior obtained from inversion of wavelength dependent turbidity, and comparisons to other data sets will be included in a publication in preparation for the Journal of Geophysical Research.

The same data set has been used to derive total ozone estimates for the six-year period beginning in January, 1980. The visible absorption band is used, as opposed to the ultraviolet bands in the standard Dobson instruments. A value for total ozone is derived by assuming a functional form for the wavelength dependence of the turbidity throughout the visible and near-infrared. A minimum chimsquared is sought by repeating leastisquares fits for different assumed ozone abundances. Total ozone derived in this fashion has large dally variability. Smoothing, using the non-parametric technique as above, or least squares fitting to sinusoidal functions, both indicate maxima in the spring and minima in the fall, with amplitudes that are in general agreement with the Dobson data from similar latitudes. During periods of volcanic perturbation, this seasonal pattern in clearly disturbed. (Dobson instruments experience problems with stratospheric aerosol perturbations, as well). We suspect that the technique is at fault, because the functional form assumed for the wavelength dependent turbidity is not followed well during those times. We will investigate functional forms and filter combinations that are more robust in this situation.

We have nearly eompleted the second phase of our program to develop low-cost solar measurement equipment. Methods to radiometrically correct our silicon cell rotating shadowband pyronometer have been derived. Empirical corrections for the temperature, spectral, and cosine dependences allow us to achieve daily integrated values of total horizontal irradiance to better than $1 \%, 2 \%$, and $2.5 \%$ on the average, compared to firstaclass pyronometers and pyreheliometers. Hourly integrated values are only slightly lower in accuracy. These results have been presented on two occasions, and a draft is ready for submission to Solar Energy. A third phase, involving the development of a low spectral resolution instruments, is being considered. Besides its clear role in solar spectral resource assessment, this device could be used for a network of lowhost aerosol and trace gas measurements.

The use of midH and high latitude auroral and ionospheric phenomena for revealing solar-terrestrial relations has gained greater appreciation as evidence regarding the wide ranging and complex interactions has become available. A major goal of the aeronomy program is to inves: tigate the coupling of the ionosphere, plasmasphere, and 
magnetosphere, primarily through the use of remote optical sensing. To accomplish this, a network of P.NL-engineered, computerecontrolled photometers has been maintained to acquire synoptlic observations of the aurora and airglow above major portions of the North American continent.

Among the varlety of auroral emission patterns that occur, the most striking at midelatitudes is the Stable Auroral Red (SAR) arc. Our studies during the past year have centered on the transport of energy within the thermosphere/ionosphere system from approximately $200 \mathrm{~km}$ to $1000 \mathrm{~km}$ altitude. We have continued our collaborations with the Southwest Research Institute team responsible for the plasma instruments on board the Dynamics Explorer ${ }^{-1}$ and +2 satellites, as well as researchers from the University of Michigan space science group. Although the spectral purity of SAR arcs excludes the possibility of significant fluxes of energetic particles into the arcs, presence of low energy electrons ( $E<10 \mathrm{eV}$ ) with fleld-aligned velocities into the body of SAR arcs has been found to be characterlstic of arcs being monitored by the PNL photometers during times of satellite overflights. An exhaustive research of the photometer and Dynamics Explorer data bases has ylelded 24 such cases, during which both optical and plasma measurements were avallable for the same regions of space above and within SAR arcs. Evidence showing the presence of downflowing electrons from the plasmapause region was present in each instance. Modeling of the atmospheric responses expected of these influxes indicate that the electrons. within the constraints imposed by uncertainties of energy extrapolations to very low energies, have sufficient total energy. to establish temperatures in the ambient ionospheric electron gas that are capable of producing the optical signature of the SAR arcs. Studies of atmospher $1 \mathrm{c}$ compositional perturbations that may be associated with these arcs is continuing, since any such perturbations could be crucial to the heat balance. within the ionosphere and are currentiy not adequately known.

Additional collaborations with researchers at the Marshall Space Flight Center and the University of Texas at Dallas have yielded results. Work with the former group led to publication of spatial relationships among plasma boundaries with the inner magnetosphere. Among the feas tures noted were that the morning plasmapause typically shows a ramp like density profile with no clear. boundary, in contrast to the evening plasmapause. Also, the boundarles of the plasmapause, the inner edge of the electron plasmasheet, and the equatorward boundary of the auroral oval electron precipitation correlate extremely. well with the $\mathrm{Kp}$ magnetic activity index. Studies with the former group have cen tered on analysis of the vibrational development of $\mathrm{N} 2+$ (1NG) emissions within low latitude aurora. The conclusion drawn from the high vibra:tional development of this band, in comparison to higher latitude emissions, is that a primary contribution to energy input at lower latitudes consists of collisional excitation by energetic heavy particles, namely oxygen, helium, and hydrogen. Final mechanical assembly of an EbertaFastie spectrometer, and generation of the 
controlling software, has been completed. Initial uses will include measurement of the relative intensities of the lines within the OH (83) band system of the X2P1 state, to establish mesopheric temperatures under a variety of geomagnetic conditions.

The design and acquisition phase of a new low light level imager, based on a charge-coupled device (CCD), was begun this year. The imager will be a major effort to enhance and supplement the utility of the photometer network, as well as representing a wholly independent instrument. Most aspects of gain, image integration time, and viewing area will be under user control, via a computer interface. 
, ,

contractor:

Contract:

Category:

Person in Charge:
SANDIA NATIONAL LABORATORIES

Albuquerque, New Mexico 87185

DEMACO4-76DP00789

Geophysics Research

W. C. Luth

A. Crustal Strain (J. B. Rundle)

The crustal strain program seeks to develop physlcal models for the interpretation and analysis of a varlety of geodetic data obtained on a continuous basis intreglons of ongoing tectonic deformation. Deformation is in general time dependent, and observations are obtained via a variety of higheselution techniques including historic triangulation and leveling; as well as more modern methods such as mlcrogravity surveys, trilateration; and the new spacembased techniques such as GPS (Global Positioning system) VLBI (Very Long Baseline Interferometry) and SLR (Satellite Laser Ranging). Models constructed to explain these data contain as much physical information as possible, so that the data can be used to examine the relative 1 mportance of the competing processes. For example, motions of a few centimeters per year, commonly observed in tectonically active areas such as the western United States, have been interpreted via the models as indicating the existence of a subtle stress relaxation process deep within the earth.

Computer codes have been developed which compute timefdependent surface deformation due to a variety of physical sources in a layered, inelas tic earth model. Additionally, other codes compute gravity, sea level, potential, and surface deformation changes due to volcanic loading of the crust; and heat flow, fluid flow, and deformation due to sources of fluld pumping and heat generation. Current efforts have concentrated on the development of physicaliy realistlc, threemdimensional models of faulting in southern California and in subduction zones. In addition to kinematic models, the mechanics of faulting have been examined using friction laws developed from laboratory experiments. Moreover, an analytic model of faulting was constructed which allows an in homogeneous distribution of stress on the fault surface. These efforts have led to the conception of the "Patch" model of faulting, in which a fault is visualized as being divided up into a number of patches, each of which has both a constant (conserved) area and a constant (conserved) stat1c stress-drop during any earthquake which involves the patch. These 1deas have been incorporated into the beginnings of a mechanical fault model for southern California, in which the far field plate boundaries are driven at some constant rate, and times, mag nitudes, and locations of earthquakes are calculated according to some préidetermined faliure criterion.

Recent work has also included kinemat ic calculations of present day strain in southern California arising from the far fleld plate motion, current aseismic slip, and historic earthquakes. Collaborators in this 
work have included scientists at the University of Tokyo, Japan; the U. S. Geological Survey; the California Institute of Technology; and the University of California, Santa Cruz.

B. Time-Dependent Deformation and Fracture of Brittle Rock (L. S. Costin and D. J. Holcomb)

This research is directed toward a basic understanding of the mechanics of microcrack growth and how this is reflected in the continuum response of the material. Both experimental and analytical efforts are in progress.

An experimental determination of the relationship between applied stresses and the density and orientation of microcracks in granite has been inftiated. These experiments use large block planetistrain specimens rather than the more traditional axisymmetric triaxial sample configuration. Using acoustic emission counting methods, the threshold stress at which microcrack growth occurs is being determined as a function of previous stress history. The previous histories include stress paths in which the principal stresses rotate relative to the material. In later experiments, acoustic emission location will be used to determine the location and extent of damage in specimens as they are deformed.

To apply the experimental results to the problem of deformation of brittle rock, a relationship between microcrack behavior and continuum behavior was established through an analyt1cal model based on fracture mechanics and damage theory. The model incorporates the effects of damage on material behavior due to the nucleation, growth and coales* cence of microcracks during compressive loading. The model has been implemented in a finite element code so that the response of rock specimens to various loading histories can be predicted and compared with experimental results.

C. Creep Mechanisms and Microstructure in Rock Salt (W. R. Wawersik)

Predicting the performance of underground structures in salt masses requires extrapolating laboratory creep measurements and the resulting constitutive models for rock salt to low stresses and long times. The validity of these extrapolations was addressed in three ways. (1) Creep measurements were interpreted in terms of plausible deformation mechanisms. (2) Microstructures, 1.e., dislocation arrangements, were determined in polyorystalline and singleAcrystal salt after laboratory testing and correlated with the models identified earlier.. (3) The microstructures (dominant deformation mechanisms) in salt after laboratory testing were compared with the microstructures in rock salt that was deformed during much longer times and at lower stresses in situ.

The first task was completed via creep measurements on natural polycrystalline rock salt from several locations. Correlations of the resulting steadyistate creep estimates and activation analyses both 
suggested that the low temperature creep of rock salt is controlled by cross-silp. Data correlations at very low strain rates (less than 10\%8 $1 / \mathrm{s}$ ) were strengthened by the development of a new technique to identify steady state creep rates in terms of upper and lower bound estimates.

Microstructural features following loading in the laboratory at tem peratures below $1100 \mathrm{C}$ were dominated by glide related features to $14 \%$ strain, which is consistent with the hypothesis that the creep process was cross-slip controlled. This conclusion is supported by low temperature creep observations on NaCl single crystals ylelding unamblguous evidence of wavy slip and effective activation energies well below the activation energy of self 4 diffusion of chlorine. The suggested role of crosstslip, of course, does not $1 \mathrm{mply}$ the absence of other mechansims including dislocation climb and subgrain formation but merely indicates that they were not dominant.

Microstructural studies of laboratory-deformed salt were augmented by systematic observations on naturally deformed rock sait from the vicinity of old mine workings in Hutchinson, Kansas; Hallstatt, Austria; Wiel 1czka, Poland; and from the Asse mine, Federal Republic of Germany. Asse salt included samples taken from the immediate vicinity of an in situ heater experiment to $280 \mathrm{C}$. In most samples, microstructures exhibited stralght and wavy slip. Ideally, perfectly regular subgrain structures were dominant only in heated salt from the Asse mine. Silp related features again support the use of existing laboratory creep measurements. However, salt deformed in situ exhiblted several additional features. The most developed of these, besides pure glide bands, are coexisting subgrains and glide bands without noticeable interactions, locally polygonized microstruct ures, accelerated recovery around brine inclusions, and recrystallization. Evidence of recrystalifization appears to be especially important be cause it is very similar to microstructural manifestations after stress drops in some stress relaxation tests, or after gradual, previously unexplained creep acceleration in a few laboratory experiments. Although some of the observed features, such as recrystallization, are not steadymstate processes; their random development over large volumes could be important, might explain systematic underpredictions of salt deformations in situ, and should be studied further.

D. Acoust1c Emissions and Damage In Geomaterials (D. J. Holcomb)

Under compress 1ve stresses, brittle polycrystali ine materials fall as the result of the accumulation of multiple microfallures. Constitutive 1 aws for such materials must incorporate the effects of the miorofallures, in particular the inelastic strain and reductions in elastic moduli. A method of incorporating accumulating fallures into a continuum model is to replace the detalls of crack density, slze, orlentation, and development with a material property which is commonly 
called damage. Although a number of theorles of damage have been proposed, there is no generally accepted technique for detecting and measuring damage. The purpose of this research is to develop such techniques, using acoustic emissions as the basic tool, and to apply the techniques to study the development of damage in geomaterials.

The first goal is to develop and demonstrate the techniques to be used. A major step toward this goal is described in a paper entitled "Detecting Damage Surfaces in Brittle Materials Using Acoustic Emissions" which has been accepted for publication in the Journal of Applied Mechanics. A method is reported for detecting various projec tions of the 6tidimensional damage surface and the existence of the damage surface is demonstrated. The initial demonstration was in granite. Further work will examine other geomaterials to see if the same methods work. Specifically, tuff, salt, and sandstones will be tested.

Damage is not expected to be generated homogeneously because of the effects of nonuniform stress conditions in the general case. Study of inhomogeneous damage generation is important for at least two reasons: validation of computer codes based on damage models and study of the fallure process. For all but the simplest, most idealized stress states, the codes predict Inhomogeneous damage gerieration. Checking these predictions requires that the spatial distribution of damage be measured, preferable as a function of stress, and not just at the end of a test. An important example of inhomogeneous damage is the process of fallure which is preceded by a localization of damage. A second goal, to measure the spatial distribution of damage, requires location of the individual mocrofaliures responsible. A system for acquiring the acoustic emission wave forms from which locations can be determined is nearing operational status.

A potential application of the acoustic emission techniques is the inverse problem of determining the inducing stress state from the measured damage surface. In particular, can the state of stress in the earth be determined from core samples by detecting the damage state induced in the rock? This technique has been explored at various times by other groups but has never been developed to a standard tool. Part of the reason may have been an inadequate appreciation of the com plexity of the damage surface and the interactions between the various stress components. A paper was presented at the $26 \mathrm{th} U$. S. Rock Mechanics Symposium on a reasonably successful attempt to apply the damage surface method to core retrieved from the vicinity of a nuclear test.

E. Advanced Concepts (W. C. Luth)

Research conducted in this program involves exploratory research in several geoscience areas. Typlcally such research efforts are of a shorts term nature and may be oriented toward assessing feasibility of a particular research task. 
Paleomagnetic and Rock Magnet ic Studies of the Inyo Dike ( J. W. Gelssman, Geology Department, University of New Mexico, and J. C. Elchelberger)

This investigation is focused on application of thermal demagnetization techniques to the cooling history of the Inyo Dike, Long Valley Caldera (CA), and the associated country rocks. Conventional thermal demag netization measurements, including evaluation of anisotropic magnetic susceptibility, have been completed. New apparatus for continuous thermal magnetization experiments has been designed and is being constructed. A quantification of subsolidus coaling rates will be attempted through laboratory evaluation of unblocking temperature spectra (thermalremnant magnetization) in addition to determination of directional fleld changes recorded during blocking. It is expected that this research progran will continue next year.

Anelastic Strain Recovery and in situ Stress Analys is: A DOE/Industry Cooperat Ive Program (L. W. Teufel)

In response to requests from Ph1llips Petroleum and Amoco, a joint program has been started here to utilize industry drill holes, oriented core, geological observations, and downhole measurements in conjunction with Sandia Measurements and analyses of anelastic strain recovery (ASR) taken on oriented core samples to assess the in situ state of stress. The cooperative venture provides a unique opportunity to evaluate local varlations of In situ stress as dependent on reservoir production, local geologic structure (folding and faulting), I1thology, and geologlc history. In the case of the joint program with PhIllips, the effort is concentrated In the Norwegian sector of the North Sea fleld with the emphasis on the role of in situ stress on subsidence and reinjection. In the study with Amoco, the rleld area is in southern England and the emphasis wIII be on the role of local geologic struciture, 11thology, and geologic history.

Moblie Geochemical Analysis Facllity (H. R. Westrich and W. F. Chambers)

An analyticâl SEM with energy dispersive analysis capability has been acquired to provide on-site capability for chemical analysts for glass and mineral phases encountered in drilling. The hardware and sof tware are beling evaluated and modifled here in the laboratory prior to installation in a specially conditioned trailer. The facility will also include blnocular and petrographlc microscopes, sample preparation capabilities, and gas/fluid analysis apparatus. 
Contractor:

Contract:

Category:

Person in Charge:
SANDIA NATIONAL LABORATORIES

Albuquerque, New Mexico 87185

DE $\div$ ACO4 76 ADPO0789

Geochemistry Research

W. C. Luth

\section{Scope of Work}

The Geochemistry Program at Sandia National Laboratories is comprised of the following projects: (A) Magmatic Volatiles, (B) ClaymWater Interactions, and (C) Chemical Diffusion in Minerals. These projects include investigations of the role of volatiles in shallow magmas, the free energies and kinetics of claymineral dissolution, and the chemical diffusion processes in selected silicate minerals. The research addresses fundamental problems and is relevant in a number of applied areas including geothermal energy, nuclear waste isolation, and the evolution of fluids in petroleumbearing strata.

A. Magmatic Volatiles (T. M. Gerlach, J. C. Eichelberger, H. R. Westrich, H. W. Stockman)

A new project is underway to investigate the role of volatiles in shallow magmas of volcanic environments. The research is focused on determining the in situ volatile contents of shallow magmas, the mechanisms and rates of their exsolution, and the chemical and isotopic trends that characterize escaping gases at various stages of the degassing process. The investigations include development of onisite fumarole data acquisition capabilities, laboratory techniques to measure the chemical and isotopic compositions of natural glasses and glass inclusions, experimental procedures to examine the kinetics of vapor exsolution and bubble growth in silicate melts at elevated presi sures, and models for the mechanics of eruptive vesiculation and outgassing. Investigations are also being performed of trace metal transport by volcanic gases and of $\mathrm{D} / \mathrm{H}$ fractionation between hydrous silicate melt and coexisting aqueous fluid. One of the long range goals of the work is to establish volatile budgets of volcanic systems. Such budgets are presently poorly def ined and are needed as benchmarks for assessing the environmental impact of energy technologies relative to that of volcanism. These studies provide supporting research for DOE programs in Continental Sclentific.Drilling and advanced geothermal energy recovery. The research performed during the 1984-1985 period is outlined below.

Considerable progress was made in developing a model for the volatile budget and degassing of Kilauea. This is the first complete model of this kind for any volcano, and it provides a useful format to be folf lowed in monitoring the degassing and environmental impact of other volcanos, especially the hot spot variety. The model provides concentrations and rates of flow of all volatiles throughout the entire system, including influx from the mantle, partitioning between summit 
hamber gas and melt; noneruptive degassing, and erupt Ive degassing. The degassing processes of Kllauea have been clarifled. It has been shown that the volcano degasses by el ther a one-stage or a two-stage process. Furthermore, the degassing can be accounted for by only three gas compositions: a $\mathrm{CO}_{2}$-rich summit chamber gas, a moderately $\mathrm{CO}_{2}-\mathrm{rich}$ volcanlc gas assoclated ${ }^{2}$ ith cont inuous summit lava lake eruptions, and a $\mathrm{CO}_{2}$-poor volcanic gas associated with eplsodic flank erupt 1 ons. The residence $t$ imes for volatiles range from hours in the case of relat tively insoluble components $\left(\mathrm{e} . \mathrm{g} ., \mathrm{CO}_{2}\right)$ to hundreds of years in the case of soluble components (e.g., F). The model can be correlated with tilt data so that volatile influx, storage, and (during eruptions) emissions are calculable from dally summit tilt records. The model offers guidance for monitoring and eruption hazards assessment acm tivities, and it provides a benchmark for assessing the environmental impact of a volcano during both eruptive and noneruptive perlods:

The degassing model also provides the first satisfactory explanation of the carbon and sulfur Isotope data for Kllauea. It has been known for almost 20 years that carbon enitted from the summit of Kilavea is enriched in ${ }^{3} \mathrm{C}$ compared to oceanic tholeiltes and other mantle derived magmas. The model predicts that the heavy carbon is of mantle origin and degassed directly from parental magmas, rather than a fractionation product of the hydrothermal fumarole system above the summit chamber, as has been concluded in previous work. The large carbon di scharges of the summit magma chamber effectively buffer the carbon isotope composit tion of the hydrothermalf fumarole system. The model also permits reinterpretation of sulfur isotope data and has been used to predict the sulfur isotope composition of the parental magmas, which does agree with that of other mantlefderived rocks. In a w1 der perspect ive, these results relate to an onfoing debate over the degree of l sotope heterogeneity of the mantle. They strongly challenge the traditional notion of a homogeneaus distribution of carbon isotopes: in the mantle.

Synthesis and reversed hydrogen isotope exchange exper 1 ments were conducted with natural rhyolite obsidian and isotopically labeled water to quanitify the degassing of hydrogen isotopes from rhyolitic magmas. Starting materials consisted of water plus anhydrous obsldian, or obsidian equilibrated with labeled water at run conditions. Experiments to date have been performed at water-saturated conditions for $50 \mathrm{MPa}$ and $1000^{\circ} \mathrm{C}, 950^{\circ} \mathrm{C}$, and $850^{\circ} \mathrm{C}$. Preliminary resuits thus far Indicate the per mill isotope fractionation fact or between water and rhyolite melt is approximately 23.6 , based on both synthes is and isotope exchange.

An 1 mproved technique was developed for analyzing the water content of natural silicate glasses. Past work has been plagued by poor precision of measurements on material containing water at levels below 0.3 wt\%. A series of experiments were performed to evaluate the effects of

$$
-87
$$


adsorbed water as a function of grain size. These tests showed that grain size must be controlled between $75 \mu \mathrm{m}$ and $150 \mu \mathrm{m}$ for rellable results on glasses with low water contents. The 1 mproved technique gives precisions of $5 \%$ (rel) at 0.1 wt $\%$ and has lowered detection limits to $50 \mathrm{ppm}$.

Work has continued on the development of an enhanced XRF analytical technique for sulfur. Traditional methods have been 1 imited by problems related to particle size effects, variable oxidation states for $S$, high machine blanks, and poor natural standards. The enhanced technique gets rid of size effects by means of micronized sample preparation, accommodates variable oxidation states by peak monitoring, has reduced the machine blank to $<10 \mathrm{ppm}$, and employs synthetic standards developed by the standard addition method. The new technique gives extremely consistent calibration curves with precision of $<1 \%$ and accuracy of $<5 \%$ at 100ppm levels. The new technique has been appl led to matrix glasses from Long Valley, Coso, Kilauea, and Mauna Loa.

B. ClayiH 2 Interactlons (J. L. Krumhansl)

Predictions regarding the course of clay'water reactions are of importance in a varlety of gèchemlcal, geophysical and energy related applications: Such predictions, in turn, depend on a knowledge of the kinetic and thermochemical constraints governing clay mineral dissolution. This problem has been approached by using a Dickson Hydrothermal system and experimentally measuring the solubilities of standard clays at 200 and $300^{\circ} \mathrm{C}$. To date, solubility products have been evaluated for kaolinite and the Wyoming bentonite SWy 1 . Further accomplishments to date include experimental evaluation of the parameters required to initiate the portion of the study dealing with the solubility of mixed layer illitersmectite, and obtalning suitable run materials for solubility studies on saponite and nontronite smectite clays. Reduction of the solubility data on kaolinite and bentonite have demonstrated that; although considerably longer than two months are required for solution compositions to stabilize, the changes introduced after this period by continued pluctuations in solution composition are much smaller than the uncertainties arising from as sumptions regarding the hydroxide complexes of iron and al uminum. Consequently, future experiments will be limited to about two months duration.

C. Chemical Diffusion Processes in Sillcate Minerals ( $R$. T. Cygan)

The occurrence of disequilibrium behavior in geological materials is of ten attributed to the IImited diffusion of chemical species through a silicate mineral. The understanding of numerous geochemical processes will therefore depend upon the examination of the energetics and mechanisms of solid state diffusion and the evaluation of diffusion parameters at applicable geological conditions. The goals of the present research is to apply theoretical and experimental methods in this form of analysis and to develop a fundamental basis for applicam tion to geochemical, nuclear waste, and materials science problems. 
Initial research has concentrated on the examination of the energet ics of cation diffusion in the garnets. Experimental diffusion annealments have been performed for pyrope garnet in the temperature range of $900^{\circ}$ to $1100^{\circ} \mathrm{C}$ and at controlled oxygen fugaclties. Ion microprobe analysis of the very limited depth proflles (less than one micron) are being performed at Arizona. State Unl versity. To complement the experimental studies, a theoretical analysis of the diffusion mechanisms and m $1 \mathrm{gra}-$ tion energies has been performed with the use of an interionic potential, energy minimization model. In this manner, the cation diffusion process can be understood by examining the interactions of ions associated with point defects in the silicate lattlce. The migration of a cation from an occupled crystallographic site to an approprlate vacancy or interstitlal site will require a specific amount of energy to overcome the energy barrier created by the local assoclar. tion of lons along the diffusion pathway. This migration energy, along with the defect formation energy, is I inked to the macroscople activaf tion energies obtalned from Arrhenius plots ( $10 g$ D versus $1 / T$ ) of experimental diffusion data. Migration energies were calculated for the diffusion of the major divalent (ME, Mn, Fe, and Ca) of the distorted cubic site in each of the endmember garnets. Simulations of the vacancy and interstitial mechanisms for each of these garnet phases suggest that the vacancy mechanism is the preferred process for cation diffusion. 


Contractor: $\begin{aligned} & \text { SANDIA NATIONAL LABORATORIES } \\ & \text { Albuquerque, New Mexico } 87185\end{aligned}$
$\begin{aligned} & \text { DELACO4-76DP00789 } \\ & \text { Contract: }\end{aligned}$
Category:
$\begin{aligned} & \text { Energy Resource Recognition, Evaluation and } \\ & \text { Utilization }\end{aligned}$
Person in Charge:
W. C. Luth

A. CSDP-High Temperature Geophysical Research Techniques (H. C. Hardee, G. J. Elbring, and C. R. Carrigan)

The objective of this task is the research leading to new or refined concepts and techniques in thermal, selsmic, and electrical methods to locate and define subsurface anomalous thermal regimes. The resulting instrumentation involve both surface and subsurface (drillhole) techniques. Surface or near-surface thermal instrumentation includes development and fleld testing or thermoplle heat flux, oriented convective heat flow sensors, and downhole fluid samplers. Selsmic techniques involve use of surface geophones and a down-hole controlled seismic source capable of swept-frequency operation at $250^{\circ} \mathrm{C}$ and event. tually $500^{\circ} \mathrm{C}$. An orlented, high temperature, 3-axis sel smometer for use in drill holes is being developed. This instrument will be used in both hole-to-hole (HTH) and surface-to-hole (STH) seismic studies. In addition to the instrumentation per se, each of these studies involves research on methods to interpret the data. Current research is con\% centrated in these areas:

1. A downhole controlled seismic source under development provides control of energy content and frequency of the downhole selsmic source. A prototype experimental version of this source capable of swept=frequency operation from 10 to $90 \mathrm{~Hz}$ is currently undergoing fieid tests. A DOE patent is pending on this source. A scaled up version of this source capable of self contained operation is six to eightinch diameter holes at depths to several thousand feet is currently being fabricated.

2. Work is continuing this year on thermopile heat flux sensors and downhole convective heat flow sensors. The thermopile heat flux sensors are used to obtain rapld downhole heat flow measurements. A permanent downhole thermopile heat flow sensor station has been installed at Indian Wells, CA to evaluate a new version of the thermopile instrument. The downhole convective heat flow sensor is used to measure ground water flow velocities and convective heat flow in permeable subsurface zones. A DOE patent was recently granted for the convective heat flow sensor.

3. A fluid sampler has been developed for obtaining downhole samples of fluids and gases in hot thermal wells. This device is capable of obtaining sealed fluid/gas samples at steady state temperatures of $250^{\circ} \mathrm{C}$ and is capable of 1 imited operation to $500^{\circ} \mathrm{C}$. The sealed

$$
-90
$$


sample container is returned to the $1 \mathrm{ab}$ where it is reneated to in situ conditions of temperature and pressure, and the resulting flulds and gases are analyzed.. At this time, a measurement of downhole pressure is also obtained. The first version of this sampler has been fleld tested in producing geothermal wells in California. An improved version of the sampler has recently been fabricated.

4. A downhole sel smometer with extended temperature (250 $\mathrm{C}$ ) capability has been designed and fabricated. This instrument is designed for use as, a passive selsmometer in geothermal areas and also for holes to-hole use with the downhole controlled selsmic source. This selsmometer has a unique positive locking clamp mechanism for improved high frequency response.

5. A high temperature $\left(800^{\circ} \mathrm{C}\right)$ thermal probe and associated cable and handling equipment has been developed for logging high temperature holes. This system uses a platinum RTD in a special probe assembly attached to a $2 \mathrm{~km}$ length of high temperature stalnless steel sheathed cable. The cable is mounted on a microprocessorcontrolled winch. Cable operation and data collection is computer controlled.

B. Magmat1c Emplacement (C. R. Carrigan)

A relative narrow zone in volcanic systems, the magmathydrothermal regime, is likely to control the majority of thermal and chemical processes of interest to investigators. This complex regime of ten includes boundary layers of the thermal, chemlcal and mechan 1 cal varlety and is the basis for much of the coupling that occurs between thermotemechanical and chemical processes associated with the evolution of magmatic systems. Further, many of the accepted surface indicators of volcanism such as heatflow, gas and steam production and oxygen isotope ratios are directly related to this regime. Currently, this investigat1ve effort deals with both mass and heat transport in the steady state and time dependent magma-hydrothermal zones using both analytical and numberical models. In addition, some fleld experiments involving heat flow data acquisition are being carried out.

A unique onefimensional model simulating cooling and infiltration in a magmakhydrothermal system has been developed... This model takes into account the effects of conveot 1 ve heat transfer in the hydrothermal zone as well as in the magma. Earlier hydrothermal models have always considered only infiltration of solidifled bodies that cool by conduction. The present model simulates magmahydrothermal heat trans fer in systems relevant to geothermal energy extraction. In the model, magma chamber convection is included using a parameterized scheme developed earlier. Boundary conditions representing a hydrothermal zone were obtained using a model for two phase darcy flow. For a one kllometer thick intrusion and a 35 md host rock permeability, typlcal infiltration rates are a few tens-of-centimeters per year. 
Eurthermore, it is found that rhyolitic magmas will permit infiltration to occur more rapidly than basaltic magma which is an effect of the difference in convect Ive vigor between more viscous rhyolitic and much less viscous basaltic magma. In principle, it should be possible to measure such infiltration rates from oxygen isotope data.

A site speciflc, time-dependent model of heat transfer in a conduct tively dominated medium has been developed for the sierran basement regime of the Long Valley Caldera. The model demonstrates that modest heat flows may be associated with a shallow magmatic heat source if it is timerdependent. Simulation of magma injection ( $850 \mathrm{C} \max$ ) and cooling ( $500 \mathrm{C} \mathrm{min}$ ) of a heat source over a $200 \mathrm{kyr}$ cycle yields heat flows of about $6 \mathrm{HFU}$. this is only about one-third to one-half of the total rate at which heat is evidently being supplied to the caldera.

Regarding magma-hydrothermal heat transfer, recent analyt 1 cal and numerical modeling suggests that the use of borehole temperatures to estimate heat transfer by darcy flow could only work in relatively narrow conduction dominated zones near magma or in impermeable rock formations. As a result, there is a lack of convective heat flow data available for comparison with theories developed by this researcher as well as others. An effort is being made, in conjunction with inf strumentation development at Sandia, to obtain data from a heat flow array based on thermopile devices. Initial data from the first heat flow station, Installed in Indlan Wells Valley, CA, will soon be avallable.

C. CSDP Long ValleyMono Craters Site Assessment (J. B. Rundle, C. R. Carrigan, H. C. Hardee, and W. C. Luth)

The Long ValleyiMono Craters region of eastern California, with its recent tectonism and seismiclty, is important as a potential site for deep continental drilling. This site has been under investigation as a thermal regimes target since 1982. Investigations have included both active and passive geophysical techniques, geochemical and petrologic sampling, both at the surface and in shallow ( $<1 \mathrm{~km}$ deep) boreholes. Investigators have included several tens of scientists from all the national laboratorles, the U. S. Geological Survey, academic institus tions, and private industry.

This site assessment activity is now complete, a final report has been written, and $a$ brief version has been published in the Transactions of the American Geophysical Union (EOS). Results of many studies, when superposed upon a map of the Long Valley caldera, clearly Indicate that a major body of magma lies in the central part of the caldera at depths as shallow as about $5 \mathrm{~km}$. While selsmicity within and to the south of the caldera continues at a low level, uplift of the central part of the caldera is currently $40-50 \mathrm{~mm} / \mathrm{yr}$, Implying magmatic injection rates of

as much as 20-30 million $\mathrm{m}^{3} / \mathrm{yr}$. Fluid samples from the surface and in shallow wells indicate isotopes of carbon that are consistent with the presence of a major shallow or ustal magma body. 
A systhesis of all avallable data indicates that the southicentral part of the caldera, near the head of Long Canyon on the old resurgent dome, is the location where magma probably exists at depths as shallow as 5 $\mathrm{km}$. There are a number of shallow drillholes in the area, and con siderable industrial interest, leading to the conclusion that drilling conditions are favorale for a deep hole. Moreover, drilling technology presently exists for the $546 \mathrm{~km}$ deep well envisloned, except at the high temperatures $\left(>300^{\circ}+400^{\circ} \mathrm{C}\right)$ in the immediate vicinity of the magma body. Many unanswered scientific questions remain concerning the interaction of the, magmatic and hydrothermal systems; and their relationship with the current selsmicity, deformation, and heat flow. These questions, while specific to Long Valley, are also generic in nature, and can be applied to understanding other caldera systems.

\section{Inyo Domes Research Drilling Program (J., C. Elchelberger)}

The goal of drilling at the Inyo Domes chain, California, is to under stand the chemical, mechanical, and thermal behavior of sillole magma as it intrudes the upper crust and the relationship of that behavior to the environment of intrusion. Such information is fundamental to determining the or $1 \mathrm{gin}$ and evolution of igneous arelated geothermal systems, and is also applicable to the problem of man'made thermal perturbations of crustal regimes. The approach is to observe and sample a simple 1 gneous system that has produced a wellidesoribed volcanic event, and has not been af fected by geologic events subsequent to emplacement. Drilling during fiscal years 1984 and 1985 , conducted where the chain 11 es Just outside Long Valley Caldera, has sampled the distal and proximal portions of Obsidian Dome, the condust of obsidian Dome, and an unvented portion of the feeder dike that underlies the Inyo chain. The 600-yearmold system was observed and sampled at depth intervals of $0 \div 50 \mathrm{~m}, 410=510 \mathrm{~m}$, and $620 \div 650 \mathrm{~m}$, and in igneous units 1$50 \mathrm{~m}$ thick that were emplaced in cold granite basement, in hot fallo back tephra, and on the surface: A proposed hole would sample the same dike where it intrudes the wet, permeable fill of the caldera.

The sampled portions of the intrusion differ dramaticallyifrom its eruption products. Glass boundary zones are two or ders of magni tude thinner to nonexistent in the intrusive units than in the dome, even though parts of the intrusion cooled much faster. The distribution of vesicles and residual magmatic water, stable isotope relations in fresh glasses, and geochemical inferences concerning pre eruption conditions Indicate that a 2 arge amount of water was lost from the system during ascent of the magma, much of 1 t above the level of observation of the intrusion, consistent with known solubility relations and extrusion of the dome without fragmentation. The magma apparently ascended as a permeable foam that collapsed to obsidian as it flowed outward from the vent. Glass was preserved in the dome by rapid dehydration, rather than rapid cooling. A numerical model for degassing by porous flow based on gas permeability measurements and geometrical constraints from drilling shows that this process occurs in hours or less, and displays critical geologic parameters controlling explosive versus nonexplosive behavior. The change from explosive eruption to dome extrusion during the Inyo event (and other silicic events) can be attributed to the

$$
-93-
$$


development of a, vent funnel fllled with fall-back tephra, within which degassing of ascending magma could occur, rather than to pre-eruption gradients in volatile concentration within the parent magma body. Rapid water loss during decompression produced an isothermally undercooled melt, which was then further devolatilized by second boiling (vapor exsolution durling crystallization) over a perlod of days (intrusion) to years (dome). The second bolling stage of chemical change involved much higher concentrations of halogens in the vapor than the decompression stage, and was much more complete in the intrur sion than in the dome. At still deeper and as yet unobserved levels where granitic rather than felsitlc textures must have developed, volatile loss was dominantly by second bolling, significant volatile content was retained by volatilembearing crystall ine phases, and cryst tallization proceeded from thermodynamicaliy stable rather than chemically undercooled melt. The observed interval of the Inyo intruts sion is within the zone of maximum mobilization of halogens, during which process uranium moved out of the intrusion as well. These obserm vations provide the first view of an intrusion that produced a young volcanic event, and show that chemical as well as thermal behavior of magma is strongly influenced by the environment of emplacement. Complementary studies of the drilling results, in terms of mechanical, thermal, and additional chemical aspects of the intrusion problem, are being conducted at three other DOE laboratories, five universities, and the U. S. and Canadian Geological Surveys.

\section{E. Geosclence Riesearch Drilling Office (Peter Lysne)}

The Driling office supports geoscientists by providing fleld logistics, generic hardware, drilling plan developments, permits, contracts and consultation for CSDP - Thermal Regimes research. In the past year, drilling activities took place at Long Valley: (Inyo Domes holes RDO-2b and RDOH3) and off shore in the Salton Sea (RDOH6 serles and RDO-7 series, nineteen holes). These efforts were in support of drilling research profects put forth by principal investigators from sandia and Lawrence Livermore National Laboratories. Plans are being made for additional drilling in Long valley and in the Valles Caldera for scientists from Lawrence Berkeley and Los Alamos National Laboratories and the University of Utah Research Institute.

A IImited instrumentation capability for borehole diagnostics is also being developed by the Drilling office. So far this includes a logging truck with a high-temperature capability, digital recording equipment and some downmole tools. Personnel in the Drilling office are also working with neutron porosity tools used in the ocean Drilling Program to extend their calibration to formations of scientific interest. 
$++$

\section{PART II}

OFF-SITE
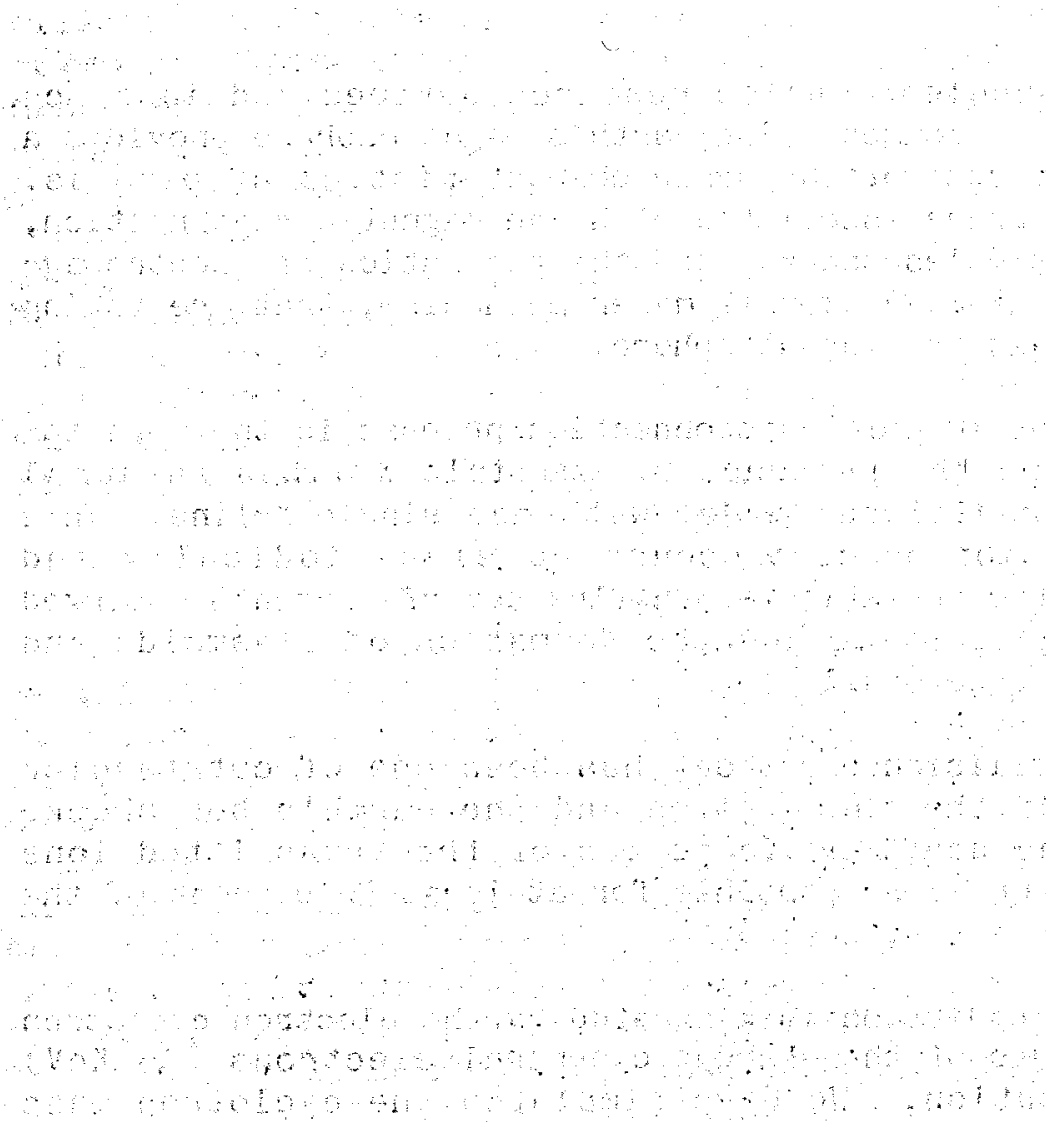

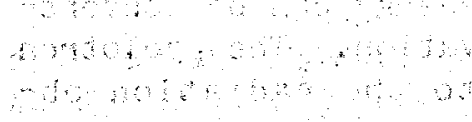

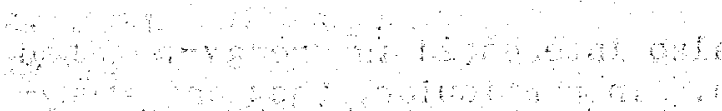

a 
Contractor:

Contract:

Title:

Person in Charge:
UNIVERSITY OF ALASKA

Geophysical Institute

Falrbanks, Alaska 9977540800

DE-ATO6-76ER70005

Magnetic Field Annihilation In The Magnetosphere And Its Applications

S.-I. Akasofu and L. C. Lee

Scope of Work

Plasmas in the thermonuclear fusion research devices and in space around the earth have much in common. The earth's magnetosphere provides a unique opportunity to study some of the basic characteristics of plasmas. We have studied basic processes associated with the magnetic reconnection, ion heating across a collisionless shock, and the generation of electromagnetic waves through electron cyclotron maser mechanism, that are taking place in the solar corona and the magnetosphere.

We have found that the magnetic reconnection process in the magnetosphere tends to occur with the presence of multiple Xilines (neutral lines), instead of the traditional model with one single X-line. This multiple $X$ line reconnection process occurs quasi periodically and impulsively. It leads to the formation of th flux transfer events observed at the earth's dayside magnetopause and the formation of plasmoids and substorms observed in the magnetotail.

Ion heating across a collisionless shock has been one of outstanding problems in the study of the theta pinch and.the earth's bow shock. Recently, we find that the nondiabatic motion of the transmitted ions across the shock front may be responsible for at least 50 percent of the ion heating.

The auroral kilometric radiation is generated by the electron cyclotron maser process in the presence of the energetic auroral electrons ( $\sim 5 \mathrm{KeV})$ with a loss-cone distribution. We have simulated the cyclotron mass process and found that a few percent of the electron energy can be converted to the wave energy, which is consistent with observation. The cyclotron maser process was recently found to be responsible to the radiation observed in some fusion devices.

University of Alaska researchers are also interested in energy-related geophysical problems in the Arctic region. In particular, they are studying the electric current induced by auroral activity in power transmission lines and in oll/gas pipelines. We have successfully demonstrated that auroral activity causes surges in the protective relay 
system in power transmission lines. An Intense surge will open the protect tive relay, causing a systematic blackout; blackouts caused by auroral activity are fairly common in Canada where many power transmission lines are rather long. By studying the characteristics of the surges, we are designing a protective relay system which will not be affected by auroral activity. This project is important for the proposed AnchoragesFairbanks tie line. We have obtained excellent data to study the relationship be tween the induced current and the protective relay and thus are analyzing them in detall.

In the arctic region, permafrost provides serlous obstacles in energy search and oll transport efforts. Thus, the determination of thickness of permafrost is increasingly an important problem. We have an impulse radar (GSSI), 100p 100 p induction system (EMF31, 34 ), audio magnetotelluric systems, and electrical resistivity devices. We made an extensive survey of permafrost in the Prudhoe Bay area last summer and are analyzing the data. 
Grantee :
$\quad$

Grant:

Title:

Person in Charge:

Scope of Work
ARIZONA STATE UNIVERSITY

Department of Geology

Tempe, Arizona $\mathbf{8 5 2 8 7}$

\section{DEFFG02K85ER13320}

Drilling investigation of a young magmatic intrut sion beneath the Inyo Domes, Long Valley, California: Structural and emplacement studies

The purpose of this project is to characterize the geometry and mechanisms of emplacement of silicic dikes beneath the Inyo Domes in east ern California. Two related types of studies have been undertaken to attain this goal: structural geologic mapping and interpretation, and microscopic analysis of drill core samples.

\section{A. Structural Geologic Studies}

The Inyo Drilling Program was originally based on the hypothesis that the 550\%year old Inyo Domes were fed by one or more silicic dikes. Prior geologic evidence for the presence of dikes included the alignt ment of the Domes and the apparent synchronicity of emplacement of deposits from the three youngest vents. As part of the present project, mapping of ground cracks, normal faults, and phreatic craters around the Inyo domes and as far south as Mammoth Mountain allowed more precise specification of the geometry of the buried Inyo dike. Structural evidence suggested that the three youngest Domes and the coeval Inyo Craters were fed by a dike that divided into at least three segments which rose obliquely toward the north and rotated in a clock wise direction as they approached the surface.

The location of the Inyo dike in drill hole RDO-3A west of a line connecting the centers of Obsidian and Glass Creek domes as well as mapping of surface structures on and around the two adjacent domes, supported the idea of 15 20 degrees of clockwise dike rotation. In order to better interpret dike segmentation and rotaion at the Inyo site we have mapped wellkexposed silicic dikes at three locations in Colorado and Arizona. In the deeply eroded Summer Coon Volcano of southticentral Colorado, silicic dikes radiate outward as far as $10 \mathrm{~km}$ from a central intrusive complex to feed outwardlytipiping lava flows. By projecting the surfaces of the flows inward we have reconstructed the volcano's original topography in order to see how dike structure varies as a function of depth of emplacement.

Initial mapping of Summer Coon indicates that segmentation of dikes is related to their depth of emplacement. Exposures near the center of the volcano (corresponding to depths of $1 \mathrm{m2} \mathrm{km}$ ) show typical segment lengths of $500 \mathrm{~m}$ to $1 \mathrm{~km}$. Where these same dikes approach flows near the volcano's paleofsurface, lengths of $10 \mathrm{~m} 15 \mathrm{~m}$ are superimposed on 
$100-200$ m long segments. Thls superposition of small segments on larger ones supports the ldea that rising dikes may continue to undergo segmentation and rotation if they continue to encounter rotating stress flelds. Where the RDO-3A Inyo drill hole penetrated the dike at a depth of $300 \mathrm{~m}$, it had undergone about 8 degrees of apparent rotation. However, if this dike behaved like those at Summer Coon, it might have continued to rotate as 1 't neared the surface, eventually producing surface structures like those observed orlented $15 \mathrm{~m} 20$ degrees of $\mathrm{f}$ of the overall trend of the dome alignment.

Additional evidence for the effects of emplacement depth on dike form comes from mapping of rhyolite and rhyodacite dike swarms intruded into schists in the Castle Dome and Kofa Mountains near Yuma, Arizona. This mapping has shown that whereas the overall strikes of the dikes are perpendicular to regional directions of maximum extension, in some cases their segmentation and rotation is controlled by anisotropic properties (schistosity) of the host rock. Such small scale influences are more likely to affect dikes relatively near the surface. Similarly, the orientations of the the Inyo dike segments are more I1kely to be affected by structural complexities at shallow depths. Locally the Castle Dome dikes expand into complex brecciated bodies up to $100 \mathrm{~m}$ wide, comparable to well-documented basaltic intrusive struc tures in Utah and New Mexico. At two sites in Summer Coon Volcano where dikes are seen to feed lava flows, the dikes also widen into complicated zones of 'brecciation and anastamozing branches. A similar intrusive body is inferred to lie beneath Obsidian Dome where the RDO2B drill hole intersected a complex widened zone of the Inyo dike.

\section{B. Textural Studies}

The Valles and Inyo drill cores have provided the most complete interior samples to date of young sllicic lava flows. We have used this unique suite of samples to investigate the factors controling the development of glassy and pumiceous textures in silicic lavas. We have used scanning electron microscopy (both normal and backscatter modes) and petrography to characterize the morphology and distribution of vesicles, phenocrysts, flow banding, and mloroforacks in varlous textures recognized in drill core samples. In conjunction with geochemical studies performed by other investigators, these textural studies lead to models for the role of volatiles in eruption and lava flow processes. Such models in turn are important for the assessment of volcanic hazards and geothermal resources.

The key result of our textural studies has been the recognition that the 550 year old Inyo obsidian dome and the 50,000 year old Banco Bonito rhyolite flow exhiblt nearly ldentical stratigraphic sequences of glassy, pumiceous, and crystalline textures. Field mapping in Long Valley and the Cascades has also correlated the textures seen in the drili cores with those observed on the surfaces of many Holecene siliclc domes. We have explained this sequence in terms of three processes: crystallization, effervescence, and shear during flow. 
Volatiles released during crystallization of the flow interior migrate through micro-cracks to the base of the flow's crust, where they pond and coalesce to form a volatile-rich, highly inflated zone capable of subsequently rising to the flow surface as diapirs, or of erupting explosively from the flow front.

The discovery of a dissected Tertiary age rhyolite dome in NW Arizona with the same stratigraphic progression has extended the relevance of our model to $8 \mathrm{~m} . \mathrm{y}$. old rocks. Examinations of samples from the 2.15 b.y. old Roolberg felsite, a rheowignimbrite from the Bushveld Complex, suggests that it also had the same textural sequence prior to total devitrification. 


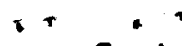

Contractor:

UNIVERSITY OF ARIZONA

Tucson, Arizona 85721

Contract:

DENACO2 80ER1 0753.A001

Title:

Solar Varlabllity: Changes in Figure and Mean Diameter

Person in Charge:

Henry A, HIII

Scope of Work

The objective of this program is to develop and use an indirect diag nostic of changes in the solar constant by monitoring the figure and diameter of the sun over long perlods of time. The difficulty of obtaining reproducible radiometer data over the period of years to decades necessary for a slgnificant study of the changes in solar luminosity motivated the search for an indirect diagnostic. Such an Indirect diagnostic of luminosity is offered by measures of changes in the solar shape and mean diameter. Techniques measuring fractional solar diameter changes over approximately $9 \mathrm{hr}$ observing runs to accuracles of $\triangle D / D 10^{-5}$ to $10^{-6}$ are

being used to measure changes over longer, climatically significant time periods. The relationship between this indirect diagnostic and the solar constant is being examined.

\section{A. Technical Developments}

The success of the program to monitor long term variation in the figure and diameter of the sun depends in large measure on maintaining the stability of the telescope over similarly long perlods. To meet this requirement, focal plane distance calibrator has been designed and built for the SCLERA astrometric telescope and is being tested. this device consists of a presiens diffraction grating, a focal plane stabi lized light source, light detectors on the solar detector, and necessary computer and computersrelated equipment. The grating, on low-expansion glass, can be placed on the stop of the primary lens for a calibration and is designed to produce firstiorder diffraction images in the focal plane with the approximate angular dlameter of the sun. The light source is a single mode stabilized hel lum neon laser. The first-order diffraction maxima are imaged on the solar detector and are used to calibrate the angular fleld. This device coexists with the Michelson measuring interferometer that measures distances in the focal plane. The Michelson interferometer has been designed and constructed so that the white 1 ight fringe can be detected, thus providing fiducial data for daystomday comparison of measurements. This system to detect the white light fringe has been in operation since the summer of 1981. The callbration system was put on-iline during the winter of 1985-86.

B. Observations

The analysis of nearly seventy days of solar dlameter measurements collected during 1983 with the white-light-fringe detecting system in

$$
-101-
$$


place is in its final stages. It is expected that these observations contain information on the variation in time of the solar figure and mean diameter and should yield a new measurement of the visual solar oblateness. Such results should be extremely valuable since solar oblateness observations at Mt. Wilson for 1983 and 1984 have been interpreted as showing that the intrinsic visual oblateness varies with the solar cycle. Analysis at SCLERA has revealed systematic errors in the Mt. Wilson work due to relative changes in $11 \mathrm{mb}$ darkening functions. The SCLERA work is not vulnerable to this type of error and is therefore of more fundamental value in looking for changes in shape and associated changes in the solar constant.

C. Theoret1cal Work

Our abllity to infer a particular luminosity change from, for example, an observed change in the mean solar diameter has been quite limited. At present there is a difference of approximately three orders of magnitude between the least and the greatest sensitivity that has been suggested. this large range in the estimates of the sinsitivity is, in part, a reflection of the several different physical processes that have been considered potentially important in producing luminosity changes. However; of equal ituportance have been differences in the treatment of the boundary conditions in the solar envelope. Considerable success has been achieved in refining the treatment of the boundary conditions. Testing of the theoretical work has been ahcleved by addressing the observational discripancy between the differential velocity observations and the solar diameter observations of the 160 min period solar oscillation. It has been discovered at SCLERA that the Doppler shift stadies of the $160 \mathrm{~min}$ period oscillation are detect ing not real velocity but an apparent velocity due to surface rotation of the sun and the perturbation of the radiation intensity due to the temperature eigenfunction of the osclilations. This discovery and reconciliation of the two types of observations represents a sig nificant test of the theory.

A major breakthrough in this area has been achieved with work on long period internal gravity modes of the sun. At SCLERA, 152 gravity modes have been successfully detected and classifled using the solar diameter observations. Evidence of these modes is also found in total irs radiance observations. For frequency of oscillation $=100 \mu \mathrm{Hz}$ it is observed that $44 \%$ of the variability in the total irradiance spectrum is due to gravity modes, with the rest due to rotation of solar active regions. Because of the very long coherence times of gravity modes, this fraction has very important implications for predicting future variations in the solar luminosity.

The combination of solar diameter obser vations and total irradiance observations for the study of the classifled gimode spectrum has another important function as well. Through the combined sets of observations, it has been possible to study the limbatightening of the radiation intensity associated with the gmodes. This permits a direct observational study of the ratio of the fractional change in luminosity to the fractional change in the solar diameter and shows a sensitivity 
to luminosity variations for solar diameter observations that is an order of magnitude higher than the corresponding sensitivity found in total irradiance observations. To the extent that this ratio is characteristic of the lowertifrequency, climatically significantly variations, these new findings should be very useful. They will be an invaluable ald in the interpretation of the results of the solar diameter observations. 


$\begin{array}{ll}\text { Contractor: } & \begin{array}{l}\text { BROWN UNIVERSITY } \\ \text { Department of Geological Sciences } \\ \text { Providence, RI } 02912\end{array}\end{array}$

Contract:

DEAAC02A79ER1 0401

Title:

Thermal Regimes of Major Volcanic Centers: Magnetotelluric Constraints on the Coupling of Deep-Seated Magma Genesis to High Reservoirs

Person in Charge: J. F. Hermance

Scope of Work

The focus of activity at this laboratory is on applying natural electromagnetic methods along with other geophysical techniques to studying the dynamical processes and thermal regimes associated with centers of major volcanic activity. We are presently emphasizing studies of the Long Valley/Mono Craters Volcanic Complex and the Cascades Volcanic Belt. This work addresses questions regarding geothermal energy, chemlcal transport of minerals in the crust, the emplacement of economic ore deposits, and op timal siting of drili"holes for scientific purposes.

\section{A. Magnetotelluric Studies of the Long Valley/Mono Craters Vollcanic Complex}

A variety of recent studies have stressed the possibility of renewed volcanism in Long Valley caldera. Beginning in october of 1978, a sequence of moderate earthquakes occurred northwest of Bishop, cul minating in May 1980 with what is now called the Mammoth lakes earthquake sequence, of which eleven events have magnitudes close to 5 or larger. In october 1981, a regional magnetotelluric survey was initiated in east central California by Brown University in an effort to study active volcanic centers along the eastern front of the Sierra Nevadas and their relationship to regional extension in the Great Basin. At present, data from some 85 field sites in the Long Valley area have been acquired. Within the Long Valley caldera, MT data reflect low resistivities associated with the caldera fill and/or features in the basement. In particular, in the southwest moat both the telluric field and magnetic induction parameters reflect a struct turally controlled east west current system at relatively shallow depth in the crust. This elongated eastfiwest zone is aligned along a belt of seismic activity, a zone of seismlc shear wave attenuation, and a zone of known hydrothermal alteration. If a strictly twondimensional intert. pretation were valid, the actual resistivity should be less than 21 ohm $\mathrm{m}$ at $7 \mathrm{~km}, 13 \mathrm{ohm} \mathrm{m}$ at $11 \mathrm{~km}$, and $9 \mathrm{ohm} \mathrm{m}$ at $18 \mathrm{~km}$. thus there is some indication of a systematic decrease of resistivity at depths greater than 6-7 km. Our present thinking suggests that the SW moat is under lain by an intensely brecciated shear zone lubricated by clays and hydrothermally altered materials associated with the same hydrothermal reservoir as the nearby Casa Diablo geothermal fleld. 
Mono Craters, to the north of Long Valley, are homogeneous, recent (less than 1000 yr old), and erupt frequently. It has been suggested that they were extruded from a single magma chamber, largely molten and perhaps still rising to the surface. If such a magma body were present, 1t should be readily detected using magnetotellur ic methods. However, we have seen little evidence for one in MT data from the area of the inferred ring fracture of Mono craters. We argue that any possible magma body is elther too thin to be resolved in our data, or too deep.

B. Delineating Major Boundary Faults in Long Valley Caldera

One of the principal tectonic elements in the Long Valley volcanic complex is a deep basin ${ }^{*} 11 k e$ caldera bounded by steeply dipping normal faults having characteristic of sets of at least several kms. In attempting to character ize the subsurface geometry of this structure we have reinterpreted regional gravity and $M T$ data in terms of simple $3 A D$ models. The similarity between our gravity and MT models clearly underscores the fact that both types of data are largely lnfluenced by the same geologic features: the caldera 1111 , topography on the underi* lying basement, and the major boundary faults. In addition, we now have clear evidence for a resistive feature (a "topographic high" or horst block) cutting across the main body of the caldera from the northwest to the southeast. The MT data show this feature to be much more continuous across the caldera than do gravity and I lmited drilling data. We feel that this feature $1 \mathrm{~s}$ int imately assoclated with the structural evolution of the resurgent dome, particularly with patterns of recent slesmiclty.

Employing MT data, we were able to locate the boundary fault in the northwest moat with a precision of better than $0.5 \mathrm{~km}$ because of the close spacing of magnetoteliuric sites in this region. In addition MT data from the eastern moat suggest that the structure there may be much steeper, than recent seism1c and gravity models seem to suggest. Thus one is inclined to reconsider the steep bounding fault (s) model proposed some years ago by Pakiser, but our data suggest a vert1cal throw across this boundary of approximately $2 \mathrm{~km}$, rather than the $5 \mathrm{~km}$ originally proposed by Pakiser.

\section{c. Numerical Modeling}

The application of geophysical techniques to real problems in the fleld are often constrained by the adequacy of modeling algorlthms necessary to interpret the actual data. Whereas there is no problem in principle in solving the complete $3^{-D}$ Induction problem for arbitrary structures and source fleld geometries, such an approach is not tractable on present day computers. As an alternative to this scheme, we have developed a number of simple algorlthms which are computat ionally efficient. For example, a new finite difference form simulates the distortion of telluric flelds by threendimensional azlmuthaliy symmetric structures: In another case, a simple three-dimensional thinm sheet model has been used to evaluate the blas of longuperlod magnetotellur $1 \mathrm{c}$ parameters in the presence of modest current channeling

$$
-105-
$$


at shallow depth. In terms of more refined 3-D models, a new set of finite difference operators has been developed to simulate broad-band electromagnetic induction in azlmuthally symmetric $3 \rightarrow \mathrm{D}$ structures. The accuracy of this algorithm was tested against known analytical solues tions leading to accuracles of better than $5 \%$.

\section{A Magnetic Variation Study of the Oregon Cascades}

The most recent research effort undertaken by this group involves a magnetic variation study of the Cascades volcanic system. During the summer of 1985 , a detalled east*west profile was conducted in central Oregon by Brown University as part of the EMSLAB Project (EOS, p. 700, 0 ctober 8,1985$)$. Made up of 75 remote reference magnetic variation stations spaced at $3-4 \mathrm{~km}$, the profile stretches for $225 \mathrm{~km}$ from Newport, on the Oregon coast, across the Coast Range, the Willamette Valley, and the High Cascades to a point approximately $50 \mathrm{~km}$ east of Santiam Pass. At all of the MV stations, data were collected for short periods ( $4 \times 100 \mathrm{sec}$ ), and at 17 of these stations data were also ob tained at longer periods $(4+4000 \mathrm{sec})$. All sites were operated from a four wheel drive van with a microcomputer (DEC PDP 11/73) based data acquisition system and a three component ring core fluxgate mag: netometer (Nanotesla) easily deployed by a single operator in rugged terrain.

Starting on the coast at the west end of our profile and moving east, we observed first a large coast effect associated with a significant wedge of sediments of fshore, next the effects of the conductive sedic ments of the Willamette Valiey to the east, and finaliy the contribution from electric currents centered beneath the High Cascades. This latter current system may be associated with the sedimentary fill of a graben structure beneath Santiam Pass, or 1 t might be part of the volcanic structure of the High Cascades. We are presently continuing the analysis of these data using a generalized $2 \Rightarrow D$ inversion algorithm. 
+ +1

Grantee:

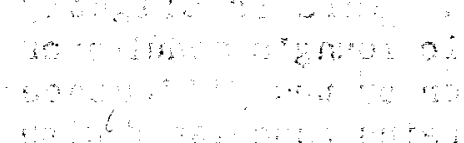

Grant:

Title:

Person In Charge:

Scope of Work

Knowledge of the in situ stress in the earth is important to our understanding of contemporary tectonic, geothermal, and rock-forming processes, and provides information which is required to exploit energy resources and store waste in the earth.

We have been developing a new type of stressmeter which employs inter ference holography and, by means of laboratory and field measurements, we are attempting to turn 1 t into a useful geophysical tool. This tool will Inttially be used to measure the $s 1 x$ (6) components of the stress tensor in deep fluid-filled scientific boreholes.

Although our previous work was carrled out with a $12^{\prime \prime}$ laboratory prototype, our present effort is directed to completion of a 6 " prototype apparatus which w111 operate uncased and in mudffilled boreholes. This new device operated as follows: Initially the device is lowered a depth incre ment in the borehole. The borehole wall is scrubbed free of mud. The differential pressure is controlled system with $N_{2}$ to equal the ambient pressure. Inflatable packers then center the device in the borehole, and then the device is locked in place. The mud in the hole sect ion to be viewed holographically is then exchanged with clear water. Then a holographic exposure is taken of the borehole wall, a sidemcore hole is drilled which relieves in situ stress, and a second hologram is taken. The resulting interference hologram ylelds a map of displacement, which is inverted to obtain the six (6) components of the in situ stress tensor. A new concept for measuring quasiastatic moduli of rock in $\mathbf{s} 1$ tu via indention and holographic interferometry, will be used to obtain the elastic moduli of the rock. The method of obtaining elastic moduli was tested in boreholes in oil shale in Garfield county, Colorado and in a marble quarry near Mojave, $\mathrm{Ca}$. In the case of the marble quarry we operated the holographic instrument completely independently of utilities in the field from the surface. To collaborate elastic measurements, laboratory ultrasonic experiments were performed on three (3) marble samples taken from the surface near the borehole. Sonic compressional wave velocities at $1 \mathrm{MHz}$ of $4.6 \pm 0.3 \mathrm{~km} / \mathrm{s}$ with a measured dens $1 \mathrm{ty}$ of $2.70 \mathrm{~g} / \mathrm{cm}^{3}$ gave a

$$
-107
$$


dynamic Young's modulus of $48 \pm 6 \mathrm{GPa}$. The uncertainty is primarily a result of the uncertainty in the velocity measurement. This is slightly lower than the holographically determined marble static Young's modulus of $56 \pm 8 \mathrm{GPa}$. Whether the difference can be accounted for by the difference in the frequency and/or amplitude of the intrinsic strains associated with these different techniques or as a result of sampling of in situ stress differences requires further study.

The recent fleld experiments indicate that the holographic method can determine the in situ Young's modulus with an accuracy of $+15 \%$. The ofl shale results suggest that this uncertainty can be lowered to $5 \%$ with careful calibration of the applied point force and high holographic image quality: Future work will concentrate on laboratory calibration of the method on materials of well-known elastic moduli and on techniques for inversion of the observed fringe patterns for the displacement fleld to achleve an estimate of Polsson's ratio. With the completion of the 6" instrument, later this year, we expect to carry out measurements of in situ stress in boreholes in the western Mojave near Palmdale (San Andreas fault) area of California. In the Palmdale (San Andreas fault) area, existing (USGS) boreholes will be reoccupled in order to obtain detalled data of the amplitude and or entation of the shear stress versus depth and to compare w1th previous hydrofracture results. "Existing data suggest that the shear stress may increase with depth at a rate of $\approx 8 \mathrm{MPa} / \mathrm{km}$ implying $\approx 50$ to 80 $\mathrm{MPa}$ shear stresses at the 6 to $10 \mathrm{~km}$ depths of earthquakes. The latter high shear stresses are difficult to reconcile with the lack of geothermal anomaly assoclated with the San Andreas fault zone and the low apparent values of stress releases assoclated with earthquakes along the fault. We also expect to carry out measurements in a cool drillhole now avallable to Sandia in the Long Valley caldera. In Long Valley, the orlentation and amplitude of the in situ stresses is expected to be radial with respect to the caldera structure and yleld radial, tensional, compressive, or regional stresses depending on the stage of evolution to which this complex has evolved. 
Grantee:

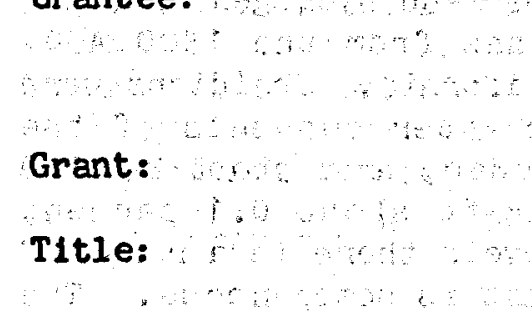

CALIFORNIA INSTITUTE OF TECHNOLOGY

Division of Geological and Planetary Sciences

Pasadena, California 91125

DE-FCO3-85ER1 3445

Infrared Spectroscopy and Hydrogen I sotope Geochemistry of Hydrous Sillcate Glasses

Person In Charge: S. Epsteln and E. Stolper

Scope of Work

Infrared spectroscopic studies have shown that "water" dissolves in s11lcate melts and glasses both as molecules of water and as hydroxyl groups. The fact that water dissolves in amorphous silicates as at least two distinct species raises interesting issues in isotopic geochemistry. For example, is there a hydrogen isotopic fractionation between the molecular water and hydroxyl groups in glasses and melts? If so, is it temperature or composition dependent? Will the vapor/melt fractionation factor $(\alpha)$ for hydrogen vary with the water content of the melt due to the changing ratio of molecular water to hydroxyl groups as the water content changes? W111 this have an influence on the varlations in hydrogen isotoplc characteristics of magma bodles as they continuously degas or otherwise exchange hydrogen with their surroundings? The answers to these and related questions would contribute to our understanding of the bas $1 \mathrm{c}$ physical chemistry of hydrogen in silicate melts and glasses, could be applled to geothermometry of volcanic glasses, and would provide data essential to understanding the evolution of volcanic systems and their assoclated hydrothermal circulation systems. These results could also be valuable in applications of glass technology to development of nuclear waste disposal strategies.

The focus of this project is the combination of infrared spectroscopy and stable isotope geochemistry to the study of the varlous hydrogenbearing specles dissolved in s111catemelts and glasses. We have demonstrated during the current grant period that infrared spectroscopy is a precise and accurate tool for measuring the concentration of "water" dissolved in natural and synthet ic rhyolitic and basaltic glasses. The advantages of the infrared technique are that it is non destruct ive; it can be almed at regions of glass as small as a few tens of microns in diameter and avolds surface-correlated (e.g., adsorbed) water; it can be used to analyze water contents as low as a few parts per million and as high as tens of welght percent; and it gives information on the concentrations of different forms of dissolved water (e.g.. molecules of water and hydroxy.1 groups) in glasses. Conventional techniques for water analysis must be used to standardize the infrared technique. Great care must be taken to avold contributions from surfacescorrelated water if conventional tech niques are used; we have found, however, that adsorbed water can usually be recognized by 1 ts distinctive isotopic composition. Surprisingly, heating to $200^{\circ} \mathrm{C}$ is not sufficient to remove all adsorbed water from fine-grained glass powders.

$$
-109-
$$


We have used our combined infrared spectroscopic and hydrogen isotopic approach to study volatiles in a serles of obsidians from the $1400 \mathrm{~A}$. D. eruption of the Mono Craters chain in central California. Obsidians were collected from domes and from tephra deposits. The water contents of the obsidian clasts declined as the eruption proceeded, from about 2.543 .0 weight percent in the earliest phase of the eruption to about 0.1 percent in the youngest dome. At most stratigraphic levels there is a range of water contents from clast to clast, though each clast is homogeneous. The $D / H$ ratio decreased along with the total water content as the eruption proceeded; the observed trend cannot be modelled as having being formed by progressive degassing from a single, waterfrich melt if a constant $D / H$ fractionation factor between melt and vapor is assumed.

The proportions of water dissolved as hydroxyl groups and as molecules of water in these glasses vary smoothly with total water content based on infrared spectroscopic measurements. Hydroxyl groups are the dominant form of dissolved hydrogen at low water contents, but molecules of water are detectable in all glasses with 0.25 welght percent or more water. The amount of water dissolved as molecules of water increases progressively with total water content until at about 2 percent by weight dissolved water, more than half of the water is present in this form. The amount of water dissolved as hydroxyl groups changes little with increasing total water content beyond this point. If $D$ and $H$ fractionate between dissolved hydroxyl groups and molecules of water as well as between these species and coexisting watertirich vapor, the variation in the ratio of molecular water to hydroxyl groups with total water content would lead to a dependence on water content of the fractionation of $D$ and $H$ between melt and vapor. We have found that it is possible to model the trend of $\mathrm{H}_{2} \mathrm{O}$ content $\mathrm{vs} . \mathrm{D} / \mathrm{H}$ ratio observed in the Mono Craters assuming a concentrationidependent fractionation factor that incorporates the observed speciation of water in glasses.

We have begun to conduct laboratory experiments aimed at determining the fractionation of $\mathrm{D}$ and $\mathrm{H}$ between melt species ( $\mathrm{OH}$ and $\mathrm{H}_{2} \mathrm{O}$ ) and hydrous vapor. Knowledge of these fractionations, their compositional dependence, and their temperature dependence should provide critical insights into the degassing behavior of magmas such as those erupted at the Mono Craters, perhaps into the temperatures at which degassing occurred, and into the local structural environments of hydroxyl groups and water molecules in melts. 
Grant :

DE-FCO3A85ER1 3419

Title:

Advect I velfDiffus l ve/Dispers Ive Transport of Chemlcally Reacting Species in Hydrothermal Systems

Person in Charge:

H. C. Helgeson

\section{Scope of Work}

The focus of this project is development and application of a com prehensive, quantitative, mult1fcomponent chemical transport model incorporat ing water-rock interaction in hydrothermal systems. "Water"rock interaction plays an important role in many geochemical processes, includa ing weathering, evolution of fluids and rocks in sedimentary basins, contalnment of radioactive waste in repository sites, and formation of hydrothermal ore deposits. Quant I tat 1 ve numer 1 cal models integrat ing mass transport with chemical reactions are essent 1 al for a fundamental under standing of such processes. The model w111 be used to describe transport of mass in porous media coupled to reversible and irreversible chemical reactions.

\section{Current Activities}

Research carried out during FY85486 can be divided into three categories: (1) code development, (11) applications, and (111) theorét 1cal modeling.

The current version of the computer code MCCTM (Multiscomponent Chemlcal Transport Mode1) can be used to calculate one-dimensional isother mal mass transport by advection and diffusion/dispersion coupled to both reversible and irreversible, homogeneous and heterogeneous chemical react tions involving minerals and aqueous solutions. The code includes an algorlthm to determine the initial and boundary conditions for the starting fluid compositions.

Several modiflcations were made to the computer code MCCTM to 1 mprove computational eff 1 clency and its ab1lity to model geologic reality. These Include addition of a switching algorithm to select as primary aqueous species those that predominate as the chemical composition of the solution changes with $t$ ime and distance. This modification is essent 1 al to model complex systems in which the concentrations of certain species $\left(e . B^{\circ} A I^{3}+\right.$ $A I(\mathrm{OH})_{4}^{+}, \mathrm{Al}(\mathrm{OH})^{2}+$, etc.) change by many orders of magnitude as the solut 10 n passes through different pH regimes. The switching algorithm is now be $\mathrm{ng}$ extended to include both homogeneous and heterogeneous react $10 n s$, which w111 permit use of the same size Jacoblan matrix regardless of the number of minerals that are in $10 \mathrm{cal}$ equilibrium with the fluid. 
Considerable progress was made during FY85-86 in testing the use of a fixed grid of node points to solve the moving boundary problem inherent in the partial differential equations representing chemical reactions and mass transport. The results of finite difference calculations were compared with exact solutions for several hypothetical minerals reacting with an aqueous phase for two cases: the steadyistate limit and transient flow regime. In the latter case, discovery of an exact solutions to the finite difference equations provided a unique opportunity to analyze the effects of a fixed grid on the finite difference calculations. One a short time scale compared to the time required for a mineral to dissolve completely at a single node point, the finite difference approximation ylelds a spurious representation for the concentration and mineral volume fraction. However, the finite difference algorithm reproduces the average behavior of the reaction front and the concentrations of reacting species, provided advance of the front is sufficiently slow to a quasicsteady state condition.

The transport model is currently being applied to metasomatic altera tion of minerals in geochemical processes such as chemical weathering, hydrothermal ore deposition, metamorphism and diagenesis. These processes involve transport of material by fluids sometimes over large distances that may be in disequilibrium or partial equilibrium with the surrounding host rock. The fluids may form relatively concentrated electrolyte solutions. As the hose rock reacts with the fluid, secondary minerals form in spaf tially separated reaction zones, which may propagate with time in response to migration of the fluids. The reaction rates of minerals in metasomatic processes range from surface-controlled rates for reacting minerals that are not in equilibrium with the fluid, to reaction rates that are control led by the rate of mass transport if local equilibrium is maintained. For silicates, surface-controlled reactions generally prevail at low temperatures.

Recent numerical calculations indicate that the thickness of a metasomatic reaction zone does not necessarily increase with time in proportion to the rate of fluid flow. Rather, only changes in flow velocity result in changes in the thicknesses of the reaction zones, except for the zone farthest downstream which advances at a retarded velocity. These calculations demonstrate that for a steady, nonidispersive fluid flow rate which is affected negligibly by changes in porosity and permeability, and for which the host rock is far from equilibrium with respect to the infiltrating fluid, the reaction zone thickness is constant for all of the zones except the last one downstream, which grows continuously with time. This behavior is a consequence of the nature of steady, nonidispersive fluid flow, referred to as plug flow. In the region in which the thicknesses of the reaction zones are constant, a steady state is established which persists either until the minerals in the host rock completely dis:solve or until changes in porosity and permeablilty are caused by the reactions, which then affect the rate of fluid flow. The steady state limit of the continuum based calculations agree approximately with the results obtained from reaction path calculations for open systems, indicating that such calculations can be applied directly to systems dominated by advective fluid flow. Although open system calculation of this kind cannot predict detalled early transient behavior, they afford reasonable apm proximation of long-term behavior with minimal computational expense. 
$+\quad+$

A double porosity model was formulated to calculate mass transport coupled to fluid/rock interaction on both macror and microscopic scales. Such a model is essential for describing geologlc systems in which the chemical composition of fluid in a fracture network is determined both by its interaction with the surrounding host rock and by fluids seeping out of the rock. The double porosity model is characterized by two distinct mass transport systems, one assoclated with fluid flow by advection and disper. sion within a fracture network, and the other by diffusion and advection within porous blocks enclosed by the fracture network. Each of these transport systems $1 \mathrm{~s}$ assoclated with greatly differing porosities and permeabilities. The larger value of porosity, referred to as the primary porosity, corresponds to the intrinsio porosity of the rock mass. The smaller value corresponds to the fracture network and $1 \mathrm{~s}$ referred to as the secondary porosity. The permeability of the fracture network (which cors responds to the secondary porosity flow system), is much larger than the permeability of the blocks in the primary porosity flow system. Two different representative elemental volumes (REVs) characterize the double porosity model. One REV pertains to the fracture network of the rock mass, and the other represents the rock matrix blocks:

Transport of fluids within the primary and secondary porosity systems are linked to one another by imposing appropr late boundary conditions at the interface between the two flow systems. A separate set of transport equations applies to each continuum. These equations are coupled by a term that is proportional to the flux of materlal between the blocks and the fracture system. The proportionality constant depends on the geometry of the fracture network and the matrix of porous blocks. The equations describing flow in the fracture network and the matrix of porous blocks. The equations describing flow in the fractures contain provision for heterogeneous reactions taking place at the surface of the blocks. These reactions alter the width of the fracture apertures either by dissolving the blocks and thereby opening the fractures, or by precipitation of minerals on the fracture surfaces, which tends to close the apertures. Reactions of this kind are responsible for the moving boundary problem at the fluid rock interface in the fracture network. Reactions between the rock matrix and pore flulds contained within the blocks are taken into account by the block transport equations.

Future work w11l develop numerical methods to.solve the double porosity cont Inuum model. Inltially, weak coupling between the fracture network and matrix blocks will be assumed to reduce the numerical effort required to solve the coupled equations.

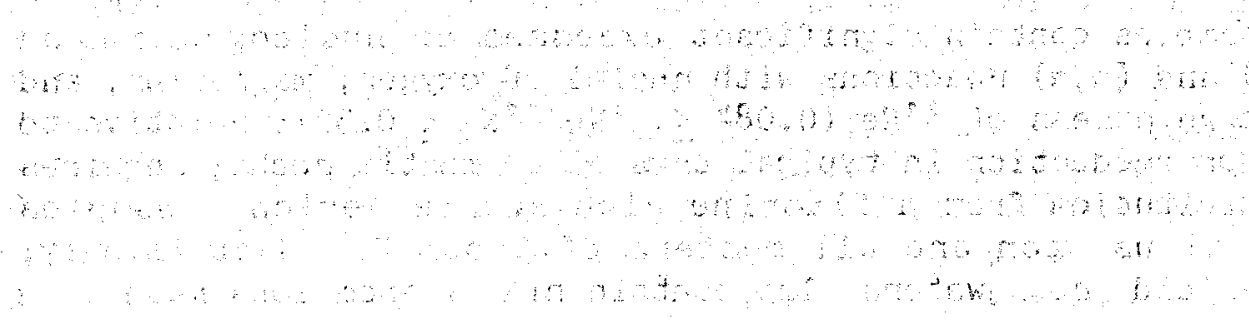


Contractor:

Contract:

Title:

Person in Charge:
UNIVERSITY OF CALIFORNIA

Department of Physics

Berkeley, California 94720

DE-AS03 7.6ER70032

Isotopic Studies of Rare Gases in Terrestrial Samples and in Natural Nucleosynthesis

J. H. Reynolds

Scope of Work

This project is concerned with research in rare gas mass spectrometry. The broad objective is to read the natural record that isotopes of the rare gases comprise as trace constituents of natural gases, rocks, and meteorites. In past years, these interests have led to the study of such diverse problems as the dating of rocks, the early chronology and isotopic structure of the solar system as revealed by extinct radioactivities, and the elemental and isotopic composition of trapped primordial rare gases in meteorites. In recent years, the project has focused progressively more on terrestrial problems.

A. Noble Gases From the Alberta Natural Gas Fields:

We have determined the elemental and isotopic composition of noble gases in samples from twenty one different methane welis located throughout the Alberta, Canada basin. There are two distinct components: the first component, Group A, is characterized by high ${ }^{3} \mathrm{He} /{ }^{4} \mathrm{He}$ ratios $(1.4 \div 5.4 \mathrm{x}$ $\left.10^{-7}\right)$, low and variable ${ }^{40} \mathrm{Ar} /{ }^{36} \mathrm{Ar}$ ratios $(\leq 2000)$, and low total hel lum and the second component, Group $B$, is character 1 zed by low ${ }^{3} \mathrm{He} /{ }^{4} \mathrm{He}$ ratios ( $\leq 2 \times$ $\left.10^{-8}\right)$, high and uniform ${ }^{\circ} \mathrm{Ar} /{ }^{36} \mathrm{Ar}$ ratios $(-10,000)$, and high total hel Ium, ( $\geq 0.1 \%$ by volume). Group B shows very little variation and has a well defined composition. The relative amounts of He and Ar in air, Group B, and typical Group A samples, are much that it is not possible to generate Group A compositions by mixing air with Group B. An apparent lack of intermediate compositions between Group $A$ and $B$, as readily seen on a heliumargon isotope correlation plot, implies there is no direct mixing. at least on a signiflcant scale, between the two Groups. In other words, Groups $A$ and $B$ are two distinct and independent components which do not communicate. It seems reasonable to assume they have different origins or subsequent histories, e.g. differing source of reservoir rocks, migration paths, etc.

Many of the samples contain significant excesses of nucleogenic neon produced by $(\alpha, n)$ and $(n, \alpha)$ reactions with nuclei of oxygen, magnesium, and fluorine. The large excess of ${ }^{22} \mathrm{Ne}\left(0.084 \leq{ }^{21} \mathrm{Ne} /{ }^{22} \mathrm{Ne} \leq 0.50\right)$, relative to values expected for production in typical crustal or mantle rocks, requires a slgnificant contribution from a fluorine rich source region. Samples with highly anomalous neon are all members of Group B. Surprisingly, nearby Canadian shield groundwaters also contain highly anomalous neon 


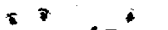

(Bottomeley et al, , 1984) of similar composition and low ${ }^{3} \mathrm{He} /{ }^{4} \mathrm{He}$ ratlos $(-1$ $x\left(0^{-}\right)$. The striking similarity between the natural gas samples and shield groundwaters may imply a similar origin (source) for these two noble gas reservolrs. Perhaps, the composition of the Group B suite is dominated by a flux of noble gases from the basement which is trapped and accumulates in the Group $B$ methane reservoir. We are investigating the possibility of a similar or 1 in for the Group $B$ methane. Although the data are preliminary, at present there is no compeling evidence to invoke such a methane source.

We are puzzled by the high Group A ${ }^{3} \mathrm{He} /{ }^{4} \mathrm{He}$ ratios, -10 times higher than Group $B$ and -10 times higher than theoretical values for "normal" radlogenic hellum (cf. Mamyrin and Tolst1khin, 1984). We have not been able to Identify any recent intrusive or extrusive volcanic activity of sufficient magnitude to supply the estimated quantity of ${ }^{3}$ He associated w1th the Group A reservolr.. Although we cannot unequivocally rule out a possible magmatic $\mathrm{He}$ source, we are inclined instead to belleve that the Group $A$ helium is a mixture of normal radiogenlc helium and nucleogenic hellum produced locally from $(n, \alpha)$ react lons wi th "L1. Groundwaters local to areas producing Group a methane are enriched in Li (H1tchon et al., 1971 ) and the methane reservolrs are thought to be "tongues" of limestone (coral reefs) interspersed in shales and anhydrites which are often strongly enriched in $L 1$ relati ye to other' sedimentary or 1 gneous rocks.

Correlated 1 inear variations between ${ }^{4} \mathrm{He}, \mathrm{nitrogen}$, and total hydrocarbons $1 \mathrm{mply}$ two component mixing. The first component contains ${ }^{4} \mathrm{He} / \mathrm{N}_{2}$ in constant proportions $(-0.06$ in Group $B$ and -0.009 in Group $A)$. In both groups, the second component is consistent with pure hydrocarbons.

B. Fluid Samples from Miscellaneous Active Hydrothermal Systems:

(1) Vent waters along the southern Iimb of the Juan de Fuca Ridge: We found the relative abundances of noble gases heavier than hellum to be $11 \mathrm{ke} 2^{\circ} \mathrm{C}$ alr saturated seawater (ASSW) identical to the ambient seawater composition. However, absolute abundances were $-80 \%$ of that expected for $2^{\circ} \mathrm{C}$ ASSW. The Juan de Fuca Ridge (JFR) fluids are chemlcally unique, in that they contain the highest chior 1 de and total lonic strength of any oceanic hydrothermal solutions previously reported. The combination of high chloride and total lonic sttength coupled with the noble gas relative and absolute abundances is consistent with mixing a chloride $\mathrm{rich}$ fluid with amblent seawater. The high chloride fluid may be a brine representing the hlgh density and gas-free phase produced during phase separdion either above or below the critical point of seawater: The chloride content of the brine is -3-6 times seawater. Silica geobarometry indicates minimum waterrrock equilibration temperatures of $-340^{\circ} \mathrm{C}$ (Von Damm and Bischoff, 1986), so that mixing must occur at high temperature and deep in the hydrothermal system.

(2) Noble gases from surface springs and geothermal wells in Long Valley: We have analyzed five samples from the Long Valley caldera: three surface springs and two flowing geothermal wells. 
The surface springs are enriched in helium relative to the other noble gases, with ${ }^{4} \mathrm{He} /{ }^{36} \mathrm{Ar}$ ratios ranging from 5.5 to 24.0 times the atmospheric rat10. The corresponding ${ }^{3} \mathrm{He} /$ " $\mathrm{He}$ ratios range from 3.7 to 5.2 times the air ratio. confirming the presence of a magmatic ${ }^{8} \mathrm{He}$ component at Long Valley as reported previously by $\mathrm{H}$. Craig's Lab (Rison et al., 1983). A direct comparison of ${ }^{3} \mathrm{He} /{ }^{4} \mathrm{He}$ ratios measured in the RARGA lab and the San Diego lab showed no significant difference at the one sigma level $(+5 \%)$. The neon and argon 1sotopic compositions are atmospheric; $\mathrm{Kr}$ and $\mathrm{Xe}$ isotopes were not measured. The relative abundances of noble gases, other than $\mathrm{He}$, are similar to compositions we have encountered in other active continental hydrothermal systems.

The geothermal wells are producing a moderate temperature $\left(-170^{\circ} \mathrm{C}\right)$ aquifer at a depth of $-200 \mathrm{~m}$ and are in the immediate vicinity of Casa Diablo Geyser, one of the surface features discussed above. The primary difference between the well fluids and the surface spring is a smaller proportion of an alrtilike component in the well samples. Casa Diablo Geyser has a "He/ ${ }^{3} \mathrm{Ar}$ ratio -24 times a1r, whereas both well samples have ratios -200 times the air value. Owing to the dearth of helium in alr (or alr saturated water), the reduced proportion of airmlike gas in the well samples does not affect the ${ }^{3} \mathrm{He} /{ }^{4} \mathrm{He}$ ratios $(3.7-5.2$ times alr) elsewhere in the caldera reflect dilution of the magmatic helium with radiogenic helium (as in Yellowstone, Kennedy et al., 1985), then the radiogenic dilution probably occurs at depths below the $200 \mathrm{~m}$ well depths. In one of the well samples there appears to be a small 20 per mil excess (relative to air) of ${ }^{\circ} \mathrm{Ar}$. If real, the excess translates to a ratio of "he to excess " $\mathrm{Ar}$ of -5.6 , com- $^{\circ}$ parable to other hydrothermal systems.

(3) Varlations in noble gas abundance in a single hydrothermal spring: We analyzed gas and water samples from Horseshoe Spring, Norris Geyser Basin; Yellowstone as a function of depth in the spring and found the relative abundances of the noble gases in both phases to be strongly dependent on depth. Surprisingly, at the surface both phases have identical compositions. We feel the expanding gas bubble, while en route to the surface, must strip enough gas from the liquid to completely overwhelm and thus mask the gas phase entering at the bottom. Although this seems reasonable, what is confusing is the surface composition is not like air saturated water (ASW) at the spring temperature $\left(-90^{\circ} \mathrm{C}\right)$. Looking carefully at data for samples from other Norris springs collected at the surface, we discovered compositions identical to the surface compositions at Horseshoe. All these springs are acid (sulfate) chloride springs ( $\mathrm{pH} \cdot 2.0$ ) Implying the unusual noble gas compositions might be related to a possible "salting out" effect. In the more controlled environment of the laboratory, we measured noble gas solubilities in water from Horseshoe, a neutral chloride spring also in Norris (Porcelain Terrace), and distilled water (for calibration) in equilibrium with air (1 atm total pressure) at $90^{\circ} \mathrm{C}$. : To our surprise the samples all had compositions similar to the surface fluids at Horseshoe and not that expected for $90^{\circ} \mathrm{C}$ ASW based on other experimentally 
determined solubilities in fresh water at moderate to high tem: peratures (Potter and Clyne, 1978; Crovetto et al., 1982; and Smith, 1985). We are aggressively pursuing this difference. One possiblilty is high temperature lab experiments are typically closed systems $-1 . e$. water and gas are isolated, brought to temperature (and the vapor pressure of water at that temperature), allowed to equilibrate, and sampled, whereas, in this quick experiment, and in the case of springs in the natural environment, the system remains open and at the ambient atmospheric pressure.

C. Noble Gases in Uraniumi and Thorlum-Rich Minerals:

In an attempt to understand the orlgin of neon isotope excesses (and particularly ${ }^{22} \mathrm{Ne}$ ) found in Ut and Thrich minerals, 12 samples with vary Ing ages and $U$, Th contents have been analyzed. For 6 of the 12 samples, allquots of He were analyzed in the RARGA mass spectrometer for absolute He quantities and ${ }^{.3} \mathrm{He} /$ "He ratios. The other noble gases ( $\mathrm{Ar}, \mathrm{Kr}$, and $\mathrm{Xe}$ ) were also measured to obtain a complete plcture and to ald in the interpretation of the neon results.

The $U$ and $T h$ concentrations in the samples vary from 0.02 to $4.2 \%$ and 0.2 to $31 \%$ respect 1 vely. From the measured He quantities $(0.2=4 \mathrm{cc} / \mathrm{gm})$ the calculated U-He ages, assuming no He loss, are 10-1300 x $10^{6}$ years.

of the $s 1 x$ samples analyzed for ${ }^{3} \mathrm{He} /{ }^{4} \mathrm{He}$ ratio, five samples gave ratios of less than 10 . The remaining Basnaesite sample which contains $0.02 \%$ uranlum and $0.32 \%$ thorlum had a surprisingly high ${ }^{3} \mathrm{He} /{ }^{4} \mathrm{He}$ rat 10 of $2.44 \pm$ $0.38 \times 10^{-}$(UHHe age: $440 \pm 80 \times 10^{8} \mathrm{y}$ ). The ithium concentration in this sample is $60 \pm 8 \mathrm{ppm}$. However, the $\mathrm{LI}(\mathrm{n}, \alpha)^{3} \mathrm{H}+{ }^{3} \mathrm{He}$ react ion does not seem able to account for the "excess" "He present in the sample (Morrison and Pine, 1955).

The ${ }^{20} \mathrm{Ne} /{ }^{22} \mathrm{Ne}$ ratio was found to range from 0.02 to 6 and the ${ }^{21} \mathrm{Ne} /{ }^{22} \mathrm{Ne}$ ratio from 0.02 to 10 . Most of the values are very different from the atmospher Ic rat 1 os $(9.8$ and 0.029$)$ and Indicate large contributions from the Wether111 nuclear reactions (Wetherili, 1954). For all the samples the oxygen $(25-50 \%)$ and the magnesium $(0.01-1.6 \%)$ contents have also been obtained. Once the fluorine concentrations for the samples are known, the calculated neon production from the $(\alpha, n)$ and $(n, \alpha)$ reactions will be compared to the measured values.

For most of the samples large ${ }^{38} \mathrm{Ar}$ excesses have also been measured. The ${ }^{38} \mathrm{Ar} /{ }^{36} \mathrm{Ar}$ ratios for three samples was greater than 1 (atmospher ic value 0.19). An explanation for these ratios seems to be the nuclear production of "Ar through ${ }^{35} \mathrm{Cl}(\alpha, n){ }^{38} \mathrm{~K} \rightarrow{ }^{38} \mathrm{Ar}+\beta^{-}$and ${ }^{41} \mathrm{~K}(\mathrm{n}, \alpha)^{38} \mathrm{Cl} \rightarrow$ "Ar+B (Wetheri11, 1954). Determination of the chlorine concentrations of the samples is in progress.

The fission components of krypton and xenon are evident and w11l be used in the interpretation of the light noble gas results. Finally, these results will have some bearing on a suggestion that neon and argon isotopes are produced by asymmetric fission of $\mathrm{U}-$ and $\mathrm{Th}$ - decay-chain nuclides (Rose and Jones, 1984; Gerling and Shukolyukov, 1959). 
Grantee:

Grant :

Title:

Person in Charge:
UNIVERSITY OF CALIFORNIA, RIVERSIDE

Institute of Geophysics and Planetary Physics Riverside, California 92521

DE $\triangle F C 03-85 E R 13408$

Sulfidetoxide-S111cate Phase Equilibria and Associated Fluid Inclusion Properties in the Salton Sea Geothermal System, California

M. A: McKIbben

\section{Scope of Work}

The goal of the research program is to understand mechanisms of metal and sulfur transport and deposition in active geothermal systems: Metamorphic and hydrothermal reactions among silicates, sulfides and oxides in geothermal reservoir rocks affect the oxidation state, $\mathrm{pH}$ and metal content of interacting geothermal brines. Systematic documentation of mineral compositions, phase relations and fluid inclusion properties allows detailed evaluation of the spatial and temporal variations of brine chemistry within the geothermal system. Knowledge of the in situ sulfur speciation and metal complexing allows prediction of the scaling and corros sion behavior of geothermal brines produced from different depths and parts of the geothermal system.

Studies are underway of core and fluid samples recently recovered by the Salton Sea Sclentific Drilling Project. Additionally, cores and fluid samples have become avallable to UCR from other new geothermal wells in the central part of the Salton Sea field. Preliminary results from all of these materials indicate that mineralized fracture orientation is uniformly vertical to subvert cal. implying that substantial episodic vertical com munication occurs between'varlous brines in the system. Fluid inclusion data suggest that boiling may be a major ore mineralizing process, yielding oxidized veins containing chalcopyrite, hematite, pyrite, calcite, epidote and chlorite. A particularly exciting find is the occurrence or relatively. abundant bedded anhydrite in the deltalc reservolr rocks. This suggests that much of the brine sulfur may be derived from stratiform evaporitic or volcanogenic sulfate sources. Sulfur isotoplc data are currently being collected to aid in modeling the sulfur cycle in the Salton Sea geothermal system. 
* *,

Grantee:

Grant:

Title:

Person in Charge:

Scope of Work

We have continued our monitoring program of hot springs and fumaroles in the Long Valley/Mono Lakes region of the Slerra Nevada Range to investigate the possible relationship between variations in the thermal and selsmlc activity in the area and changes in the gas chemistry of nearby hydrothermal fluids. The focus of our study has been on ${ }^{3} \mathrm{He} / \mathrm{He}^{4} \mathrm{rat}$ os, as they have proven remarkably sensitive indicators of mantie volatiles, but we have also analyzed samples for $\mathrm{Ne}, \mathrm{H}_{2}, \mathrm{CO}_{2}, \mathrm{~N}_{2} \mathrm{O}_{2}$ and $\mathrm{CH}_{4}$.

We have obtained results for helium isotopes at $\mathrm{s} 1 \mathrm{x}$ of the locallties within the tectonicaliy active region During the period of most intense selsmic activity (October 1978, to June 1983) the ${ }^{3 e /}$ He natio (R), normals ized to 1 ts value in air. ( $R)$, Increased monotonically at the Hot Creek locality from 4.7 to 5.6 indicating an increasing contribution to an al ready significant proportion of primordial (mantie) hellum. since then the $R / R$ rat 10 has dropped, both at Hot creek and other springs in the vicinity, concomitant with an approximately 10 -fold decline in the level of selsmicity. The most recent sampling trip (January, 1986) has, however, revealed a signiflcant increase in the $R / R$ value at four or five sites monitored on a longfterm basis; in spite of the continuing decrease in the rate of seismlcity.

There are several possible reasons why the helium isotope rat 10 should respond to changes in seismic activity and migration of magma. If the highest ${ }^{3} \mathrm{He} /{ }^{4} \mathrm{He}$ rat $10_{4}$ observed $\left(6.5 \mathrm{R}_{2}\right)$ is indlcative of the magmatic sourge, then lower ${ }^{3} \mathrm{He} / \mathrm{He}$ ratigs must be due to elther admixture of a low ${ }^{3} \mathrm{He} / \mathrm{H}$ He water or leaching of. He from crustal rocks. In either case, new fractures related to earthquakes would facilitate the migration of hydrothermal fluid. This would result in a greater percentage of the magmat1c component relative to the crustal one in the observed fiuld or in a shorter residence time in the reservoir for the hydrothermal fluid, 
thereby reducing the amount of leaching of ${ }^{4} \mathrm{He}$. Similarly, movement of magma to shallower depths would increase the convective heat flux in the region, thereby bringing more of the magmatic hydrothermal component to the surface. Interestingly, the South Mono Lake hot spring, $25 \mathrm{~km}$ to the north of Long Valley, also seems to respond to the changes in selsmic activity; thus, this hydrothermal system is responding to similar changes in thestress regime and fracture pattern as Long Valley, or, perhaps more speculatively, the Long Valley and Mono magma chambers are connected. The significance of the recent increase in $R / R_{2}$ values in terms of the above scenar10, is currently being assessed but may well prove to signal impor ${ }^{2}$ tant changes in the hellum source at depth.

The ${ }^{3} \mathrm{He} /{ }^{4} \mathrm{He}$ ratios also have a bearing on present hydrological models, which generaily assume recharge to the west of long Valley and lateral flow of fluid through the Bishop Tuff aquifer in an easterly direction. The consistentiy higher ${ }^{3} \mathrm{He} / \mathrm{He}$ ratios on the eastern side of the caldera, at Hot Creek, Little Hot Creek and Big Alkaline Lake, if indicative of a more direct magmatic input to this area, imply that the fluid regime in the east is controlled principally by circulation of fluids in close coptact with the thermal resource, whereas to the west of the lower ${ }^{3} \mathrm{He} / \mathrm{He}$ ratios, measured at Casa Diablo for example, could reflect an increased fluld component of shallow or $1 \mathrm{gin}$. Such interpretations must however be able to account for apparent inconsistencles between adjacent localities, such as the continued decline in $R / R$ at Hot Creek while nearby springs show the opposite trend. If such difficulties can be overcome the helium isotope yarlations may offer the very real possibility of delineating areas of geothermal potentlal within the caldera. 
Contract :

Title:

Person in Charge:

Scope of Work

We are continuing work on the thermal properties of the highly compressible alkali metals: Lithlum, sodlum, potassium, rubidium, and cesium. Melting points were determined to 35 kbar with highly 1 mproved accuracy using in situ pressure and temperature measurements and a hydrostatic pressure medium. Some strong systematic deviations from previous nonhydrostat 1c piston-cylinder work and new theoret 1 cal calculations were observed. We, therefore, bullt an externally heated diamond anvil cell for studying melting at much higher pressires. This cell operates conveniently to melting temperatures of $400^{\circ} \mathrm{C}$, which is the upper 1 imit of rellable in situ pressure measurements by the ruby method. With this diamond cell, we have measured the melting temperatures of $\mathrm{Na}$ and $\mathrm{K}$ to 110 and $145 \mathrm{kbar}$, respectively, and found a continuous rise in the melting temperature for $\mathrm{Na}$ and the triple point of the phases bco-fec ${ }^{2} 11$ quid in potassium. This strongly suggests a systematic relationship among the phase diagrams of the heavier alkali metals, potasslum, rubidium, and ceslum. For the measuref. ment of melting far beyond the s-tod electronic transition, we have designed an internally heated diamond cell in order to extend these studies to higher temperature. tis

The encapsulating technique that we have developed to contain Ilquid Cs at high hydrostatic pressures in the piston cylinder apparatus was used to measure adiabats and phase diagrams of ammonia-water suites. These compounds are considered to be major constituents to 1 cy Jovian and Saturnian satellites. We found significant discrepancles between the boundaries sensed by thermal probes in the piston-cylinder apparatus and the visual observations in the diamond anvil cells, since these techniques have dif* ferent sensitivities to metastability. These studies located the $\mathrm{H}_{2} \mathrm{O}-\mathrm{NH}_{3}$ : $2 \mathrm{H}_{2}$ eutectic and determined the adiabatic gradient of the eutectic and some other compounds, Including liquid water, 1 ce VI, and ice VII. These experimental adiabats place important constralnts on the temperature distributions and thermal histories of such planets. 
Grantee:

Grant:

Title:

Person in Charge:

Scope of Work
UNIVERSITY OF CALIFORNIA AT LOS ANGELES

Department of Earth and Space Science

Los Angeles, California 90024

DE F F03 -84ER1 3203

Determination of Thermodynamic Functions of Minerals at High Temperature

0. L. Anderson

High temperature elasticity and expansivity measurements with sufficient quality to compute the thermodynamic information required to determine the thermodynamic functions of solids are measured in this laboratory.

The measurements emphasize the determination of the elastic constants $C_{1}$ from which the adiabatic bulk modulus $K_{S}=-V(\partial P / \partial V)_{S}$ is determined in the range of $300^{\circ} \mathrm{K}$ to above the Debye temperature. Most in inerals of geophysical interest have values of $\theta$ in the range of $500^{\circ} \mathrm{K}$ to $850^{\circ} \mathrm{K}(\mathrm{e} .8$. , $\theta$ for forstertie is $760^{\circ} \mathrm{K}$ ).

By applying the special measuring technique called the Rectangular Paralleleplped Resonance method (RPR), fundamental resonance frequencies are measured up to and beyond the Debye temperature into the $1200^{\circ} \mathrm{K}$ range.

Many thermodynamic properties can be calculated with the data from measurements. The RPM method is workable only at one bar pressure, but there are high pressure thermodynamic properties predicted by the results. Some of these predicted thermodynamic properties can be found from high pressure experiments, and correlations between experimental methods are possible.

We have just finished the RPR measurements on NaCl, from which we determine the elastic instants of $\mathrm{NaCl}$ at temperatures up to two times the Debye temperature. Our results on $\mathrm{C}_{11}$ agree with the $\mathrm{C}_{1 j}$ of Spetzler et al. (1972). Using the thermal expansivity along with the $C_{1}$ data, we determine the thermal pressure vs. T. We found that our results ion thermal pressure agree very well with the measurements of Boehler and Kennedy (1982) on NaCl. This means that the RPR method can be used to either supplement or complement the $P \neq V-T$ measurement of the thermodynamic properties. Our measurements of the gruneisen constant vs. $T$ at high $T$, indicates a slight departure from the results found by Boehler, and we are investigating this departure. 
We have finlshed the theory by which the elastic constants of a trigonal crystal can be determined by means of the RPR method. We have been able to demonstrate complete agreement between observed and calculated resonance spectra up to the thirty-ninth mode. This is the first time that this has been done for crystals of such low symmetry. We found that it required a computing program with the capacity to invert a matrix of order $210 \times 210$ in order to avoid dispersion in the upper modes $(20-40)$. The RPR data taken on cor undum at room temperature were used to calculate the elastic constants. 
Contractor:

Contract:

Title:

Person in Charge:
THE UN IVERSITY OF CHICACO

Chicago, Illinols 60637

DE $\rightarrow$ ACO2 $\cong 80$ ER1 0763

Depth to and Concentrations of Water in Large Bodies of Silicic Magma

A. T. Anderson and S. N. Will lams

Scope of Work

Silicic magmatism plays an important role in the compositional evolut tion of the crust and in the development of certain ore deposits and geothermal fields. We use vacuum fusion and capacitance manometry to estimate the concentration of $\mathrm{H}_{2} \mathrm{O}$ in inclusions of glass (quenched melt) preserved within phenocrysts of quartz. Together with evidence of gas saturation, the concentration of $\mathrm{H}_{2} \mathrm{O}$ in the melt leads to an estimate of the pressure of crystallization ${ }^{2}$ and thus the depth at which the body of magma was crystallizing.

Our analyses of clinozolsite and other hydrous sllicates with structural hydroxyl water agree with other methods. However, our analyses of silicic glasses yield low concentrations of $\mathrm{H}_{2} \mathrm{O}$ compared to other methods. Tests to date suggest that part of the discrepancy may be caused by partial loss of $\mathrm{H}_{2} \mathrm{O}$ from silicle glass at room temperature in a hard vacuum. We determined that inclusions of glass which are sectioned before analysis lose about as much $\mathrm{H}_{2} \mathrm{O}$ at $400^{\circ} \mathrm{C}$ as at $1250^{\circ} \mathrm{C}{ }_{-4}$ Virtually no $\mathrm{H}_{2} \mathrm{O}$ is detected at $200^{\circ} \mathrm{C}$, after pumpdown to a pressure of $<10^{-5} \mathrm{~mm} \mathrm{Hg}$ at room temperature for about 48 hours. To eliminate the possibility of evaporation of $\mathrm{H}_{2} \mathrm{O}$ from silicic glass during pumpdown, we have analysed some unsectioned inclusions of $\mathrm{glass}$. The $\mathrm{H}_{2} \mathrm{O}$ is released at $1250^{\circ} \mathrm{C}$ when the crystal rupi tures and the melt vesiculates. No $\mathrm{H}_{2} \mathrm{O}$ is detected at el ther $200^{\circ} \mathrm{C}$ or $400^{\circ} \mathrm{C}$ from unsectioned inclusions. Three inclusions in three separate crystals released $2.0 \pm 0.8 \mathrm{wt}$. percent $\mathrm{H}_{2} \mathrm{O}$. The three inclusions were relatively small (about 100 microns long), located near the centers of the crystals and partially faceted (negative crystals). A fourth inclusion was large (almost $300 \mathrm{microns} 1 \mathrm{ong}$ ), round and located near the rim of the crystal. It yielded $4.4 \pm 1.0$ percent $H_{2} 0$. Possibly, the small, faceted inclusions were trapped at an early stage of crystallization in a melt with comparatively little $\mathrm{H}_{2} \mathrm{O}$ whereas the large inclusion was trapped later after the concentratfon of $\mathrm{H}_{2} \mathrm{O}$ in the liquid had increased. Preservation of a record of increasing $\mathrm{H}_{2} \mathrm{O}$ with orystallization within a single 1 ump of pumice suggests that the change occurred in less than about 100,000 years; otherwise, diffusive exchange would result in uniformity. 
$\therefore$ i.

Grantee:

Grant:

Title:

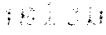

Person in Charge:

Scope of Work

A detalled characterization of silicate liquids is required for a predictive understanding of the evolution of nat ural magmas within the earth's crust. A magma's crystallization behavior and interaction with 1 ts surrounding determine, among other things, the potential for geothermal energy extraction and the formation of ore deposits. The thermodynamic evolution of magmatic systems depends not onl y upon the thermochemical detalls of the solidification products, but also on the thermochemical properties of the initial magmatic liquids. These properties are rather more poorly known for the liquids than for the solids. It is the putpose of this project to ald in the characterization of the thermodynamic properties of silicate 1lquids by a novel experimental approach \& thermal diffusion studies.

Thermal diffusion is the phenomenon of chemlcal migration in response to a thermal gradient. In a substance with more than one component, chemical heterogeneity can develop in an Initially homogeneous subs tance as $a_{i}$ result of a diffusional mass flow consequent on heat flow. The detalls of this response are conditioned by the thermochemical properties and constitution of the substance. We have experimentally demonstrated that silicate 1 iquids do undergo substantial thermal diffusion differentiation and that observations of this differentiation provide the data necessary to evaluate the form and quantitative values of silicate liquid solution parameters. This information supplements calorimetric and phase equilibrium data on silicate liquids. Silicate liquids show mixing behavior which requires models as least as complex as an as ymmetric regular solution. Parameters quantitatively extracted so far include ordinary diffusion coefficients, heats of transport, and energies of mixing for. $\mathrm{SiO}_{2}$ in silicate liquid: 
Grantee:

Grant:

Title:

Person in Charge:
COLUMBIA UNIVERSITY

Lamont-Doherty Geolog1cal Observatory

Palisades, New York 10964

DE $\sim F G 02-84 E R 13221$

Seismo-tectonics of the Eastern Aleutian Arc and Associated Volcanic Systems

K. Jacob and J. Tabér

\section{Scope of Work}

The geophys 1cal processes of subduction and archmagmatism are investigated by seismological methods to obtain a fundamental understanding of convergence at a plate margin and to assess selsmic risk to future energy projects in an active arcitrench back arc system. We interpret selsmotectonic information for most of the Eastern Aleutians. In the Shumagin Islands we study a $300^{\circ} \mathrm{km}$ long arc segment by operating a digital seismic network with 14 remote stations linked by telemetry. This segment is a seismlc gap with a high probability for a great earthquake (M>8). In the next two decades. Research topics include: the geometry of the descending Pacific slab; velocities in the upper mantle and crust of the over-riding North American plate; selsmic source and strongtmotion properties; invert sion of travel time residuals for velocity pertubations in the arc's magmat1c root zone; seismic and eruptive activity of Pavlof Volcano; and the integration of these results with geodetic deformation data to invesi tigate plate coupling. Applications concern the geothermal energy potential of the Aleutian arc; seismic, volcanic and tsunami hazards to off shore oil lease-sale areas directly adjacent to the Shumagin Seismic gap. Technical objectives are the sensing of wide dynamic range, selsmic ground motions of small and large earthquakes for engineering applications. The selsmortectonic results for the Shumagin network area are integrated with results from teleselsmic and other geophysical observations from the Aleutian arc outside the Shumagin seismic gap.

\section{Results}

Between October 9 and November 14, 1985, a sequence of 5 moderatensized events with magnitudes $M_{p}-6.4,5.0,5.2,5.0$, and 5.6 occurred in the Shumagin Islands seismic network region of the Eastern Aleutian arc. In addition to this cluster of moderate-sized events, the microseismicity rate in the shumagin region has increased by 35 to $80 \%$ for at least a 6 -months period beginning in April 1985. While we cannot be sure that these unusual seismicity patterns are part of a precursory activity to a large impending Shumagin earthquake, such a possibility must at least be considered. 


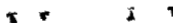

Contractor:

Contract:

Title:

Person in Charge:

Scope of Work

This project involves laboratory studies of the permeability of joints in rock, taking into account both mechanical/hydraulic and chemical aspects of the problem.

A study of the mecanical properties of joints has recently been completed. A constitutive law that relates jolnt closure and effective normal stress was formulated and confirmed by laboratory measurement. The law is an extension of the Greenwood and Williamson (1966) contact theory for two rough surfaces in contact. It shows that the closure property is as much a property of the topography oof thhe fracture surfaces as of the elastic contants of the substrate. A broad bandwidth study of the topog raphy of natural rock surfaces showed that a wide variety of such surfaces have fractal-ilke topography.

Experiments of water/rock interactions during flow of water through fractures in quartzite and marble have shown that a number of solutiondissolution processes can affect permeability in such situations. Current studies of this type involve flow experiments of water through fractured alabaster and fractured quartzite under hydrothermal conditions. 
Contractor:

Contract :

Title:

Person in Charge:
HARVARD UNIVERSITY

Department of Geological Sciences

Cambridge, Massachusetts 02138

DE-AC02-83ER1 3096

Energetic and Thermochemical Properties of Rocks and Minerals

$\mathrm{J}$ : B. Thompson, Jr. and S. K. Dobos

Scope of Work

Any thorough understanding of the earth's crustal processes and energy budget must take into account the energetics and thermochemical properties of rocks and their constituent minerals, notably their heat capacities and their enthalpies and entropies of transformations. Such thermodynamic data, and physico-chemical models derived from them, are of direct concern in such fields as the extraction of geothermal energy, nuclear waste disposal, terrestrial heat-flow studies, the geochemistry of ore deposits and igneous, metamorphic and sedimentary petrology.

Much of the requisite thermochemical data to handle problems in the above fields is unknown or poorly characterized. We propose to augment the data base for the thermochemical properties of rocks and rock-forming minerals, as well as heterogeneous transformations in rocks involving the appearance or disappearance of mineral phases of a given phase assemblage. Such studies comprise one of the most basic energy-related branches of scientific investigation in the geosciences, and are fundamental to our understanding earth processes and earth materials.

Our calorimetry lab is now complete and fully equipped with three thermanalytic instruments: (i) a power-compensated differential scanning calorimeter fot eht emperature range -170 to $725^{\circ} \mathrm{C}$, (ii) a heat-fiux differential scanning calorimeter for the range 25 to $1700^{\circ} \mathrm{C}$, and (iii) a thermogravimetric analyzer for the range $25^{\circ} \mathrm{C}$ to $1200^{\circ} \mathrm{C}$, capable of operation with controlled atmospheres from a moderate vacuum to ambient pressure. The instruments may be run semi-automatically, and are interfaced to computers for real-time monitoring, data collection and data reduction, 
Grantee:

Grant:

T1tle:

Person in Charge:
UNIVERSITY OF HAWAII AT MANOA

Hawa 11 Inst 1tute of Geophys1cs

Honolulu, HI 96822

DE-FC03-85ER 13418

Physical Characterization of Magma Samples

M. H. Manghnan1

\section{Scope of Work}

This program involves two areas of laboratory lnvestigation: (1) characterization of physical, selsmic ( $V_{p}, V_{s^{\prime}}$ and $\left.Q\right)$ and electrical properties of core samples from Kllaeua Ik $S^{\prime}$ lava lake as a function of temperature, and (2) electrical conductivity, and $v_{p}, v_{s}$, and $Q^{-1}$ of melts or these and related basalts as a function of pressure and temperature and volatile $\left(e .8 ., \mathrm{H}_{2} \mathrm{O}, \mathrm{CO}_{2}\right)$ content.

The goals of the proposed research are threefold: (1) to understand how the high'temperature behavior and thermodynamic properties of basalts and relevant silicate melts pertaining to geothermal exploration and thermal modeling in a volcanically active area are affected by a total environmental system; (2) to investigate interrelationships between the varlous physical and thermodynamic properties of such melts; and, (3) to develop Brillouin Scattering technique for measuring the elastic and anelastic properties of melts.

Chemical and mineralogical analyses of KIlauea IkI and other samples are belng conducted in cooperation with W. C. Luth at Sandia National Laboratories.

The physical, acoustic and electrical properties of selected lava lake core samples, for which chemical composition and mineralogy have been determined by Sandla Laboratories (Dr. W. C. Luth) have been interpreted in terms of chemistry, glass content, and mineralogy of these core samples.

We have focused our efforts on the elastic, anelastic, and electrical properties of melts of basaltic and related composition using ultrasonic interferometry and recently wet up 4-electrode conductivity measurement experiments. We are currently testing our high-temperature furnace for Brillouin Scattering measurements. Based on the ultrasonic data to date, the temperature and frequency dependence of ultrasonic compressional velocity $(V)$ and attenuation $(Q)$ ) measurements for various melt compositions are ihterpreted in terms of viscosity, relaxation time, and structure of melt. The $V_{\text {. }} Q^{-1}$ frequency temperature data for melts of 10 basalts have been systematlzed in terms of compositional and structural variations. A linear relationship between velocity and density (constant molecular welght M), simllar to Birch's law, has been, found. We have also found a good relationshlp between the measured $Q_{p}$ and $v i s c o s i t y$ values for various types of basalt melts. 
The temperature dependence of the melt conductivity of the eight samples from Kilaeua IKI samples from different depths is almost the same and follows the Arrhenius equation.

The proposed research, involving close cooperation between the University of Hawall and the Sandia National Laboratories, provides an impetus to basic energy research needed for acquiring a better knowledge of the fundamental in situ high-temperature physical properties of rocks and their melts relevant to geothermal exploration and to planned projects such as the U.S. Continental Sclentific Drilling Program. 
2

Grantee: 0 UNIVERSITY OF MARYLAND

Department of Chemistry and Blochemistry

College Park, MD 20742

Grant:

DE-FG05-85ER 13410

Title:

Sfudy of the Salton Sea Geothermal System Using Be Isotope and Trace Element Chemistry

Person in Charge:

N. J. Valette-ASilver

Scope of Work

The aim of the proposed work is to characterize the dominant prpgesses acting in the Salton Sea geothermal reservoir using the 1sotope $\mathrm{Be}$ and trace elements. The use of a welleprqyen tool such as the trace elements and of a promising new technique, $\mathrm{Be}$, constitutes a unique and potentially powerful combination never used before in a geothermal system. To makfo an adequate use of these indicators, we propose to study the behavior of $\mathrm{Be}$ and of the selected trace elements (As, Se, Sb, $\mathrm{Hg}, \mathrm{V} . .$. ) in the highly saline environment of the Salton Sea. From the analysis of waters, ore deposits, sediments and rocks, we will address the following problems.

1. We expect the aquifers in the geothermal field to have distiffet chemical signatures as defined by their trace element and $\mathrm{Be}$ concentrations. By characterizing the aquifers in this way we will be able to identify the mixing processes occurring in the hydrothermal system.

2. We seek to estimate the ages of the rocks and sefiments of the reservolr as well as the various aquifers by using ${ }_{\mathrm{Be}}$ as a tracer and as a dating tool.

3. We want to determine the origin of the ore deposits: in par ticular, whether the metals are of sedimentary or volcanic origin.

We propose to perform this work in two steps: the first one deals with the water samples and has to be carried out during the first half of the proposal to avold spollage of the samples. The second one deals with the solid samples and will be carried out during the second half of the year.

\section{Current Activity}

Preliminary study of liquid samples from the Salton Sea geothermal fleld, obtained mostiy from the Well Fee 5 belonging to Republic Geothermal Inc., enabled us to develop and refine analytical techniques that w111 be used on the Salton Sea scientific drilling project samplesf on the Feef 5 samples, we tested mostly our chemical separation for the $\mathrm{Be}$ study, and 
measured the isotope concentrations using the Tandem Accelerator at the University of Pennsylvania. The concentrations reached the very high value of $2 \times 10^{\circ}$ atoms/g. Analysis using INAA, ICP, and AA, for major and trace elements determination were also performed in order to evaluate the effect of the very high salinity of the samples on the chemical analysis.

The first SSSDP fluid samples were made avallable to us in January 1986 and their study is in progress. We are awalting the second series of fluid samples as well as the core samples. 


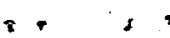

Grantee:

Grant:

Title:

Person in Charge:

Scope of Work

The objective of this project is to develop the scientific basis for understanding microcracks in rocks.

Open microcracks control such important properties of rocks as hydraulic permeability, electrical conductivity, compressibility, thermal expansion, and the velocities of elastic waves. Healed microcracks provide data on the history of a rock, including pressure, temperature, and fluid composition. The potential applications include (1) site characterization for waste repositories; (2) estimation of the change of permeability of rock in situ due to changes of temperature associated with exploitation of a hot-drymrocks geothermal reservoir: (3) prediction of the behavior of certain isotopes in radioactive waste emplaced in orystalline rocks; and (4) Improvements in the exploration techniques for uranium in crystalline rocks.

Microcracks and their mineral deposits are characterized with the petrographic microscope, scanning electron microscope equipped with an energy dispersive $x$-ray system, and various physical properties measured as a function of pressure. Open microcracks are characterized with the SEM and a high precision strain measuring technique (differential strain analysis, DSA).

\section{A. Granite Mountains and Sherman Granites}

This project is investigating why the Granite Mountains granite lost as much as $2 / 3$ of its or 1 ginal uranium, as shown in a series of papers by the USGS Isotope Group, but the Syerman granite retained most of its original uranium for more than $10^{\circ}$ years.

In the Sherman granite, primary $U$ is contained in uraninite, thorite, allanite, sphene, apatite, and zircon. Secondary $U$ occurs in microcracks and alteration products in coffinite, thorite, bastnesite group minerals, hematite, and calcite. The $U$,present in microcracks was $11 \mathrm{kely}$ derived from primary 1 gneous minerals of the granite itself - chiefly allanite, uraninite, and thorite. The temperature of alteration and redistribution of $U$ was $330-400^{\circ} \mathrm{C}$. The $U$ was $11 \mathrm{kely}$ transported in soluble uranyl carbonate complexes. The effect 1 veness of this granite in retaining $\mathrm{U}$ for $1.4 \mathrm{~b} . \mathrm{y}$. $1 \mathrm{~s}$ attributed to the general absence of open fractures and hot fluids.

$$
-133-
$$


In the Granite Mountains granite, the remaining primary uranium is contained in morizite, sphene, zircon, apatite, and allanite. It also occurs in blotite and hornblende where it is homogeneously distributed in relatively low abundances $(<2 \mathrm{ppm} U)$. Secondary uranium occurs in alteration products and in microcracks as coffinite, bastnesite group minerals, epidote (a typical alteration mineral in this granite), and an yttrium carbonate, probably tengerite. On the basis of the secondary monazite in microcracks and the corrosion and alteration of primary monazite grains, we infer that the uranium was transported as one or more uranyl phosphate complexes.

Our hypothesis to account for the major differences in loss of uranium between the Sherman and Granite Mountains granites is that (1) phosphate was available for complexing in the Granite Mountains granite but no suitable complexing agent was available in the Sherman grantte and (2) fracturing was more pervasive in the Granite Mountains granite allowing access by fluids to the primary uranium sites).

B. Uranium in Clays

The uranium in clay-rich regions, a few mililmeters in size, in several granites occurs in smail ( $<2$ microns) grains of non-clay minerals, rather than on, or in, the clay minerals themselves. The clays are smectite, nontronite, and vermiculite. The uraniferous minerals are bastnesite group minerals, hematite, siderite, secondary monazite, secondary thorite, and several different $Y$-bearing niobates. We sug gest tentatively that the presence of uranium in clay may not be indicative of the long-term retention of radioisotopes.

C. Migration of $U$ in and Near a Lamprophyric Dike

The uranium content of lamprophyric dikes in the Conway and Mount Osceola granites of New Hampshire is lower than the host granites by an order of magnitude.

Examination of core samples of one lamprophyric dike and its host rock, Conway granite, with an SEM, fission track radiography, and a delayed neutron technique shows the following:

1. The uranium content of the host rock decreases logarithmically with distance from the dike.

2. $U$ in the host adjacent to the dike is $2 X$ the content of the granite at large distance from the dike and $10 \mathrm{X}$ the content of the dike.

3. $U$, homogeneously distributed in the dike at scales of 10 microns and greater, occurs in zircon and apatite grains.

4. Th in the host adjacent to the dike is $2 x$ the content of the granite at large distance from the dike and $20 \mathrm{X}$ the content of the dike.

5. Th is homogeneously distributed in the dike at scales of centimeters. 
Model temperatures calculated for a slab with same thickness as the dike and embedded in an infinite medium with thermal properties comparable to those of the dike and host granite show that the increase of temperature of the host rock at the time of intrusion was largely confined to a zone of a few meters width and lasted a few tens of days, at most.

The observed decrease of $U$ and Th with distance in the country rock cannot be attributed to high values in the dike. They may be accounted for with the following models: (A) The dike intruded along a preexisting fault that was the channel for $U$ and $T h$ bearing hydrothermal flulds. (B) The $U$ and $T h$ were controlled by the excess temperature due to the dike and may have been derived from the granite itself or from hydrothermal fluids accompanying the intrusion.

$\mathrm{U}$ and $\mathrm{Th}$ and isotopes that behave similarly should be $1 \mathrm{mmob} 1 \mathrm{le}$ in a nuclear waste repository for times of order of $10^{+6}$ years provided that the geochemical conditions are similar to those at the Redstone Quarry. 
Grantee:

Grant:

Title:

Person in Charge:
MASSACHUSETTS INSTITUTE OF TECHNOLOGY

Department of Earth, Atmospheric and Planetary Sciences

Cambridge, Massachusetts 02139

DE $-F$ G02\%86ER 13636

In-Situ Permeability Determination Using Borehole and Seismic Logging Data

M. Nafi Toksoz, Roy H. Wilkens, and C. H. Arthur Cheng

Scope of Work

Borehole seismic measurements are contributing to the detection and characterization of subsurface open fractures and the determination of in situ permeability. Vertical Selsmic Profiling (VSP), with a surface source and a receiver (hydrophone or clamped borehole geophone) array in the borehole, has been effective in detecting and imaging open fractures. The hydraulic conductivity of a fracture can be determined from the amplitude of tube waves generated by the fluid flow from the fracture into the borehole. The inclination (dip) and extent of the fracture can be determined from attenuation of seismic waves across the fracture and the waves scattered from the fracture. Theoretical models of flow and wave scattering are being developed for horizontal as well as dipping fractures.

Full waveform acoustic logs also detect fractures. An important study is the determination of fracture width or hydraulic conductivity from the attenuation of the Stoneley pulse, which is the dominant pulse in the wave train. The theoretical formulations relating attenuation to hydraulic conductivity have been done, for horizontal fractures, with simplifying assumptions. Laboratory tests are underway now to confirm the validity of the assumptions. Similar studies on attenuation-permeability relationships are being carried out for boreholes in permeable rocks. The results show that Stoneley wave attenuation is sensitive to permeability. To determine the absolute value of permeability it is necessary to establish the at tenuation in the borehole fluid, either from laboratory measurements or from jolnt analysis of all phases of the full waveform acoustic logs. 
Grantee:

Grant:

T1tle:

Person in Charge:

Scope of Work

Samples from the Inyo drilling program offer a unique opportunity to evaluate magmatic processes, and eruption and emplacement dynamics. The Inyo Chain is a $9-\mathrm{km}$-long chain containing at least seven silicic domes and flows, explosion pits, and a serles of faults and cracks allroughly allgned N07 ${ }^{\circ} \mathrm{W}$. The most recent activity ( 550 years ago) consists of the three largest domes (Obsidian, South Glass Creek, and South Deadman domes). Detalled structural studies and drilling have shown that the Inyo Chain is a surface expression of a dike or a system of dikes. The initial activity at Obsidian Dome consisted of explosive magmatic eruptions, near-vent pyroclastic fall and flow deposits. After this explosive activity stopped the rhyolite flows were extruded. Drilling has provided cont inuous samples from: the flow at Obsidian Dome, the condult to Obsidian Dome, and the dike that connects Obsidian Dome and the South Glass creek Dome. These continuous samples of the dike, conduit and dome provide a detalled record of magmatic processes, and the emplacement and eruption dynamics of this system.

During the past year we have continued our detalled chemical and mineralogical study of the continuous drill samples from the conduit and dike. We have nearly completed our detalled major and trace element analyses. We are in the process of data analysis in order to evaluate magmatic and emplacement processes. Microprobe studies on the chemical varlation of ferrmagnesian minerals and the Fe-TI oxldes are continuing.

In summary, two rock groups are present in these samples, a high-Ba, lower slllca group and a low $\mathrm{Ba}$, higher sll1ca group. These two groups ar characterlzed by compositional and mineralogical differences. The high-Ba group occurs at the base of Obsidian Dome, and at the margins of the condult. The low-Ba group occurs in the middle and upper portions of obsidian Dome, the center of the conduit and in the dike.

Blotite, orthopyroxene, and magnet1te occur in both of these groups. In addition, the high-Ba group contains abundant amphibole and 1 lmenite, whereas the low-Ba group contalns abundant auglte. The amount of disequilibrium phenocrysts among the ferromagneslan phenocrysts changes

$$
-137
$$


within the two groups. The greatest number of disequilibrium phenocrysts occur inthe high-Ba group and decreases in a regular fashion to the low-Ba group. Disequilibrium phenocrysts are rare in the low-Ba end'member.

There is a linear trend in the chemical varlation of these samples, and most of this variation occurs in the conduit margins and at the base of Obsidian Dome. Multiple linear regression of major elements from intermediate samples with the end-member samples are remarkably consistent with magma mixing, with a $R^{2}=.999$ and the sum of the squares of the residuals less than 0.25 . A further test of magma mixing was made by selecting two end-members in each group and calculating the theoretical hyperbola that would be generated by mixing these end-members using trace element ratios. The theoretical mixing curve fits the actual data from the conduit margins. A further test of mixing is that the linear equations calculated from the regression analyses on the major elements can be used to predict the trace element concentrations; these are very close to the measured values. A major conclusion of this study is that the rock compositions at the margins of the conduit are due primarily to physical mixing of two finely prophoritic magma types it the high-Ba and low $\mathrm{Ba}$ group.

Based on the linear chemical variation and the distribution of disequilibrium phenocrysts, the lowest flow of Obsidian Dome and the margins of the conduit represent mixed magmas. In the conduit, the number of disequilibrium phenocrysts decreases in the regular manner from the edge to the center, although even the center of the conduit has a significant percentage of disequilibrium phenocrysts. Disequilibrium phenocrysts are virtually absent in the dike.

End-member samples of the low $\mathrm{Ba}$ group represent a pure, unmixed, higher silica end"member; in contrast, all samples of the high-Ba, lower silica magma utype represent mixed magma. Based on theoretical work on dike emplacement (Delany and Pollard, 1981), the dike would have to be emplaced earlier than the conduit. The dike is the earliest intrusion, and did not intrude to the surface. It represents emplacement of the low-Ba, unmixed end-member and presumably erupted from the top of the layered magma body. The conduit represents a highly mixed, high-Ba magma at the margin, and only slightly mixed magma at the center. The first magma erupted to the surface are identical to the margins of the conduit and are the high-Ba, mixed magmas. The middle and upper parts of Obsidian Dome are identical to the center of the conduit.

The chemical and mineralogical data obtained from drilling the conduit, dike and dome at Obsidian Dome provide severe constraints on the manner in which magma fills dikes and localizes eruption centers. In the coming months we hope to quantitatively evaluate these constraints. 
Grantee:

Grant:

Title:

Person in Charge:
MICHIGAN TECHNOLOGICAL UNIVERSITY

Department of Geology and Geological Engineering Houghton, Michigan 49931

DE FCO285ER13409

Geothermal Alteration of Sediments in the Salton Sea Scientific Drill Hole

S. D. McDowell

Scope of Work

The purpose of this investigation is to characterize the overall pattern of alteration of sandstone/siltstone of mudstone in the Salton Sea Sclentiflc Drill Hole, and to compare the alteration to that observed in similar sediments in 11 drillholes under investigation in the geothermal field. The investigation will utilize a variety of techniques including thin section petrography, $X$-ray diffraction, XRF major and trace element chemistry of selected 1 ithologles, paleomagnetic polarity measurements, and various petrophysical measurements. The overali alm is to put the Scientific Drill Hole in context relative to the fleld as a whole.

The investigation is in a preliminary stage since the first core samples were made avallable in March; 1986. The Investigations thus far suggest clay-carbonate facles alteration to roughly $800 \mathrm{~m}$ depth, and chloriteficalcite zone (greenschist facles) alteration to at least $2000 \mathrm{~m}$ depth. Shale porosities vary systematically with depth from $-20 \%$ near 500 in through $-5 \%$ near $1400 \mathrm{~m}$ to $<2 \%$ below $2500 \mathrm{~m}$ depth. The porosity variations in this well are generally similar to those observed in shales from other geothermal wells, based on very limited core avallability in the older wells, and imply significant compaction of muds at depths $<1500 \mathrm{~m}$. other aspects of the investigation are just getting underway. 
Grantee:

Grant:

Title:

Person in Charge:
NATIONAL ACADEMY OF SCIENCES/

NATIONAL RESEARCH COUNCIL Washington, DC 20418

DE-FG01-82ER1 2018

I. Studies in Geophysics

T. M. Usselman

Scope of Work

The Geophysics Research Forum (GRF) of the National Research Council, National Academy of Sclences in conducting a serles of studies in Geophysics dealing with timely scientific and societal aspects of geophysics and the corresponding demand on geophysical knowledge.

The studies include: (1) problem-oriented studies such as demands on geophysical knowledge in connection with climatic varlations, fresh water resources, mineral resources, geothermal and other energy sources, natural hazards, and environmental maintenance; and (2) science-oriented studies such as geophysical data and impact of technology on geophysics. Each study is conducted by a panel selected for the specific purpose. The preliminary findings of each study are presented to the scientific community for comment at a suitable symposium. Two or three studies are expected to be completed each year.

The studies are guided by the Geophysics Study Committee (GSC). Members of the committee are Arthur E. Maxwell (Chairman), Allan F. Agnew, Richard A. Anthes, D. James Baker, Gordon P. Eaton, Devrie S. Intriligator, J. Murray Mitchell, Richard J. O'Connell, Martin Walt, and Ferris Webster; Thomas M. Usselman is the staff officer.

\section{Studies Completed}

THE EARTH'S ELECTRICAL ENVIRONMENT

E. Phillp Krider and Raymond G. Roble, panel co-chairmen, 1986, $263 \mathrm{pp}$.

ACTIVE TECTONICS

Robert E. Wallace, panel chairman, 1986, 266 pp.

GROUNDWATER CONTAMINATION

John D. Bredehoeft, panel chairman, 1984, 179 pp.

EXPLOSIVE VOLCANISM: INCEPTION, EVOLUTION, AND HAZARDS

Francls R. Boyd, panel chalrman, 1984, 176 pp.

FUNDAMENTAL RESEARCH ON ESTUARIES

L. Eugene Cronin and Charles B. Officer, panel co-chairmen, 1983,

$79 \mathrm{pp}$.

CLIMATE IN EARTH HISTORY

Wolfgang H. Berger and John C. Crowell, panel co-chairmen, 1982, $198 \mathrm{pp}$.

SOLAR VARIABILITY, WEATHER, AND CLIMATE

John A. Eddy, panel chairman, 1982, 104 pp.

$$
-140
$$


SCIENTIFIC BASIS OF WATER RESOURCE MANAGEMENT

Myron B. Fiering, panel chalrman, 1982, $127 \mathrm{pp}$.

MINERAL RESOURCES: GENETIC CONSIDERATIONS FOR PRACTICAL APPLICATIONS

Paul B. Barton, Jr., panel chairman, 1981, 119 pp.

CONTINENTAL TECTONICS

B. Clark Burchfiel, Jack E. Oliver, and Leon T. Silver, panel coschairmen, $1980,197 \mathrm{pp}$.

IMPACT OF TECHNOLOGY ON GEOPHYSICS

Homer E. Newell, panel chalrman, 1979, 136 pp.

GEOLOGICAL PERSPECTIVES ON CLIMATIC CHANGE

Preston Cloud, ad hoc committee chairman, 1978, 46 pp.

GEOPHYSICAL PREDICTIONS

Helmut E. Landsberg, panel chairman, 1978, 215 pp.

THE UPPER ATMOSPHERE AND MAGNETOSPHERE

Francis S. Johnson, panel chairman, 1977, 169 pp.

ESTUARIES, GEOPHYSICS, AND THE ENVIRONMENT

Charles B. Officer, panel chairman, 1977, $127 \mathrm{pp}$.

CLIMATE, CLIMATIC CHANGE, AND WATER SUPPLY James R. Wallis, panel chairman, 1977, 132 pp.

ENERGY AND CLIMATE

- Roger R. Reyelle; panel cha1rman, 1977, 158 pp.

\section{Studies in Preparation}

Searlevel change (Roger R. Revelle, panel chairman). Symposium held December 1984; publication expected 1986.

High pore pressure in active tectonic regimes (John D. Bredehoeft and Den1s L. Norton, panel co-chairmen). Symposium scheduled for Nov.

1986 Annual Meeting of the Geologlcal Society of America (San Antonio).

Scope of Work

The modular pattern for the Studies in Geophysics was designed to permit selection of the most timely topics to meet the following objectives:

(1) to set forth the current and prospective contributions that the geophyslcal sclences can make to such concerns of mankind as energy, non renewable resources, and the environment.

(2) to provide government officlals with technological and scientific evaluations that can serve as a basis to assist in decision making in matters involving geophysical research and knowledge, both in policles and programs;

(3) to provide to the scientific community a basis for judgments with respect to the development of the basic science or geophysics in the broad sense and with respect to the relative importance to society of the developments within various branches of geophysics. 
Grantee:

Grant:

Title:

Person in Charge:

\section{Scope of Work}

The Committee on Selsmology meets twice a year to discuss current topics of major importance relevant to selsmology, to review with government agency personnel, in particular, the actions that have resulted from recommendations of the committee and its panels, and to take actions to assure $a$ healthy science which is in a position to provide maximum benefits to the nation and to society: These activities are directed at fulf 111 ing the fundamental mission of the committee, as follows: to maintain an active surveillance of major trends in selsmology and of developments related to seismology in allied scientific and technical fields; to provide special studies for government agencies on appropriate subjects or problems; to maintain cognizance of and to provide advice on international selsmological activities; to provide advice to government agencies concernd ing the operation of $U$. S. governmentasupported seismograph networks and data-dissemination facilities; and to coordinate seismologically related activities within the National Research Counc1l, particularly in the fields of earthquake engineering, rock mechanics, geodesy, geodynamics, and geology. Panels are established to conduct ad hoc studies on toplcs specified by the committee.

Members of the Committee are: Paul W. Pomeroy (chairman), Lawrence W. Braile, Robert S. Crosson, Shamita Das, Thomas H. Jordan, Kenneth L. Larner, Robin K. McGuire, George Plafker, Frank M. Richter, Robert V. Whitman, and Joseph W. Berg, Jr., staff director.

\section{Products}

The Committee polled the selsmological community on manpower and research capabilities and the results are being prepared for publication. A report on seismic hazard analysis is being prepared.

\section{Current Activities}

The Committee on Seismology has established the Panel on Selsmic Hazard Analysis which will report on the statistical and deterministic approaches to the problem. The Committee is considering a study on the outlook for the complete field of seismology. 


\section{Grantee:}

Grant:

Title:

Person in Charge:
NATIONAL ACADEMY OF SCIENCES/

NATIONAL RESEARCH COUNCIL

Washington, DC $2041 \overline{8}$

DE-FG01-82ER 12018

III. U. S. Geodynamics Committee

Pembroke j. Hart

Scope of Work

The U. S. Geodynamics Committee (USGC) was estabilshed in 1969 to foster and encourage studies of the dynamic history of the earth, with approprlate attention to both basic science and applications. The USGC work is based largely on the recommendations developed by its reporters (currently 25) and their assoclated groups. In 1976, at the request of the Geophysics Research Board, the USGC began planning U. S. research activities in solid-earth studies in the 1980 !s. In the following years, the committee devoted a considerable effort to this task this led to the report, Geodynamics in the 1.980 's, pubilshed In $1980 . \therefore$ This report emphasizes the origin and evolution of continental and oceanic crust, the continent ocean transition, the relation of mantle dynamics to crustal dynamics, and a geodynamic framework for understanding resource systems and natural hazards.

Members of the committee are Jack E. Oliver (chalrman), Robin Brett, Arthur R. Green, William C. Kelly, Marcia K. McNutt, J. Casey Moore, Nell D. Opdyke, Frank Richter, Selwyn-Sacks, Mary Lou Zoback; ex off1c10 Edward A. Flinn, and Pembroke J. Hart, staff of flcer.

\section{Current Activities}

The roster of special topics of the USGC and respective reporters has been subject to continual review and revision. A major revision in 1984 included addition of 15 topics corresponding to speclal topics adopted by the International Lithosphere Program. Other topics are: drilling for sclentific purposes; geodynamic data; continent-ocean geodynamic transects; electrical properties of the asthenosphere; seismic networks; sedimentary geology. Highlights of activities of the USGC and its reporters are out: lined below.

In 1973, the USGC strongly urged the application of selsmic reflection profiling techniques to the structure of the earth s crust and upper mantle. Two years later a consortium of four universities. (COCORP) began applying this technique. That group has completed profiles totalling more than $7000 \mathrm{~km}$. This technique has become a standard tool in investigating the earth's crust and upper mantle. 
The USGC strongly supported efforts to develop a continental scientific drilling program. The work of the USGC reporter led to two workshops (1974 and 1978). The report of the 1978 workshop, Continental scientific Drilling Program (1979), contained the principal conclusion that, with advance planning, a greater scientific return could be obtained through add-on experiments involving a relatively small increased expenditure to the existing large investment in drilling by government and industry. The 1979 report recommended that a National Continental Scientific Drilling Program be organized to facliltate the necessary communication and coordination. As a result of the response by federal agencies to the report recommendations, a Continental Scientific Driling Committee was created in January 1980 under the Geophysles Research Board. The USGC actively encourages the development of this drilling program, including add-on investigations in mission-oriented holes and the drilling of holes dedicated to basic scientific objectives.

The reporter for plate boundarles organized nineteen cross sections across ancient plate boundaries; all have been published.

The USGC places strong emphasis on the importance of the transition zone between continental and oceanic lithosphere. The USGC recommended that a series of transects be prepared to set forth existing geological, geochemical, and geophysical data along a series of 23 corridors around the North American coast - U. S., Canada, and Mexico $-\rightarrow$ from the continental craton across the transition zone to oceanic lithosphere. The resultant maps and sections for 10 corridors have been published; completion is expected in 1987.

The objective of the USGC in this transect program is twofold: (1) an assessment of the state of understanding of the structure and history of the transitional regions of North America between typlcal cratonal and oceanic lithosphere; (2) Identification of the major problems and cort responding recommendations regarding the most promising research to solve these problems. The Reporter convened a workshop of Transect Group leaders in 1985 to develop conclusions and a recommendations from the group of transects as a whole. This is expected to lead to a report of the USGC.

The USGC has addressed two main issues regarding geodynamic data: the needs of users and archiving problems. The two USGC reporters for geodynamic data are actively involved with the current study on geophysical data and public policy and the task of modernizing the Guide to International Data Exchange through the World Data Centers. The USGC is addressing the question of digitizing the maps and sections of the North American Transect Program and related planning for the Global Transect Program.

The USGC took initiative in the mid-seventies to encourage and assist the production of gravity and magnetic maps of the United States; the effort expanded to include North America. Preparation of these maps was strongly supported by the Society of Exploration Geophysicists and federal 
agencles. The gravity and magnetic maps for the United States were pubIlshed in 1982 and were the subject of special SExG symposia on applications. Publication of the maps for North Amerlca is expected within the next year.

The reporter for electrical properties of the asthenosphere has worked closely with the International committee for a program of the same title. Several meetings have been held with the objective of developing a specific cooperative program between the United States and Canada.

In 1980, the USGC appointed a reporter and associated working group to ensure coordination among major geodynamics-related programs, especially the Circumpacific Map Project, Consortium for Continental Reflection Profiling (COCORP), Continental Sclentific Drilling Program, ContinentOcean Transects, Early Crustal Evolution, Deep Sea and Continental Margins Drilling, Gravity Anomaly Map for North America, LASE, Magnet1c Anomaly Map for North America, Tectonic Map of North America, and the USGC Geological Framework Program. An Important result: agreement was reached that the major maps will be published on the same projection and at the same scale.

International LIthosphere Program. The USGC serves as the U. S. counterpart to the International Lithosphere Program -- an international program of geodynamics for the $1.980^{\prime} \mathrm{s}$ (successor to the Geodynamics Project, which formally ended in December 1979). The subtitle of the new program is "Dynamics and Evolution of the Lithosphere: The Framework for Earth Resources and the Reduction of Hazards". International guidance is provided by the Inter-Union Commission on the Lithosphere. The emphasis has shifted toward the continents and the continent-ocean transition for reasons of scientific and societal relevance, especially in the areas of resources and natural hazards. A major new initiative is the Global Transect Program, modelled on the North American Transect Program.

The USGC has reporters corresponding to all activities of the Lithosphere Program. A reporter was added in 1985 to provide linkage to the proposed international program of sedimentary geology that has $t$ imely promise of providing important information regarding the behavior and development of sedimentary basins and the past behavior of the lithosphere.

Workshop on the LIthosphere. The USGC organized a workshop on problems of the lithosphere (Austin, Texas, March 1982) that focused primarily on areas of scientific controversy in connection with the lithosphere, with the expectation that this will provide guldance regarding the most productive areas for research in the coming years. Proceedings were published in The Lithosphere: Report of a Workshop (1983).

Future Work of the USGC

(1) Assess new directions for the committee and new priority topics to which the committee can react directly or via a reporter. This assessment w1ll take especlally into account Geodynamics in the $1980^{\prime} \mathrm{s}$, the discussion at the Workshop on the Lithosphere, the 
Continental Scientific Driling Program, the International Lithosphere Program, and recommendations of reports of the Board of Earth Sciences (e.g., Selsmological Studies of the Continental Lithosphere; and report of the Committee on Global and International Geology).

(2) Increase interaction with the International Lithosphere Program. Encourage cooperative research activities that will benefit $U$. $S$. science and the international program, for example, activities based on the deep seismic reflection program, continent-ocean transects, global transect program, international sedimentary geology program, and continental driliing. 
Grantee:

Grant:

Title:

Person in Charge:
NATIONAL ACADEMY OF SCIENCES/

NATIONAL RESEARCH COUNCIL

Washington, DC 20418

DE-FG01-82ER12018

IV. Continental Scientific Drilling Committee

Scope of Work

The Continental Scientific Drilling Committee (CSDC) was established in 1980 to implement the recommendations in the report Continental Scientific Drilling Program (U. S. Geodynamics Committee, 1979). This report iden tified as a major goal the development of a multiagency program to maximum the scientific value of current and planned drilling activities of federal agencles and of industry through add-on experiments, and supplementing these efforts with "dedicated" holes drilled for scientific purposes.

Members of the CSDC are: William W. Hay (chalrman). Charles R. Bacon, W. Gary Ernst, William L. Fisher, Kate H. Hadley, William Hinze, Marcus E. Milling, Robert N. Schock, Francls G. Stehli, and Hatten Yoder. William Benson serves as staff officer.

Scientific objectives for continental scientific drilling have been formulated by the panels of the CSDC: Thermal Regimes; Drilling, Logging, and Instrument Technology; Mineral Resources; Basement Structures and Deep Continental Basins; Downhole Physical Property Measurements and Fault Zone Drilling; and Sample Curation and Data Management. CSDC and hoc task groups to address specific research drilling targets and objectives include: Salton Sea geothermal fleld; Valles caldera; Yellowstone; Creede, Tonopah, and Red Mountain mining areas; southern Appalachians; sample curation facilities; and coring requirements and technology.

Accomplishments

The objectives of the CSDC have been accomplished through committee meetings, sponsored symposia, and issuing reports and a newsletter which inform the scientific community about plans for the national research drilling program, opportunities for scientists to become involved, and priorities for scientific objectives and targets. The DEW NEWSLETTER (Drlliing Early Warning), deslgned by the Committee as 1ts mechanism for communicating with scientists, is distributed to approximately $2700 \mathrm{U}$. S. and forelgn researchers in universitles and other academic institutions, industry, government laboratorles and geoscience administrators, and geosclence socleties. Fourteen newsletters have been distributed to date.

Three longer reports are in review and will be published in 1986-89. These will represent the final work of the committee.

$$
+147=
$$


Future

As forecasted last year, DOSECC (Deep Observation and Sampling of the Earth's Continental (rust) has become operational, and between it and DOE's geothermal program, nearly all of the CSDC's original objectives have been fulfilled and its continuing functions taken over. CSDC is therefore phasing out and will be discontinued when its reports are published. 
Grantee:

NATIONAL ACADEMY OF SCIENCES/

NATIONAL RESEARCH COUNCIL

Washington, DC 20418

Grant :

DE- FG01-82ER12018

Title:

V. Board on Earth Sciences

Person in Charge:

J. W. Berg, Jr.

Scope of Work

The fundamental mission of the Board on Earth Sciences of the Commission on Physical Sclences, Mathematics, and Resources is to provide oversight of the solidsearth science activities within the National Research Council, to provide a review of research and public activities in the solidearth sciences, to assess the health of the disciplines, and to identify research opportunities. This group is to take a leading role in helping to establish scientific policy bearing on larger earth science programs in and on behalf of the United States. A major charge of the Board and its committees is to assess and recommend basic research and its applications to meet national and societal needs:

Members of the Board are W. G. Ernst (chairman), Don L. Anderson, Paul A. Bailly, Robin Brett, Randolph W. Bromery, Lawrence M. Cathles, Larry Finger, Kate H. Hadley, Michel T. Halbouty, Philip Oxley, C. Barry Raleigh, Sean C. Solomon, Steven M. Stanley; and Joseph W. Berg, Jr., staff director.

The committees of the Board are: Committee Advisory to the U. S. Geologlcal Survey, Committee on Geodesy, Committee on Geological Mapping, Committee on Global and International Geology, Committee on Seismology, Committee on Guidelines for Paleontological Collecting, Continental Sclentific Drilling Committee, Workshop on Physics and Chemistry of Earth Materials, U. S. Geodynamics Committee, USNC/Geochemistry, USNC/Geology, USNC/International Geographical Union, USNC/International Union of Geodesy and Geophysics, and USNC/International Union for Quaternary Research.

\section{Current Program}

The Board maintains an awareness of the national, societal, scientific, and technological demands that solid-earth sciences will be expected to meet in the future and takes actions which help meet the demands. Such actions are taken using existing National Research Council activities where possible.

The Board held four briefings for members of Congress and their staffs during the past year on the topics of new initiatives in the earth sciences; geologic hazards; volcanoes; and prediction of an earthquake at Parkfield, California. The last topic was presented to the Director of the Office of Science and Technology Policy as an additional briefing. A meeting of presidents and executive directors of major earth science professional societies was held in February 1986 to help obtain the coordination, communication, and cooperation in the earth sciences. 
A workshop on the Physics and Chemistry of Earth Materials was held in April 1986 and a report on the needs of the fleld is being prepared.

A national symposium on geographical information systems is being planned for 1987 in cooperation with the U. S. Geological Survey and the Association of American State Geologists.

Products

Reports of committees of the Board on Earth Sciences during the past year are: (1) Mapping and Charting: A Perspective for the office of Charting and Geodetic Services, Committee on Cartography; (2) Geodesy: A Look for the Future (COG); (3) A Proposed Initiatlve for Capitalizing on the Parkfield, California, Earthnuake Prediction (BES); and (4) Summary of Summit Meeting of Professional Society Presidents and/or Executive Directors, February 7, 1986 (BES). 
Grantee:

Grant:

Title:

Person in Charge:
NATIONAL ACADEMY OF SCIENCES/

NATIONAL RESEARCH COUNCIL

Washington, DC 20418

DE-FG01-82ER12018

VI. Geophysics Film Committee

Barbara Valentino

Scope of Work

The Geophysics Film Committee was established in the National Academy of Sciences to provide scientific guidance for, and to ensure the sctens t1fic Integrity of, the film series entitled "Planet Earth" that was produced by PBS station WQED/Pittsburgh in association with the National Academy of sciences. The serles aired on public television beginning on January 2?, 1986.

The series includes seven one-hour films as well as a study guide entitled "Planet Earth and the New Geosciences" to be used as part of a university telecourse.

The Film Committee's responsibilities included the following tasks:

(1) Selection of specific toples and titles for the films in the serles. The areas for the seven flims are: comparative planetology, sol1d earth, resources, oceanography, climatology, solart terrestrial relations, and a concluding segment on fate of the earth.

(2) Appointment of a panel for each f1lm. Each panel required meetings of the entire panel and of selected subgroups to accomplish its tasks. Each panel (a chairman and approximately five members) has:

- worked closely with WQED to explore subtoples for its film and to identify scientists who are at the frontiers in their respective fleld of study and whose experiments are expected to have a major impact in science.

- assisted in the preparation of the film soript.

- participated as requested in arrangements for the actual filming.

$\rightarrow$ reviewed the film and its script as production progressed.

- reviewed the corresponding section in the study guide.

(3) At appropriate stages of production, the Committee met to screen and review the seven films for scientific content and accuracy, as well as to confirm that the overall theme of the series had been addressed. 
Members of the Geophysics Film Committee are: Roger R. Revelle (chairman), G. Arthur Barber, Charles L. Drake, Herbert Friedman, Laurence M. Gould, Thomas F. Malone, Stanley Ruttenberg, John P. Schaefer, Alan H. Shapley, Eugene M. Shoemaker, Walter S. Sullivan, Verner E. Suomi, James A: Van Allen, J. Tuzo Wilson, and James H. Zumberge; Barbara Valentino, staff: 


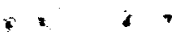

Grantee:

Grant :

Title:

Person in Charge:
UNIVERSITY OF NEVADA RENO

Seismological Laboratory

Reno, Nevada 89557

DE-FC08-86ER13628

Shallow-Crustal Magma Zones In and South of Long Valley Caldera

Scope of Work

The occurrence of an abundance of earthquakes in and south of Long Valley caldera since 1978, together with the implementation of a dense network of seismic stations funded by the USGS and DOE, have led to a library of hundreds of thousands of seismic traces. In the course of our work, we have discovered quite a few novel features on seismic records that appear directly or indirectly related to shallow crustal anomalous zones in and south of the caldera. This work compliments other programs funded by DOE and the USGS, wherein intense efforts have been made to study the subsurface structure under the caldera. Like those studies, we find evidence that magma may be occurring at shallow depths in the area south of the caldera, particularly associated with the Hilton Creek fault. The evidence consists of hundreds of anomalous seismic phases, whose existence defies explanation of terms of commonly-observed phenomenology such as phase conversions or source radiation patterns.

Reported observations support the hypothesis that a shallow crustal anomaly of significance occurs near the south end of Hilton Creek fault. Observations of a strong phase between $P$ and $S$, as recorded on a 3component wideband digital seismograph, are consistent with a lateral reflection from a shallow (1 to $1.5 \mathrm{~km}$ deep) reflector near this location. This same area is persistently aseismic, in spite of the occurrence of thousands of earthquakes in the near vicinity. This together with the evidence on S-wave shadowing provides three independent lines of evidence for the existence of this anomaly.

The work proposed for this grant is to extend our analysis of the Hilton Creek crustal anomaly, using observations of pre-S phases at 15 other stations. These pre-S observations seem to center over the south end of Hilton creek fault. In addition to a more careful search of our large data base for such phases, we intend to acquire more fundamental information on the nature of the pre-s phases. To do this, we will place a smalldimension array over the site where the pre-s phases are recorded, permitting a direct measurement of the azimuth of approach and apparent velocity of the phase. This information tightly constrains the range of possible reflection points for the pre-s phase, and allows quantitative consideration of other possible explanations (for example, $S$ to $P$ conversions on an as-yet unknown interface). 
We have observed a prers phase at the station SLK, northwest of the caldera, which has about the right time delay to be an $S$ to $P$ to $S$ conver. sion in the proposed magma zones within the Long Valley caldera. We intend to place a small-aperture array near this station to determine azimuth of approach and apparent velocity also.

A final part of this work is the placement of wideband digital in strumentation, on a permanent basis, on a hard-rock site south of the caldera. We intend to digitize the signals from 3 components at the site and transmit to Reno for recording on $1 / 2$ inch magnetic tape. The data w11l be used to provide fundamental information about the sources of the Mammoth Lakes events, including selsmic moment and the characteristic frequency of the events. 
Grantee :

Grant:

Title:

Person in Charge:
THE RESEARCH FOUNDATION OF THE CITY UNIVERSITY OF NEW YORK

Department of Geology

Brooklyn, New York 11210

DE-FG02-85ER1332

Deep-Burlal Diagenesis in Carbonates

Scope of Work

G. M. Friedman

The purpose of this study is to obtain an understanding of the processes relating to the ups and downs of porosity in carbonate rocks under conditions of progressively greater depth of burial. These processes involve both loss of porosity with depth through cementation and compaction as well as generation of porosity through deep-burial dolomitization, subsurface dissolution, and fracturing. Since porosity is the key to hydrocarbon accumulation, studies involving subsurface pore systems are critical in evaluating deep-burial reservolr potential. A related focus in this study is to gain an understanding of criterla that reflect deep-burlal diagenesis in carbonate rocks and to apply these criteria to carbonate rocks now at shallow depth that were formerly deeply buried.

During the past year the deep basin selected for study was the Permian Basin of western Texas and southeastern New Mexico. Core samples of interpreted shallow subtidal and peritidal carbonates in the Ellenburger Group (Lower Ordovician) were examined to investigate the effects of deep burlal on diagenesis. Present burial depth of core samples ranges from $5,000 \mathrm{ft}$ $(1.5 \mathrm{~km})$ to $23,000 \mathrm{ft}(7.0 \mathrm{~km})$.

Carbonates below $10,000 \mathrm{ft}(3.0 \mathrm{~km})$ are exclusively dolostone showing evidence of deep-burlal dolomitization such as the presence of coarsecrystalling dolomite, xenotopic texture, homogeneous cathodoluminescence, nigh fluidminclusion homogenization temperatures, and light oxygen isotope compositions.

Although neomorphism of older fine-crystalling dolomite occurs locally, the preservation of depositional textures in coarse-crystalline, xenotopic dolomite indicates a nonobliterative replacement or $1 \mathrm{~g}$ in in deep-burlal environments. Millimeter-size crystals of euhedral saddle dolomite are commonly observed as vug- and fracture-filling.

Dolomites are nonferrous and $\mathrm{Mg}^{+2}$ lons were probably derived from basinal brines via high porosities and fractures. Higher temperatures and longer reaction times coupled with the addition of $\mathrm{Mg}$. Ions from circulating waters are apparently responsible for deep-burial dolomitization.

Samples of saddle dolomite from outcrops in the northwestern Appalachian Basin of New York (Middle Silurian Lockport Formation) and Ozark Dome of Arkansas (Lower Ordovician Powell and Everton Formations) reveal that fracture- and vughilling late cemegts contain relatively light oxygen isotopic compositions $(-7$ to $-11 \%$ PDB $\delta(0)$ which suggest diagenetic changes occurred under deepmburial conditions, even though these rocks are now exposed on the surface. 
Freezing temperatures of the twotphase (Iiquid + vapor) aqueous fluid inclusions in late diagenetic minerals both in surface Hexposed and deeply buried carbonates indigate very saline precipitating fluids with a considerable amount of $\mathrm{Ca}^{+2}$ in addition to $\mathrm{NaCl}$ in the solution. High homogenization temperatures (uncorrected for pressure) in the range of about 100 to $260 \mathrm{C}$, are linked to formation under deep"burlal conditions.

Under normal geothermal gradients of $25^{\circ} \mathrm{C} / \mathrm{km}$, measured in the study areas, the homogenization temperatures of fluidinclusions in late diagenetic cements in the range of $150 \pm 50^{\circ}$ require maximum depths of burial of about $5,000 \mathrm{~m}$ for the Lockpor $\bar{t}$ strata in the nor thwestern Appalachian Basin. A temperature range of $135 \pm 25^{\circ}$ for the Powell strata in the 0zark Dome requires burial depths of a maximum of about $4,250 \mathrm{~m}$. These interpretations lead to frightening questions: what was the paleogeography before removal of these strata and what happened to the great thicknesses os strata that have now vanished.

Our investigations on saddle dolomite from surface-exposed carbonates showed a non-ideal, non-stoichiometric dolomite with an average composition of $\left(\mathrm{Ca}_{52}, \mathrm{Mg}_{47}, \mathrm{Fe}_{<0.01}, \mathrm{Mn}_{<0.01}\right)\left(\mathrm{CO}_{3}\right)_{2}$. The present data suggest that the crystal curvature of late saddle dolomite resulted from enrichment of calcium with respect to magnesium in the crystal lattice of dolomite. XRD studies on powdered late-saddle dolomite samples showed $d 1014^{\text {-reflection at }}$ $2.88 \mathrm{~A}$, which is consistent with ideal dolomite of $\mathrm{Ca}_{50} / \mathrm{Mg}_{50}$. Therefore, a new calibration curve for the relationship between $\mathrm{CaCO}_{3}$-content and posi-

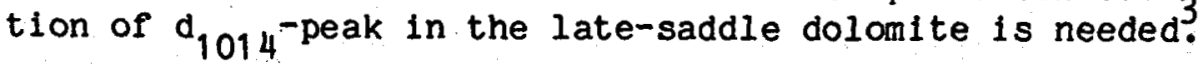


$\therefore$;,

Contractor:

Contract:

Title:

Person in Charge:

Scope of Work

Our research objective is to assess the usefulness of ${ }^{40} \mathrm{Ar} /{ }^{39} \mathrm{Ar}$ age spectrum analyses of detrital microcline in providing thermochronological information necessary for reconstructing the thermal evolution of sedimentary basins. Detrital microclines preserve a record of thermal events in the temperature range $-100^{\circ} \mathrm{C}$ to $200^{\circ} \mathrm{C}$, depending on length of heating and several mineralogical variables.

Having demonstrated the viability of this approach on deep drill core samples from a variety of active basins (San Joaquin Valley, California; Albuquerque Basin, New Mexico; North Sea Graben), our focus In 1985 was on two issues: the application of microcline thermochronology (MTC) to old basins which may no longer be at peak temperature conditions and the development of microanalysis techniques to allow measurements of single crystals.

The most useful application of MTC is to older basins which have experienced retrograde temperature histories. Both economic assessment and geodynamic analysis of basins are complicated in cases where peak temperatures and heating durations are now known. We are investigating drill core samples from the Anadarko Basin, Oklahoma, in this role as it is suggested that peak temperatures were reached during the Tertiary. We sampled wells containing the "granite wash" lithology (coarse mlcrocline bearing granitold clasts) and preliminary analyses reveal these samples to be excellent monitors of basin thermai history as sufficient material for isotopic measurement was obtained from single clasts avolding complications of mixed provenances.

To avold this general problem of analyzing aggregates of het erogeneous provenance and kinetic properties, we are developing techniques for analysis of single crystals of $\mathrm{K}$-feldspar while maintaining temperature control needed for kinetic analysis. By mating a miniaturized double vacuum furnace/extraction line with a VG 1200 s mass spectrometer, a sensitivity and background have been achleved that allow a cretaceous Kfeldspar crystal of $1 \mathrm{~mm}$ on edge to yield 20 gas fractions with < 1\% precision in isotope ratio measurement. Further development should allow us to realize analysis of still smaller crystals. 
Grantee:

Grant:

Title:

Person in Charge:
STATE UNIVERSITY OF NEW YORK

Department of Earth and Space Sciences

Stony Brook, New York 11794

DE-F G02-85ER1 3416

Geochemistry and Origin of Regional Dolomites

G. N. Hanson and W. J. Meyers

Scope of Work

The goals of this project are to develop geochemical approaches for testing models describing the geochemistry and dynamics of fluid systems responsible for the development of regional dolomites, which are major reservoirs for petroleum. The Mississippian Burlington-Keokuk Fms. of Iowa, Illinois, and Missouri, in which we have a detalled calcite cement and dolomite zonal stratigraphy, have been used for developing these approaches. $\mathrm{C}, 0, \mathrm{Sr}, \mathrm{Pb}$ and $\mathrm{Nd}$ isotopes and a range of trace elements are being used to characterize the various generations of dolomite and calcite. Quantitative approaches are being developed to predict how the isotope values and trace element abundances of the carbonates w1Il vary depending on the extent and mechanism of fluid-rock interaction and the composition of the fluid. Approaches that will allow one to determine how and when dolomites and their porosity formed will help in evaluating the potential of a given carbonate sequence as a petroleum reservolr.

Petrographic studies of the Burlington-Keokuk Fms. have defined the essential framework for our geochemistry. Specifically, the cathodoluminescent petrography has defined 7 calcite cement zones that can be mapped throughout the approximately 80,000 square kilometers of our study area. The oldest four zones have been dated as pre-Pennsylvanian, possibly pre-st. Louis, based on petrography of paleokarstic features and distribution of cement zones. The younger two zones are probably Pennsylvanian in age. The cement stratigraphy has given the foundation for a detalled paragenetic sequence that includes dolomites, cherts, compaction, and Mississippi Valley Type mineralization.

Petrographic work has also defined three regionally extensive dolomite generations, which based on geometric relationships with the calcite cement zones can be dated. Dolomite I pre-dates all except the oldest cement and therefore is clearly pre-Pennsylvanian. Dolomite II pre-dates the youngest two Pennsylvanian calcite cements and therefore is probably prePennsylvanian. Dolomite III also pre-dates the youngest calcite cements, but could be Pennsylvanian.

Porosity is largely restricted to dolomites, with intercrystalline pores being the most important. Porosities range up to $40 \%$, and are commonly partly plugged by late stage cements, chert, and microcrystali ine non-carbonate phase.

$$
-158-
$$


Dolomites I and II are the most important and are geochemically distinct. Dolomite I contains less $\mathrm{Fe}, \mathrm{Mn}$, and $\mathrm{Mg}$ than dolomite II, and dolomite III is the most enriched in $\mathrm{Fe}$ and $\mathrm{Mn}$. These data indicate that dolomitization was a protracted process in which less stolchiometric dolomite was replaced on a regional scale by more stolchiometric and more $\mathrm{Fe}$ and Mn rich dolomites.

Dolomite I has $\mathrm{Sr}$ isotope ratios near estimated Mississippian seawater values, 0 isotopic compositions near expected seawater dolomite values but depleted $C$ isotopic compositions. By comparison, dolomite II has radiogenic $\mathrm{Sr}$ and markedly depleted 0 isotopic compositions.

Rare earth element (REE) profiles for all the dolomites are similar as are Nd isotopic compositions. These are similar to those of coeval shaly units with the important difference that the dolomites have a distinct negative Ce anomaly, which is interpreted as an original seawater signature.

We interpret these data to indicate that dolomitizing fluids significantly altered the $\mathrm{Sr}, \mathrm{C}$, and 0 isotopic compositions and $\mathrm{Fe}, \mathrm{Mn}$, and $\mathrm{Sr}$ abundances of precursor carbonates, whereas the REE patterns and Nd isotopic compositions are inherited from Mississippian seawater. The REE are reset only in carbonate gangue minerals associated with minor Mississippi Valley Type deposits which indicates that the REE are affected in the carbonates only when the extent of water to rock interaction is large.

Due to the relatively $h i g h \mathrm{Rb} / \mathrm{Sr}$ ratios in dolomites $\mathrm{I}$ and $\mathrm{II}$, which are a result of minor, but significant, amounts of clay (mainly glauconite), it is necessary to correct for the in situ growth of radiogenic $\mathrm{Sr}$. This correction is possible, because the glauconite can be shown to be authigenic or, when diagenetic, coeval with the dolomites which formed during the Mississippian.

We have good estimates, based on compositions of pristine brachiopods, of the $\mathrm{C}, \mathrm{O}$, and $\mathrm{Sr}$ isotopic composition of Mississippian seawater. These are probably better than any previous estimates.

Stable isotope, Fe and Mn compositions of dolomite I and II show regional variations which we are using to interpret regional flow direch tions of dolomitizing fluids.

Crinoids show linear covarlance of $C$ and 0 isotopes within a single measured section, and show a regional variation in $C$ isotopes, which most likely reflects the chemistry of the early diagenetic fluids.

The occurrence of radiogenic Sr in brachiopods and crinolds which have marine $C$ and 0 isotope values suggest the possibility that an early diagenetic fluid was a brine with relatively radiogenic $\mathrm{Sr}$.

Preliminary quantitative geochemical modeling suggests that dolomite I may have resulted from a range of mixtures of seawater and fresh water, and dolomite II may have resulted from interactions between brines and dolomite I. 
Taken together the petrography, distribution and geochemistry of diagenetic phases suggests a regional model involving southward flowing fresh waters forming early calcite cements and interacting with seawater to from dolomite $I$, and involving generally northward and upward flowing brines forming dolomite II and probably dolomite III.

Our future research will comprise use of the Burlington-Keokuk Fms. as a proving ground for developing other new geochemical approaches. One of our long term goals has been to apply approaches developed in the Burlington-Keokuk study to dolomites in other tectono-sedimentary settings and in strata of more direct economic interest. We are doing this through our recently initiated studies in Devonian carbonates in Alberta and in the Canning Basin region of Western Australia. 
Grantee:

Grant:

Title:

Person in Charge:
UNIVERSITY OF NORTH CAROLINA

Department of Geology

Chapel Hill, North Carolina 27514

$D E-F G 05-85 E R 13414$

Activity-Composition Relationships in Silicate Melts

A. F. Glazner

Scope of Work

The purpose of this investigation is to gain insight into the relationship between the composition of a magma and its thermochemical properties. These studies are useful for understanding the energy balance in a cooling magma body and for using samples of crystallized magma to infer the pressure-temperature conditions of crystallization.

Current Activities (A. F. Glazner, W. Ussler III)

A. One-Atmosphere Experimental Studies of Magmas

We recently completed construction of a one-atmosphere, gas-mixing furnace laboratory which will be used for studies of crystal-melt relationships in mafic and intermediate magmas. The first set of experiments is a study of phase relationships along a basalt-rhyolite mixing line. Initial results indicate that the liquidus of magmas produced by magma mixing is significantly higher in temperature than the liquidus of a magma of comparable silica content produced by crystal fractionation. In addition, magnesian olivine is the liquidus phase in mixed magmas up to high-silica andesite composition. These relationships mimic relationships seen in natural magmas of mixed parentage.

Future experiments will be used to improve the calibration of olivinemelt and plagloclase-melt geothermometers. Existing experimental data on the compositions of coexisting crystal-melt palrs is confined to natural compositions. Our experiments will explore comositions outside the natural trend by doping natural compositions with single oxides or oxide mixtures. These experiments will allow the effect of a given melt component $\left(e .8,, K_{2} 0\right)$ on a given mineral component $(e . g$. , forsterite) to be isolated.

B. Depth of Magma Chambers

The one-atmosphere olivine-melt and plagloclase-melt geothermometers can be combined with high-pressure experimental data to produce an olivine-plagioclase-melt thermobarometer. We have applied a preliminary calibration of this method to Quaternary basalts from Pisgah and Amboy Craters in the Mojave Desert. These results indicate 
that olivine and plagloclase phenocrysts in the basalts grew in uppermantle magma chambers, at 30-35 km depth. One-atmosphere melting experiments on one of the basalts yield a crystallization sequence that is significantly different from the sequence observed in the rocks. The difference in crystallization sequence is consistent with the hypothesis that the phenocryst assemblage grew at high pressure. Neither of the volcanoies is associated.with rhyolite. These results indicate that some basalt volcanoes are not associated with rhyolite because they do not establish magma chambers in the crust. We have collected several basalt samples from bimodal basalt-rhyolite fields in California in order to see if these basalts predict crustal depths for olivine-plagioclase-melt equilibration.

C. Enthalpy-Compositions Relationships in Magmas

The cooling history of a magma body depends upon the relationship between enthalpy $(H)$, temperature $(T)$, and composition $(X)$. Although temperature is routinely controlled as an independent variable in experimental petrology, in nature temperature is a dependent variable whose value depends upon the total enthalpy of the system. We hre developed a computer program whlch allows the enthalpy of a magma, relative to an equivalent crystalline assemblage at $298^{\circ} \mathrm{K}$, to be calculated. Calculation of H-T-X diagrams for simple binary phase diagrams (e.g., forsterite-quartz) indicates that inferences about cooling history derived from standard $\mathrm{T}-\mathrm{X}$ diagrams may be greatly in error. For example, these diagrams indicate that a model magma body that cools by loss of heat at a constant rate will spend a large amount of time at invariant points, where the temperature is constant.

Magma mixing can be considered to be a constant-enthalpy process, as a first approximation. Construction of $\mathrm{H}-\mathrm{T}-\mathrm{X}$ diagrams for the magmamixing experiments described above will allow estimation of the temperature and phase assemblage present in a mixed magma, given the temperatures and compositions of the magmas being mixed. 
$x+1$

Grantee:

Grant:

Title:

Person in Charge:

UNIVERSITY OF OKLAHOMA

School of Geology and Geophysics

Norman, Oklahoma 73019

DE-FCO5-85ER 113412

A Study of the Source Material, Mechanisms of Generation, and Migration of 011 s in the Anadarko Basin, Oklahoma

R. P. Philip

\section{Scope of Work}

The major objectives of this research are designed to study the origin and migration pathways of olls in the Anadarko Basin, Oklahoma. Despite the large quantitles of 011 and gas produced from this basin a great deal of uncertainty remains concerning the source(s) of the major oil accumulations. The organic geochemical approach being used in the study makes extensive use of the blomarker concepts for unraveling source relationships and migration pathways. Migration mechanisms of crude oils is an area that is not well understood at this time. If relationships can be established between specific families of oils and their suspected source rocks in this basin, it will provide an opportunity to study both the mechanisms of primary and secondary migration and the effects of migration on crude oll composition.

In the first year of this study a great deal of time has been spent in the collection of crude olls and suitable source rock samples from throughout the basin. 011 samples from different producing horizons have been collected an a number of these samples from specific locations have been fractionated and analysed by gas chromatography-mass spectrometry (GC/MS). The source rock samples that have been obtained are also being prepared for analysis.

The major emphasis of this study is evaluating, on a basin-wide scale, the or 1 in and migration of the Anadarko Basin olls. In addition, two more locallzed geochemlcal studies have also been initiated within this basin. The first involves a study of a number of oll seeps, occurring in the Ordovician 011 Creek Sandstone, that have been biodegraded to differing extents. Preliminary analyses of the seep samples show that extent of alteration ranges from extreme at the surface to samples at a depth of 240 $f t$ that show the presence of $n$-alkanes and hence as such are probably unaffected by biodegradation. Al'ternatively, the deeper samples may be mixtures of altered and unaltered olls, with the unaltered samples being responsible for the addition of the $n$-alkanes. The aim of this work is to study the sequential effects of blodegradation on the biomarkers typically used in oll/source rock correlation studies and to use the results in future interpretations of data thought to have been affected by biodegradation. 
The second smaller and more localized study involved oils and source rocks from the Pauls Valley area of the Anadarko Basin. In this region a detalled study of the blomarkers in 25 oils mainly from the Simpson Group and 10 source rock samples has shown that the majority of oils present in the Viola Formation are derived from a similar source of material. The second step of this project will be to examine the potential source rocks in order to determine the origin of the o1ls in this region. 
$\because 1+1$

Grantee:

Grant :

Title:

Person in Charge:
UNIVERSITY OF OKLAHOMA

School of Geology and Geophysics

Norman, Oklahoma 73019

DE-FG05-86ER 3470

Workshop in Continental Sclentific Drilling

Scope of Work

A workshop was held at the University of Oklahoma, Norman, in January 1986, to discuss the role of organic geochemistry in the Continental Sclentific Drilling Program. A number of speakers made presentations on topics that it was felt could benefit from this program. In particular the areas of migration of fluids, origin, and stability of deep gases and microblal activity at depth were discussed in detall. In addition to the formal presentations, a number of discussion sessions were held. In these, topics such as sample collection protocol, possible drilling targets, scientific program, and how to continue the effort were all discussed.

It was felt that from an organic geochemical point of view, the drilling of a series of shallow holes would be more beneficial than one deep hole. Such an array would permit a detalled study of migration to be undertaken. Migration is an area of geochemical research currently receiving a great deal of attention. No particular drilling targets were delineated. However, it was felt that it would be most advantageous to interact as closely as possible with researchers proposing to drill holes in various areas. In this way, if any sedimentary sequences were drilled, organic geochemists would be ready to analyze the samples.

In brief, this workshop was successful in arousing the interest of organic geochemists in the CSDP. As a result of this workshop, organic geochemist representatives have attended a number of subsequent workshops to make an input into a number of other driling programs. A final report for the workshop is currently being finalized and should be ready for circulation to attendees in June. 
Grantee:

Grant:

Title:

Person in Charge:
THE PENNSYLVANIA STATE UNIVERSITY

College of Earth and Mineral Sciences

University Park, Pennsylvania 16802

Objectives

The principal objective of the study is to seek an understanding of the processes involved in the transformation of 1igno-cellulosic cell walls of higher plants into coal-forming entities during the early stages of coal formation.. It is felt that this is one valid and potentially valuable approach to solving the problems of coal structure.

\section{Scope of Work}

The tactical approach has been to select samples of very immature coals that exhibit differing degrees of preservation of woody structure, and examine them by optical microscopy, using transmission of light through thin sections, with and without polarizing screens, and fluorescence ex cited by blue or U.V. 11ght. Specimens characterized in this way were then studied by Fourler Transform Infrared spectroscopy, ${ }^{13} \mathrm{C}$ NMR and varlous pyrolysis/mass spectrometric techniques. Samples from three different sites were avallable, but most of the work was on a large set of samples collected from the Brandon lignite in Vermont; plants whose remains are seen in this lignite include many of these now populating parts of the Okefenokee Swamp in Georgia and the Everglades of Florida. A number of samples of peatified wood were included in the microscopic studies, in order to document the earliest changes and provide materials for comparison.

\section{Principal Accomplishments}

It was observed that roughly $10 \%$ of the Brandon lignite seam consisted of material having the external morphology and texture of blocks of wood of varying degrees of preservation. Woody material of this $k$ ind has been noted in some other lignite seams, and referred to by others as "coalified logs". The rest of the seam had evidently been through a process of "gelification", which destroys the macroscopically visible woody structure. Microscopic examination of sections showed that the degrees of preservation of the walls of vessels relative to tracheld cells varied within a block of woody material, but generally these tended to show increasing swelling and distortion of cell walls towards the outer margin of the block. FTIR spectra of inner zones of several blocks did not differ as much as dif ferences in cell wall preservation would suggest. However, the bands were relatively sharp and quite closely resembled those of lignin; not much evidence of preservation of polysaccharides could be seen. 
The infrared spectra of the gelified material or "matrix" showed broad bands and closely resembled those prevlously published for lignites. Spectral subtraction routines indicate that the outermost margins of woody blocks were mixtures of gelified with lignintilke material.

${ }^{13} \mathrm{C}$ NMR spectra (CPMMAS) showed major differences in chemistry between matrix and woody material. The latter evidently is phenolic and retains some methoxyl groups; experience of some degree of oxidation was indicated by the presence of some $C$ in carbonyl groups.

It was observed in the pyrolysis studies that there appeared to be a correlation between the intensity of cell wall birefringence of peatified wood and the abundance of hexosan derivatives from cellulose in pyrolys1s/GC/MS traces. As one compares the mass spectra in the sequence fresh plant, peatifled wood, Brandon woody samples, a series of chemical changes are evident, including demethylation and demethoxylation. However, the altered lignin remains mostly in polymeric form. Pentosans from hemicelluloses and perhaps bacterlal sources disappear quite early in the sequence, but a little cellulose can persist in coalified logs.

The phenomenon of gelification in coal formation has been known to coal petrographers for at least 25 years. It was thought that this was a process that always occurred as a stage in coalification, having the effect of converting the morphology and anatomical structure of wood to the relatively poorly structured huminitic and vitrinitic macerals. This is no doubt still a reasonable view, with the added implication that destruction of morphology is accompanied by extensive alteration of the chemical structure of lignin and any other remaining plant polymers.

The occasional occurrence of coalified logs in coal seams has also been on record for some time. It is now known, from our work and that of others, that coalified logs can retain much of the chemistry of lignin (and, in some cases, cellulose), as well as retaining the texture and external morphology of wood. The distinctive feature of our study is that the samples that were studied chemically had first been carefully characterized botanically. It was in this way possible to show that preservation or anatomy and of chemistry go hand in hand; if one occurs, so does the other. However, how and why some woody material in a peat swamp or marsh can escape gelification while the rest of the sediment becomes lignite is st1ll far from clear.

It is probably best to regard coalified logs as fossils, well-preserved for some adventitious reason, and representing a stage most of the coal went through much earlier. This view is supported by the microscopic studies referred to, whlch show that differing degrees of swelling, gelification and granularity can be observed in different tissues of the same peat sample. Like everything else about coal, its diagenesis and metamorphism are heterogeneous. 
The evidence certainly favors chemically altered lignin as the principal (but by no means the only) precursor of coals. As water is squeezed out of the young sediment during induration, and exposure to somewhat elevated temperatures is experienced, slow reactions in the solid state will further alter the polymeric lignin-related materials, and initiate cross-linking into the threedimensional network macromolecular structure characteristic of mature vitrinites. It should be noted that polysaccharides readily dehydrate to aromatic (phenolic) structures on low temperature pyrolysis, and so, to the extent that their carbon survives in coals, they will no longer be recognizable as such.

A Final Report is in preparation. 
Grantee:

Grant:

Title:

Person in Charge:
PRINCETON UNIVERSITY

Department of Geological and Geophysical Sciences

Princeton, New Jersey 08544

DE-FG02 $85 E R 13437$

Silicate, Aluminosilicate and Borosilicate Melts: Thermochemical Studies by HIgh Temperature Calorimetry

A. Navrotsky

Scope of Work

High temperature solution calorimetry is used to determine heats of mixing in aluminosilicate and borosilicate glasses and melts. The substitution of $B$ for $A 1$ along the foin NaAlsi, 0 , has been studied by calorimetry and NMR spectroscopy. The energetics of mixing are complicated by the presence of some nontetrahedral $B$ and $A l$ at intermediate compositions. Heats of mixing in ( $\mathrm{Li}, \mathrm{Na}) \mathrm{AlS}_{3} \mathrm{O}_{2}$ glasses are being studied and correlated with other manifestations of the "mixed alkali effect" such as electrical conductivity. We are continuing the modeling of phase equilibria. The emphasis is on ascertaining the usefulness of the twolattice model for the entropy of mixing and in developing more appropriate complex structural entropy models.

Hydrous glasses and melts in the system albite-water have been studied in three ways. Drop calorimetry (hot furnace to $85^{\circ} \mathrm{C}$ calorimeter) at high pressure measured heat contents. Transposed temperature drop calorimetry (room temperature to hot calorimeter) measured the heat of evolution of water from a hydrous glass. The heat of solution of the resulting anhydrous decrepitated powder was measured by oxide melt solution calorimetry. The results indicate small exothermic heats of solution of $\mathrm{H}_{2}$ 0 in albite glass and melt. The enthalpies of mixing become more ideal with increasing temperature and show their largest magnitude at compositions corresponding to maximum $\mathrm{OH}$ concentrations.

A Setaram $1500^{\circ} \mathrm{C}$ calorimeter has been used for transposed-temperaturedrop (cold to hot) calorimetry. The heat of fusion of diopside has been measured directly (by the melting of crystal), confirming earlier values obtained by conventional drop calorimetry (which produces glass) and heat of solution of glass and crystal. The incongruent melting of diopside was observed directly in calorimetry at $1350-1390^{\circ} \mathrm{C}$. The heat capacities of the supercooled liquid (glass taken above $\mathrm{Tg}$ ) and of the stable 1 lquid are similar. Work on albite and on $A b-A n^{-D} 1$ is in progress.

A solution calorimetric study of glasses in the system An-Di-Fo will commence as soon as the calorimeters are operating at Princeton. Much of late 1985 and early 1986 were taken up with moving the labs from Arizona State University to Princeton University. All equipment should be fully functional by summer 1986. 
The data and models developed in this work are correlated to the struch ture and physlcal properties of silicate melts and have potential applications in such diverse fields as geochemistry, magma energy gener ation, ceramic science, nuclear waste disposal, and reactor safety. 
Grantee: SOUTH DAKOTA.SCHOOL OF MINES AND TECHNOLOGY Rap1d City, South Dakota 57701-3995

Grant :

DE-FG01-84ER+13259

Title:

Thermally Induced Chemical Migration:

A Natural Analog Approach

Person in Charge:

J. J. Papike

Scope of Work

The major objective of this research is to gain a quantitative understanding of chemical migration in the geolog1c environment over a range of temperatures and pressures and in diverse geolog 1c media. Contact metamorphic occurrences serve as geologic analogs for the underground storage of nuclear, waste, with igneous intrusion providing the heat and trace element source, and the country rock the medium through which migration takes: place. The specific sites for this studyare pegmatite/wallrock interaction zones in the Black Hills, South Dakota. This type of study provides information on chemical mignation over geologic times, a time span that cannot be duplicated in laboratory experiments or with presently available calculation procedures.

\section{Some Findings from Pegmatite/Wallrock Studies}

T. Exsolution of a fluid phase during crystallization of a volatile-rich pegmatitic melt provides a medium for fluid transport of relatively incom patible elements out of the pegmatite system and into surrounding country rock: Interaction between pegmatite-der 1 ved fluids and country rock can result in the formation of extensive exomorphic aureoles. Compositional characteristics of these aureoles are dependent upon fluid composition and therefore provide an indirect method for constraining the chemistry of pegmatite fluids. Aureoles adjacent to three Black Hills pegmatites (Etta, Peerless, Bob Ingersoll I) 11 lustrate the relationship between aureole characteristics, pegmatite mineralogy and possible fluid composition. The aureole associated with the Etta pegmatite (spodumene-bearing, tourmalinepoor) Is enrlched in alkall elements (Rb, Cs, L1), whereas the aureoles associated with the Peerless and Bob Ingersoll I pegmatites (spodumene absent; tourmaline and lepldolite or lithia mica bearing) are enriched in alkall elements, F and $B$. Fluld compositions approximated from trace element modeling and extent of halogen substitution in sheet silicates indicate pegmatite-derived solutions have relatively high solute concentrar tions (alkall elements) $1000 \mathrm{ppm}$ ) and exhlbit compositional differences between pegmatites. The most noticeable differences in fluid compositions are (1) alkali element ratios $\mathrm{Rb} / \mathrm{Cs}$ and $\mathrm{Rb} / \mathrm{Ll}$ decrease in the order Peerless $\triangle \mathrm{Bob}$ Ingersoll I Etta, $F(2)$ boron content is relatively high in the fluid phase derived from the Bob Ingersoll I and Peerless pegmatites, and (3) $\log \left[\mathrm{f}\left(\mathrm{H}_{2} \mathrm{O}\right) / \mathrm{f}\right.$ (HF)] of the fluid phase assoclated with the Bob Ingersoll $I$ and Peerless pegmatites may be responsible for the stabllity of lepidolite and 1 ithia mica relative to spodumene in these pegmatites.

$$
-171-
$$


Grantee:

Grant :

Title:

Person in Charge:
SOUTH DAKOTA SCHOOL OF MINES AND TECHNOLOGY

Rapid City, South Dakota 57701+3995

DE-FG01-85ER13407

Cores from the Salton Sea Scientific Drilling Program: Metamorphic Reaction. Progress as a Function of Chemical and Thermal Environment

J. J.Papike and C. K. Shearer

Scope of Work

We are studying the downhole progressive metamorphism at the Salton Sea site by means of monitoring and evaluating discontinuous and continuous metamorphic reactions with emphasis placed on (1) the progress of reack tions, (2) mineral-fluid reactions and interaction of rock with external fluid reservoirs, (3) volatile species evolved and consumed during reactions, (4) changes in style and progress of metamorphism with changes in original porosity and fluid flow, (5) evaluation and correlation of mineral phases and organic material geothermometry, and (6) alteration and developi ment of oxide mineralogy.

Variables such as temperature, pressure, fluid composition, and fluid flow-porosity can be measured in situ. The correlation of mineral assemblages, mineral chemistries, and mineral reactions with these measured variables will provide invaluable insight into the dynamics of metamorphism.

The initial phase of this study is to Identify stable mineral as semblages and to document variations in mineral chemistries. Preliminary modal analysis and interpretation of textural relationships between mineral phases can be performed using standard petrographic techniques. A random orlentative X-ray diffraction technique will be used to ensure statistical relevance of the modes and to determine the modal mineralogy of finegrained metamorphic rocks. This X-ray technique has been developed into a routine and reliable methodology at the South Dakota School of Mines and Technology. Mineral chemistries will be determined by electron microprobe. Using these data with temperatures measured in situ, isothermal compositional diagrams can be constructed and the sequence of prograde continuous and discontinuous reactions can be identified.

This work is being done in collaboration with J. C. Laul (Pacific Northwest Laboratories), who is conducting the INAA and RNAA analyses. 
Grantee:

Grant:

Title:

Person in Charge:
UNIVERSITY OF SOUTHERN CALIFORNIA

Department of Geological Sclences

Los Angeles, California 90089-0741

DE $-F G 03-85 E R 13336$

Continental Scientific Drilling Program: The Seismology of Continental Thermal Regimes

K. Ak1

Scope of Work

This program was started as an involvement in two major geothermal projects; namely, the Hot Dry Rock Geothermal Energy Development Project of the Los Alamos National Laboratory and the Magma Energy Project of Sandia National Laboratories. The theory and methods developed for interpretation of various seismic experiments conducted at Fenton Hill, New Mexico, and Kilauea IK1, Hawa11, however, found a variety of applications to other geothermal areas and volcanoes, and our research has been evolving into what might be called volcanic selsmology.

In this program we are applying the methods of passive selsmology using natural selsmlc sources occurring in geothermal areas as well as active selsmology using artificial sources to the candidate sites for the CSDP, such as Long Valley and Jemez Mountains, in order to delineate the geometrical and mechanical properties as well as the mass and energy transport mechanism of the geothermal system.

During the past year, we have accomplished the following work, covering both experimental and theoretical aspects of the project: completing a review paper of the origin of volcanic tremors; initiating study on seismic signals attributed to tensile cracks (so call long weriod events) discovered at the Los Alamos Hot Dry Rock site; initlating theoretical study on slow waves trapped in a fluid-filled crack for modeling long-period events; inftiating a pllot study on borehole seismic experiments at Oroville, Callf and discovering gulded waves trapped in a fault zone; initiating a simultaneous interpretation of borehole seismic data and surface seismic data for a quantitative characterization of subsurface material; archiving and processing U.S.G.S. selsmic data from geothermal areas as the SLAC computation center and monitoring coda $Q$ for prediction of earthquakes and volcanic eruptions; further confirming and study ing theoretically the distinct difference in the frequency local, reglonal and teleselsmic data in the Jemez Mountains by a network of digital event recorders, and participating in planning the Katmal Scientific Drilling Project. 
Grantee:

Grant:

Title:

Person in Charge:
STANFORD UNIVERSITY

Stanford, California 94305

DE-FG03-86ER-13601

Porosity with Fluids: Origin and Effects on Physical Properties of Crustal Rocks

Scope of Work

The general objective of the past year's work was to continue: our investigations of physical phenomena in cracked and porous rocks with fluids, and to apply the results to geophysical exploration, reservoir evaluation, and the study of shall crustal processes.

(1) Wave propagation. We extended the study of velocities in clay bearing rocks to poorly-consolidated and unconsolidated sandstones. We have obtalned velocity and porosity vs. pressure data for sandiclay mixtures as well as for clean sand and pure smectite clay. We have discovered, in surprising contrast to consolidated sandstones, that the presence of clays in unconsolidated sand causes velocity to increase. This effect is probably due to the flling of grain contacts and the space between grains with clays. We have set up a proadband ( $5 \mathrm{KHz}$ to $1 \mathrm{MHz}$ ) acoustic system to study velocities and $Q$ vs. frequency in porous rocks. The system has been completed, and results for Berea were obtained: We have found that $Q^{-1}$ varles with frequency, and that this variation depends on saturation. The results will provide for much better interpretation of seismic data for exploration and crustal studies.

(2) Dielectric properties. We have measured the dielectric constant of rock as a function of saturation and frequency. We have dis covered that the dielectric response of porous rocks is controlled by the surface area density of the pore space (pore surface area/porosity). Furthermore, a large and systematic hysteresis in the dielectric constant occurs between saturation and desaturation runs. This effect $*$ which was not known for rocks before $\rightarrow$ is most likely due to the way water in partially saturated pore space organizes itself. The results have fasoinating potential applicat tions for logging in gas or steam bearing reservoirs.

(3) Network modeling. We have developing a rigorous inversion method, to obtain rock state parameters (porosity, clay content, etc.,) from physical measurements on rock. The method is based on maximum entropy consideration, and has been applied to cracked rock. A related model was developed to relate the exponent $m$ in Archies law to the distribution of pore shapes within a given rock. It appears that for a given porosity, $m$ is strongly 
dependent on the distribution of pore shapes thus promising to provide constraints on the inversion of electrical resistivity data. Furthermore, a program has been written and tested, using a boundary elements algorithm, which enables us to obtain the elastic response of arbitrarily shaped pores very rapldiy. This very efficlent progran has now been placed on a $5: 1 / 2 "$ floppy disk, and is routinely run on an IBM PC or equivalent. It is thus possible, for the first time; to compute elastlic response for pore shapes which cannot be handled analytically on the one hand, or for which finite elements or finite difference methods are much too cumbersome.

(4) Nuclear magnetic resonance studies (NMR). We have found that the intensity of magnetization in some rocks is greater when they are partially saturated with water (typlcally around: $60 \%-70 \%$ water saturation) than when they are fully saturated. This discovery has already led to heated, if not virulent debate among several physlcists who work on rock NMR $<$ with some olaiming that the effect must be wrong, whereas others consider the discovery to be a break through in NMR and NML logging. 
Grantee:

Grant:

Title:

Person in Charge:
STANFORD UNIVERSITY

Department of Applied Earth Salences

Stanford, California 94305

DE-FC03-85ER13319

Structure and. Emplacement of the Inyo Domes Intrusion, Long Valley, California

\section{Scope of Work}

When a silicic dike intrudes to within a few hundred meter of the Earth's surface, several processes become important which may eventually control the character of the eruption. These processes include the development of fissures and faults at the surface above the dike, growth, and disruption of vesicles (Elchelberger et al., in press), mixing of magma with groundwater, flashing of groundwater to steam near the dike, and extensive brecciation of the host rock.: The objective of this project is to understand the roles of some of these processes in the emplacement of slicic dikes using the Inyo Domes Volcanic Chain near Mammoth Lakes, California, as an example.

Several features at the Inyo Chain make 1t an unusually good location for such a study. At the south end of the chain, a set of prominent phreatic craters (the Inyo Craters),. normal fault scarps, and open fissures indicate that the Inyo Domes dike came within a few hundred meters of the surface. Unlike many other places, these features were not destroyed by subsequent eruptive activity: At the north end of the chain, two core holes have been drilled into the feeder conduit beneath one of the domes (Obsidian Flow), and into a dike between two of the domes. The core contains zones of extensive brecciation of the granitic host rock near both the dike and the conduit. Within $\$ 30$ meters of the dike, fractures of a variety of orientations are filled with granitic, and in a few places, magmatic debris which was apparently injected during emplacement of the dike.

During the 1985 calendar year, the following studies were conducted:

(1) A 1:6,000 scale map was prepared of fissures, faults and craters in a 1.0 by 1.5 kilometer area around Inyo Craters (Mastin and Pollard, 1985b). The pattern of these features indicates that the area is underlain by two left stepping, north-northeast trending en echelon dike segments. The eastern dike lies beneath Inyo Craters. The western one underlies South Deadman Dome. The spacing and cumulative opening displacement on fissures and faults immediately south of Inyo Craters suggest that, in this area, the dike is no more than a few hundred meters beneath the surface, and is at least a few tens of meters wide. This map and our interpretation of the subsurface structure will be used to locate future drilling sites. 
(2) Deformation around several possible arrangements of en echelon dikes was modelled using two programs: a boundary element program for elastic stress around cracks under twodimensional plane strain loading (Mastin and Pollard, 1985a); and a dislocation program for stress and strain around opening mode dislocations in an elastic half space. The results of these models: (1) support the fleld evidence for two en echelon dikes in the Inyo craters area; (2) suggest that the westernmost dike extends farther south near the surface than is indicated by the surface evidence; (3) indicate that the dike beneath Inyo Craters is either vertical or dips 70 or more degrees to the east. A manuscript for submission to the Journal of Geophysical Research, covering this modelling and the mapping described is in preparation.

(3) Preliminary petrographic studies were made of deformation and filled fractures in the core from the dike and conduit holes. The wide varlety of filled fracture orientations indicates that the fluid pressure in the fractures was greater than the least compressive stress by a magnitude equal to a significant fraction of the difference between the greatest and least stresses. It is remarkable that the brecclated host rock Immedlately around the dike contains no obvious magmatic debris in hand sample or thin section. Unlike some maflc intrusions (Sheridan and Wohletz, 1983), intermixing of fragmented magma and groundwater apparently was not an important mechanism of heat transfer from magma to groundwater.

For calendar 1986, the following studies are planned or in progress:

(1) The strat1graphy and petrology of hydroclast1c debris around Inyo Craters will be mapped and examined. The objectives will be, among other things, to determine the type and history of the eruptive events, and to identify the sequence of crater development.

(2) Scanning electron microscopic studles, mlcroprobe work, fluld inclusion analysis, and additional petrographic work will be done on the breccia and fracture fillings in the core near the dike and the condult. The objectives of the core studies will be to estabilsh whether there is any magmatic debris mixed with brecclated host rock near the dike margins, to identify how the breccia formed, and to determine the temperature and phase relationships (steam versus water) of breccla-forming fluids in the host rock. 


\begin{abstract}
Grantiee:
TEXAS A\&M UNIVERSITY

Department of Geophysics and

Center for Tectonophysics:

College Station, Texas 77843

Grant :

DE-FG05 86 ER 13165

Title:

Stress-Induced Seismic Anisotropy

Person in Charge:

R. L. Carlson

\section{Scope of Work}

Particle motions detected on arrays of 3-component digital seismographs and on borehole instruments used in vertical seismic profiling (VSP) and oblique seismic experiments (OSE) indicate in situ elastic anisotropy. The observed anisotropy is thought to arise from alignments of cracks which, in turn, are caused by tectonic stresses. Such interpretations are supported by theoretical and numerical models and by a few experiments conducted at low stress levels, but the phenomenon of stress-induced elastic anisotropy in rocks has not been thoroughly investigated.

We are undertaking a series of laboratory experiments with the aim of ascertaining the effects of deviatoric stress on rocks containing natural. microcracks. More specifically, our objectives are: (1) to relate the dynamic elastic stiffness tensor to the stress tensor for different stress fields; (2) to determine how the elastic stiffness coefficients are affected by the level of stress; and (3) to replicate fleld observations in the laboratory under known stress conditions.

The materials used in these experiments will be Westerly Granite and Maryland Diabase. Specimens will be machined to form cubes $15 \mathrm{~cm}$ on a side, and suitably oriented $P$ - and Smave ceramic transducers will be mounted on the faces, edges, and corners of the cubes. Dynamic elastic constants will be calculated from measured $P$ and $S$ wave velocities. Stresses up to $40 \mathrm{MPa}$ will be applied using flat jacks. The free faces of the cubes will be instrumented with strain gauges to monitor the uniformity of the applied stresses. Replication of fleld experiments will be done using transducers mounted on the free faces of the specimens.
\end{abstract}




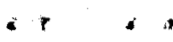

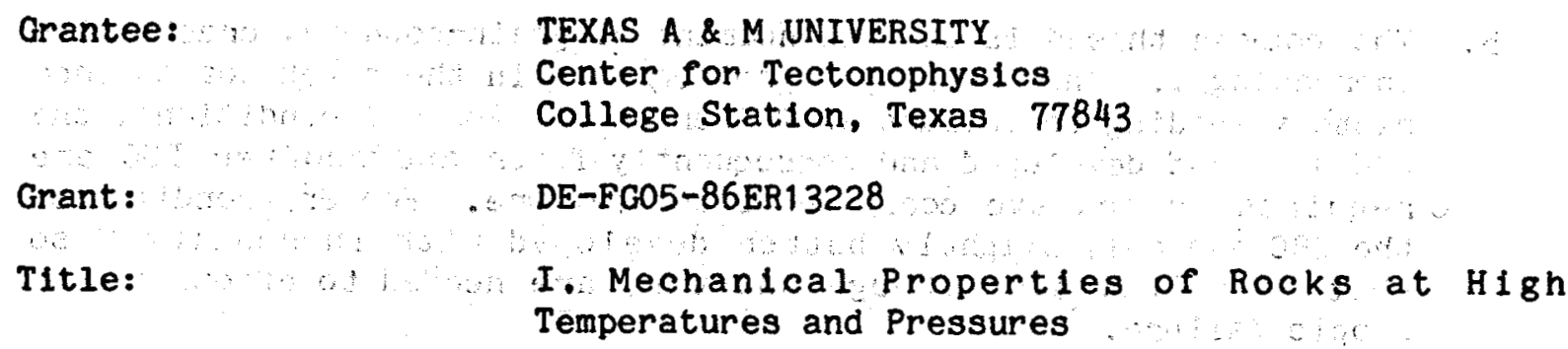

Person in Charge:

Scope of Work

In continuation of our studies of borehole stability and the fracture of rock in environments of hot fluids, differential stress and relatively low effective pressures, we are investigating the (1) tensile strengths of Sloux quartzite and Westerly granite, (2) fracture surfaces and microfracture types, abundances and coalescing tendencies in extension experiments in an effort to understand why strength decreases with increasing temperature, particularly when the specimen is water-saturated, and if fracture, is a thermally activated process, and (3) role of blotite crystals as stress concentrators and facilitators of slip leading to the semi-brittle fallure of granite. The necessity to move our experimental apparatus in advance of building renovation has delayed most of our experimentation. Results to date are as follows:

1. Five extension tests of notched Westerly granlte specimens were performed at room temperature and confining pressures between 30 and $145 \mathrm{MPa}$. Tentative corrections to the measured differential forces at catastrophic failure give an average tensile strength of about $20 \mathrm{MPa}$ and confirm the very important finding that the tensile strength of a rock is independent of the confining pressure (Pc) up to the point where $\mathrm{PC}=\mathrm{C}_{0}$, the unconfined compressive strength.

2. The ultimate strengths of Westerly granite previously deformed in extension (and used in our observational studies) decrease with increasing temperature $\left(\mathrm{T}, 25^{\circ}\right.$ to $\left.800^{\circ} \mathrm{C}\right)$, and are lower when watersaturated than when dry. Weakening with temperature $\left(600^{\circ}\right.$ to $800^{\circ} \mathrm{C}$ ) is dramat1c in the wet environment.

3. In dry tests, intragranular cracks (IGC) and grain-boundary cracks (GBC) increase in linear and areal density (abundance) with increasing $T$ at constant confining pressure ( $P C$ ); ICC increase in abundance with increasing $\mathrm{PC}$ at constant $\mathrm{T}$; and IGC tend to be shorter with increasing $T$.

4. In wet tests, IGC decrease with increasing $T$; $G B C$ tend to be better developed with increasing $T$ (as perhaps expected in that water occurs primarily at the grain boundaries); and the IGC tend to be shorter w1th increasing $T$

$$
-179-
$$


5. The common thread is the enhancement of grain-boundary cracks with increasing $T$. The GBC play a greater role in the crack coalescence history leading to fallure as $T$ increases. For wet conditions, the GBC are best developed and consequently fewer and shorter IGC are required to achieve coalescence and fallure. For dry conditions, the GBC are only slightly better developed with increasing $T$ so that more IGC, even though shorter, are needed to affect macroscopic failure.

6. Perhaps the most surprising result of this study is the indication that the length of ICC decreases with increasing $T$, wet or dry. 
Grantee:

TEXAS A \& UNIVERSITY

Center for Tectonophysics

College Station, Texas 77843

Grant:

DE-EG05-86ER1 3228

Title:

II. Geosciences Research Counc1l

Person in Charge:

M. Friedman

Scope of Work

In Fall, 1985, the Geosclences Researoh Councll was formed to recognize and advance research activities within the geosciences and the purview of DOE/OBES. A broadly based council of fifteen geoscientists from academia, goverment laboratories, and industry agreed to serve. In addition to chalrman M, Frledman (Texas A\&M University, geology), the council currently consists of Phillip Abelson (generalist); D. J. Baker (President of JOI; oceanography), J.D. Bredehoeft (USGS, groundwater), W. G. Clement (industrial consultant, geophysics), J. A. Eddy (UCAR, solar and terrestrall atmomospheric science), W. C. Luth (Sandia, geology), T. V. MCEvilly. (LBL, geophysics), D. L.CPeck (USGS, geology), D. E.. Powley (AMOCO Research, petroleum geology), R. N. Schock (LLL, geochemistry), L.: T. Silver (Cal. Tech., geochemistry), J. T. Smith (Shell Dev.: Co., petroleum geology and geochemistry), s. C. Solomon (MIT, geophysics), and J.T. Whetten (LANL, geology).

The Individual members of the council are charged to: (1) evaluate the status, potential value, and relevance of current geosciences research to meet the nation's energy needs; (2) identify energy-related geosciences research areas that need to be developed or strengthened; and (3) facilitate the above by serving as a liaison group among the geosciences community, DOE, and other sponsors of geosciences research, through sponsorship and organization of workshops and technical sessions and the promulgation of corresponding reports. 
Grantee:

UNIVERSITY OF TEXAS ARLINGTON

Department of Geology, Box 19049

Arlington, Texas 76019

Grant:

Title:

DE-FGO5-85ER 13413

Volcanological Investigation of the Banco Bonito

Eruption (c. 100,000 yr) and Subsurface Geology

of the Ring Fracture Zone, Valles Caldera,

New Mexico

Person in Charge:

S. Self

Scope of Work

This study involves integrated fleld and laboratory work on the youngest post-Valies caldera eruptive units in the Jemez Mountains. The units involved are the Banco Bonito obsidian lava flow, the Battleship Rock Ignimbrite, and the El Cajete pumice fall deposits. All were probably produced during the same eruptive interval, about 100,000 years ago.

The E1 Cajete pumice fall member was extensively sampled throughout the southern Jemez Mountains, thereby documenting its dispersal. Detailed stratlgraphic sections through the El Cajete were made for correlation purposes. Interbedded ash-flow and surge units and their significance in the eruptive cycle are being examined. Sieve analyses, petrography of pumices, and distribution of the plinian fall units (delineated by median diameter, maximum pumice, maximum lithic, and thickness parameters) are being synthesized to estimate size, dispersal, eruption column heights and paleowind directions for this portion of the eruptive phase. Age dating of the El Cajete pumice by uranium series disequilibrium on 3 to 5 of the mineral phases and glass is being attempted. This is due to failure of prevlous attempts at precise age dating by conventional K/Ar techniques. Xenocrystic minerals are common and contaminate the mineral population, giving too-old ages. The U-Th method should allow xenocrystic material to be detected and yield an isochron. Valuable data pertinent to the crystallization history of the magma body will also be obtained.

The Battleship Rock ignimbrite is being investigated to determine its position in the Banco Bonito eruptive cycle and its original extent. Field work included outlining the ignimbrite through fleld mapping, delineating relationships with under- and over-lying units, and recognizing flow units within the ignimbrite. Petrographic studies on the pumice may also be used to determine its position in the eruptive cycle, as well as to correlate ash-flow units.

The youngest eruptive unit, the Banco Bonlto obsidian lava flow, was mapped, exclusive of that portion on the Baca Location. Air photos and fleld characteristics are being used to decipher the number and extent of obsidian lava flow units. Samples from several of the lava lobes are being used to determine any petrographic and compositional variation during this last effusive phase of the eruptive cycle.

$$
-182-
$$


The integration of stratigraphic fleld relationships and stratigraphy from the VC-1 Continental Scientific Drilling Project core will provide a basis for an eruptive model and paleotopographic reconstruction. Also, the stratigraphy under the southern ring fracture zone of the Valles caldera using the VC-1. stratigraphy and the lithic assemblage in the El Cajete/Battleship Rock fall units is being 1nvestigated. During explosive eruptions of this type, rock fragments may be excavated from the conduit wall in a progressive manner, and this is represented in the lithic content of the fall units. At present, lithlcs collected in the El Cajete type section are being examined for variation through the deposit. Petrologic studies on the pumices in the type section to determine magma chamber parameters based on mineralogy are just beginning. This youngest eruptive post-caldera event may be significant in indlcating the possibility for future eruptions in the Jemez Mountains.

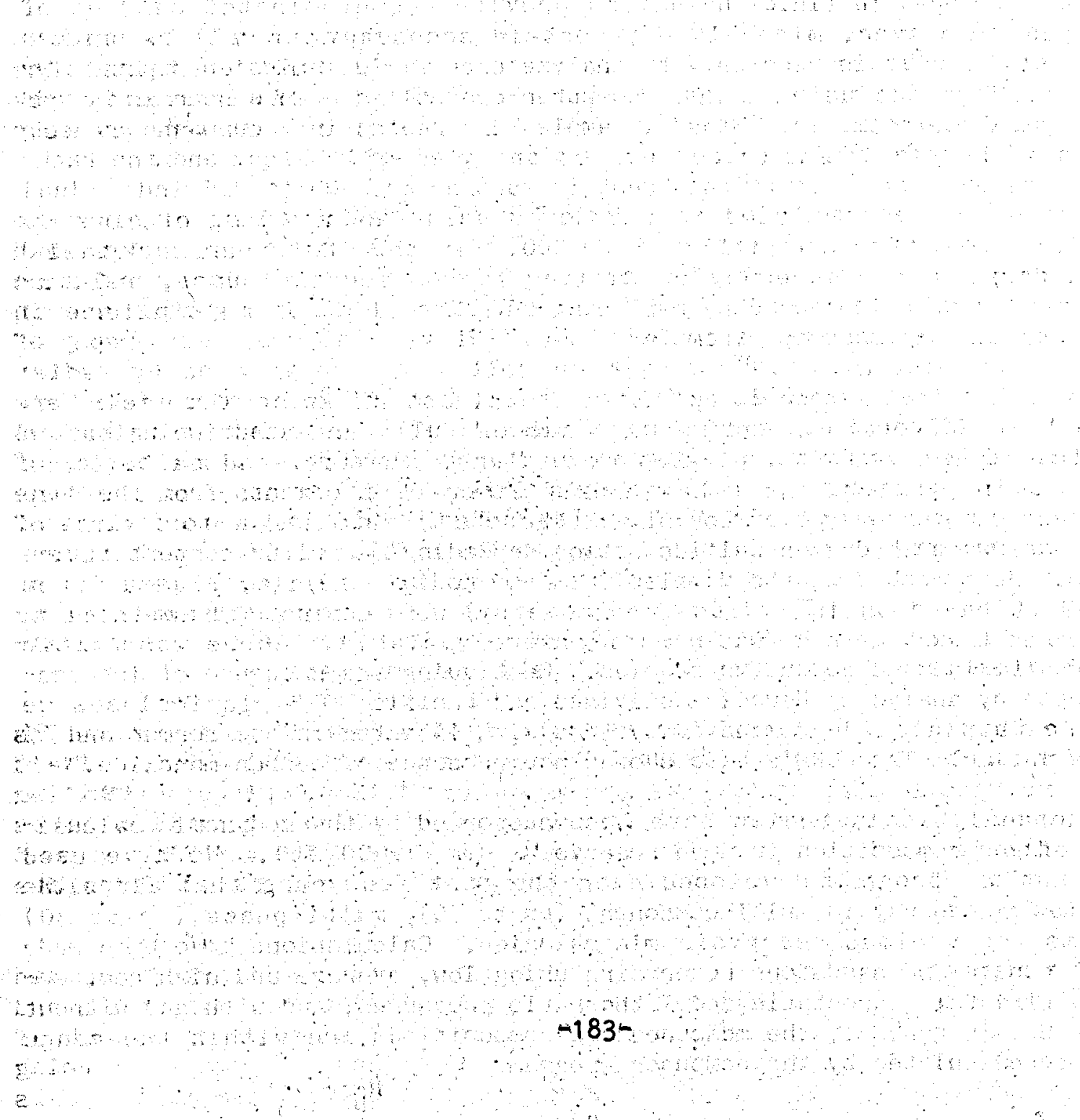


Grantee:

Grant:

Title:

Person in Charge:
UNIVERSITY OF TULSA Tulsa, Oklahoma 74104

DE-FG05-85ER13417

Stability of Natural Gas in the Deep Subsurface

C. Barker and N. Takach

Scope of Work

We have continued to investigate the stability of natural gas in the deep subsurface using a combined theoretical and experimental approach.

Gases trapped in fluid inclusions provide uncontaminated samples of deep gas. However, minerals may contain secondary as well as primary inclusions, and it is necessary to analyze each fluid inclusion separately. We are doing this using a microcomputer-controlled, rapid scanning quadrupole mass spectrometer. Mineral samples are heated in vacuum and as each inclusion bursts the released gas is analyzed in $25 \mathrm{msec}$. and the background immediately prior to the burst is subtracted. Up to 225 individual inclusions can be analyzed in two hours using about $10 \mathrm{mg}$ of mineral. Dynamic range is close to 1 part in 10,000. In the last year background values have been reduced by installing turbomolecular pumps, and sensitivity has been increased by replacing both the electron multiplier and ion source of the mass spectrometer.

The analytical method is applicable to almost all minerals including those that are opaque, and we have successfully analyzed inclusions in calcite, dolomite, quartz, plagloclase, galena, olivine, and salt, among others. In particular, we have analyzed calcite cements from the deep Smackover carbonate section Louisiana $(20,000 \mathrm{ft})$ and found a wide variety of methane/water/hydrogen sulfide ratios depending on sulfur content of the system. Metamorphic quartz samples from the Kodiak melange, Alaska (from $50,000 \mathrm{ft}$ based on inclusion geobarometry) were dominated by methane in many cases though methane/water ratios were variable. There was little carbon dioxide and no sulfur species. Continuing the sequence of increasing depth by analyzing Hawailan olivines and Pacific MORB plagloclases we found carbon dioxide dominated systems with 1\% water in the former and $6 \%$ in the latter. The MORB's also showed the presence of carbon monoxide.

The analytical studies have been supported by thermodynamic calculations of gas composition in deep reservoirs $(\leq 40,000 \mathrm{ft})$. We have used the computer program developed over the past few years that finds the minimum free energy in multi-component (up to 70), multi-phase (up to 30 ) systems for various reservoir mineralogies. Calculations have been made for carbonate and sandstone reservoirs using low, average and high geothermal gradients; hydrostatic and lithostatic pressures; and with and without graphite. In general, the measured gas compositions are within the range of those calculated by the computer program. 
Grantee:

Grant:

Title:

Person in Charge:

Scope of Work

VC-2a will be the second Continental Scientific Driling Program corehole to be drilled in the Valles Caldera. The scientiflc aspects of this project are being jointly managed by University of Utah Research Institute and Los Alamos Scientific Laboratory. Scientists will be on-site at all times during the drilling. They will be responsible for preliminary descriptions of core and cuttings, record keeping, marking and boxing of core according to curatorial protocol, and cooperative work with investigators with regards to special cores and experiments.

Following completion of VC-2a, preliminary scientific studies will be performed on the core. These studies will include hydrothermal alteration mineralogy, correlation of stratigraphy with that present in nearby holes and in the Redondo Creek area, and an evaluation of the structural setting revealed by the corehole.

A data release meeting w11l be convened within two months of the completion of VC-2a. This meeting will be a forum for discussion of results and transfer of information among collaborating scientists.

A final report will be prepared and presented at a briefing to OBES. In addition, resuits of the project will be presented at the fall meeting of the American Geophysical Union. 
Grantee:

UNIVERSITY OF UTAH RESEARCH INSTITUTE

Earth Science Laboratory

Salt Lake City, Utah 84108

Grant :

DE-FG02-86ER13467

Title:

Logging and Hydrothermal Alteration Studies

of Hole VC-1, Valles Caldera, New Mexico

Person in Charge:

D. L. Nielson and J. B. Hulen

Scope of Work

VC-1, the first Continental Scientific Drilling Program Corehole in the Valles-Toledo caldera complex, penetrates the Jemez fault zone, a major regional structure, near its intersection with the Valles caldera's southwestern ring fracture. In part, because of this favorable structural setting, the rocks penetrated by the corehole have been repeated and extensively brecciated, hydrothermally altered, and mineralized. We have begun to characterize this alteration and mineralization as it relates to development of the caldera complex and associated hydrothermal systems.

Paleozoic sedimentary rocks and the Precambrian basement in VC-1 have been tectonically and hydrothermally brecciated in multiple episodes. Secondary porosity and permeability created during brecciation have focused hydrothermal fluld flow, leading to intense alteration and mineralization. Hydrothermal pyrite, sericite, quartz and chlorite are widespread in the breccias; chalcopyrite, sphalerite, galena, magnetite, hematite, barite, and dolomite occur locally. Molybdenite and phengite are confined to an 8 $m$ interval of strongly quartz-sericitized and quartz-veined hydrothermal breccia. Mineralogic evidence suggests that this phyllic alteration took place at higher temperatures (probably greater than $250^{\circ} \mathrm{C}$ ) than those currently prevailing at these depths in VC-1 (about $160^{\circ} \mathrm{C}$ ). The relationship of hydrothermal breccias and alteration in pre-Cenozolc rocks of corehole VC-1 to formation of the Valles'Toledo caldera complex and associated geothermal systems remains to be determined. Detailed study of alteration mineralogy and texture as well as age-dating of hydrothermal sericites and phengites should allow us to clarify this relationship.

Initial results of our VC-1 research were presented at a special session of the American Geophysical Union 1985 Fall Meeting. Publication will follow completion of more detailed characterization in progress. 
Grantee: :

UNIVERSITY OF WASHINGTON

Geophysics Program AK-50

Seattle, Washington 98195

Grant :

DE-FCO6-86-ER13472

Title: $\quad$ Two-and Three-Dimensional

Magnetotelluric Inversion

Person in Charge: J. R. Booker

Scope of Work

Our objective is tosinterpret magnetotelluric (MT) data when the electrical properties of the earth vary laterally as well as vertically. Since most real MT data is significantly effected by lateral structure, understanding the multi-dimensional inverse problem is critical to rellable use of MT in exploring for thermal and hydrocarbon energy resources. Our approach uses the fact that the Frechet derlivative of MT data with respect to vertical conductivity structure is closely related in the one- and nigher dimensional cases. In fact, they are the same, except that the electric field that must be used in calculating the Frechet derivative is the true electric fleld existing in the laterally varying structure. This fact suggests an efflclent 1 terat ive inverse scheme, At each step, the data at each site are inverted as though they were one-dimensional, except that the Frechet derivat I ves use the electric field from a forward calculation using a laterally varying model based on all the one-dimensional inverses at the previous step. This process should converge to a depth and laterally varying model which fits the data. Understanding this convergence and subsequent appraisal of the model are our major tasks.

We have developed a very stable one-dimensional inversion which produces models which have least posisible structure. This is important because unnecessary structure which has a lateral gradient from site to site can produce large varlations in electric field which can swamp the structure we are looking for. In the process of doing this, we have demonstrated the need to spread the data misfit uniformily across the frequency spectrum (1.e., a "white" fit) as well as to minimize the overall misfit. Overfitting one spectral band for a given levél of overall misfit always results in unnecessary structure in some depth range. We have developed a statistical test for whiteness of $\mathrm{flt}$, and have developed a method to adjust the norm used to define the model with least structure so as to achleve a white fit. A corollary to these results is the need to accurately characterize the errors in any data set to be inverted. We have also shown that the reciprocal of the MT data usually inverted leads to an almost linear inverse problem for conductivity. By this we mean that the results are linearly close to the truth looked at through a known window. This will become extremely important in the appraisal part of the project.

The next step towards inverting two- and three-dimensional data is to produce a program for calculating the subsurface electric field for a model specified only along a series of vertical lines beneath measurement sites. 
Grantee:

Grant:

Title:

Person in Charge:
UNIVERSITY OF WISCONSIN

Department of Geology and Geophysics

Madison, Wisconsin 53706

DE-FCO2-84ER1 3184

Thermal Stress Microfracturing of Granite

Scope of Work

H. F. Wang

The primary accomplishment of the current grant year was to complete differential strain measurements and crack petrography measurements on a suite of Westerly granite samples heated to temperatures between 20 and $300^{\circ} \mathrm{C}$. In addition, DSA derived crack spectra were obtained for heated and unheated samples of climax quartz monzonite and stripa granite. These spectra suggest that newly created thermal cracks have-lower aspect rat los than those in the original crack population.

The crack petrography measurements indicate that most thermally-induced cracks are grain boundary cracks. We have found it important to count the grain boundary cracks by type. The crack index is defined to be the number of open grain boundaries of a given type divided by the total number of such grain boundaries. The crack index for different grain boundaries indicates that quartz-quartz grains crack early, quartz-feldspar pairs also crack early but are not all completely cracked by $300^{\circ} \mathrm{C}$, and feldsparfeldspar cracks just begin to be significant at temperatures between 200 and $300^{\circ} \mathrm{C}$. These results are in agreement with a spherical inclusion crack model.

We have also completed research on the crack porosity and crack petrography of granites from Illinois borehole UPH-3. Our detailed understanding of the pre-existing open and healed cracks in these granites will make them a good cholce for future temperature cycling experiments.

The major experimental objective for the coming year will be to obtain significantly more DSA and crack count data at intermediate temperatures between 20 and $300^{\circ} \mathrm{C}$. The existing DSA results indicate differences in the amount of newly generated crack porosity for the different granites over the maximum range of temperature. We currently hypotheslze that the number of cracks along a scan line are distributed in a Poisson fashion. We will make many more crack counts to test this idea. The primary synthesis will be to obtain a quantitative comparison between our previously proposed crack model with these data. 
Grantee:

UNIVERSITY OF WISCONSIN

Department of Geology and Geophysics

Madison, Wisconsin 53706

Grant :

DEAFC02-86ER13593

Title:

Deformation and Stress Modeling of Recent Magmatic Tectonics at Long Valley, Callfornia

Person in Charge: H. F. Wang

Scope of Work

The research program is to develop deformation and stress models for the south moat region of the Long Valley caldera as part of the Department of Energy's effort on the thermal regimes portion of the continental Sclentific Drilling Program. In preliminary calculations, surface deformation associated with an Inflated magma chamber is modeled by an elastic half-space containing an inclined ellipsold which undergoes a uniform dilatation. The analytical solution has been developed in terms of elliptical integrations. The inverse problem has been carried out using the linearization method and applied to the Long Valley uplift data for the period 1975-1983. The best fit given by our triaxial ellipsold model Indicates: (1) the depth to the center of the magma chamber under the resurgent dome is about $10 \mathrm{~km}$; (2) the injected magma volume into the chamber is about 0.18 cublc kilometers i. and (3) the chamber has a major elongation along the approximately vertical direction. Although the absolute values of the ellipsoldal axes cannot be resolved uniquely by the uplift data, selsmic refraction and attenuation studies indlcate that the top of the magma chamber is unlikely to be shallower than $3 \mathrm{~km}$; hence, the maximum vertical axis of the triaxial ellipsold in the model cannot be greater than $7 \mathrm{~km}$ and a maximum volume of the magma body is estimated as 700 cuble kllometers. 
Grantee:

Grant:

Title:

Person in Charge:
WOODS HOLE OCEANOGRAPHIC INSTITUTION

Woods Hole, MA 02543

DE-FC02-86ER1 3466

Organic Geochemistry of Outer Continental Margin and Deep Ocean Sediments

J. W. Farrington, J. K. Whelan, and J. M. Hunt

\section{Scope of Work}

The objective of this program is to develop a better understanding of the processes of hydrocarbon generation and migration in coastal and of $f_{-}$ shore sedimentary basins as an ald in predicting favorable exploration areas for petroleum. Research has concentrated on the light hydrocarbons (C1-C15) because these are the compounds which migrate most easily by diffusion, solution in pore waters, or in ofl and gas phases. Methods of pyrolysis-gas chromatography (GC) and.pyrolysis-GC mass spectrometry have also been developed and utilized in examining high molecular weight sedimentary organic matter, kerogen, the precursor to petroleum. Recent efforts have expanded our analytical capabilities to the $\mathrm{C15}$ + compounds.

Detalled analyses have been completed on seven Alaskan North Slope wells. Pyrolysis parameters Tmax (the peak temperature of pyrolyzable organic matter) and the production index (P.I., the ratio of generated to total petroleum generating potential) were plotted against each other for various maturity ranges and were found to distinguish sections influenced by maturational as contrasted with migrational effects. By this method, the Ikplkpuk and Seabee wells were found to be' optimal for examination of thermal maturational as contrasted with migrational geochemical characteristics, respectively. Changes of maturity. (Vitrinite Reflectance) with depth for the two wells were identical so that a number of pyrolysis and sorbed light hydrocarbon trends previously proposed to be diagnostic of the two processes could be compared.

Deep overmature formations (Vitrinite Reflectance, Ro, greater than about 2.5\%) from a number of wells were found to give methane as the only sorbed light hydrocarbon gas. Pyrolysts of these same sections also produced methane as the only light hydrocarbon. Concentrations of methane decreased to background levels (about $30 \mathrm{ppm}$ ) at the highest maturities (Ro $=4 m 5 \%)$. The ratio of pyrolyzable $\mathrm{C1} /(\mathrm{cl}+\mathrm{C2}+\mathrm{C3})$ gave an excellent correlam tion with Ro in two wells, one in Alaska and one in the Texas Gulf coast, suggesting that this ratio should be tested further as an experimentally simpler maturation indicator.

The Alaskan North Slope-Work carried out this year promises to produce closer collaboration between-our laboratory and the U. S. Geological Survey so that the extensive USGS North Slope sample and computerized data base can be fully utilized in addressing fundamental organic geochemical questions. 
Grantee:

YALE UNIVERSITY

Department of Geology and Geophysics

P. O. Box 6666

New Haven, Connect 1cut 06511

Grant:

$D E=A C 02-79 E R 10445$

Titie:

Opening Mode Crack Growth in Rock

Person in Charge: R. B. Gordon

Scope of Work

This research is a study of how the tensile fracture characteristics of rock are determined by microstructure. The data are intended to be used in the interpretation of fractures in rock in the field, particularly where the passage of fluids through the rock $1 \mathrm{~s}$ of interest. Measurements of fracture energies were made earlier in the project on a set of different types of rocks having a wide range of fracture characteristics; the focus of the research is now to show how the fracture energy and the distance that a crack must advance before attaining steady state propagation are determined by the microstructure of the rock. Polished specimens are split while on the stage of an optical microscope and the progress of the crack is followed as successively greater loads are applied. The passage of the crack through the different mlcrostructural constituents is observed. Detection of cracks with the optical microscope is sensitive to the surface preparation of the sample, the magnification used, and the force applied at the time of observation, but geometrical characteristics of the crack pattern can be determined which are independent of subjective judgments by the observers.

Marble, granites, diabase, and basalt are now being examined to determine the mean crack density (the ratio of total crack length to the length of the rupture path), mean branching frequency, process zone width, the fraction of the fracture pattern developed on preexisting cracks, and the ratio of intergranular to transgranular cracking. Detalled study of marble shows that opening of preexisting, noncoherent grain boundaries is the principal structural change in the process zone. In the early stages of rupture about $45 \%$ of the total fracture is on newly-created surface and $55 \%$ is on noncoherent grain boundaries; the latter decreases to about $33 \%$ as the process zone becomes fully developed. Eventually a rupture path is selected from the network of cracks in the process zone and final separation is accomplished as interlocking faces along the rupture path are freed. During the growth of the process zone, the crack density increases to about five and the mean distance between branch points in the fracture pattern decreases to about two grain diameters. These structural changes explain the observed increase in fracture energy during crack growth. Markedly different behavior is found in the other types of rock being studied. 


\section{GEOSCIENCES RESEARCH (ERDA/DOE) \\ Historical Summary \\ (Operating Funds - Thousands)}

\begin{tabular}{|c|c|c|c|c|c|c|c|c|c|c|}
\hline ON-SITE & FY 197 & FY 1978 & FY 1979 & FY 1980 & FY 1981 & FY 1982 & Fr 1983 & FY 1984 & FY 1985 & FY 1986" \\
\hline ANL & $\mathbf{E}$ & 100 & 140 & - 240 & 310 & +330 & 1330 & 360 & 360 & 355 \\
\hline LANL & 750 & 810 & 1.084 & 1.420 & 1,500 & 1,375 & 1.684 & 2,343 & 2,280 & 2.253 \\
\hline LBL & $\infty$ & 660 & 735 & 195 & 1,075 & 1.180 &., 405 & $.1,485$ & 1,696 & 1.620 \\
\hline LLNL & 130 & 250 & $\infty$ & 910 & 1.060 & 1.110 & 1.280 & 1.815 & 1.898 & 1.521 \\
\hline ORNL & 150 & 180 & 240 & 2000 & 380 & $\therefore 400$ & $\mathbf{4} 80$ & 470 & 480 & 492 \\
\hline PNL & 250 & 280 & 450 & 605 & 600 & 1020 & 520 & 678 & 695 & $\cos$ \\
\hline SNL/A & 450 & 800 & $\infty$ & 1.165 & 1,310 & 1.546 & 1.682 & 2,087 & 1,861 & 2,256 \\
\hline On-Site Totals & 2.400 & 12,780 & 84.079 & 5.575 & 6,215 & 6.491 & 7.331 & 9.138 & 9.079 & 9.350 \\
\hline Total Off-Site & $+\cos$ & $\$ 1.152$ & 11.085 & $\$ 2,509$ & $\$ 3.030$ & $\vdash 3.141$ & +4.523 & (3.309 & 4.253 & 3.507 \\
\hline TOTAL OPERATING & $\$ 3.299$ & $\$ 3.932$ & $\$ 5.974$ & $\$ 8.084$ & $\$ 9.245$ & $\$ 9.600$ & $\$ 11,854$ & $\$ 12,447$ & 13,330 & 12.857 \\
\hline TOTAL EQUIPMENT & - & $\cdot-$ & 1350 & - 860 & 1223 & $1 \quad 200$ & 1600 & 1800 & 1.100 & 1.094 \\
\hline$\overline{\text { TOTAL GEOSCIENCES }}$ & 63.299 & 83.232 & $\$ 6,329$ & 68,644 & $\$ 10.168$ & $\$ 10.532$ & $\$ 12.744$ & $\$ 13.407$ & $\$ 74.439$ & 13.951 \\
\hline
\end{tabular}

-Reflects Gramm-Rudman-Hollings Reduction of 3.8\% 


\section{GEOSCIENCES RESEARCH (ERDA/DOE) \\ Historical Summary/Off-Site \\ (Operating Funds-Thousands) \\ (Continued)}

Institution (PI)

CUNY-B (Friedman) CUNY-Q (Schreiber) SUNY.A (Dewey)

SUNY.A (Harrison) SUNY.SB (Hanson) SUNY.SB (Papike) U/N. Carolina (Glazner) U/Oklahoma (Philp) U/Oregon (Weill)

Oregon State (Fehler)

Penn State (Martin)

Penn State (Given)

Princeton U (Navrotaky)

RPI (Friedman)

Rice (Ave Lollement)

- S. Dakota MET (Papike)

- U/S. California (Aki)

U/S. Florids (Sockett)

SMU (Blackwell)

Staniord U (Llou)

Stantord U (Nur)

Stanford U (Parks)

- Stanford U (Pollard)

- UTTexas-AR (Self)

U/Texas.AU (Barker)

Texas AGM (Cerison)

Toxes A\&M (Corter)

Toxas ASM (Friedman)

Texas A\&M (Glibert)

U/Tulse (Barkier)

USGS (Haas)

UURI (Nielson)

U/Washington (Booker)

u/Wisconsin (Wang)

Woods Hole (Wholan/Farrington)

Woods Hole (Hunt)

- Woodwerd-Clyde (Burdick)

XDATA (Dinas)

Yale $U$ (Gordon:

Other

Otf-Sire Torals:

Continontat Scienthic Drillina Aetivity

\begin{tabular}{|c|c|c|c|c|c|c|c|c|c|c|}
\hline FY 197 & & FY 1978 & FY 1979 & FY 1980 & FY 1981 & Fr 1982 & FY 1983 & FY 1984 & FY 1985 & FY 198 \\
\hline$=$ & & - & - & - & - & - & - & - & 85 & 86 \\
\hline- & $:$ & - & - & - & $: \boldsymbol{2}$ & 81 & 49 & - & 116 & - \\
\hline$-\cdots$ & & - & - & - & 86 & $-\cdots$ & - & - & - & - \\
\hline - & & - & - & - & - & 39 & 136 & - & 58 & 60 \\
\hline- & & - & - & - & $-\quad \cdots$ & - & 112 & 118 & 120 & 120 \\
\hline- & & - & 51 & 69 & 65 & - & $-\cdots$ & - & $-\therefore$ & - \\
\hline- & & - & - & - & - & - & - & $-\therefore$ & 38 & 39 \\
\hline- & & - & $-?$ & - & - & $-\quad$ & - & $-\quad$ & 4 & 88 \\
\hline- & & - & - & - & - & $-\therefore$ & 103 & 8 & - & - \\
\hline- & & - & - . & $-\quad \cdots$ & $-\therefore$ & 38 & - & - & - & - \\
\hline$=$ & & - & - & 62 & 83 & NFX & - & - & - & - \\
\hline- & & - & - & - & $-\cdots$ & - & - & 100 & - & NFX \\
\hline- & & - & - & - : " & $-\cdots$ & - & - & - & 100 & - \\
\hline- & & - & - & - & 81 & 9 & 150 & - & - & $-:$ \\
\hline- & & - & - . & $-\therefore$ & - & - & 120 & 121 & - & - \\
\hline- & & - & - & - & - & $\boldsymbol{7}$ & 100 & 190 & 150 & 89 \\
\hline- & . & - & - & - & - & - & - & - & 150 & 150 \\
\hline- & & - & - & - & 4 & - & & - & - & - \\
\hline- & & - & - & - & 84 & 70 & - & - & - & - \\
\hline- & & - & - & - & $-\cdots$ & 34 & 45 & NFX & - & - \\
\hline 6 & & 104 & 147 & 140 & $140^{\circ}$ & 125 & 160 & 172 & 172 & $\because 165$ \\
\hline- & & $-\quad \ldots$ & - & - & $-\cdots$ & 57 & 66 & 86 & - & - \\
\hline- & & - & $-\therefore:$ & $:-z^{3}:$ & - & $-\therefore$ & - & - & 9 & 42 \\
\hline- & & - & - & - & - & - & - & - & 43 & NFX \\
\hline- & & - & - & - & - & - & 8 & - & - & - \\
\hline- & & - & - & - & - & - & - & $\therefore$ & - & -1 \\
\hline- & & - & - & - & $-\quad$. & - : & - & 70 & - & - \\
\hline- & & - & 6 & 208 & 2002 . & 200 & 201 & $\mathbf{3}$ & 100 & 194 \\
\hline- & & - & - & - & - & - &.- & - & - & 88 \\
\hline- & & - & $\infty$ & NFX & 75 & $\pi$ & 75 & $\therefore \boldsymbol{\infty}$ & $\infty$ & 11 \\
\hline 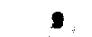 & & 84 & 54 & $\quad-$ & - & $-\ldots$ & - & - & - & - \\
\hline- & & - & - & - & - & - & - & - & - & 114 \\
\hline- & & - & - & - & $-\because$ & - & - & - & - & 27 \\
\hline- & & - & - & 67 & $\because 8$ & - & - & 48 & 12 & 87 \\
\hline- & & - & - & - & - & - & - & - & 20 & 223 \\
\hline 37 & & - & 100 & 141 & 180 & 150 & 190 & 200 & - & - \\
\hline- & & - & - & - & - & 100 & 100 & 100 & 40 & - \\
\hline- & & - & & - & - & 8 & 68 & $=$ & - & - \\
\hline- & & - & 45 & 4 & 25 & 26 & 8 & 184 & - & - \\
\hline- & & 5 & - & es & 4 & - & - & $=$ & $=$ & - \\
\hline 8699 & & $\$ 1.152$ & 61.055 & 9,609 & 13,000 & $\overline{13,141}$ & $\overline{M .53}$ & 63.209 & $\overline{4,260}$ & 03,507 \\
\hline
\end{tabular}




\section{GEOSCIENCES RESEARCH (ERDA/DOE) ' Historical Summary/Off-Site (Operating Funds-Thousands)}

Institution (P))

U/Alesks (Akasofu)

U/Alaske (Pulpou)

U/Arizona (Hill)

U/Arizona (Norton)

- Arizona Stote (Fink)

Arizone State (Navrotsky).

Aspen Institute (Roberts)

- Brown U (Mermance)

- Cal Tech (Ahrens)

- Cal Tech (Stolper)

U/Calfiornie-B (Helgeson)

U/Californie-8 (Reynolds)

U/California-D (Mac Gregor)

U/Californie-LA (Anderson)

U/California-LA (Boehler)

U/Callfornis-LA (Kennedy)

U/Californis-LA (Werren)

-U/California - R (Mc Kibben)

- U/Californie-SD (Craig)

U/Chicago (Anderson)

Columbia U (Engelder)

Columbia U (Jacob)

Columbia U (Walker)

DOSECC, Inc. (Raleigh)

Marvard U (Thompson)

U/Hawaii (Manghnani)

Headquarters Senvices

U/Maryland (Valette-Silver)

U/Minnesota (Johnson)

MIT (Aki)

MIT (Simmons)

MIT (Toksoz)

- Michigan Stoto (Vogel)

- Michigan Tech (McDowell)

NAS/NRC (Hart)

- U/Nevada (Poppin)

- U/Neveda (Ryall)

- U/Oklahoma (Philp)

\begin{tabular}{|c|c|c|c|c|}
\hline FY 197 & FY 1978 & FY 1979 & FY 1980 & FY 1981 \\
\hline 179 & - & 88 & 184 & .108 \\
\hline 42 & 69 & 113 & 87 & 70 \\
\hline - & - & - & 91 & 26 \\
\hline - & - & - & - & 66 \\
\hline - & - & - & - & - \\
\hline - & - & - & 35 & 2 \\
\hline - & 48 & 57 & 71 & - \\
\hline - & - & 95 & 140 & 164 \\
\hline - & - & - & - & - \\
\hline - & - & - & - & . \\
\hline - & - & - & - & - \\
\hline 127 & 148 & 127 & 168 & 144 \\
\hline - & 7 & 61 & 23 & - \\
\hline - & - & - & - & - \\
\hline - & - . & - & - & 46 \\
\hline$\infty$ & 60 & $\boldsymbol{7 2}$ & $\boldsymbol{7 2}$ & - \\
\hline 41 & 50 & 103 & 107 & 121 \\
\hline - & - & - & - & - \\
\hline - & - & - & - & - \\
\hline - & - & - & 64 & NFX \\
\hline 2 & $\pi$ & 100 & 140 & 150 \\
\hline 240 & 256 & 274 & 312 & 318 \\
\hline - & - & - & - & - \\
\hline- & - & - & - & - \\
\hline - & - & - & - & - \\
\hline - & - & - & - & - \\
\hline - & - & - & - & - \\
\hline - & - & - & - & - \\
\hline - & - & - & - & 68 \\
\hline 130 & 113 & 102 & 152 & 160 \\
\hline - & 100 & 100 & 90 & 100 \\
\hline - & - & - & - & - \\
\hline - & - & - & - & - \\
\hline - & - & - & - & - \\
\hline 13 & 9 & 4 & 116 & 168 \\
\hline - & - & - & - & - \\
\hline - & - & - & - & - \\
\hline - & - & - & - & - \\
\hline
\end{tabular}

\begin{tabular}{|c|c|c|c|c|}
\hline FY 1982 & FY 1983 & FY 1984 & F 1985 & f $1986^{\circ}$ \\
\hline 113 & $\div 117$ & 120 & 1126 & 126 \\
\hline- & - & - & - & - : \\
\hline 90 & 101 & $\boldsymbol{x}$ & 121 & - \\
\hline$\infty$ & 48 & - & - & - \\
\hline- & - & - & 2 & 23 \\
\hline 6 & 123 & - & - & - \\
\hline- & - & - & - $\cdots$ & - \\
\hline 165 & 333 & - & 166 & - \\
\hline- & $\boldsymbol{n}$ & 81 & 160 & - \\
\hline - & - & - & 50 & $\mathbf{9 8}$ \\
\hline - & 204 & - & 120 & 120 \\
\hline 150 & 165 & 196 & 223 & 200 \\
\hline- & - & - & - & - \\
\hline - & - & $\infty$ & 74 & - \\
\hline NFX & 60 & 66 & 75 & - \\
\hline - & - & - & - & - \\
\hline NFX & - & - & - & - \\
\hline - & - & - & 50 & - \\
\hline - & - & 35 & 41 & 41 \\
\hline 38 & 58 & NFX & 46 & - \\
\hline 156 & 289 & - & 150 & 75 \\
\hline 378 & 337 & 359 & 360 & 360 \\
\hline- & - & 73 & 7 & 106 \\
\hline - & - & - & 6 & - \\
\hline- & 372 & - & 115 & - \\
\hline 8 & 86 & 99 & 200 & - \\
\hline 6 & 1 & 3 & 15 & 5 \\
\hline- & - & - & 43 & $\cdots$ \\
\hline 57 & NFX & - & - & - \\
\hline 151 & 158 & 147 & - & - \\
\hline 106 & 106 & 110 & $\infty$ & 80 \\
\hline- & - & - & - & 142 \\
\hline - & - & - & 31 & NFX \\
\hline- & - & - & 50 & - \\
\hline 280 & - & 200 & 187 & 124 \\
\hline- & - & - & - & 143 \\
\hline 75 & 87 & 85 & - & - \\
\hline- & - & - & - & 28 \\
\hline
\end{tabular}

-Reflects Gramm-Rudman-Hollings Reduction 
TOPICAL INDEX

GEOLOGY, GEOPHYSICS, AND EARTH DYNAMICS

Large Scale Earth Movements.............................81,126 Evolution of Geolog 1c Structures.................98,126,157,176-177 Properties of Earth Mater1als............7,10,11,30-34,45-48,84 $\div 85,107$, $\ldots \ldots \ldots \ldots \ldots \ldots \ldots \ldots \ldots \ldots 121-123,129-130,136,155-156,174,175,178-180$ Rock Flow, Eracture, or Fallure....11,28-30,46,82-85,127,133-135,188,191

\section{GEOCHEMISTRY}

Thermochemical Properties of Geologic Materials...3,4,5,6,14-15,51,68-69 $\ldots \ldots \ldots \ldots \ldots \ldots \ldots \ldots \ldots \ldots \ldots \ldots \ldots \ldots \ldots \ldots \ldots \ldots \ldots \ldots \ldots \ldots \ldots \ldots \ldots \ldots \ldots \ldots \ldots 128,16162,169+170$ Static Rock-Water Interactions........................... $3,4,16,17,88$ Organic Geochemistry......................15,36-37,49-50,163-168,190 Geochemical Migration....................... $2,16,17,19,35-36,50-52$, $.64 \div 73,86-88,109-120,124+125,131-132,171$

\section{ENERGY RESOURCE RECOGNITION, EVALUATION, AND DEVELOPMENT}

Resource Definition and Utilization..........24,25,42,43,72,73,74,87,

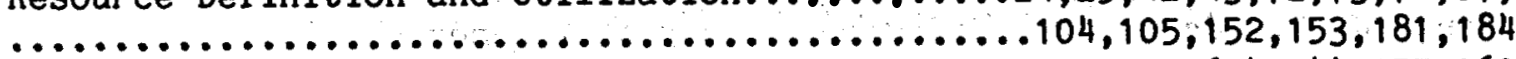

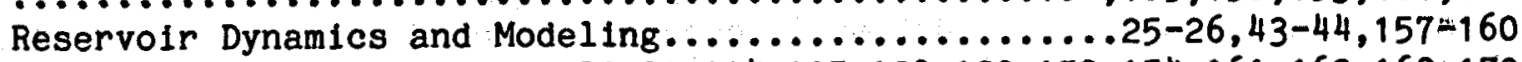
Magma Energy Resources.....90-91,124-125,129-130,153-154,161-162,169-170 Information Compilation, Evaluation; and Dissemination...22, 24-25, 43-44,

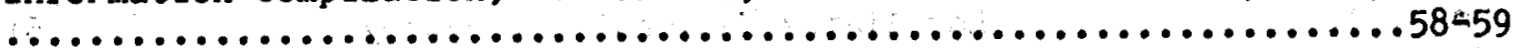
Continental Scientific Drilling Program.........21-25,38-43,55-59,90-94,

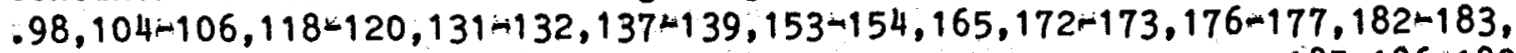

\section{SOLAR -TERRESTRIAL-ATMOSPHERIC INTERACTIONS}

Magnetospheric Physics and Chemistry................60-63,96-97

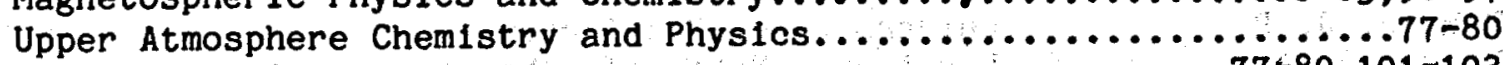
Solar Radiation.................................77-80,101-103 
INDEX OF TECHNICAL CONTRIBUTORS

CONTRIBUTOR

Ahrens, T. J.

Akasofu, S. $-I$.

Aki, $K$.

Albright, J. N.

Alvarez, $L$.

Alvarez, W.

Anderson, A. T., Jr.

Anderson, $0 . \mathrm{L}$.

Ankeny, L. A.

Apps, J. A.

Asaro, F.

Baker, D. N.

Baldridge, W. S.

Barker, C.

Bayhurst, G. K.

Benjamin, T. M.

Benson, W. E.

Berg, J. W., Jr.

Berryman, J. G.

Birn, J.

Bish, D. L.

Blaclc, J. D.

Boehler, R.

Boggs, S., Jr.

Bonner, B. P.

Booker, J. R,

Brown, J. A.

Brown, L. F.

Burkhard, N. R.

Burnham, A. K.

Carfaso, F. A.

Carlson, R. L.

Carmichael, I. S. E.

Carnahan, C. L.

Carrigan, C. R.

Carter, N. L.

Chambers, W. F.

Charles, R. W.

Cheng, C. H. A.

Chin, $Y$.

Cohen, A. D.

Cole, D. R.
INSTITUTION

California Institute of Technology

University of Alaska

University of Southern California

Los Alamos National Laboratory

Lawrence Berkeley Laboratory

Lawrence Berkeley Laboratory

The University of Chicago

University of California at Los Angeles

LANL

Lawrence Berkeley Laboratory

Lawrence Berkeley Laboratory

Los Alamos National Laboratory

LANL.

University of Tulsa

Los Alamos National Laboratory

Los Alamos National Laboratory

National Academy of Sclences/ National Research Council

National Academy of Sciences/ National Research Council

Lawrence Livermore National

Laboratory

Los Alamos National Laboratory

LANL

Los Alamos National Laboratory

University of California at Los Angeles

Argonne National Laboratory

Lawrence Livermore National

Laboratory

University of Washington

Los Alamos National Laboratory

Los Alamos National Laboratory

Lawrence Livermore National Laboratory

Lawrence Livermore National Laboratory

Argonne National Laboratory

Texas A\&M University

Lawrence Berkeley Laboratory

Lawrence Berkeley Laboratory

Sandia National Laboratories

Texas A \& M University

Sandia National Laboratories

Los Alamos National Laboratory

Massachusetts Institute of Technology

Lawrence Livermore National

Laboratory

PAGES

107

96

173

46

19

19

124

122

56

16

19

60,62

55

184

53

50,53

147

142,149

33,43

61

49

46

121

2

28,33

187

47

47

40

36

2

178

15

17

$90,91,92$

139

85

49,50

136

33

49

Los Alamos National Laboratory

Oak Ridge National Laboratory 
Cook, N. G. W.

Lawrence Berkeley Laboratory

Costin, L. S.

Sandia National Laboratories

Cra1g, H.

University of California

119

Crowe, B. M.

Curt1s, D. B.

Cygan, R. T.

Los Alamós National Laboratory

52

Los Alamos National Laboratory

51

SNLA

88

Dally, W. D.

LLNL

43

Harvard UnIversity

128

Drummond, S. E.

Oak Ridge National Laboratory

64

Duba, A. G.

Lawrence Livermore National

Laboratory

Durham, W. B.

Lawrence Livermore National

Laboratory

Eichelberger, J. C.

Sandia National Laboratories

Elbring, G. J.

Eliason, J. R.

Epstein, S.

Farrington, J. W.

Sandla National Laboratories

Pacific Northwest Laboratory

California Institute of Technology

Woods Hole Oceanographic

Institution

Fink, J. H.

Finnegan, $D$.

Arizona State University

LANL

Paclfic Northwest Laboratory

Friedman, A. M.

Argonne National Laboratory

Frledman, G. M.

The Research Foundation of the

City University of New York

Friedman, M.

Texas A\&M UnIversity

155

Los Alamos National Laboratory

179,181

Gardner, J. N.:

Los Alamos National Laboratory

57

Gary, S. P.

Sandia National Laboratories

60

Gerlach, T. M.

University of New Mexico

86

Geissman, J. W.

The Pennslyvania State University

84

University of North Carolina

166

Glazner, A. F.

Los Alamos National Laboratory

161

Goff, F. E.

LANL

57,58

Goff, $S$.

Lawrence Berkeley Laboratory

Yale University

58

Goldstein, N. E.

State University or New York

Hanson, G. N.

Hardee, H. C.

Sandla National Laboratories

State University of New York

National Academy of Sclences/

National Research Council

Heard, H. C.

Lawrence Livermore National

Laboratory

$10,22,7$

191

158

90,92

157

Harrison, T.
Hart, P. J.

LLNL

Hearst, J. R.

Lawrence Livermore National

Laboratory

University of California

143

Hedstrom, G. W.

Brown Und versity

University of Arizona

28

43

Helgeson, H. C.

Sandla Nat Ional Laboratorles

33

111

104

Hill, H. A.

Los Alamos National Laboratory

101

Holcomb, D. J.

Argonne

82,83

Howell, D. A.

University of Utah Research

Inst Itute

Hulen, J. B. 
Hunt, J. M.

Jacob, $K$.

Janecky, D. R.

Johnson, C.

Johnson, G. K.

Kasameyer, P. W.

King, M. S.

Kleckner, E. W.

Krumhansl, J. L.

Lange, D. A.

Larson; N. R.

Laul, J. C.

LeBaron, B. A.

Lee, L. C.

Lesher, C. E.

Livermore, $D$.

Luth, W. C.

Lysne, P.

Majer, E. L.

Manghnani, M. H.

Marusak, N.

Mc Dowell, S. D.

McEvilly, T. V.

McKibben, M. A. Mesmer, R. E. Meyers, W. J. Michalsky, J. J. Michel, H. V. Miller, D. G.

Morrison, H. F. Myer, L. R.

Myers, C. W. Nakanishi, K. K.

Naney, M. T. Navrotsky, A. Newmark, R. L.

Nicol, M.

Nielson, D.

Nur, A. M.

O'Hare, P. A. G.

Olsen, $\mathrm{K}, \mathrm{H}$.

Painter, P. C.

Palmer, D. A.

Papike, J. J.
Woods Hole Oceanographic Institution

Columbia University

Los Alamos National Laboratory

Argonne

Argonne National Laboratory

Lawrence Livermore National Lab.

Lawrence Berkeley Laboratory

Pacific Northwest Laboratory

Sandia National Laboratories

LBL ,

Pacific Northwest Laboratory

Pacific Northwest Laboratory

Pacific Northwest Laboratory

University of Alaska

Columbia University.

Argonne National Laboratory

Sandia National Laboratories

SNLA

Lawrence Berkeley Laboratory

University of Hawali at Manoa

LANL

Michigan Technological University

Lawrence Berkeley Laboratory

University of California, Riverside

Oak Ridge National Laboratory

State University of New York

Pacific Northwest Laboratory

Lawrence Berkeley Laboratory

Lawrence Livermore National

Laboratory

Lawrence Berkeley Laboratory

Lawrence Berkeley Laboratory

LANL

Lawrence Livermore National Laboratory

Oak Ridge National Laboratory

Princeton University

Lawrence Livermore National Laboratory

University of California at Los Angeles

University of Utah Research Institute

Stanford University

Argonne National Laboratory

Los Alamos National Laboratory

The Pennsylvania State University

Oak Ridge National Laboratory

South Dakota School of Mines and Technology
190

126

50

2

5

40,43

11,26

77

88

15

77

72

77

96

125

2

$81,84,86$

90,92

94

9,23

129

47

139

$7,9,13,14$

$21,22,23$

24

118

64

158

77

19

35

$7,10,22$

$11,24,25$

26

47

26

64

169

40

121

58 ,

185,186

174

5

56

166

64

171,172 
Patton, H. J.

Pawloski, G.

Pearson, E. W.

Peppin, W. A.

Perrin, R.

Perry, D. L:

Phillp, R. P.

Phillips, S. L.

Pitzer, K. S.

Piwinskil, A. J.

Pollard, D. D.

Rard, J. A.

Raymond, R.

Remer, J. S.

Reynolds, J. H.

Rogers, P. S. Z.

Rokop, $D$.

Rowley, J. C.

Rundle, J. B.

Ryerson, F. J.

Schock, R. N.

Scholz, C. H.

Schreiner, $F$.

Seitz, $M$.

Self, S.

Shankland, T. J.

Simmons, $G$.

Slater, D. W.

Smith, A. T.

Snyder, D. A.

Somerton, W. H.

Spackman, W.

Stockman, H. W.

Stokes, G. M.

Stolper, E.

Sturchio, N.

Sweeney, J. J.

Taber, J.

Takach, N.

Tasker, I. R.

Taylor, S. R.

Teufel, L. W.

Thigpen, L.

Thompson, J. B., Jr. Toksoz, M. N.

Tsang, C. F.
Lawrence LI vermore National

Laboratory

LLNL.

PNL.

77

Unlversity of Nevada $\quad 153$

LANL $\quad 51$

Lậnence Berkeley Laboratory

University of Oklahoma

Lawrence. Berkeley Laboratory

163,165

25

14

Lawrence Berkeley Laboratory

Lawrence Livermore National

Laboratory

30,39

Stanford University

176

Lawrence, LI vermore National

Laboratory.

Los Alamos National Laboratory

35

Lawrence Berkeley Laboratory.

49

17

114

University of Callfornia

Los Alamos National Laboratory

LANL.

$50,51,53$

Los Alamos National Laboratory

51

57

Sandia National Laborator less

Lawrence Liverwore National.

. Laboratory.

81,92

LLNL

n.

30,39

Columbia University

34

127

Argonne National Laboratory

4

Argonne National Laboratory

2

182

$32,45,46$

Los Alamos National Laboratory

Massachusetts Institute of Technology

133

Pacific Northwest Laboratory

77

Lawrence Livermore National

LBL

Laboratory

40

15

LBL $\quad \vdots \quad 25$

The Pennsylvania State University $\quad 166$

Sandia National Laboratories $\quad 86$

Pacific Northwest Laboratory $\quad 77$

California Institute of Technology 109

Argonne National Laboratory

Lawrence Livermore National

Laboratory

Columbla University

36

University of Tulsa

Argonne National Laboratory

184

LLNL

5

SNLA

33

Lawrence Livermore National

Laboratory

85

Harvard University

$\begin{array}{lr}\text { Massachusetts Inst Itute of Technology } & 136 \\ \text { Lawrence Berkeley Laboratory } & 17\end{array}$ 
Tsang, $Y . W$.

Ullman, $W$.

Usselman, T. M.

Valentino, B.

Valette-Silver, N. J. Vaniman

Vetter, U. R.

Vogel, T. A.

Walker, $D$.

Wane, H. F.

Wawersik, W. R.

Weed, H. C.

Weres, 0.

Wesolowski, D. A. Westrich, H. R.

Whelan, J. K.

White, A. F.

Wilkens, R. H.

Williams, S. N.

Wise, W. S.

Witherspoon, P. A.

Wollenberg, H. A.

Wukelic, G. E.

York, J. E.

Younker, L. W.

Zucca, J. J.
Lawrence Berkeley Laboratory

Argonne National Laboratory

National Academy of Sciences/. National Research Council

National Academy of Sclences/ National Research Council

151

131

University of Maryland

55

121

137

125

University of Nevada
Michigan State University

Columbia University

University of Wisconsin

188,189

82

Lawrence Livermore National Laboratory

Lawrence Berkeley Laboratory

Oak Ridge National Laboratory

Sandia National Laboratories

Woods Hole Oceanographic Institution

30,39

15

64,71

85,86

Lawrence Berkeley Laboratory

190

Massachusetts Institute of Technology 136

The University of Chicago

Argonne

124

5

Lawrence Berkeley Laboratory

Lawrence Berkeley Laboratory

Pacific Northwest Laboratory

PNL

Lawrence Livermore National Laboratory

Lawrence Livermore National

Laboratory

0

.

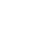


$-\because$

$\therefore$

1 
